\title{
The Clinical and Genetic Heterogeneity of Autosomal Dominant Cataract
}

To be submitted to the University of London for the degree of MD

September 2000

Alexander C W Ionides

Department of Molecular Genetics

Institute of Ophthalmology

University College London

Bath Street

London EC1V 9EL

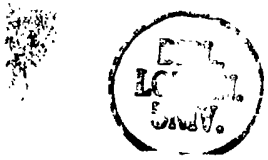


ProQuest Number: 10010096

All rights reserved

INFORMATION TO ALL USERS

The quality of this reproduction is dependent upon the quality of the copy submitted.

In the unlikely event that the author did not send a complete manuscript and there are missing pages, these will be noted. Also, if material had to be removed, a note will indicate the deletion.

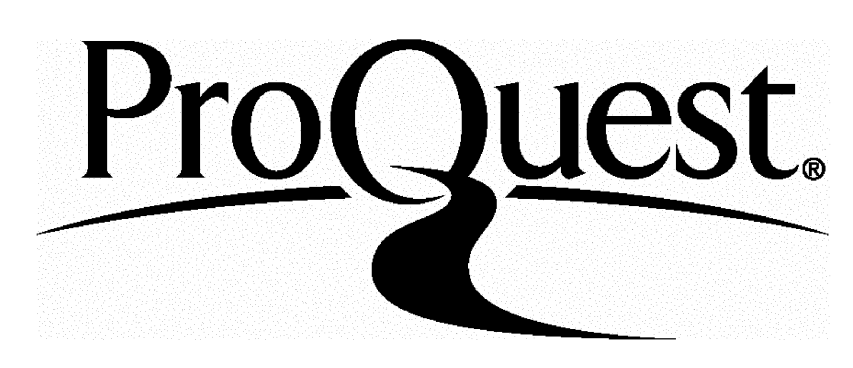

ProQuest 10010096

Published by ProQuest LLC(2016). Copyright of the Dissertation is held by the Author.

All rights reserved.

This work is protected against unauthorized copying under Title 17, United States Code. Microform Edition $\odot$ ProQuest LLC.

\author{
ProQuest LLC \\ 789 East Eisenhower Parkway \\ P.O. Box 1346 \\ Ann Arbor, MI 48106-1346
}




\section{Abstract}

Aim: The aims of this study are to assess the clinical heterogeneity of autosomal dominant cataract (ADC) between and within different pedigrees and find the loci for genes causing ADC.

Methods: Patients with $\mathrm{ADC}$ were recruited from the genetic clinic data base at Moorfields Eye Hospital and invited to attend for an eye examination where particular attention was given to the lens, including anterior segment photography. Blood was extracted for DNA analysis and a linkage study undertaken using microsatellite markers.

Results: Three hundred and thirty-six individuals were assessed (including members of 16 large pedigrees) and 180 patients found to be affected. In all pedigrees the cataract morphology could be classified as one of the eight following phenotypes; anterior polar, posterior polar, blue-dot (cerulean), lamellar, cortical, nuclear, coralliform and pulverulent. The visual outcomes were found to be related to the phenotypes and the age at time of surgery. Linkage studies identified the gene locus for six pedigrees. A pedigree affected by posterior polar cataract demonstrated linkage to chromosome $1 \mathrm{p}$, a pedigree affected by nuclear cataract to $2 \mathrm{q}$, linkage was also demonstrated for three pedigrees affected by pulverulent cataract, one to $1 \mathrm{q}$ and two to $13 \mathrm{q}$ and a pedigree affected by anterior polar cataract to $17 \mathrm{p}$. In one of the pedigrees affected by pulverulent cataract a mutation in the connexin 50 gene on chromosome 1q was found to give rise to the cataract. Two separate mutations in the gene encoding connexin 46 was found to be the cause of the cataract in the two pulverulent pedigrees that demonstrated linkage to $13 \mathrm{q}$.

Conclusion: ADC is clinically and genetically heterogeneous. Ten loci have now been shown to contain genes causing $\mathrm{ADC}$ and the underlying mutation has been identified in seven genes. There is wide clinical and genetic heterogeneity, but a close correlation exists between the phenotype and the underlying genetic aetiology. 


\section{Contents}

Page no.

Title page

1

Abstract

2

Table of contents

3

Table of figures

4

List of tables

7

Acknowledgements

8

Abbreviations

9

Conjoint statement

Introduction

Patients and Methods

$\underline{\text { Results }}$

Discussion

$\underline{\text { References }}$

$\underline{\text { Appendices }}$ 


\section{Figures}

Figure

1

2

3

4

5

6

7

8

9

10

11

12

13

14

15

16

17

18

19

20

21

22

23

\section{Illustration}

Zones of discontinuity

Anterior polar cataract: Pedigree A. Pyramidal

Anterior polar cataract: Pyramidal in Retroillumination

Anterior polar cataract: Pedigree A.Plaque

Anterior polar cataract: Plaque in Retroillumination

Anterior polar cataract: Pedigree A. Retroillumination of capsule irregularity

Stationary post polar cataract. Stationary cataract. Ped $B$, ind. 2.8

Posterior polar cataract: Retroillumination

Posterior polar cataract: Pedigree B. Stationary cataract

Posterior polar cataract: Retroillumination.

Posterior polar cataract: Small Stationary cataract.

Posterior polar cataract:Small stationary cataract.

Progressive Posterior polar cataract.

Progressive Posterior polar cataract: Retroillumination.

Posterior polar cataract: Pedigree C. Progressive.

Nuclear cataract: Pedigree D. Dense central opacities

Nuclear cataract: Retroillumination

Nuclear cataract: Pedigree D. Fine central opacities including opacification of the Y-sutures.

Nuclear cataract: Retroillumination.

Nuclear cataract: Pedigree D. Fine opacities with opacification of the $Y$-sutures.

Nuclear cataract: Retroillumination.

Nuclear cataract: CCL. Pedigree E.Fine central opacities.

Nuclear cataract: CCL. Retroillumination.

Nuclear cataract: CCL. Pedigree E. Fine opacities

Nuclear cataract: CCL. Retroillumination.

Nuclear cataract: CCL Pedigree E.Dense central opacities.
Page No.

14

57

57

58

58

59

61

61

62

62

63

63

64

65

65

67

67

68

68

69

70

70

71 
Figure Illustration opacities. opacities.
Nuclear cataract: CCL. Retroillumination.

Page No.

Nuclear cataract. Coarse central opacities. 73

Nuclear cataract. Retroillumination. 73

Lamellar cataract. 75

Lamellar cataract. 76

Lamellar cataract: Retroillumination. 76

Lamellar cataract: 77

Lamellar cataract: Retroillumination 77

Coralliform cataract. 78

Blue-dot cataract. 80

Blue-dot cataract: Retroillumination $\quad 80$

Cortical cataract. Pedigree K. $\quad 82$

Cortical cataract: Retroillumination $\quad 82$

Cortical cataract. Pedigree K. 83

Cortical cataract: Retroillumination 83

Pulverulent cataract:Pedigree L. Fine opacities. 86

Pulverulent cataract: Retroillumination 86

Pulverulent cataract:Pedigree L. Sutural opacities. $\quad 87$

Pulverulent cataract: Retroillumination 87

Pulverulent cataract:Pedigree L. Fine opacities. 88

Pulverulent cataract:Pedigree L. Retroillumination 88

$\begin{array}{ll}\text { Pulverulent cataract: Posterior cortical opacities. } & 89\end{array}$

Pulverulent cataract: Retroillumination $\quad 89$

Pulverulent cataract: Pedigree O. Dense central 90

Pulverulent cataract: Retroillumination $\quad 90$

Pulverulent cataract: Pedigree O. Dense central 91 Pulverulent cataract: Retroillumination $\quad 91$

Pulverulent cataract: Pedigree O. Fine opacities. 92

Pulverulent cataract:Pedigree O. Fine opacities. 92 

years of age. years. the ages of 6-10 years. the ages of 11-20 years. who underwent single or multiple surgical procedures. who underwent multiple surgical procedures. who underwent a single surgical procedure. and unoperated eyes.

Posterior polar (stationary) cataract. Visual outcome in operated and unoperated eyes. in operated and unoperated eyes. unoperated eyes.

Lamellar cataract. Visual outcome in operated and unoperated eyes. operated and unoperated eyes. unoperated eyes. 


\section{Tables}

Table

$\underline{\text { Title }}$

Page no.

1

2

3

4

5

6

7

8

9

10

11

12

13

14

15

16

17

18

19 $\begin{array}{ll}\text { Autosomal dominant cataract loci. } & 38\end{array}$

Loci of mouse cataracts $\quad 43$

Major candidate genes for autosomal dominant cataract. 53

Pedigree details and phenotypes. $\quad 55$

Age at diagnosis for different phenotypes. 97

Final visual acuity and age at time of surgery for 164

eyes.

Visual outcome for those patients aged under 16 yrs who $\quad 104$ underwent single or multiple procedures.

106

112

Age at time of surgery for individual eyes of different

113

Complications; Glaucoma

114

115

Mapped Phenotypes

116

118

120

Two point LOD scores (Z) for linkage between CCL and

121

Two point LOD scores (Z) for linkage between

122

Two point LOD scores (Z) for linkage between

pulverulent cataract ( pedigree $M$ ) and chromosome $13 q$ markers.

Two-point lod scores (Z) for linkage between the anterior polar cataract locus and chromosome 17 markers.

Mutations giving rise to $A D C$ 


\section{Acknowledgements}

I would like to thank my two supervisors: Tony Moore, Consultant

Ophthalmologist at Moorfields Eye Hospital and Addenbrooks Hospital, Cambridge and Shomi Bhattacharya, Professor of the Molecular Genetics

Department at The Institute of Ophthalmology, London. Tony Moore's help with grant applications, the clinical aspects throughout the project and preparation for presentations at scientific meetings has been enormous. Shomi has created an efficient and hard working lab with people who are extremely helpful and very knowledgeable. His enthusiasm is legendary. I would mainly like to thank the 'cataract team' consisting of Alan Shiels ('team leader'), Vanita Berry ('post-doc') and Donna Mackay ('prize-winning $\mathrm{PhD}$ student'). Their help with my lab work has been crucial, their patience more than long suffering and their own work fantastic. The results of the molecular genetic research is largely their work. I would also like to thank Neil Ebenezer and Chris Inglehearne for answering questions and discussing lab techniques.

The Medical Illustration Department at Moorfields Eye Hospital has been wonderful and their ability to capture the smallest detail of lens opacity has resulted in this collection of photographs. In particular Kulwat Sehmi and Tony Sullivan. The genetic database at Moorfields Eye Hospital set up by Marcelle Jay and currently managed by Catherine Plant made the collection of families affected by cataract easier and it allows projects such as this to happen. David Taylor and Isabel Russell-Eggitt at Great Ormond Street Hospital for Sick Children gave me access to their patients which increased the clinical resources of the project and allowed the completion of pedigree $P$.

I am grateful to The Friends of Moorfields who generously funded my salary for the project and the Special Trustees of Moorfields who funded the running costs in the lab as well as the travelling expenses of the patients. I would especially like to thank Noel Rice who was behind the original idea for the project and for his help in obtaining the funding.

Finally I would like to thank the individual patients who took part in this study for their enthusiasm and willingness to participate. 


\section{Abbreviations}

$\alpha$

$\beta$

$\gamma$

$\delta$

$\varepsilon$

$\tau$

$\zeta$

ADC

APC

CAE

CAM

CCL

CCV

cM

Cx

CRYA

CRYB

CRYG

CRYZ

DNA

EDTA

ENO 1

GJA

kD

NADPH

LOD
Alpha

Beta

Gamma

Delta

Epsilon

$\mathrm{Tau}$

Zeta

Autosomal dominant cataract

Anterior polar cataract

Zonular pulverulent cataract (Ev family cataract).

Cataract Marner

Coppock-like cataract

Volkman cataract

Centi-Morgan

Connexin

Alpha ( $\alpha-)$ crystallin gene locus

Beta ( $\beta$-) crystallin gene locus

Gamma $(\gamma-)$ crystallin gene locus

Zeta $(\zeta-)$ crystallin gene locus

Deoxyribonucleic acid

Ethylenediaminetetraacetate

Enolase gene

Gap junction

Kilodaltons

Nicotinamide dehydrogenase phosphate

Logarithm of the odds (that two loci are linked) 


$\begin{array}{ll}\text { MP } & \text { Membrane Protein } \\ \text { MIP } & \text { Major Intrinsic Protein (polypeptide) of the lens } \\ \text { PCR } & \text { Polymerase Chain Reaction } \\ \text { PPC } & \text { Posterior polar cataract } \\ \text { RFLP } & \text { Restriction fragment length polymorphisms } \\ \text { RNA } & \text { Ribonucleic acid } \\ \text { V/A } & \text { Visual acuity }\end{array}$

\section{Statement regarding conjoint work.}

All the clinical work has been conducted solely by myself. This involved researching the family trees from the probands seen in the genetic clinic, contacting the families and arranging to see them at Moorfields Eye Hospital, or a local eye department, or in their homes. The ophthalmological examination, blood samples and clinical assessment were carried out by myself.

The laboratory work was then carried out by a team of people that formed the cataract group at the Institute of Ophthalmology; Alan Shiels, Vanita Berry and Donna Mackay. I extracted all the DNA and was competent at each stage of the linkage process, including; PCR amplification of DNA, radio-labelling of the markers, gel electrophoresis and radiographic imaging, 'reading' the gel and the computer analysis of results. A total of approximately 200 'markers' were run by myself. 


\section{Introduction}

The lens

Anatomy \& Embryology $\quad 12$

Molecular Biology $\quad 21$

Autosomal dominant cataract

$\begin{array}{ll}\text { Clinical Background } & 31\end{array}$

Molecular Genetics $\quad 37$ 


\section{$\underline{\text { THE LENS }}$}

The lens is one of the most specialised tissues of the human. A variety of mechanisms combine to create this transparent tissue capable of altering its shape to focus images on the retina. The lens must withstand the potentially damaging effects of optical radiation to last the entire human lifespan.

The study of lens molecular genetics offers the chance to analyse lens function and cataract formation. Cataract is by far the commonest cause of blindness worldwide and cataract extraction is one of the commonest surgical procedures performed on the National Health Service. An improved understanding of the pathogenesis of inherited cataract may lead to new treatments for age-related cataract.

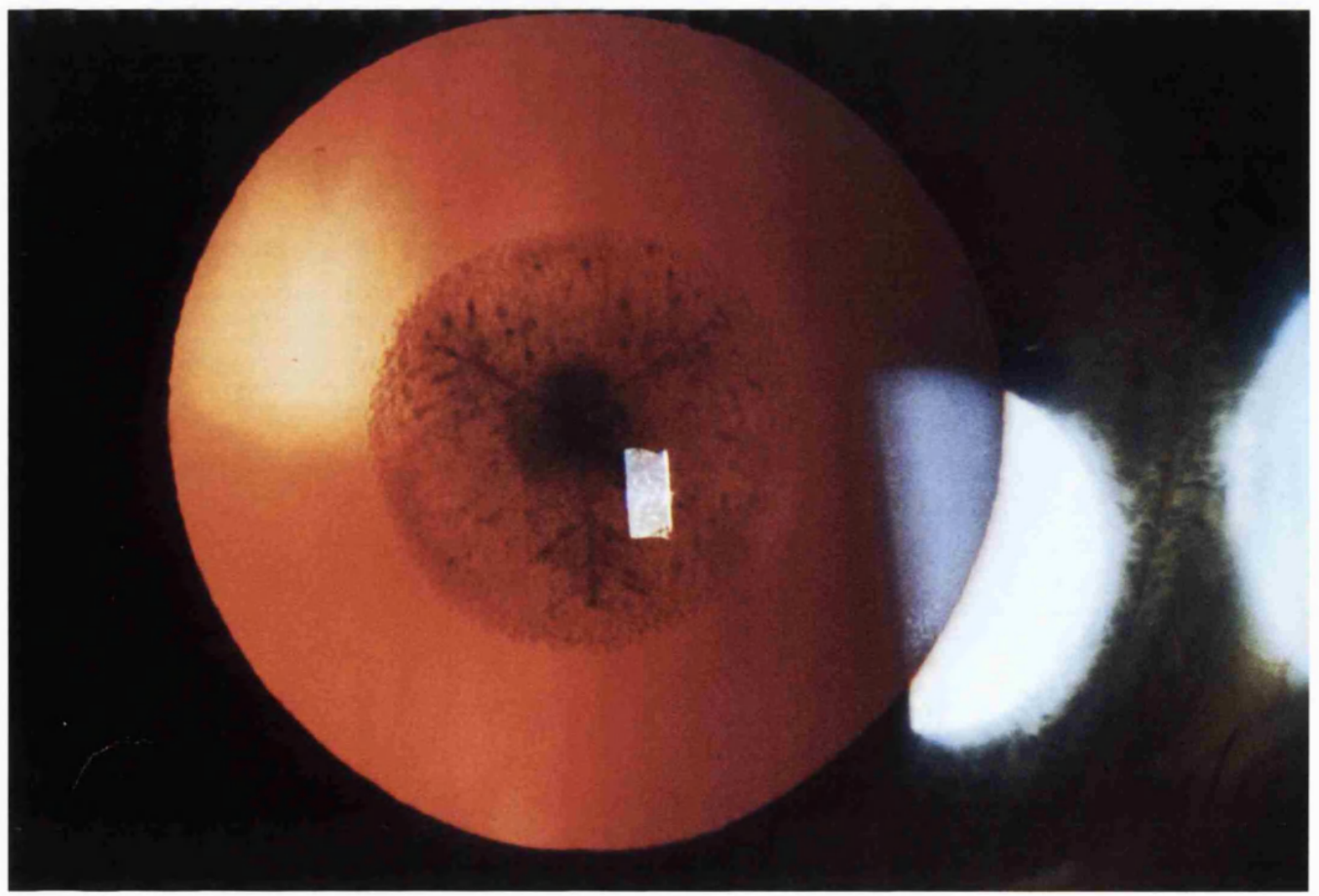

(See figure 27, page 72) 


\section{Anatomy of the lens}

Introduction: The adult lens is a transparent biconvex structure with an equatorial diameter of $9-10 \mathrm{~mm}$ and a thickness of 3.5-4mm (Donaldson 1976). It is suspended in the eye between the aqueous humour and the vitreous body by the zonular ligaments. The aqueous humour is the source of nutrients for the lens and is responsible for the removal of its waste products. The lens is contained within a basement membrane called the lens capsule and immediately behind the anterior lens capsule is a single layer of epithelial cells. These cells divide and move towards the equator where they elongate to form the lens fibre cells. The lens continues to grow throughout life and the slit lamp appearance of the lens anatomy is continually changing.

The function of the crystalline lens is to focus light onto the retina. The lens must therefore be transparent and this is achieved by the uniform arrangement of the lens fibres (Kuszak JR et al, 1986) and the organisation of the major cytoplasmic proteins (Vérétout $\mathrm{F}$ et al, 1989; Tardieu $\mathrm{A}$ et al, 1988). To understand lens architecture and to appreciate the formation of some morphologies of inherited cataract it is important to understand the anatomy and development of the lens. Of particular importance are the zones of discontinuity, the formation of the primary and secondary lens fibres, the structure of the lens sutures and the embryology of the lens.

Zones of discontinuity: Slit lamp examination of the lens reveals layers of optical discontinuity (Vogt A, 1919) that correspond to different ages of lens development (Figure 1). Understanding these boundaries and the ages of the different optical zones allows for an estimate as to the timing of the insult associated with the site of opacification in congenital and inherited cataract. Although the secondary lens fibres are continually laid down throughout life they do not form an optically homogenous lens but create sharp bands with different optical qualities. These bands are formed by abrupt changes in the refractive index previously thought to be caused by a temporary slowing in the growth of 
the lens but now believed to be caused by changes in suture patterns (Garland DL et al, 1996; Koretz JF et al, 1994).

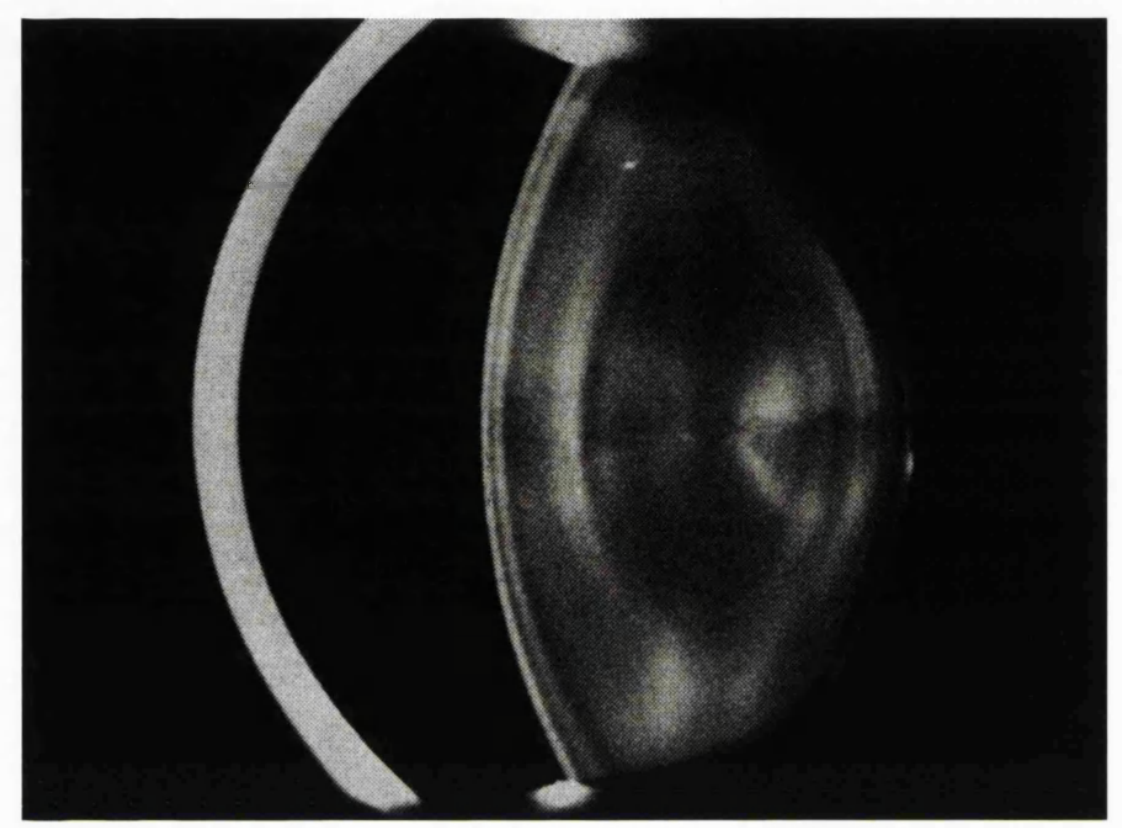

Figure 1. Zones of discontinuity.

The terminology of these zones is ambiguous (Duke-Elder S 1961). Vogt's original description (Vogt A 1919) was; central dark interval, inner and outer embryonic nuclei, adult nucleus and cortex. This was later changed (Goulden and Harris, 1925) substituting fetal for embryonic. As Duke-Elder points out, the central dark area is formed during the first three months in utero and is therefore the embryonic nucleus, after this the embryo is termed a fetus, so from three to eight months the fetal nucleus is formed. Duke-Elder then states that the remaining layers are formed during infantile and adult life, with the infantile nucleus being formed during the last weeks of intra-uterine life until puberty, and the adult nucleus formed after puberty. The cortex is described as the soft and young superficial fibres between the nuclei and the subcapsular epithelium. More recent classifications do not include the infantile nucleus but refer to the fibres laid down from birth until puberty as the 'adult' nucleus (Kuszak JR et al, 1986). 
Phelps Brown and Bron reject this nomenclature on the grounds that the same sets of lens fibres are regarded as being cortex at one period and nucleus at a later date (Phelps Brown N, 1996). They regard the nucleus as being the total lens at birth comprising the embryonic and fetal nuclei and the cortical fibres are those laid down after birth (Sparrow JM, et al.1986). This nomenclature creates two broad zones of the adult lens; nucleus (formed in utero) and cortex (which forms after birth). As will be seen later the phenotypes of autosomal dominant cataract (ADC) appear to reflect this nomenclature in that the boundary between the outer fetal nucleus and the cortex is a watershed in the development of lens opacities. However, this also dictates that all congenital cataracts are therefore nuclear by definition. The embryonic nucleus measures about $0.3 \mathrm{~mm}$ in diameter whilst the fetal nucleus measures $6-8 \mathrm{~mm}$ in equatorial diameter and is the size of the lens at birth (Phelps Brown, 1996). This is supported by the findings of Garland et al (1996) who describe a characteristic protein pattern seen on electrophoresis that distinguishes the lens nucleus ( $7 \mathrm{~mm}$ in diameter) from the lens cortex (outside the $7 \mathrm{~mm}$ core).

Throughout life the lens fibres are subjected to 'compaction' such that as more lens fibres are laid down, the inner fibres become compressed and the size of central opacities therefore reduces throughout life. Nuclear compaction takes place during the first 20-30 years of life and thereafter the 'compaction' affects only the cortical fibres (Brown NAP et al, 1988).

The lens fibres: The lens fibre cells develop from the lens epithelium lining the anterior capsule. The anterior epithelium is divided into different regions according to the stages of cellular development. The central zone consists of flattened cuboidal cells surrounded by a concentric region referred to as the pregerminative zone which consists of cuboidal cells that are less flattened with some of the cells entering mitosis. The next concentric region is the germinative zone and consists of many cells undergoing mitosis. This continued cell division pushes the fibre-precursor cells into the transitional zone (Beebe DC et al, 1980), where they take on a more columnar shape. The uniform shape and ordered 
alignment characteristic of the fibre cells is established in this region. When the cells reach the lens bow at the equator, they rotate by 90 degrees, lose their high columnar shape and elongate into the slender lens fibre cells (Kuszak JR et al, 1983).

The morphology of the lens fibre cells is different according to the site they occupy within the lens. The outer fibres are flatter having a smaller crosssectional diameter, whilst the inner fibres have more abundant membranous inter-digitations and a greater cross-sectional diameter. Transmission electron microscopy (EM) and scanning EM of the different regions of the lens show all the fibre cells to contain homogeneous cytoplasm (Taylor VL et al 1996).

Further maturation of the lens fibre cell is accompanied by the loss of the cell nucleus and the organelles, and an increase in the concentration of crystallin protein and the number of gap junctions (Bassnett $S$ et al, 1992). The loss of the organelles results in the fibre cell becoming metabolically inert with metabolites and ions passing to the inner fibre cells from the outer cells of the lens via the intercellular junctions. The crystallins that are laid down at this time must therefore survive the entire life of the individual, as they cannot be exchanged nor removed.

Lens sutures: The lens sutures are formed by the interlocking ends of the secondary lens fibres and are opacified in many of the phenotypes of ADC. As the secondary fibres form around the embryonic nucleus of primary lens fibre cells, they meet at the anterior and posterior poles. There are different suture patterns formed by the interlocking of the secondary fibres across different species (Duke-Elder S et al, 1970). The simplest pattern is called umbilical and is when all the fibres pass from one pole to the other, converging on the same point. There is considerable tapering at the distal ends of the fibres to enable them all to converge on the same spot. The remaining three patterns are called line sutures, Y-sutures (Marshall J et al, 1982) and star sutures (Kuszak JR, et al, 1986). All occur in the human lens at different stages of development although they are 
generally more prominent in childhood and less obvious in adulthood. The line suture is present during the development of the early fetal lens, the Y-suture during the late fetal lens and the star suture appears later in life. The tapering at the end of the fibre cells varies according to the number of branches in the suture (Kuszak JR et al, 1984). In umbilical sutures, the fibres are fusiform as all fibres interlock at the poles. In lenses with line sutures the ratio of fibre width at the equators compared to that at the poles is 3:1. In Y-sutures this ratio measures 2:1. In star sutures fibres flare rather than taper. In all suture types the extreme ends of the fibres flare as they interlock, because sutures are formed not by the simple abutting of the fibre ends but by an overlapping of the distal fibre ends. In figures 18-19 the upright anterior $Y$-sutures are clearly visible leading into the complex star shaped branching pattern of the more mature suture seen in figures $\mathbf{2 6}$ and 27. The lens fibres of the $\mathrm{Y}$-sutures and the star sutures do not run from pole to pole. These fibres are 'S' shaped and as they extend to a pole of the lens, they curve away from the pole to run in a latitudinal arc within and between growth shells and end by overlapping with the ends of specifically defined groups of fibres to form the lens sutures (Kuszak JR 1995).

\section{Embryology of the lens}

Introduction: An understanding of lens embryology is important in order to appreciate the developmental periods during which the lens is susceptible to adverse influences. These affect the type of cataract that may occur and gives rise to the temporal and spatial patterns seen in autosomal dominant cataract. The embryology of the eye is part of a series of sequential events that starts with the fertilisation of the ovum and culminates in the birth of a normal baby. Embryonal and fetal development can be divided into three main periods. The embryonal developmental period sees the development of the embryonic nucleus of the lens and consists of both embryogenesis, which occurs during the first three weeks of gestation (during which the primary organ rudiments are laid down) and organogenesis, from the fourth to the eighth week (during which 
these primary organ rudiments -including the embryonic lens, are developed). The fetal development is dominated by differentiation, in which the organs develop into fully or partially active organs (Y. Robert Barishak, 1992). It is during this period that the fetal lens develops.

Embryogenesis covers the first three weeks of development and results in the formation of the three germ layers; ectoderm, mesoderm and endoderm and the establishment of the primary organ rudiments. Although the eye is composed of three primordial tissues; neural ectoderm, surface ectoderm and mesoderm, the lens is derived from only the surface ectoderm. There is no evidence of the lens at this stage.

The first evidence of the future lens appears at the $4 \mathrm{~mm}$ stage, during the fourth week, with the formation of the lens plate or placode (Ida C Mann, 1928) at which point the ectodermal cells become epithelial cells (Zigman S, 1985). The lens placode is a thickening of the surface ectoderm overlying the optic vesicle. The ectodermal cells become epithelial cells and failure of this stage of development results in a primary aphakia, a rare developmental abnormality of the eye. The lens plate gives rise to the lens pit during the fifth week of gestation and the formation of the lens vesicle which remains temporarily attached to the surface ectoderm by the lens stalk.

The lens vesicle is covered by a basal membrane, which develops into the lens capsule and surrounds the lens vesicle completely as the lens stalk degenerates. Persistence of the optic stalk as a corneolenticular connection (Coulombre AJ, 1979) may be associated with anterior polar cataract (see figures 2-3 p57). The formation of the lens vesicle, enclosed within the capsule, seals off the lens cells from the rest of the body. This semi-permeable lens capsule gives the lens immunological privilege, allows for the development of osmotic cataract as seen in diabetes, galactosaemia (Chylack LT Jr et al, 1981) and the Nakano mouse (Nakano T et al, 1960; Kinoshita JH et al, 1974). As the lens increases in size 
throughout development, so does the capsule, and abnormal capsular development may result in capsular irregularities and polar cataract.

The sixth week sees the initial development of the primary lens fibres from the posterior cells of the lens vesicle and during the seventh week these elongate to obliterate the lumen of the lens vesicle and form the embryonic nucleus which measures about $0.3 \mathrm{~mm}$ in diameter. This elongation is accompanied by the formation of intra-cellular microtubules parallel to the axis of elongation and if these fail to develop the cells enlarge with the accumulation of crystallins but do not develop their strap-like shape resulting in cataract (Byers B et al, 1964).

Influences from outside the lens at this stage may result in cataract. It has been demonstrated that in chick embryos the vitreous produces lentropin that stimulates crystallin synthesis (Piatigorsky J, 1981) and the neural retina provides growth factors that stimulate lens development (Simmoneau L et al, 1983). It has been shown experimentally that removal of the neural retina results in abnormal lens development and cataract formation, whilst replacement of the neural retina allows normal lens development (Coulombre J et al, 1965). Even in cases where cataract is the only abnormality, as in ADC, extra-lenticular factors may still be involved in the pathogenesis.

With the addition of successive layers of lens fibres, the primary lens fibres lose contact with the capsule and the nuclei of these cells as well as some of the cell organelles degenerate (Kuwabara T, 1975). This degeneration limits the time period during which genes that may result in cataract formation can be expressed, offering some protection to the embryonic nucleus. The transition of the epithelial cells to fibre cells is completed with elongation and the loss of the organelles.

There is rapid development of the lens during the eighth week as the secondary lens fibres form. The anterior epithelial cells divide and the newly formed cells are pushed posteriorly and become elongated. Each successive layer of cells grows over the previous one and results in the formation of the two following 
structures: The lens bow is formed by the nuclei of the secondary lens fibres as they move forward and form an arc with the convex anterior; the lens sutures develop because all fibres of the same age have similar lengths and meet anteriorly and posteriorly.

Differentiation: At the end of the third month an embryonic and an inner fetal nucleus can be identified (Ozanics Vet al, 1982). The outer fetal nucleus develops during the fourth month and new suture lines appear as bifurcations in the arms of the sutures. Lens growth occurs in the same manner in an adult lens as in an embryonic lens by the addition of the secondary lens fibres. The changing shape of the lens from a sphere to an elliptical form takes place from the fourth to the sixth month as the lens equatorial cells continue to proliferate (Sivak JG et al, 1987) and at eight months of development the lens is approximately 6-8mm in diameter.

Summary: The anatomy of the lens as seen through the slit lamp is composed of different regions each of which are associated with a particular period of development. The small central embryonic nucleus measures approximately $0.3 \mathrm{~mm}$ and is formed by the primary lens fibres during the first two months of development. Thereafter the secondary lens fibres continue to be laid down throughout life and form the remainder of the lens. The fetal nucleus is formed up until birth and contains the $\mathrm{Y}$-sutures and measures approximately $6-8 \mathrm{~mm}$ in equatorial diameter at birth. The secondary lens fibres laid down after birth make up the cortex of the lens.

Autosomal dominant cataract can therefore be pre-natal, affecting the lens nucleus, post-natal, affecting the lens cortex, or have opacities throughout the lens reflecting abnormal development both before and after birth. 


\section{Molecular Biology of the lens}

\section{Introduction}

In this section the molecular biology of the lens is discussed. Many of the genes encoding major lens proteins such as the crystallin proteins, the membrane proteins and the cytoskeletal proteins have been identified and are good candidate genes for inherited cataract in man.

\section{Crystallin Proteins}

The mature lens fibre cell has no nucleus nor cell organelles and there is therefore little turnover nor renewal of protein in the inner fibres of the lens (Kuwabara T, 1975). For the lens to maintain its transparent and refractive properties it requires a high concentration of regularly packed proteins that are very stable and can resist denaturation from optical radiation, free radicals and heat. These proteins also need to last the entire life of the lens as they cannot be degraded nor replaced. The crystallin proteins fulfil these requirements. Previously thought to be structural proteins with a unique function in a highly specialised tissue, it is now realised that the crystallins are expressed in other tissues of the body in very different guises (Piatigorsky $J$ et al, 1983).

The crystallin proteins make up over $90 \%$ of the water-soluble proteins of the lens and are responsible for conferring and maintaining lens transparency (Cartier $\mathrm{M}$ et al, 1994; Delaye M et al, 1983; Wistow GJ et al, 1988). Crystallins can be divided into two categories; the ubiquitous crystallins that are present in all vertebrate lenses ( $\alpha, \beta$ and $\gamma)$ (Bloemendal H, 1989) and the taxon specific crystallins, only present in certain species (Piatigorsky J et al, 1989). The three major classes of human crystallins are $\alpha, \beta$ and $\gamma$, the high molecular weight fraction being the $\alpha$-crystallins, the intermediate fraction the $\beta$-crystallins and the low molecular weight fraction the $\gamma$-crystallins (Bloemendal $\mathrm{H}$ et al, 1989). The $\alpha$-crystallin proteins are thought to have evolved from one gene and the $\beta$ - and $\gamma$ crystallins are so closely related to each other that they are also thought to have evolved from a single gene (WW de Jong et al 1989). The $\beta$ - and $\gamma$-crystallins are 
now often grouped together and referred to as the $\beta \gamma$-crystallins. A $\zeta$-(zeta) crystallin gene has recently been described in humans, although it has a very low level of expression (Heinzmann et al 1994).

The order of appearance of the crystallins in development as well as their position within the lens differs according to different species (Piatigorsky J, 1981). $\alpha$-crystallin is found in the lens placode and is synthesised in the epithelial cells whilst the $\beta$ - and $\gamma$-crystallins appear after or during fibre cell elongation (Harding J, 1991, McAvoy 1978). The heavier molecular weight proteins predominate in the epithelium and outer cortex while $\gamma$-crystallins and the lower molecular weight proteins predominate in the protein-rich inner nucleus (McAvoy JW, 1981). This creates a protein dense nucleus resulting in a higher refractive index of the nucleus as compared to the cortex. The optical benefit is a decrease in both the spherical and chromatic abberations that affect lenses of uniform refractive index.

The crystallins have traditionally been regarded as soluble, structural proteins restricted to the lens although it is now apparent that they have close homology to other proteins outside the lens and in some cases are coded by the same or similar genes as these other proteins. It is probable that these proteins were recruited by the lens to form the crystallins because of their stable structure enabling them to survive within the lens fibre cells and maintain lens transparency (Wistow $\mathrm{G}$ et al, 1987). The crystallins may have arisen by gene duplication and divergence, specialising for the lens environment. This is particularly illustrated by the study of the taxon specific crystallins that show close homology with enzymes. These taxon (or species) specific crystallins will be discussed later.

$\alpha$-crystallins: The $\alpha$-crystallins comprise $30-40 \%$ of the soluble protein and are polypeptides $(20 \mathrm{kDa})$ that aggregate to form larger complexes (approximately $800 \mathrm{kDa}$ ). They are coded by two genes that share nearly $55 \%$ sequence homology, $\alpha \mathrm{A}$ (chromosome 21;22.3) and $\alpha \mathrm{B}$ (chromosome 11; 22.3-23.3), that 
give rise to one acidic and one basic polypeptide. Post-translational modifications to the protein by phosphorylation, deamidation, acetylation, degradation and racemization lead to a variety of $\alpha$-aggregations in the lens (Spector A et al, 1985). These modifications may have a role in altering the interactions of $\alpha$ crystallins with each other and with other lens components.

The $\alpha B$-crystallins show sequence homology to a number of proteins found elsewhere in nature. These include heat shock proteins (Ingolia TD et al, 1982) and a schistosoma mansoni egg antigen (Nene V et al, 1986). Similar proteins have been found in skeletal muscle, heart, kidney, retina and lung where they may have a function as heat-shock proteins. Proteins similar to $\alpha \mathrm{B}$-crystallin have also been found in the brains of humans affected by neurological diseases including multiple sclerosis (van Noort JM et al, 1995), Creutzfeld-Jakob disease (Jahal C et al, 1992), Alexander's disease (Iwaki T et al, 1989), Huntingdon's disease, Parkinson's, Pick's and Lewy body diseases. They gave also been found in the brains of hamsters with scrapie (Duguid JR et al, 1988). More recently the $\alpha \mathrm{B}$-crystallins have been found to have chaparone activity which may stabilise other crystallins in the lens preventing uncontrolled aggregation (Rao PV et al, 1995). The similarites of the $\alpha \mathrm{B}$ crystallin to heat shock proteins suggests a role in the reaction of the lens to stress. $\alpha \mathrm{B}$-crystallin can be induced by heat-shock and other insults including osmotic stress, ischaemia and expression of some oncogenes (Wistow $G, 1995$ ). The function and mechanism of action of the heat shock proteins is not known but they are present in chloroplasts of plants where they may protect against damage from light and heat. Unlike $\alpha \mathrm{B}$ crystallin, $\alpha \mathrm{A}$ crystallin is not expressed so widely outside the lens although it has been found in spleen and thymus (Kato K et al, 1991) and may also function as a heat shock protein (Van den Ijssel et al, 1996). A mutation in the human $\alpha$ A crystallin has been shown to cause a range of eye disorders including microphthalmia and cataract (Litt et al, 1998).

Little is known about the regulation of the genes for the $\alpha$-crystallins in the human lens, although $\alpha \mathrm{A}$-crystallin mRNA has been detected in fetal lenses 
(Brakenhoff RH et al, 1990). The $\alpha$-crystallins are the first crystallins to appear during the development of the lens in rodents and are present in the lens vesicle before the development of the primary lens fibre cells and are synthesized mainly in the lens epithelium (van Leen RW et al, 1987). The mRNA for both $\alpha \mathrm{A}$ - and $\alpha \mathrm{B}$-crystallin can be detected at all stages of lens development although as already stated the outer layers contain a greater proportion of the $\alpha$-crystallins.

$\beta$-crystallins: The $\beta$-crystallins also form aggregates and are also divided into basic ( $\beta$ B1-3) and acidic ( $\beta$ A1-4) sub-types. Like the $\alpha$-crystallins they undergo various modifications including phosphorylation, oxidation, cross-linking and deamidation. The $\beta$-crystallins are mainly encoded by genes on chromosome 22 (22q 11.2-13.1), although $\beta A 1$ and $\beta A 3$ are on chromosome 17 (17q11.1-q12) (Sparkes RS et al, 1986). The developmental regulation of the $\beta$-crystallin genes has been studied in the chicken and the rat but little is known about the regulation in humans, although $\beta B 3$ is known to be expressed early and $\beta B 2$ in the later stages (Brackenhoff RH et al, 1992) of lens development in humans. The chromosome 22 locus for $\beta A 1$ and $\beta A 3$ has been shown to be linked to a cerulean cataract in humans (Kramer $\mathrm{P}$ et al, 1996) and a chain termination mutation has been identified in CRYBB2 as causing the cataract. In the Philly mouse a dominant nuclear and subcapsular cataract (Kador PF et al, 1980) is caused by a deletion in the $\beta B 2$ cDNA (Chambers $C$ et al, 1991) resulting in a mutant $\beta \mathrm{B} 2$ protein being formed that is thought to give rise to the cataract.

$\gamma$-crystallins: The $\gamma$-crystallins unlike the other crystallins are monomers and can be divided into two groups; one containing the $\gamma$ s present in all vertebrate species, and the other made up of six closely related proteins known as $\gamma \mathrm{A}, \gamma \mathrm{B}$, $\gamma \mathrm{C}, \gamma \mathrm{D}, \gamma \mathrm{E}$ and $\gamma \mathrm{F}$ which are absent in fish and some reptiles. The $\gamma$-crystallins have a high internal symmetry and are very stable enabling them to withstand dehydrated environments. The $\gamma \mathrm{s}$ gene is located on chromosome 3 and the $\gamma \mathrm{A}-\gamma \mathrm{F}$ genes are clustered together on chromosome 2 (Shilloh $Y$ et al, 1986) region q33q35. In the embryonic nucleus of humans the $\gamma \mathrm{C}$ and the $\gamma \mathrm{D}$ account for $82 \%$ of 
the $\gamma$-crystallin transcripts, the $\gamma \mathrm{A}$ gene contributes $14 \%$ and the $\gamma \mathrm{B}$ gene $5 \%$ (Brackenhoff $\mathrm{RH}$ et al, 1992). The $\gamma \mathrm{E}$ and $\gamma \mathrm{F}$ are considered pseudogenes although a low level of $\gamma \mathrm{E}$ transcript has been detected. There is also a segment of the $\gamma \mathrm{F}$ gene that is duplicated within the gene cluster, called $\gamma \mathrm{G}$ but it is nonfunctional. The $\gamma$-crystallins are located primarily in the lens nucleus and most of the genes are expressed early in development and have reduced activity after birth. At 22 months only the $\gamma \mathrm{D}$ can be detected and remains present until 10 years of age.

The $\gamma$-crystallin gene complex is important regarding cataract formation and linkage has been demonstrated for two cataract phenotypes to this locus in humans; the Coppock-like cataract (Lubsen et al 1987) in which the opacities are confined to the nucleus, and the polymorphic cataract (Rogaev EI et al, 1996) which has more widespread and variable opacities. The Coppock-like cataract (figures 20 - 25) has been shown to be caused by an over-expression of the $\gamma \mathrm{E}$ pseudogene (Brakenhoff RH et al, 1994). In the Elo (eye lens obsolescence) mouse, a single nucleotide deletion in the $\gamma \mathrm{E}$-crystallin gene is responsible for the dominant cataract (Cartier M et al, 1992).

Zeta crystallin: The $\zeta$-crystallin lens protein has been associated with an autosomal dominant cataract in the guinea pig (Rodriguez IR et al, 1992), and is a major protein in the lenses of guinea pigs and camels where it comprises about $10 \%$ of the total soluble protein (Garland D et al, 1991). The $\zeta$-crystallin gene (CRYZ) has recently been mapped in humans to chromosome 1p22p31(Heinzmann C et al, 1994) and although it has a low level of expression it provides an important candidate gene to be included in linkage studies for autosomal dominant cataract.

Taxon specific crystallins: Amongst the taxon specific (or species specific) crystallins some are active enzymes and others are related to enzymes but have no activity. In the lenses of crocodiles and birds, $\varepsilon$-crystallin was found to be essentially identical to lactate dehydrogenase (Wistow GJ, 1987) and $\tau$-crystallin in the lens of some fish, birds and lampreys is closely related to enolase in 
humans and in yeast (Wistow GJ et al, 1988). The major protein of the embryonic lens in birds and reptiles is $\delta$-crystallin which has significant sequence homology to the urea cycle enzyme argininosuccinate lysase in humans (O'Brien W et al, 1986) and $\zeta$-crystallin in guinea pigs (Huang QL et al, 1987) has recently been found to have NADPH-dependent quinone reductase activity. The $\zeta$-crystallin gene is unusual in that the high expression in the lens of guinea pigs is mediated by an alternative lens-specific promoter distinct from that responsible for expression of the enzyme in other tissues (Gonzalez P et al, 1994). These taxon specific crystallins are not only similar to these enzymes but are products of the same genes as the enzymes. The crystallins that resemble enzymes but have no activity are $\rho$-crystallin in frogs (Gause GG et al, 1985) and $\lambda$-crystallin in rabbits and hares (Mulders JWM et al, 1988).

Most of the enzymes that are associated with the crystallins are related to enzymes involved in carbohydrate metabolism and these enzymes are in turn induced by stress (Nickells RW et al, 1988). This is relevent as the metabolic energy required by the lens is largely obtained from anaerobic glycolysis (Harding JJ et al, 1984). It is not yet clear why the crystallins have been recruited from these particular enzymes, it may be the stable structure, the individual enzyme function or even the propensity for readily inducible gene expression explaining their presence in such large amounts within the lens fibre cells (de Jong WW et al, 1989).

The relevance of the taxon specific crystallins to a human linkage study is illustrated by the linkage demonstrated for the Volkmann cataract (Eiberg $\mathrm{H}$ et al, 1995 ) and the stationary posterior polar cataract (Ionides et al, 1997) in humans to chromosome 1p36. Within this region lies the gene ENO1 (enolase 1 alpha that also codes for $\tau$-crystallin, a crystallin not found in humans). Although this has not yet been shown to be involved in the formation of the Volkmann cataract nor the posterior polar cataract, this has yet to be fully assessed. 


\section{Lens membranes}

The embryonic and fetal nuclei of the lens contain some of the longest lived cell membranes in biological systems. Although the crystallins are the major water soluble proteins accounting for $80-90 \%$ of the dry weight of the lens, the remaining $10-20 \%$ is made up of the cytoskeletal and membrane proteins and is collectively referred to as the water insoluble fraction. The standard nomenclature for the plasma membrane proteins is 'MP' standing for 'membrane protein' followed by the molecular weight in kilodaltons (Bloemendal $\mathrm{H}$ et al, 1977). Major intrinsic protein (MIP) is therefore called MP-26, having a molecular weight of $26 \mathrm{kD}$ and is the the principle constituent of this fraction (Zigman S, 1985).

The histological differentiation of the lens epithelial cell into a fibre cell is associated with the synthesis of large amounts of two classes of lens proteins; the crystallins and the membrane proteins (Bloemendal H, 1979). The membrane proteins are known to be involved in the formation of intercellular junctions called 'gap junctions' and the percentage of the membrane involved in these junctions is as high as $64 \%$ (Kuszak $J$ et al, 1978). The loss of the organelles reduces light scatter and the increased number of intercellular junctions is thought to permit the passive diffusion of ions and metabolites between the cells (Rae J et al, 1983. Bassnett S et al, 1994). The outer epithelial cells therefore fulfil the metabolic requirements of the inner fibre cells via this large network of fibre cell gap junctions (Kinsey et al 1964, Mathias et al 1997, Goodenough et al 1992). There are no blood vessels in the lens. Another important role of the membranes is the control of the ionic balance which is achieved by the $\mathrm{Na}, \mathrm{K}$ ATPase and the Ca-ATPase. Sodium is pumped out of the cells followed by chloride and water, preventing swelling and clouding of the lens. The gap junction also maintains a very narrow intercellular space which is critical for lens transparency and the disruption of this may result in cataract.

Connexins: Gap junctions are channels that connect neighbouring cells and allow the passive diffusion of inorganic ions and small molecules (Elfgang et al 
1995). The trans-membrane proteins that make up the gap junctions are called connexins $(\mathrm{Cx})$ and are encoded by family of genes that have recently been identified (Kumar \& Gilula 1996). Connexons are classified according to their molecular weight. Six connexin molecules aggregate to form a ring called a connexon, within the plasma membrane (Cascio et al 1995). Two connexons from neighbouring cells then align with each other and 'dock' together to form the gap junction channel. Gap junctions then cluster together in the plane of the membrane to form gap junction plaques. The permeability of the gap junctions varies according to the constituent connexins (Elfgang et al 1995). Cataracts have been shown to occur in mice lacking $\mathrm{Cx} 43$ (Gao et al 1998) which is predominantly expressed in lens epithelial cells. Two connexins are known to be present in the human lens, Cx46 and Cx50.

MP-70 (Cx 50): The gene for MP70 has been mapped to chromosome 1q21.1 (Church RL et al, 1994) in humans and a murine homologue protein called connexin 50 has been shown to be a gap junction protein. The CAE pedigree studied first by Nettleship, later by Renwick and Lawler and more recently as part of this study maps to this region on 1q. As will be discussed later we have demonstrated that a mutation in this gene is responsible for the cataract in the CAE family (Shiels et al 1998) Pedigree P in appendix 1. Connexin 46 (GJA3) has been assigned to chromosome 13q11-q12 (Willecke et al 1990, Mignon et al 1996) we have shown that two mutations in this gene give rise to the cataract in two different pedigrees affected by pulverulent cataract (Mackay et al 1999). The pedigrees are pedigrees $\mathrm{L}$ and $\mathrm{M}$ in appendix $\mathbf{1}$.

MP-26 (MIP): MP-26 (Main Intrinsic Polypeptide) also called aquaporin, is the major protein of the cell junctions (Sas DF et al, 1985), forms $40 \%$ of the fibre membrane and the increase in inter-cellular junctions during the maturation of the fibre cells is accompanied by a large increase of MP-26. The increased protein content of the ageing cells (Horwitz JN et al, 1979) has however been associated with cataract in later life (Zigman S, 1985; Spector A, 1979). MP26 is present in both the lens nucleus and cortex and is a member of a large family of 
integral membrane channel proteins involved in the regulation of water movement (Reizer J et al, 1993). There are several types of inter cellular junctions between the lens fibres and MP26 is organised differently with each type (Zampighi GA et al, 1989), it is also present in non-junctional membrane. The MP-26 gene has been mapped to the distal end of chromosome 10 in the mouse (Griffen CS et al, date) and to chromosome 12q in humans (Sparkes RS et al, 1986) and a mutation of MP-26 has been implicated as the cause of the cataracts in both the $\mathrm{Cat}^{\mathrm{Fr}}$ and the Lop mouse cataracts (Shiels A et al, 1993; Shiels A et al, 1991; Shiels A et al, 1996). It is therefore an important candidate gene for inherited cataract in mice and humans.

MP-19: The second most abundant membrane protein is another intrinsic protein (Mulders JWM et al, 1988), MP-19 (also referred to as MP-17 and MP-18) and is again thought to be involved in the formation of these osmoregulatory transmembrane channels. Like MP26 (MIP) it is distributed throughout the lens (TenBroek E et al, 1992) and has been shown to bind calmodulin (Galvan A et al, 1989) although its role is still uncertain (Zampighi GA et al, 1992). The gene has been mapped to chromosome 19 in humans and mutations in the mouse gene for MP19 has been shown to cause inherited cataract.

\section{Cytoskeletal elements}

As the fibre cells elongate and become internalised into the lens nucleus, the alteration in shape is reflected by an alteration in the cytoskeletal architecture. Initially, cytokeratins, vimentin and two lens specific intermediate filaments, phakinin (CP49) and filensin are expressed in the embryonic lens (Sandilands A et al, 1995). In the mature lens fibre cell keratin and vimentin are not expressed leaving CP49 and filensin as the only remaining intermediate filaments. These two cytoskeletal proteins are unique to the lens and are the major components of the beaded filament that combine with $\alpha$-crystallin (Carter JM et al, 1995). Filensin and CP49 have now been cloned and the genes localised to chromosomes 20 and 3 (Hess JF et al, 1996). 
Introduction. The Lens; molecular biology

\section{Molecular Biology and Cataract}

General features of cataract formation include the presence of vesicles, lens fibre swelling, disordered orientation of fibre cells and loss of membrane integrity (Berman ER, 1991). At the molecular level there are aggregates of high molecular weight proteins caused by the unfolding of crystallins, products of proteolysis, abnormal levels of sodium, potassium and calcium and decreased amounts of glutathione and soluble crystallins. These changes have been studied mainly in senile cataract but they point to potential mutation sites that may give rise to inherited cataract such as the crystallin genes, the genes for membrane proteins and genes known to play a role in lens development.

Whilst biochemical studies have implicated these molecules in cataract formation, it has not been possible to determine whether their involvement was a primary or a secondary event. Molecular genetic studies can screen the genes for these proteins and the finding of pathological mutations will provide evidence that defective crystallins and other lens proteins can be a primary cause of cataract. 


\section{ADC: Clinical background}

Historical background: Congenital cataract is a major cause of childhood blindness (Lambert SL et al, 1996; Evans J et al, 1996; Lloyd IC et al, 1994) and has a genetic basis in over $25 \%$ of cases (Merin S et al, 1971). Inherited cataract has been recognised for many centuries and can be inherited as an autosomal dominant, autosomal recessive or X-linked trait. Doyne (Doyne RW, 1889), Nettleship (Nettleship E, 1905; Nettleship E, 1909; Nettleship E, 1909), Harman (Harman N, 1909; Harman N, 1910) and others (Sæbø J, 1949; Priestly Smith, 1910) have documented enormous numbers of pedigrees affected with inherited cataract and have clearly illustrated the patterns of inheritance. The great majority of inherited cataract is autosomal dominant in the mode of transmission.

The phenotypes of inherited cataract have not been systematically investigated. In 1910 Bishop Harman described the appearance of the lens opacities seen in families with inherited cataract and listed five groups; lamellar, coralliform, stellate, anterior and posterior polar and finally an undefined group (Harman N, 1910). Clapp divided congenital cataract of all aetiologies into two broad groups; complete and partial. He then subdivided the partial cataracts into zonular, coralliform, punctate, discoid, pyramidal, Y opacities, floriform, fusiform, discshaped and Morgagnian (Clyde A Clapp, 1934). Duke Elder (Duke-Elder S, 1964) François (François J, 1963) and Vogt (Vogt A, 1979) describe in detail the different kinds of cataract that can be inherited in individuals but no study has been undertaken examining the different phenotypes of pedigrees.

\section{Mapped Phenotypes}

At the start of this study, linkage had been demonstrated for three phenotypes and the gene had been isolated at one of these loci (at the $\gamma$-crystallin gene complex, Lubsen et al 1987). Ten loci have now been shown to contain genes for human cataract and the mutations have been identified in seven of these genes. This study demonstrated linkage at five loci and has identified three mutations in two novel genes that give rise to cataracts (Table 1, page 38). Mutations in the genes 
encoding $\alpha$-, $\beta$ - and $\gamma$-crystallins as well as in the genes for connexins have now been shown to give rise to inherited cataract. There is no generally agreed classification for the phenotypes of ADC. Initially the names of the phenotypes were taken from the surname of an affected ancestor (Coppock, Volkmann), the resemblance to a previously described phenotype (Coppock-like) or even the ophthalmologist involved in their care (Marner). More recently the phenotypes have been named according to a description of the opacity (anterior or posterior polar etc) but a classification has never been accepted into general ophthalmological use. A clinical classification would not be able to successfully encompass the enormous heterogeneity of ADC. There has yet to be a common terminology amongst researchers for describing the lens opacities and the phenotypes.

Below is a description of the phenotypes from the pedigrees that had been mapped to specific loci at the onset and during the initial years of this thesis.

Zonular pulverulent Cataract (CAE): Renwick and Lawler studied a family affected by zonular pulverulent cataract that was described in their original paper to be "family Ev. from Southern England" (Renwick and Lawler 1963). This family was first documented by Nettleship (Nettleship E, 1909). The opacity is described as being in the centre of the lens, 'about $4 \mathrm{~mm}$ in apparent diameter and sometimes, within this zone, (contains) a distinct denser part in the nuclear region. Each cataract was composed of innumerable powdery opacities... The cataract...was bounded by a smooth envelope consisting of a thin layer of particularly fine opacities and, outside this, was clear in about five eyes out of six. In the remaining eyes, this outer zone had one or more shells also consisting of these powdery opacities.' This zonular pulverulent cataract is often mistakenly called the Coppock cataract. The Coppock cataract has never been included in any published linkage study, has opacities confined to the embryonic nucleus and is called the 'central pulverulent cataract' (as opposed to the zonular pulverulent cataract described here). It was at one time also called the Doyne's discoid cataract (Adams PH, 1942) after the author of its first description. Although the 
Coppock pedigree was studied by Nettleship (Nettleship E, 1906) no kinship between the Coppock and the Everett families (family Ev) could be found.

Coppock-like Cataract (CCL): The 'Coppock-like cataract' family were originally described by Priestly Smith (Smith P, 1910) and Bishop Harman (Harman NB, 1910) in 1910. Smith's paper is titled 'A pedigree of Doyne's discoid cataract' and states that the Forman pedigree 'bears much resemblance to the Coppock pedigree.' The cataract is described as 'discoid in form...its size varies in various individuals, producing various degrees of visual impairment.' Bishop Harman describes the phenotype as being 'circular, about $3 \mathrm{~mm}$ in diameter, and of a granular appearance.' Duke-Elder classifies the Coppock and Coppock-like cataracts as central (nuclear) cataracts (Duke-Elder S, 1964). No connecting link between the Coppocks and the Formans suggesting kinship could be detected at this time. The descendants of the Forman family have participated in this study and Figures 22-27 (pp70-72) are slit lamp photographs of the phenotype of the Coppock-like cataract from two different individuals showing the central, nuclear position of the opacity. There have never been any previously published illustrations of the cataract from the Coppock-like pedigree.

Marner Cataract: The Olsen family from Denmark affected with this cataract were first described by Giersing in 1878 (Giersing OM, 1878) updated by Norrie in 1896 (Norrie G, 1896) and then studied by Marner from whom the phenotype received its name. Marner describes the cataract as having 'fine, dispersed, pulverulent opacities in the embryonic nucleus. In the outer zone of this nucleus, equatorially orientated, linear condensations are found...opposite the extremities of the anterior Y-suture. These condensations may be slightly arched with the concavity directed centrally making the circumference of the embryonic nucleus look triangular...Outside the embryonal nucleus one or more zones with pulverulent opacities may be seen, and peripherally to this some 'riders' may be located. Sometimes, star shaped opacities located in the posterior cortical layer of the lens are observed.' There is also considerable inter-individual and intrafamilial variation of the phenotype (Marner E, 1989). In an earlier paper the 
different morphologies were described as being zonular, central, stellate or with an anterior polar opacity (Marner E, 1949).

Cerulean cataract: Linkage has been demonstrated for two pedigrees affected by cerulean (blue-dot) cataract to two different loci. The cerulean cataract was first described by Vogt in 1922 (Vogt A, 1922) and Armitage et al demonstrated linkage of a pedigree affected by this phenotype to chromosome 17q (Armitage MM et al, 1995). The pedigree they studied had an early onset bilateral cataract characterised by tiny blue or white opacities that formed in the superficial layers of the fetal lens nucleus and could be detected by slit lamp examination from the age of 18-24 months. There was no sign of the cataract at birth. The opacities progressed to involve the adult nucleus and cortex 'forming concentric layers, with central lesions orientated radially.' The cataracts were slowly progressive with the affected individuals requiring cataract surgery between the ages of 16 and 35 years.

A second locus for cerulean cataract was then reported a year later by Kramer et al mapping to the $\beta$-crystallin region on chromosome 22q (Kramer $P$ et al, 1996) and a mutation of the $\beta$ crystallin gene detected (Litt $M$ et al 1997). The cataract was described in younger members as having 'peripheral blue flakes and occasional spoke-like central opacifications' with minimal effect on visual acuity. 'In most cases cataract extraction became necessary between 20 and 40 years of age.'(Bodker FS et al, 1992). The slit lamp photographs of an affected individual from a family affected by blue-dot (cerulean) cataract included in this study are shown in figures 36 and 37 , page 80 .

Zonular-sutural cataract: A three-generation family with isolated autosomal dominant cataract was studied by Padma et al (Padma T et al, 1995) in which the phenotype consisted of zonular and sutural opacities. They state that all 'affected family members showed a zonular cataract that measured $3.5-4 \mathrm{~mm}$ in diameter, an erect $\mathrm{Y}$-shaped anterior sutural cataract, and an inverted $\mathrm{Y}$-shaped posterior sutural cataract. The fetal and embryonic nuclei within the zonular cataract were 
clear except for a few dotlike white opacities.' This description is very similar to lamellar pedigrees examined as part of this study and illustrated in figures 30-34 pp75-78. As in the zonular pulverulent and Marner cataract pedigrees, the zonular sutural cataract pedigree shows intra-familial phenotypic heterogeneity in that the cataract may vary from a uniform dense opacity to a collection of fine dots forming a hazy cloud.

Volkmann cataract: This phenotype is named after the earliest known ancestor of the affected Danish family. It has been followed for ten generations and consists of 426 people. The cataract is 'characterised by a progressive, central and zonular cataract, with opacities both in the embryonic, fetal and juvenile nucleus and around the anterior and posterior Y-suture.' It has a 'highly variable expression ranging from hardly recognisable opacities in the lens to dense cataracts.' (Eiberg H et al, 1995).

Polymorphic: A study of the Turkmen population in the former Soviet Union found a high incidence of autosomal dominant cataract. A seven-generation pedigree consisting of 254 members of whom 103 were affected by a polymorphic cataract underwent linkage analysis. The phenotype 'is characterised by partial opacity of the lens, which has a variable location on the periphery between the fetal nucleus of the lens and the equator. The form of the opacity is irregular and looks similar to a bunch of grapes or a lump of cotton. The opacities can be located simultaneously in the different lens layers. The colour of the opacities varies from shining crystal-like to snow-white. This cataract is different from nuclear cataracts and more similar to zonular or lamellar types of cataracts.' (Rogaev EI et al, 1996). The detailed description is to illustrate the difference of this polymorphic phenotype to that of the Coppocklike cataract as they both link to the $\gamma$-crystallin cluster on $2 \mathrm{q}$.

Pedigrees affected by anterior polar cataract, posterior polar cataract and two pedigrees affected by pulverulent cataract have been linked to different loci as part of this project and these phenotypes will be discussed later. 


\section{Other linkage studies:}

There have been many other linkage studies with families affected by ADC and whilst these have excluded loci they have not demonstrated positive linkage. Many of the phenotypes in these linkage studies resemble mapped phenotypes, which suggests considerable genetic heterogeneity. Hammerstein and Scholz (Hammerstein W et al 1974), conducted linkage analyses on a family with cataracts in the embryonal nucleus similar to the central pulverulent cataract, Huntzinger et al (Huntzinger RS et al, 1977) studied a family with dense nuclear cataract, Conneally et al (Conneally PM et al, 1978) studied a cataract resembling the zonular pulverulent cataract which suggested linkage to the same locus on chromosome 1 but was inconclusive and Stabile et al (Stabile M et al, 1983) performed linkage on a family with a pulverulent cataract. Bateman et al (Batemen JB et al, 1986) studied a family with a nuclear cataract, Beaumont et al (Beaumont C et al, 1989) and Birdwood et al (Birdwood SC et al, 1968) excluded loci an a family with lamellar cataract and Barrett et al (Barrett D et al, 1988) showed exclusion for a family with an embryonal cataract. More recently, negative linkage studies were still being published and Basti et al reported the negative findings from a linkage study on a family affected by zonular cataracts and sutural opacities (Basti et al, 1996).

\section{Summary:}

These phenotypes that have been mapped to genetic loci represent a fraction of the broad clinical spectrum seen in ADC. Clinical heterogeneity exists not just between different pedigrees but also within certain pedigrees. Similar phenotypes map to widely separated loci, as seen with the blue-dot phenotype, and very different phenotypes appear to be allelic, as with the Volkmann and posterior polar cataract phenotypes. However, the phenotypes that have demonstrated linkage and have had the underlying gene mutation analysed show startling correlation to the molecular biology. 


\section{$\underline{\text { Molecular Genetics }}$}

\section{Introduction}

In recent years there have been considerable advances in the field of molecular genetics (Antonarakis SE, 1994. Yates JRW, 1996) and there are now ten loci known to be involved in the development of ADC. At the outset of this study in 1994 there were only three loci identified as being involved in cataract formation; the early linkage in 1963 by Renwick and Lawler (Renwick and Lawler 1963), the linkage of the Coppock-like cataract to the $\gamma$-crystallin gene complex on $2 \mathrm{q}$ in 1987 (Lubsen et al 1987) with the subsequent mutation in the $\gamma$-E crystallin gene. And finally the linkage of the Marner cataract to 16q in 1988 (Eiberg et al 1988). The linkage by Renwick and Lawler was performed using protein polymorphisms such as blood group and serum protein markers. The small numbers of such proteins and the low heterozygosity (leading to uninformative results) restricted such linkage studies to small isolated areas of the genome. With the development of the more numerous restriction fragment length polymorphisms (RFLPs) it became possible to exclude a greater proportion of the genome. In 1987 the first human genetic map was published using mainly RFLPs (Donis-Keller et al.,1987). The average spacing between markers was greater than $10 \mathrm{cM}$ and the markers were not very informative and were difficult to type. Microsatellites are now the accepted and most advanced method to perform linkage studies (Hearne $\mathrm{CM}$ et al, 1992) and a 1cM microsatellite map is now available (Dib C et al, 1996). Microsatellite markers are also described as short tandem repeat polymorphism (STRPs) and are abundant, dispersed throughout the genome and are highly informative. They are also much easier to type then their predecessors.

The advances in linkage technology have been accompanied by an explosion in linkage studies. With the onset of microsatellite marker systems linkage studies became more numerous and in 1995 alone, after the start of this research, three new loci were demonstrated (Eiberg et al 1995, Padma et al 1995, Armitage et al 1995). There are now ten loci and the underlying mutations have been isolated at 
seven of these. Animal models and chromosome abnormalities in individuals affected with cataract have also been useful in suggesting candidate loci for cataract genes.

Linkage Studies: The term linkage refers to the simultaneous transmission of two chromosomal loci from one parent to an offspring at a higher frequency than that expected by chance. This means that they are not only on the same chromosome, but are very close to each other. Many linkage studies into the molecular genetics of cataract have been undertaken, most have excluded loci and some have demonstrated linkage. There are now ten loci for dominant cataracts discovered so far and the muatation in the underlying gene has been identified in seven cases. These are shown in Table 1 below.

Table 1. Autosomal Dominant Cataract Loci.

\begin{tabular}{|c|c|c|c|}
\hline & Phenotype & Locus \& Protein & Authors \\
\hline \multirow[t]{2}{*}{1} & Volkmann & $1 \mathrm{p} 36$ & Eiberg et al.(1995) \\
\hline & Posterior polar & $1 \mathrm{p} 36$ & Ionides et al (1996) \\
\hline \multirow[t]{2}{*}{2} & Zonular Pulverulent & $1 \mathrm{q} 21-25$ & Renwick \& Lawler (1963) \\
\hline & & Connexin50 & Shiels et al (1998) \\
\hline \multirow[t]{4}{*}{3} & Coppock-like & $2 q 33-36$ & Lubsen et al (1987) \\
\hline & & $\gamma \mathbf{E}$-crystallin & Brackenhoff et al (1994) \\
\hline & Polymorphic & $2 q 33-36$ & Rogaev et al (1996) \\
\hline & Juvenile & $2 q 33-36 \gamma$ D-crystallin & Stephan et al (1999) \\
\hline \multirow[t]{2}{*}{4} & Pulverulent & $13 q$ & Mackay et al (1997) \\
\hline & & Connexin46 & Mackay et al (1999) \\
\hline 5 & Marner & $16 \mathrm{q} 22.1$ & Eiberg et al. (1988) \\
\hline 6 & Anterior polar & $17 \mathrm{p}$ & Berry et al (1996) \\
\hline \multirow[t]{2}{*}{7} & Zonular-sutural & $17 q 11-12$ & Padma et al. (1995) \\
\hline & & $\beta A 3 / A 1-c r y s t a l l i n$ & Kannabiran et al (1999) \\
\hline 8 & Cerulean (Blue-dot) & $17 q 24$ & Armitage et al. (1995) \\
\hline 9 & Zonular central & $21 \mathrm{q} 22.3 \alpha \mathbf{A}$ crystallin & Litt et al (1998) \\
\hline \multirow[t]{2}{*}{10} & Cerulean (Blue-dot) & $22 \mathrm{q} 11.2-12.1$ & Kramer et al. (1996) \\
\hline & & $\beta$ B2-crystallin & Litt et al (1997) \\
\hline
\end{tabular}


The details of the successful linkage studies with families affected by ADC are given below. Although Table 1 includes all the known loci and mutations published up to the end of 1999, only those published up 1997 will be discussed as part of the introduction to this thesis. It was these publications that made a significant impact on our linkage approach at that time and were therefore of great interest as they appeared in the scietific press.

Zonular pulverulent Cataract: In 1963 Renwick and Lawler demonstrated linkage of a large family with congenital zonular pulverulent cataract to the Duffy blood group locus (Renwick JH et al, 1963) and so described the first human disease to be mapped to a specific autosome (Maumenee IH, 1979). The Duffy locus was later mapped to chromosome 1q (Donahue RP et al, 1968). The linkage was achieved using blood group systems and a maximum LOD score of 3.78 was obtained at $\theta=0$. Work related to this MD has now described the mutation in a gene encoding connexin50 to be the cause of the cataract in this family.

Coppock-like Cataract: In 1987 linkage was demonstrated for the Coppock-like cataract to chromosome $2 \mathrm{q}$ using restriction enzyme fragment length polymorphisms, demonstrating a maximum LOD score of 7.58 at $\theta=0$ (Lubsen $\mathrm{NH}$ et al, 1987). Most of the crystallin genes had been cloned by this time (Bloemendal H, 1985) allowing a candidate gene approach to successfully demonstrate linkage to the $\gamma$-crystallin gene complex on chromosome $2 \mathrm{q}$. Although abnormalities in the crystallin proteins had been shown to give rise to hereditary cataract in mice (Carper D et al, 1982; Garber AT et al, date) this was the first such example in human ADC. This is the only linked phenotype in which the underlying genetic aetiology has been further assessed. There is an over expression of the $\gamma$ E pseudogene (Brakenhoff $\mathrm{RH}$ et al, 1994) owing to a cluster of sequence changes within and around its TATA box which is thought to give rise to an improperly folded $\gamma$-crystallin fragment. More recently the original authors have expressed doubt as to whether this mutation is indeed the cause of the cataract but have yet to publish any further details. 
Marner Cataract (CAM): Linkage of this phenotype using polymorphic marker systems was demonstrated in 1988 to haptoglobin with a maximum lod score of 8.31 at recombination fraction $\theta=0.05$. This places the gene causing the cataract within band 16q22 (McGill JR et al, 1984) although no candidate gene has been identified in this region (Eiberg $\mathrm{H}$ et al, 1988). DNA had been collected from 104 affected and 85 unaffected family members and there was only a single recombination. A pedigree affected by a different phenotype, a posterior polar cataract has been described by Maumenee (Maumenee IH, 1979) and may also be linked to this same locus. In this second pedigree 60 family members were examined including 21 affected individuals and the LOD score calculated was 2.11 (Richards J et al, 1984). This falls below the current criteria for linkage (demanding a minimum LOD score of 3.0). If this posterior polar cataract and the Marner cataract do both link to this locus, it may be that the two different phenotypes are alleles of the same gene.

Cerulean cataract: Linkage has been demonstrated for two pedigrees affected by cerulean (blue-dot) cataract, to two different loci. Armitage et al demonstrated linkage of this phenotype to a 6cM interval on chromosome $17 \mathrm{q}$ in 1995 (Armitage MM et al, 1995) during a genome wide search using microsatellite markers. The highest LOD score was 9.46 at $\theta=0.085$ for marker D17S802, with multipoint analysis giving a LOD score of 13.71 for the region between D17S802-D17S836. The 17q24 region contains four genes including the galactokinase gene. This gene is known to cause autosomal recessive cataracts but has not yet been cloned. The other three genes were excluded as being the causative gene by linkage analysis to intragenic DNA repeat polymorphisms.

A second locus for cerulean cataract was then reported a year later by Kramer et al mapping to the $\beta$-crystallin region on chromosome 22q (Kramer $P$ et al, 1996). This region contains three $\beta$-crystallin genes; CRYBB2, CRYBB3 and CRYBB2P1. An initial linkage study demonstrating exclusion had been published six years earlier (Bodker FS et al, 1992) but with the development of microsatellite markers a more detailed analysis of the candidate regions was 
undertaken. A LOD score of 6.80 was reached with the marker D22S258 and multipoint analysis showed a maximum multipoint location score of 7.59 for this marker. A chain-termination mutation in the $\beta$-crystallin gene (CRYBB2) has since been detected and is associated with the cataract in this family (Litt M et al, 1997).

Zonular-sutural cataract: A three generation family with this phenotype was studied by Padma et al (Padma T et al, 1995). After exclusion of the regions on the genome known to contain cataract loci, other genes were considered as candidates and close to the $\beta \mathrm{A} 3 / \mathrm{A} 1$ crystallin gene locus on chromosome $17 \mathrm{q}$ they demonstrated linkage with a maximum lod score of 3.9 at D17S805 with a $17 \mathrm{cM}$ interval. A mutation in this gene has now been shown to give rise to the cataract (Kannabiran C et al 1999).

Volkman cataract: The linkage study into this family excluded approximately $95 \%$ of the human autosomes by typing 300 polymorphic loci in 91 family members (Eiberg $\mathrm{H}$ et al, 1995). The closest linkage was reached at marker D1S243 with a lod score of $Z \max =14.04$ at $\theta_{M}=0.025 \theta_{F}=0.000$. The enolase 1 alpha gene (ENO 1) is close to this region and codes for both an enzyme and $\tau$ crystallin, which is present in lower species. This has yet to be excluded as causing the Volkmann cataract.

Polymorphic: A seven generation pedigree consisting of 254 members of which 103 were affected by a polymorphic cataract underwent linkage analysis (Rogaev EI et al, 1996). The polymorphic cataract gene was found to be linked to a $15 \mathrm{cM}$ region with a maximum lod score of 10.62 for the CRYG 1 locus marker. Multipoint analysis increased the LOD score to $>17.0$ at the CRYG 1 locus and the authors have started to screen for mutations.

\section{Other linkage studies:}

Many linkage studies have been performed that have resulted in exclusion of certain candidate loci, but have failed to demonstrate linkage. Most of the studies 
were performed before the availability of microsatellite markers (Dib C et al, 1996) and so genome wide searches were not possible. Other polymorphic systems were used (Jay M, 1982) and only the major candidate loci were able to be excluded. Many of the phenotypes in these linkage exclusion studies resemble mapped phenotypes which suggests considerable genetic heterogeneity.

\section{Animal models:}

Many animal models exist for inherited cataract including mice, rats, guinea pigs and dogs (Zigler JS, 1990; Tripathi BJ et al, 1991; Sidjanin et al 1998). The advantages of animal models include the comparative ease of breeding large litters that provide statistically significant data, as well as the availability of lens material allowing the course of the disease to be followed histologically and biochemically from the earliest stages. Another advantage in mice is that the mouse genome is well characterised with many mouse-to-human homologies (Peters J et al 1996). Extensive linkage studies can be carried out and transgenic animal models can test the role of different mutations on cataract formation. The identification of loci for eye diseases in mice has in turn led to the identification of the corresponding human genes (Travis GH et al, 1991) owing to the strong evolutionary conservation of genomic regions between mice and men.

In many animal models the clinical phenotype and age of onset has been documented and in many cases the underlying abnormality has been detected. Of particular importance are the Philly mouse in which a 12 nucleotide deletion in the $\beta B 2$ cDNA (Chambers $C$ et al, 1991) results in a mutant $\beta B 2$ protein that is thought to give rise to the cataract. A chain termination mutation in the human $\beta B 2-c r y s t a l l i n$ is associated with autosomal dominant cerulean cataract (Litt et al 1997). In the Elo mouse the mutation consists of a single base pair deletion in the $\gamma \mathrm{E}$-crystallin gene (Cartier $\mathrm{M}$ et al, 1992) resulting in a failure of the lens fibre cells to elongate. A mutation in the human $\gamma \mathrm{E}$-crystallin gene is associated with the nuclear CCL cataract and a splice site mutation in the $\gamma$-crystallin gene causes an autosomal dominant cataract in the guinea pig (Roderiguez IR et al 1992). The $\mathrm{Cat}^{\mathrm{Fr}}$ and the Cat ${ }^{\text {lop }}$ mice have cataracts caused by mutations in the gene for MIP- 
particularly mouse cataract, provides useful information that is relevant to the human genome (Kerscher $\mathrm{S}$ et al, 1996). Over 60 autosomal dominant cataract mouse mutants have been described (Sidjanin et al 1997) indicating the extent of the genetic heterogeneity in both mice and humans (Doolittle DP et al, 1996).

\section{Chromosomal Abnormalities associated with cataract:}

In humans, translocations and deletions have been noted to be associated with cataract and although they have not led to the discovery of new loci for ADC, they have contributed candidate regions to linkage studies concerning inherited cataract.

A reciprocal translocation between the short arms of chromosome 3 and 4 in a father and son with cataract but no other ocular nor systemic abnormalities has been reported (Reese PD et al, 1987) and although this does not prove a causal relationship it suggests candidate loci at the break points involved in the translocation at 3p26.2 and 4p15. A translocation between chromosomes 2 and 14 associated with anterior polar cataract (Moross T et al, 1984) similarly suggests that two loci at $2 \mathrm{p} 25$ and $14 \mathrm{q} 24$ may be involved in cataract formation. Cataract has also been described in association with other chromosomal disorders but has included more generalised ocular and systemic abnormalities (Rubin SE et al, 1994; Miller BA et al, 1992; Yokoyama Y et al, 1992; Bonneau D et al, 1995). The causative genes in these cases may well have a wider role than that limited to cataract formation and have not been included as candidate regions for $\mathrm{ADC}$.

Summary: As knowledge concerning the molecular biology and genetics of lens development and cataracatogenesis increases, a longer list of candidate regions emerges for those undertaking a linkage study in $\mathrm{ADC}$. In the remaining chapters of this thesis a description is given of how the families were collected and clinically assessed, and the approach taken to the linkage study and how, from the 15 pedigrees, linkage was demonstrated for five pedigrees and mutations isolated in three of these pedigrees. 
aquaporin (Griffen et al 1992, Muggleton-Harris et al 1987) which maps to $12 \mathrm{q}$ in humans and is an important candidate gene for human cataract (Francis et al submitted).

The remainder of the mouse mutants and the corresponding human regions are shown in table 2 below.

Table 2. Loci of the mouse cataracts with the corresponding human regions.

\begin{tabular}{|c|c|c|c|}
\hline $\begin{array}{c}\text { Mouse } \\
\text { Chromosome }\end{array}$ & Mutant & Genetic defect & $\begin{array}{l}\text { Human } \\
\text { Synteny }\end{array}$ \\
\hline \multirow[t]{9}{*}{1} & $\mathrm{Cat2}^{t}$ & Cryge & CRYG / CCL \\
\hline & Cat $2^{\text {nop }}$ & Crygb & - \\
\hline & $\mathrm{Cat} 2^{E N U-436}$ & Cryga & \\
\hline & Cat $^{n z}$ & & \\
\hline & Cat $2^{n s}$ & & \\
\hline & Cat $2^{r o}$ & & \\
\hline & $\mathrm{Cat}^{\mathrm{no2}}$ & & \\
\hline & $\mathrm{Cat} 2^{\text {tol }}$ & & \\
\hline & $\mathrm{Cat}^{\text {elo }}$ & $\gamma-\mathrm{E}$ crystallin mutation & \\
\hline 2 & Lop ${ }^{4}$ & Cp 49 & Filensin on Ch 20 \\
\hline \multirow[t]{2}{*}{4} & Cur & & \\
\hline & Dyl & & \\
\hline \multirow[t]{2}{*}{5} & Philly & $\beta B I$-crystallin & $\beta$-crystallin 22q \\
\hline & $N p p$ & & $4 p 16-21 q$ \\
\hline 7 & To3 & $\operatorname{Lim} 2, M P 10$ & \\
\hline \multirow[t]{4}{*}{10} & $\mathrm{Cat}^{\mathrm{Fr}}$ & MIP & MIP, 12q \\
\hline & $\mathrm{Cat}^{\mathrm{lop}}$ & & \\
\hline & To 2 or Cat 5 & & $6 q 21-q 27$ \\
\hline & Cat3 & & $12 q$ \\
\hline \multirow[t]{2}{*}{16} & Opj & & $16 \mathrm{p}$ or $2 \mathrm{q} t(2 ; 16)$ \\
\hline & & & break \\
\hline 19 & $a k$ & Pitx3 & \\
\hline $\mathbf{X}$ & Xcat & & \\
\hline
\end{tabular}

Note: This table is adapted from Francis et al 1999.

The wide genetic heterogeneity of inherited cataract in humans is a major obstacle in the isolation of the causative genes and the study of animal models, 


\title{
Patients \& Methods
}

\author{
Patients
}

Clinical Assessment

46

Laboratory techniques

Genotyping \& Linkage Analysis

49

Candidate genes 


\section{PATIENTS \& METHODS}

\section{Clinical assessment:}

The patients were recruited from the genetic clinic data-base at Moorfields Eye Hospital and invited to attend for a single visit to participate in the study. A medical and ophthalmological history was taken along with family details to construct a family tree. The patients underwent visual acuity testing, tonometry, anterior segment examination both before and after pupil dilatation including lens photography where possible, and finally examination of the retina. The findings were recorded on the sheet below. A blood sample was taken for DNA analysis. The parents, siblings and children of all affected individuals in any single pedigree were then contacted and invited to participate in the study. 


\section{AUTOSOMAL DOMINANT CATARACT}

\section{PRO-FORMA}

Date

NAME

ADDRESS

TEL

\section{CATARACT}

- Age at onset

- Microphthalmia

- Morphology

- Surgical procedures Place

- Management of aphakia

- Refraction

$\mathrm{R}$

Date

R L
NO.

DOB 
- Strabismus

- Registration

- Education

- Family Tree

\title{
EXAMINATION
}

\section{Nystagmus}

\section{Medication $y$}

\author{
V/A \\ c \\ RAPD
}

lids

conj

cornea

\section{Gonioscopy}

O 0

Disc 


\section{LABORATORY TECHNIQUES.}

\section{Genotyping}

Genomic DNA was extracted from EDTA-sequestered blood samples using the Nucleon II DNA extraction kit (Scotlab Bioscience) as described below.

\section{Preparation of DNA from whole blood.}

Eighteen millilitres of whole blood was collected from each subject in two separate sterile tubes containing $0.5 \mathrm{M}$ ethylenediaminetetraacetate (EDTA). They were stored at $-80^{\circ} \mathrm{C}$ in separate freezers until the pedigree was large enough to begin the linkage analysis. The blood was then thawed at $37^{\circ} \mathrm{C}$ to allow for DNA extraction performed using the Nucleon II DNA Extraction kit. This method entails the following steps.

1) Cell Preparation. The blood sample was poured into a $50 \mathrm{ml}$ falcon tube and reagent A (see below) was added to a total of 50mls. This was carefully mixed and then centrifuged at $1400 \mathrm{rpm}$ for ten minutes. The supernatant was discarded leaving the leucocyte pellet.

2) Cell lysis. Two millilitres of reagent $B$ (see below) were then added to the pellet which was broken up by gentle pipetting and the cell lysate transferred to a $5 \mathrm{ml}$ tube.

3) Deproteination. $500 \mu \mathrm{l}$ of $5 \mathrm{M}$ sodium perchlorate were added to the lysate and rotary mixed for 15 minutes at room temperature. They were then incubated at $65^{\circ} \mathrm{C}$ for 25 minutes whilst rotary mixing.

4) DNA extraction. After removal from the oven the samples were cooled on ice and

$2 \mathrm{ml}$ of chloroform and $300 \mu \mathrm{l}$ of nucleon silica suspension were added. The contents

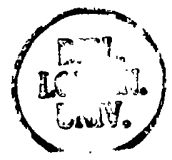


were then rotary mixed for five minutes at room temperature. Separation of the aqueous and organic phases was achieved by centrifuging at 1400rpm for 6 minutes.

5) DNA precipitation. The top aqueous layer containing the DNA was transferred to a universal tube using a pipette and two parts of ethanol equal to the amount of aqueous were added to precipitate the DNA.

6) DNA resuspension. The precipitated DNA was picked out of the universal using sterile needles and transferred to a sterile $1.5 \mathrm{ml}$ Eppendorf tube and washed with $70 \%$ alcohol. The pellet of DNA was then resuspended in $400 \mu$ l of sterile distilled water and left for 24 hours. Twenty microlitre aliquots were then removed and diluted in preparation for linkage analysis and the remaining stock kept at $-20^{\circ} \mathrm{C}$.

\section{Nucleon II DNA Extraction Kit Solutions.}

\begin{tabular}{|c|c|c|c|}
\hline \multirow[t]{5}{*}{ Reagent A: } & $10 \mathrm{mM}$ Tris- $\mathrm{HCl}$ & Reagent B: & $400 \mathrm{mMTris}-\mathrm{HCl}$ \\
\hline & $320 \mathrm{mM}$ sucrose & & pH 8 with $\mathrm{mM} \mathrm{NaOH}$ \\
\hline & $5 \mathrm{mM} \mathrm{MgCl}_{2}$ & & 60mM EDTA \\
\hline & $1 \%$ Triton $X-100$ & & $150 \mathrm{mM} \mathrm{NaCl}$ \\
\hline & $\mathrm{pH} 8$ with $2 \mathrm{M} \mathrm{NaOH}$ & & $1 \% \operatorname{SDS}$ \\
\hline
\end{tabular}

\section{Genotyping}

Genethon microsatellite markers (Gyapay $G$ et al, 1994) were amplified using the polymerase chain reaction (PCR). The forward PCR primer was 5'-end labelled using $\left[\gamma-{ }^{32} \mathrm{P}\right] \mathrm{dATP}(\sim 110 \mathrm{Tbq} / \mathrm{mmol})$ and $\mathrm{T} 4$ polynucleotide kinase prior to amplification. The standard PCR mix $(10 \mu \mathrm{l})$ contained 200ng DNA, 2.5pmol of each primer, $50 \mathrm{mM} \mathrm{KCL}, 10 \mathrm{mM}$ Tris- $\mathrm{HCl}$ ( $\mathrm{pH} 9.0$ ), 0.15\% Triton-X 100, 1.5 
Patients \& Methods: Clinical assessment

$\mathrm{mM} \mathrm{MgCl} 2,250 \mu \mathrm{M}$ od each dNTP and $0.6 \mathrm{U}$ of Taq DNA polymerase. Standard PCR conditions were: 1 cycle at $94^{\circ} \mathrm{C}$ for $3 \mathrm{~min}$, followed by 30 cycles at $94^{\circ} \mathrm{C}$ for $1 \mathrm{~min}, 50$ or $55^{\circ} \mathrm{C}$ for $1 \mathrm{~min}, 72^{\circ} \mathrm{C}$ for $1 \mathrm{~min}$, then 1 cycle at $72^{\circ} \mathrm{C}$ for $5 \mathrm{~min}$. Radiolabelled PCR products were separated on denaturing $6 \%$ polyacrylamide gels and detected by autoradiography.

\section{Linkage analysis.}

Data was collated using the LINKSYS (version 3.1) data management package (Attwood J et al,1988). Two-point LOD scores were calculated using the MLINK and ILINK sub-programmes of the LINKAGE (version 5.1) package (Lathrop GM et al, 1984) Allele frequencies calculated from the spouses in the families were similar to those quoted by Généthon. Multipoint analysis was computed using LINKMAP run on the computing facilities of UK Human Genome Mapping Project Resource Centre computing facilities. Full penetrance and a gene frequency of 0.0001 were assumed for the disease locus. 


\section{Candidate Gene Approach}

Candidate genes: A candidate gene approach involves creating a genetic map of loci known to be relevent to the formation of cataract. These loci are then the first areas of the genome to be screened for the disease-causing gene in the affected families, prior to undertaking a genome wide search. This approach is the accepted method for linkage studies and has been successfully used in locating the genes for the Coppock-like cataract, the Volkmann, polymorphic, Marner, zonular-sutural and cerulean cataract.

The different candidate loci are placed in an order of priority. In this study the first loci to be assessed were those that had already been demonstrated to be linked to inherited cataract phenotypes (see Table 3, p53). The crystallin genes were then excluded followed by the membrane proteins, cytoskeletal proteins and finally the genes for relevent enzymes and the taxon specific crystallins. A genome wide search was then undertaken.

For each locus microsatellite markers were picked at $5 \mathrm{cM}$ intervals where possible. The initial temperature for the PCR was $55^{\circ} \mathrm{C}$, and if this failed to give a meaningful result, the temperature would be altered to either $51^{\circ} \mathrm{C}$ or $58^{\circ} \mathrm{C}$. If this failed or the marker was uninformative for the family, then a neighbouring marker would be picked as an alternative. 
Table 3. Major Candidate Genes for Autosomal Dominant Cataract. (Excluding the taxon specific genes, translocations and mouse loci).

Volkmann (CCV), Posterior polar (CTPA)

$1 \mathrm{p} 36$

Zonular Pulverulent (CZP1)

$1 \mathrm{q} 21-25$

Coppock-like (CCL), Polymorphic

$2 \mathrm{q} 33-36$

(CCP), aculeiform, juvenile.

Pulverulent

$13 q$

Marner

$16 \mathrm{q} 22.1$

Anterior polar (CTAA2)

$17 \mathrm{p} 12-13$

Zonular-sutural (CCZS)

17q11-12

Cerulean (CCA1)

$17 \mathrm{q} 24$

Zonular central

$21 \mathrm{q} 11.2-12.1$

Cerulean (CCA2)

$22 \mathrm{q}$

\section{Human Crystallin genes}

$\alpha A$ (CRYA1)
$\alpha B$ (CRYA2)
$\beta A 1 / A 3$ (CRYBA1/3)
$\beta A 2$ (CRYBA2)
$\beta A 4$ (CRYBA4)
$\beta B 2$ (CRYBB2)
$\beta B 3$ (CRYBB3)
$\gamma A-F$ (CRYGA-F)
$\gamma s(C R Y G S)$
$\mu(C R Y M)$
$\zeta(C R Y Z)$

$21 \mathrm{q} 22.3$

11q22.3-23.3

$17 \mathrm{q} 11.1-\mathrm{q} 12$

2q34-36

$22 \mathrm{q} 11.2-13.1$

$22 \mathrm{q} 11.2-\mathrm{q} 12$

$22 \mathrm{q} 11.2-\mathrm{q} 12$

$2 \mathrm{q} 32-36$

3

16p13.11-p12.3

1p22-31

Membrane proteins

MIP (MP-26), Aquáporin.

MP70 / Cx50 (GJA8)

MP19 (LIM2)

Cx 46 (GJA3)
$12 \mathrm{q} 13-14$

$1 \mathrm{q} 21.1$

19

$13 q$

\section{Cytoskeletal proteins}

Phakinin (CP49 kD)

Filensin (CP94 kD)
$3 q 21-25$

20 


\section{Results}

Clinical assessment

Visual outcome \& complications of surgery

Age at diagnosis

Age at surgery and visual outcome

Number of surgical interventions and visual outcome

Visual outcome for the different phenotypes

Complications

Linkage Analysis

Positive Linkage:

Posterior polar (CTPA) cataract

Nuclear (CAE) cataract

Nuclear (CCL) cataract

Pulverulent (CZP2) cataract, two

$13 \mathrm{q}$

pedigrees

Anterior polar (CTAA2) cataract

$17 \mathrm{p}$ 


\section{Clinical Assessment}

180 patients affected by autosomal dominant cataract were examined. 163 of these came from 16 pedigrees that were large enough for linkage analysis. The remaining 17 patients were from small pedigrees. The families had no other ocular nor systemic abnormalities. Families were included for linkage analysis if there were three generations of affected individuals with at least four affected members. Male to male transmission was seen in 12 families and in the remaining families the severity of affected members was equal in both males and females suggesting autosomal dominant inheritance. The number of family members examined (excluding partners-although partners were examined and genotyped) and the number of affected individuals is shown in Table 4. In cases where surgery was performed early, a description of the phenotype was taken from the notes.

Eight phenotypes could be recognised that included all the individuals seen in the study. These phenotypes were; anterior polar, posterior polar, nuclear, coralliform, cortical, lamellar, blue-dot (cerulean) and pulverulent.

Table 4. Pedigree details and phenotypes.

\begin{tabular}{lrc}
\hline Phenotype & $\begin{array}{l}\text { No. of } \\
\text { affected } \\
\text { patients }\end{array}$ & $\begin{array}{l}\text { No. of pedigrees } \\
\text { (large enough for } \\
\text { a linkage study) }\end{array}$ \\
\hline Anterior polar & 27 & 1 \\
Posterior polar & 23 & 2 \\
Nuclear & 20 & 2 \\
Lamellar & 38 & 3 \\
Coralliform & 8 & 1 \\
Blue-dot (cerulean) & 7 & 1 \\
Cortical & 6 & 1 \\
Pulverulent & 51 & 5 \\
\hline Total & 180 & 16 \\
\hline
\end{tabular}


In any single pedigree the phenotypes of all the affected individuals was the same, varying only in the severity and density of the opacity. For example, in pedigrees affected by anterior polar cataract the opacity was always at the anterior pole of the lens, never in the nucleus nor elsewhere in the lens. The size of the opacity varied between affected individuals however, as will be seen in the subsequent illustrations. In pedigrees with the pulverulent phenotype there was considerable variation in the cataract phenotype amongst individuals from the same family.

\section{Anterior Polar Cataract}

In a single family with anterior polar cataract (pedigree A, Appx 1, p122) 21 members were found to be affected with the cataract. 7 patients had undergone surgery and the phenotype was examined in the remaining 14 cases. The opacity was always in the same position of the lens, the anterior pole, but varied in severity. The larger opacities (figures $2 \& 3$ ) were pyramidal with a base of $4 \mathrm{~mm}$ and extended into the anterior chamber, whilst the smaller opacities consisted of a flat plaque measuring under $1 \mathrm{~mm}$ in diameter (figures $4 \& 5$ ). In one case the only sign of an anterior polar abnormality was an irregularity of the anterior capsule (figure 6). Anterior polar cataract has traditionally been regarded as having a minimal effect on visual acuity but 11 of the affected patients who had not undergone surgery in the pedigree were amblyopic in one eye; the amblyopia occuring in the eye with the denser opacity. 


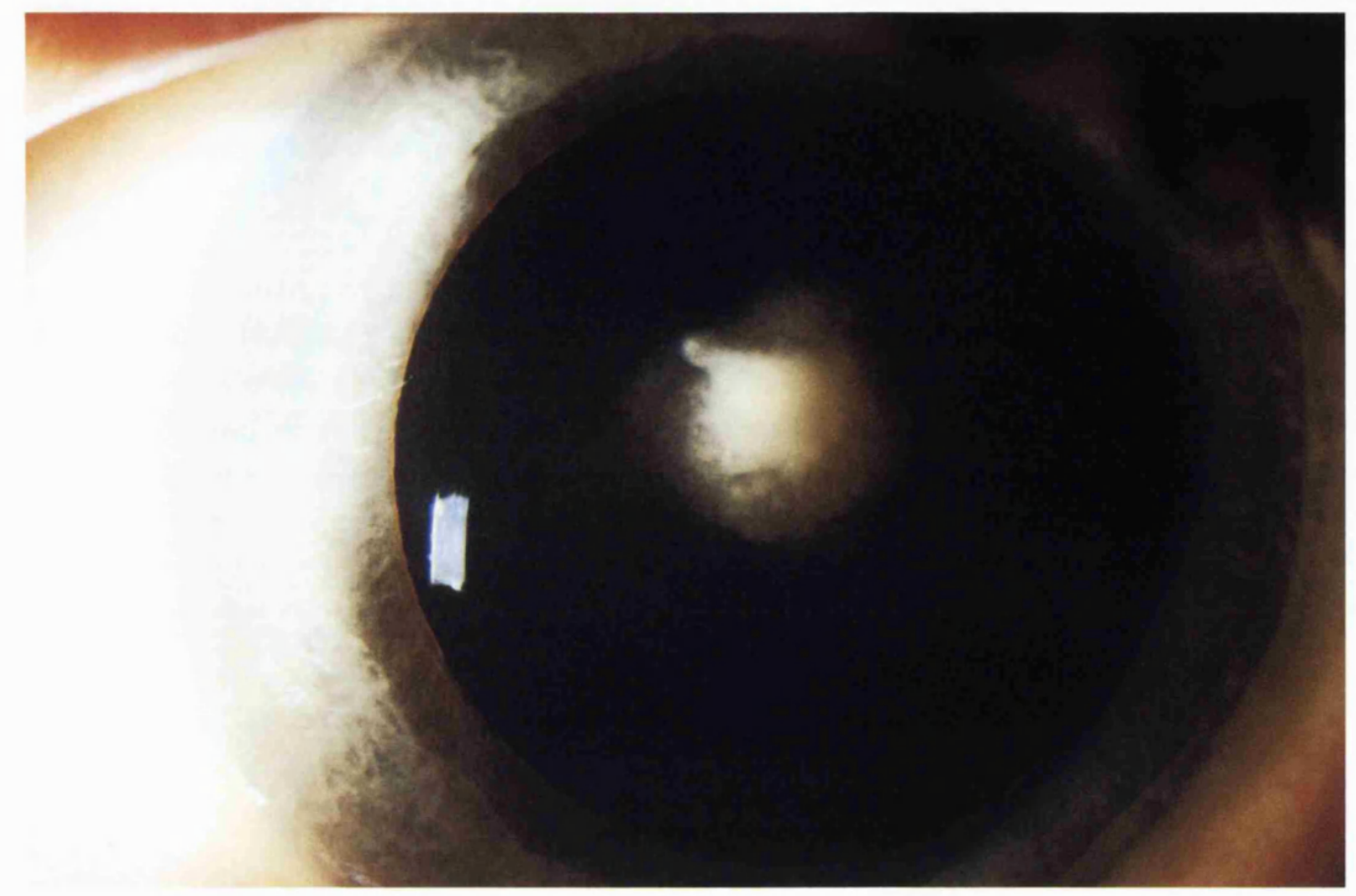

Figure 2. Anterior polar cataract: Pedigree A. Pyramidal. $\quad$ Individ 4.2

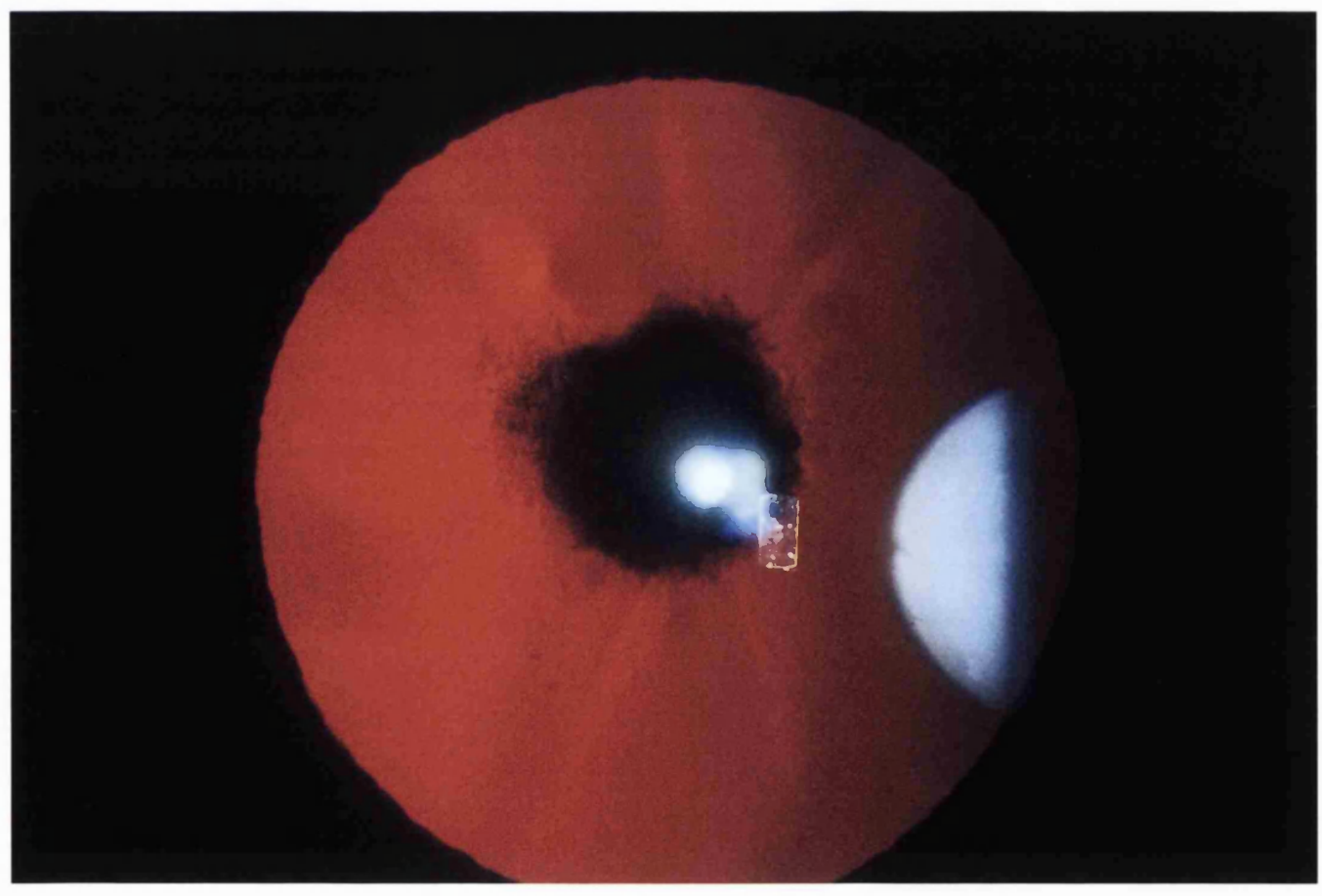

Figure 3. Anterior polar cataract: Pyramidal in retroillumination. Individ 4.2 


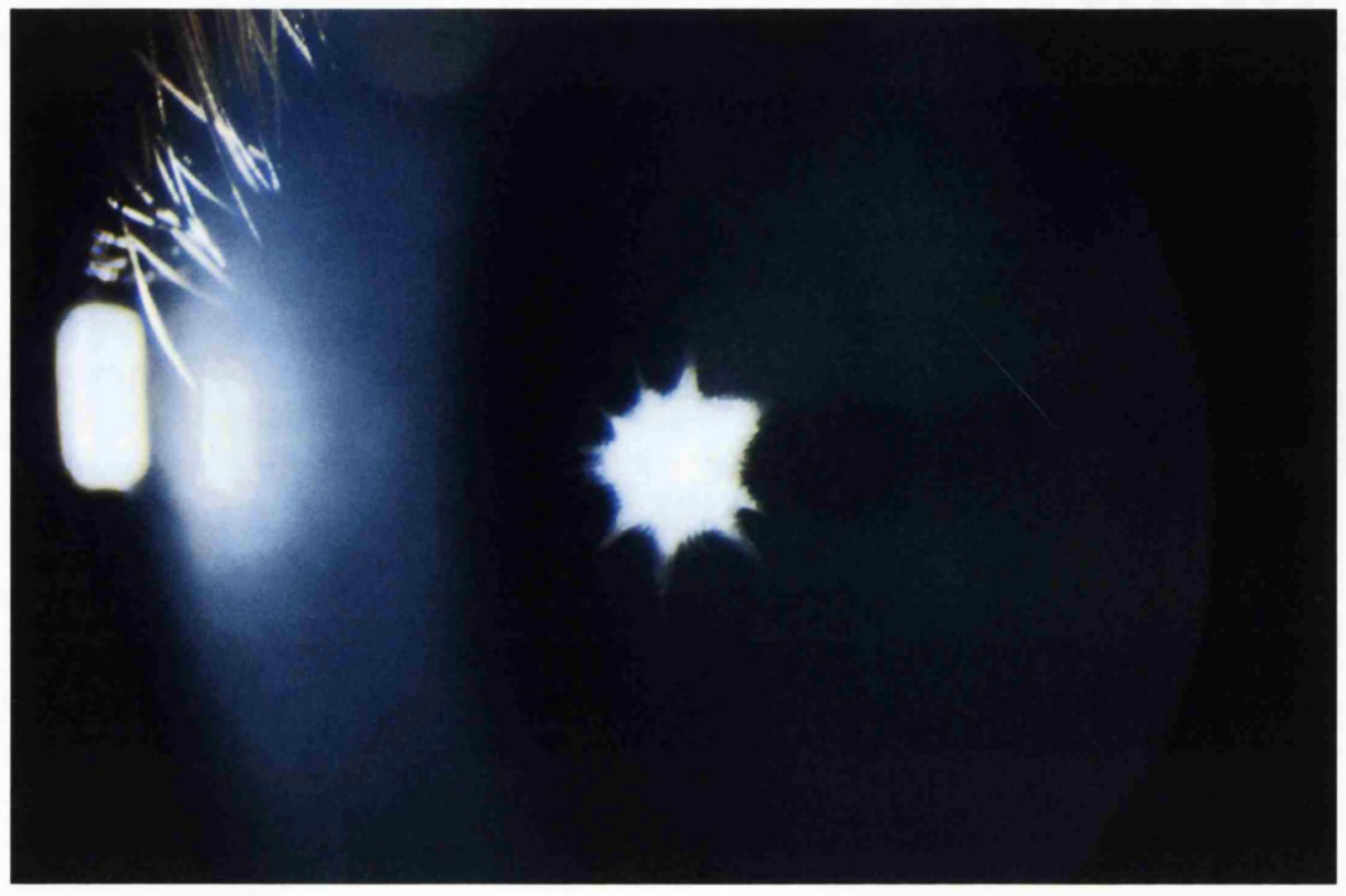

Figure 4. Anterior polar cataract. Ped A. Plaque. Individ 4.3

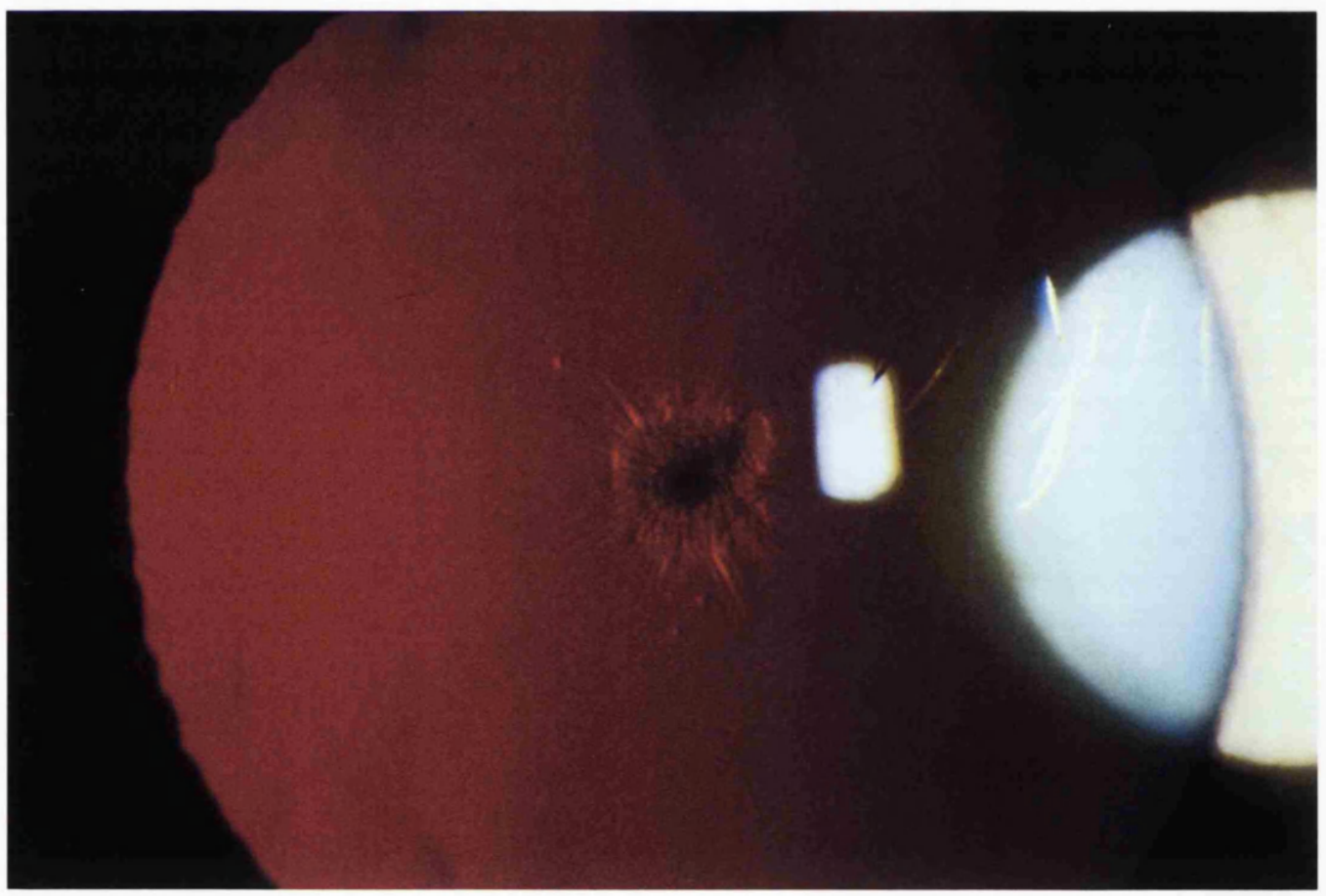

Figure 5. Anterior polar cataract: Plaque in retroillumination. $\quad$ Individ 4.3 


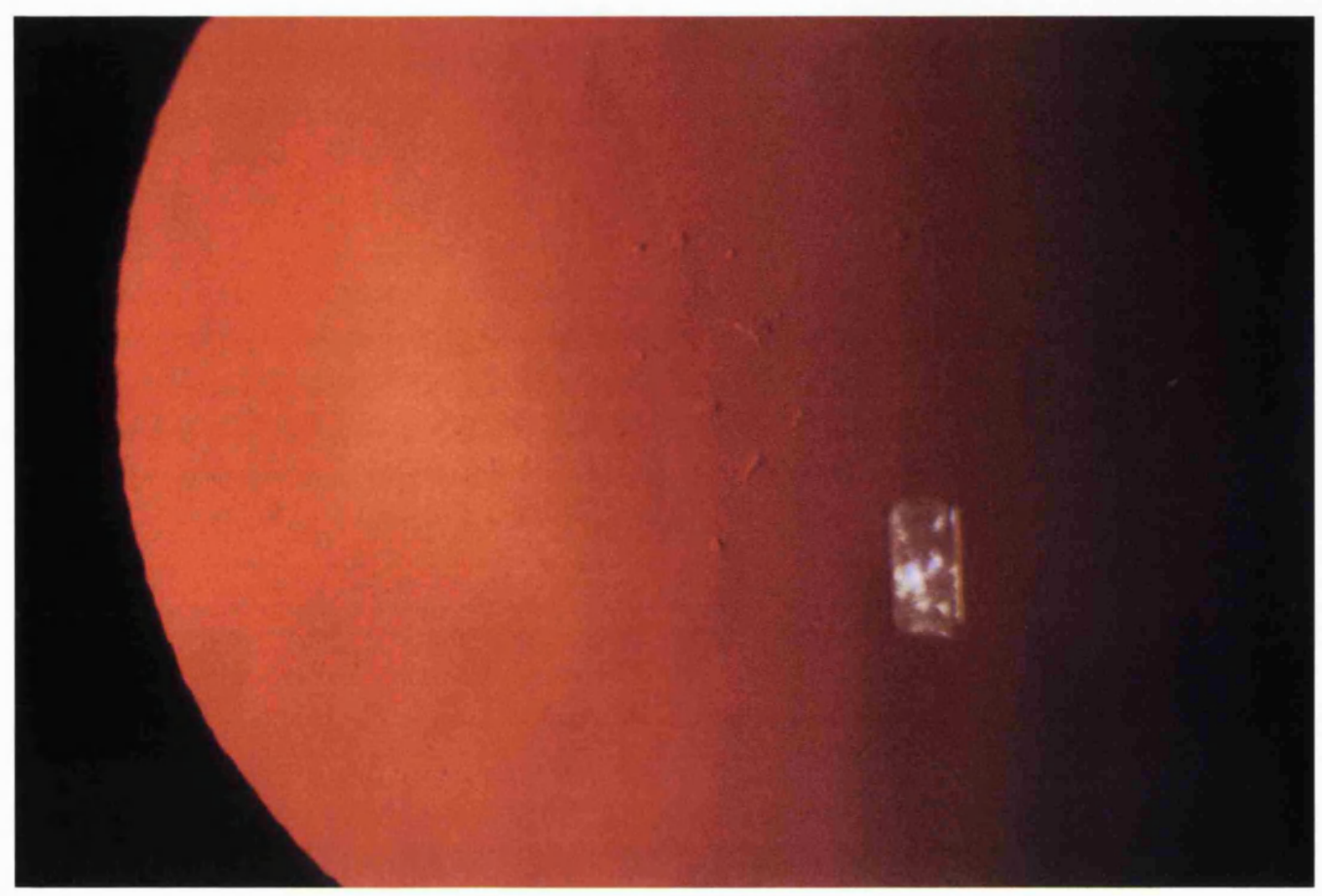

Figure 6. Anterior polar cataract: Retroillumination of capsule irregularity. Individ 5.6 


\section{Posterior polar cataract.}

Two families affected by posterior polar cataract were studied. In one pedigree (Pedigree B) ten peopole were affected and of these seven patients had undergone surgery. Details of the cataract were obtained from the notes in four of the cases, all of whom were described as having posterior polar or posterior subcapsular cataract. Three patients had not had surgery and the cataract consisted of a single well defined posterior polar plaque (Figures $7 \& 8$, right eye) that varied in size both between individuals (Figures $9 \& 10$ ), as well as between the eyes of an individual (Figures $11 \& 12$, left eye). Although we have not studied the family over a prolonged period of time, the hospital and optometrists notes suggest that the cataracts did not progress. The operated eyes underwent surgery at a mean age of 22 months (range 2-72 months, median of 3 months, mode 2 months) with a final V/A of $6 / 6$ to NPL (median $6 / 12$, mode $6 / 9$ ). The unoperated eyes had a V/A of $6 / 5$ to $6 / 36$.

In the second family with posterior polar cataract (Pedigree C), 11 were affected and all but one unilateral case had undergone surgery. Clinical records were available in nine cases and the opacity consisted of a posterior plaque that developed posterior cortical extensions (Figure 13) with punctate opacities causing a deterioration of the visual acuity requiring cataract extraction. No records were available in one case. The progressive nature of the cataract is also suggested in that the average age of diagnosis was 5 years but the surgery was performed at a mean age of 20 years (range 3-40, median 19, mode 16). The final V/A ranged from 6/5 to NPL (mode and median of 6/9). The age at surgery was older in this second family affected by posterior polar cataract and the visual outcome better.

One patient from a small pedigree affected by progressive posterior polar cataract is illustrated in Figures 14 and 15. This 13 year old developed a deterioration in visual acuity associated with the appearance of the early cortical extensions and punctate opacities. 


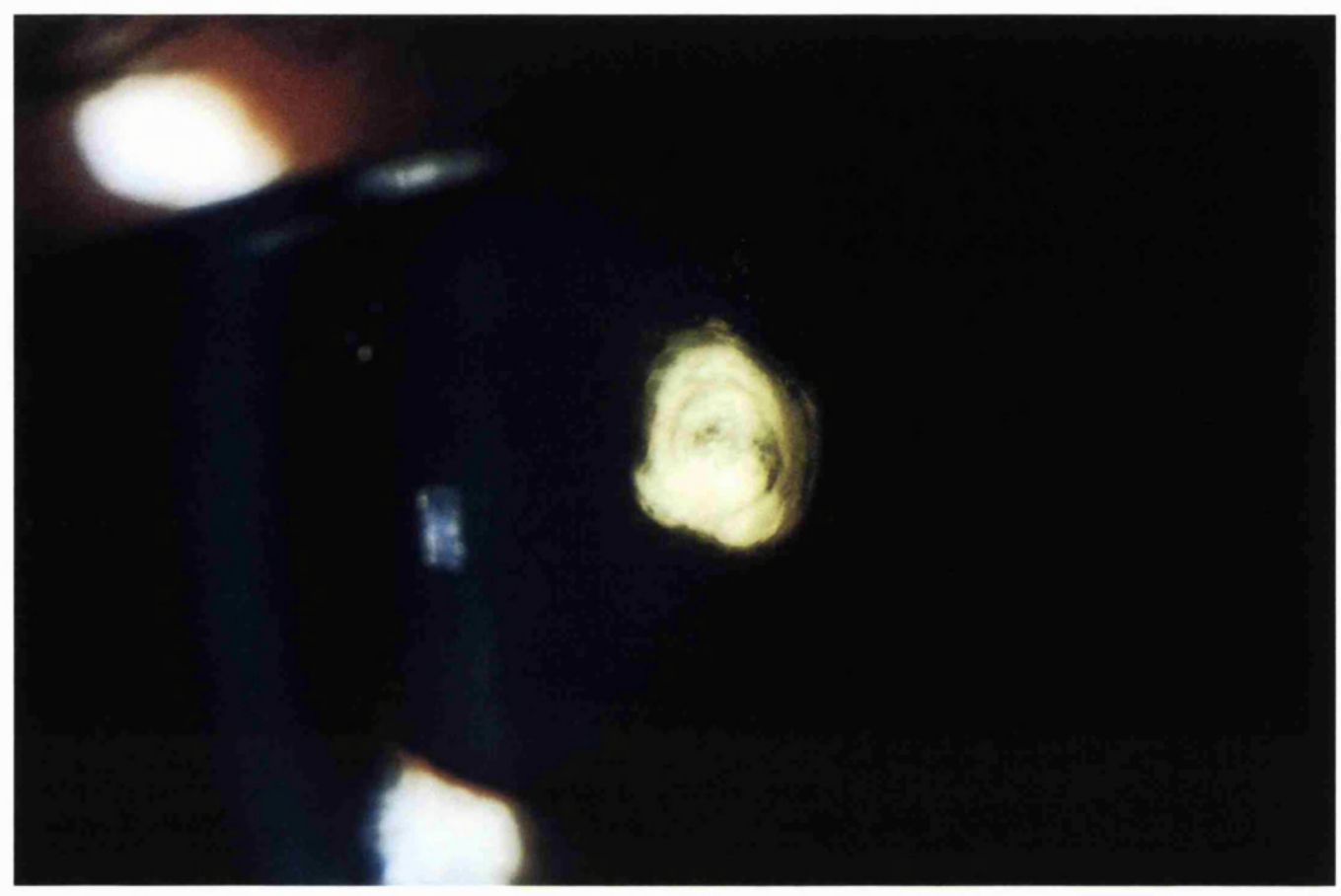

Figure 7. Stationary post polar cataract. Ped B indiv. 2.8

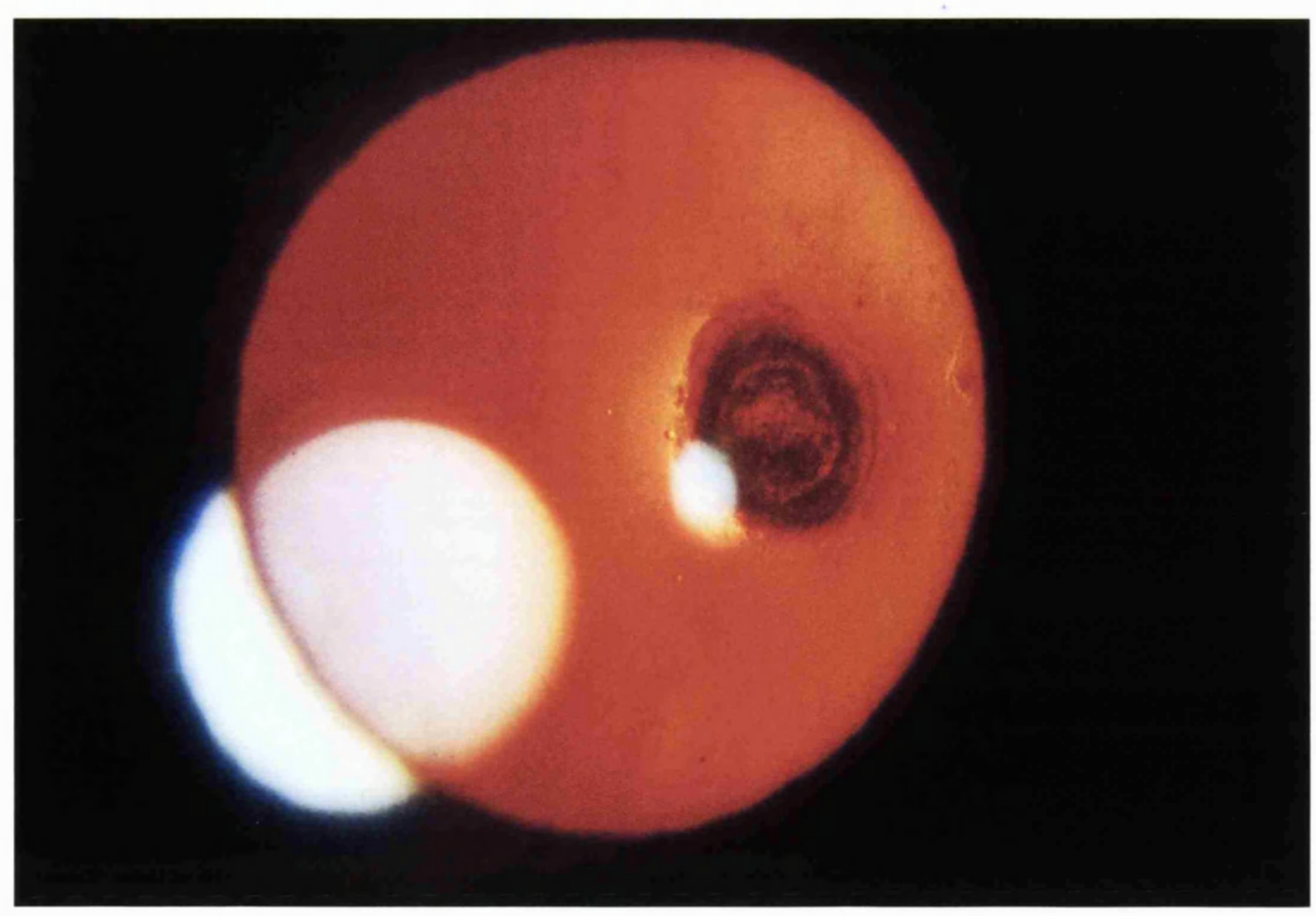

Figure 8. Stationary posterior polar cataract: Retroillumination. Ped B Individ 2.8 


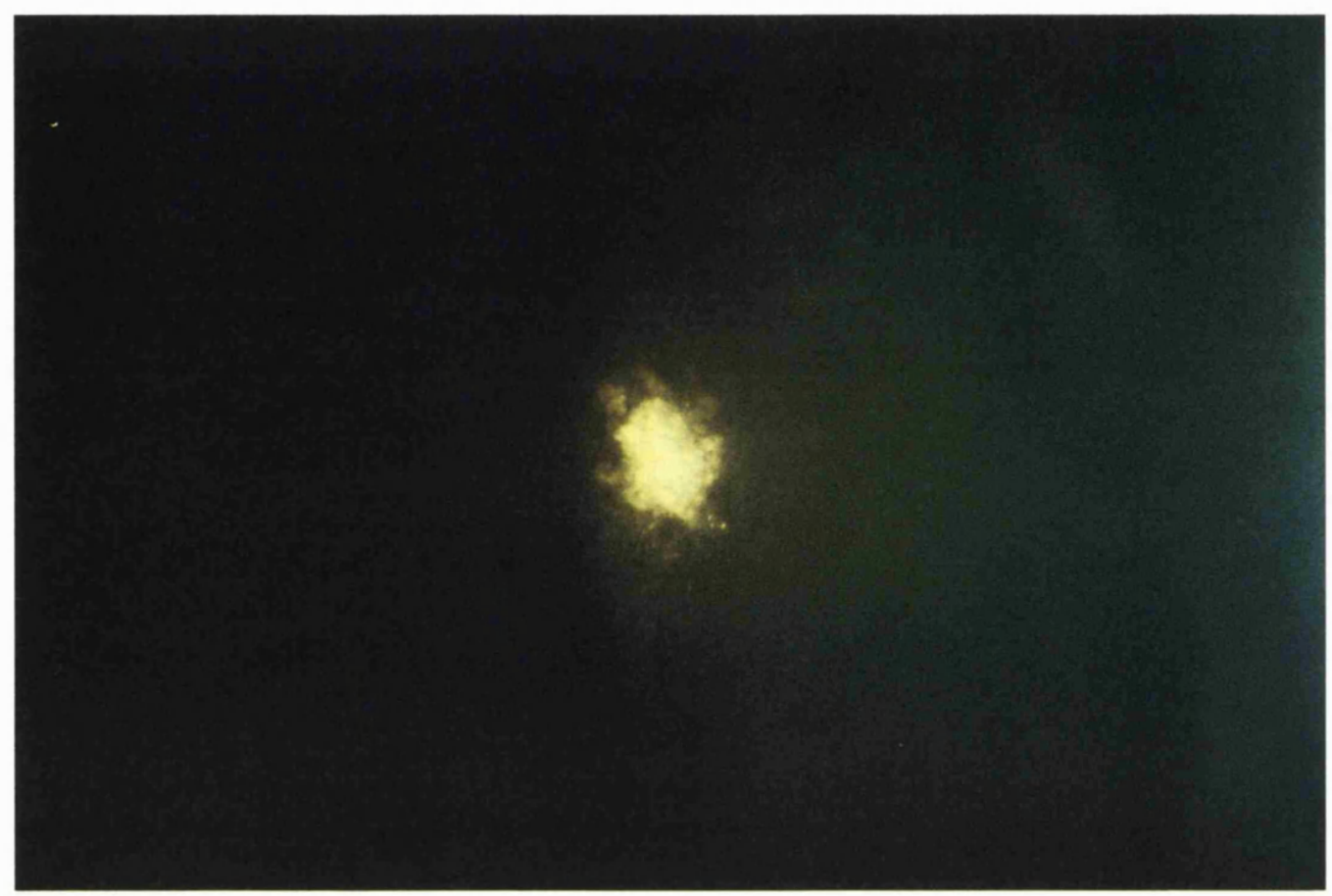

Figure 9. Stationary posterior polar cataract. Pedigree B Indiv. 2.1.

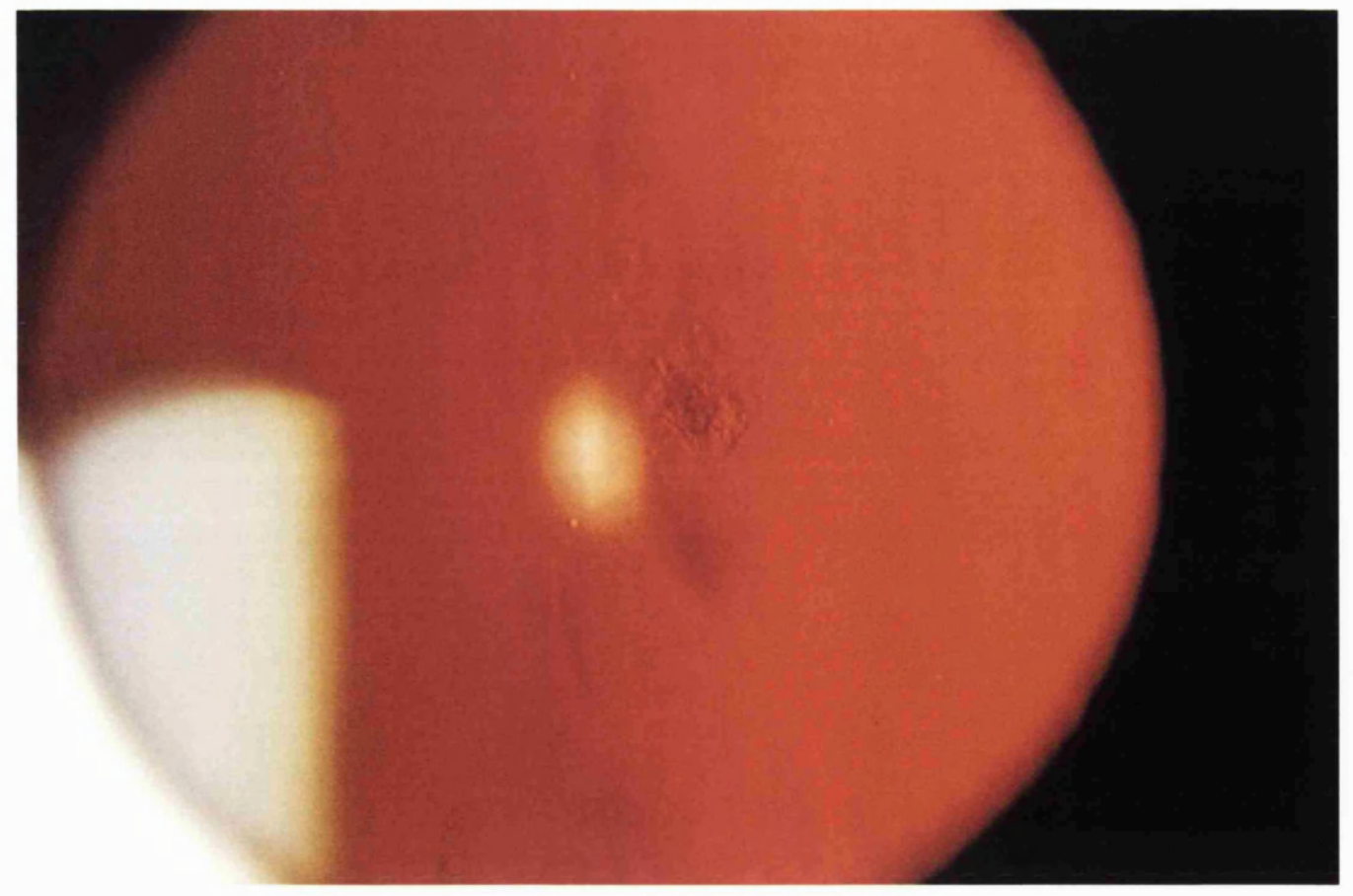

Figure 10. Posterior polar cataract: Retroillumination. $\quad$ Ped B Individ 2.1 


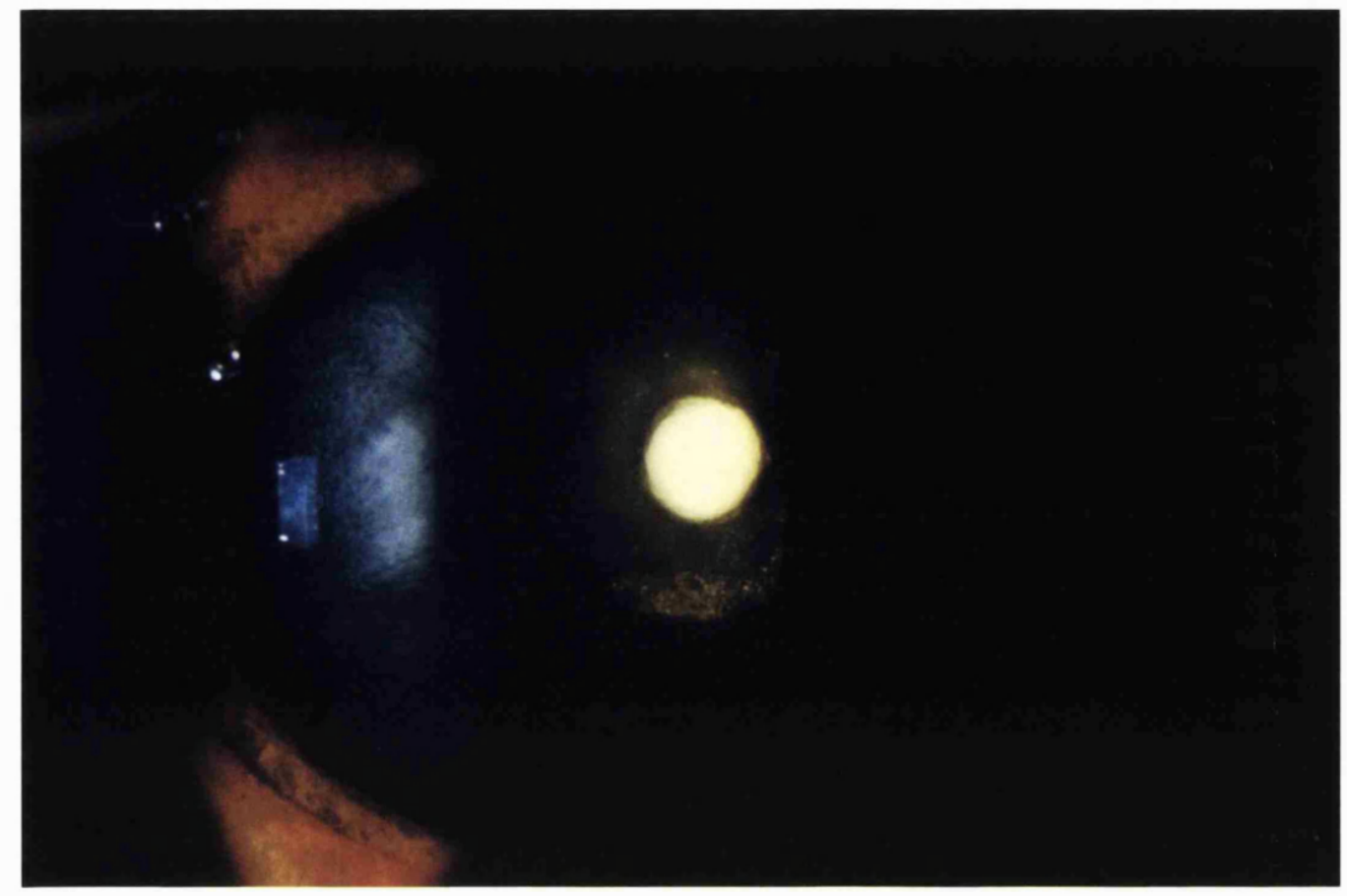

Figure 11. Posterior polar cataract: Small stationary cataract. Ped B Individ 3.6

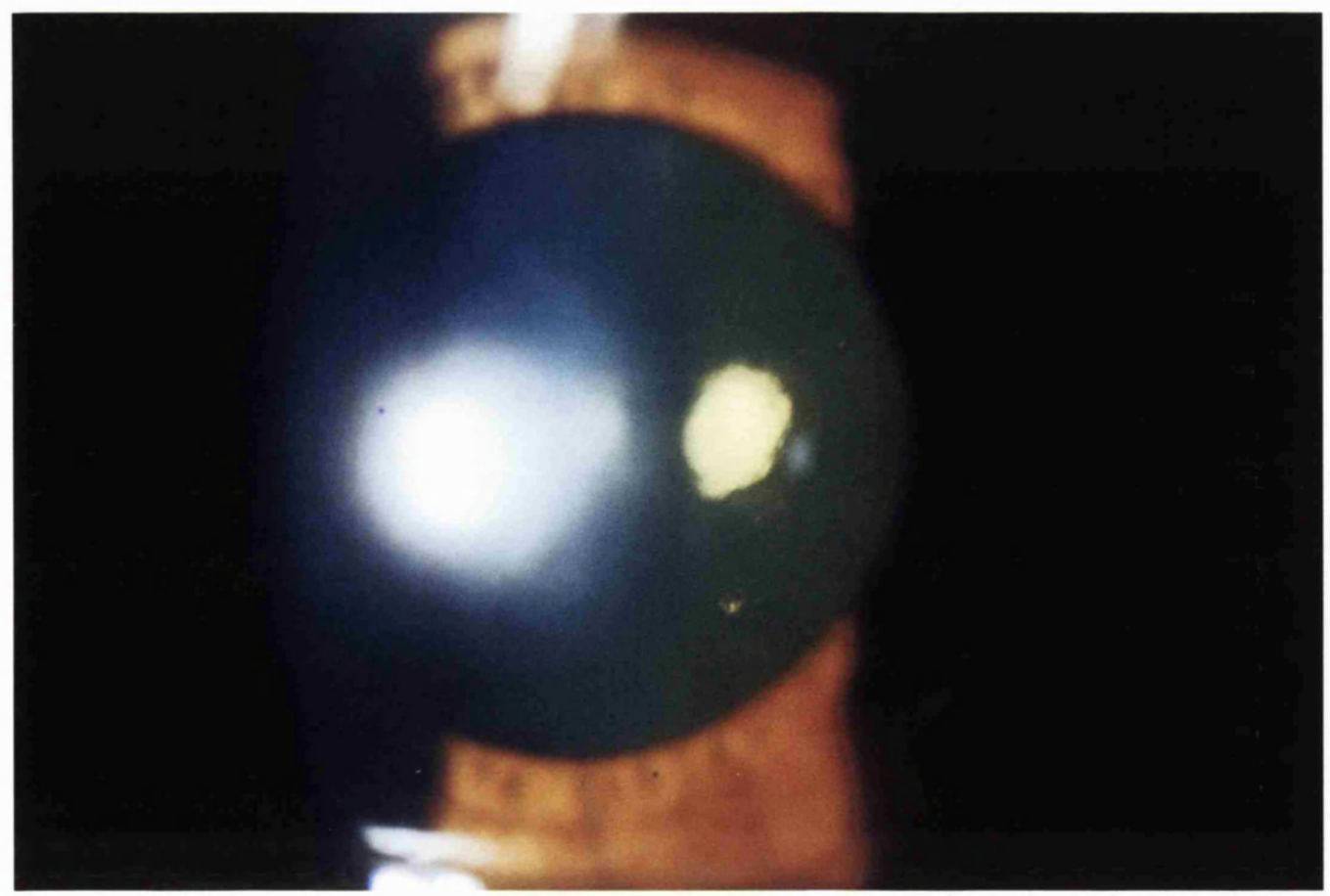

Figure 12. Posterior polar cataract:Small stationary cataract. Ped B Individ 2.1 


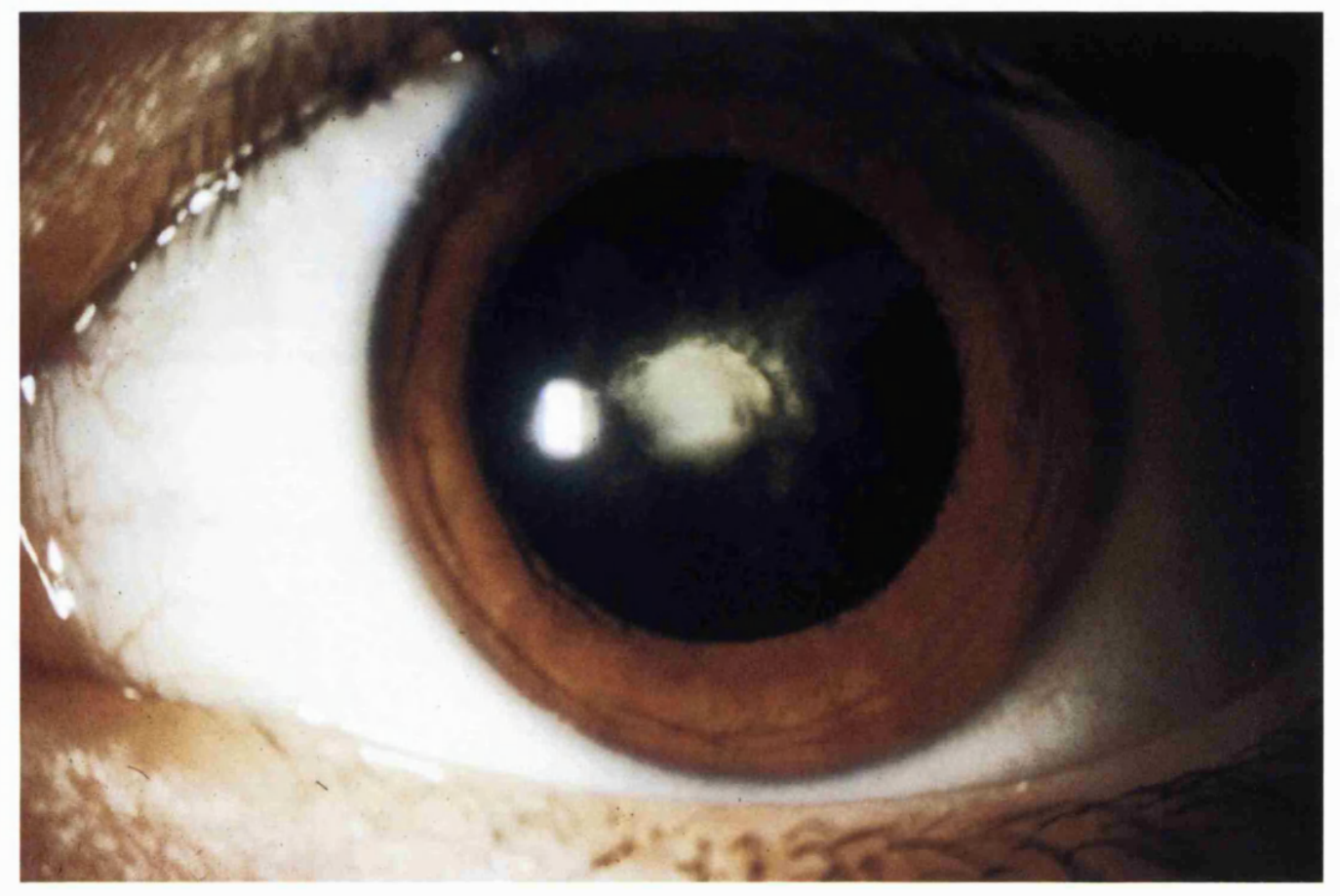

Figure 13. Posterior polar cataract. Progressive. Ped C Individ 4.11 


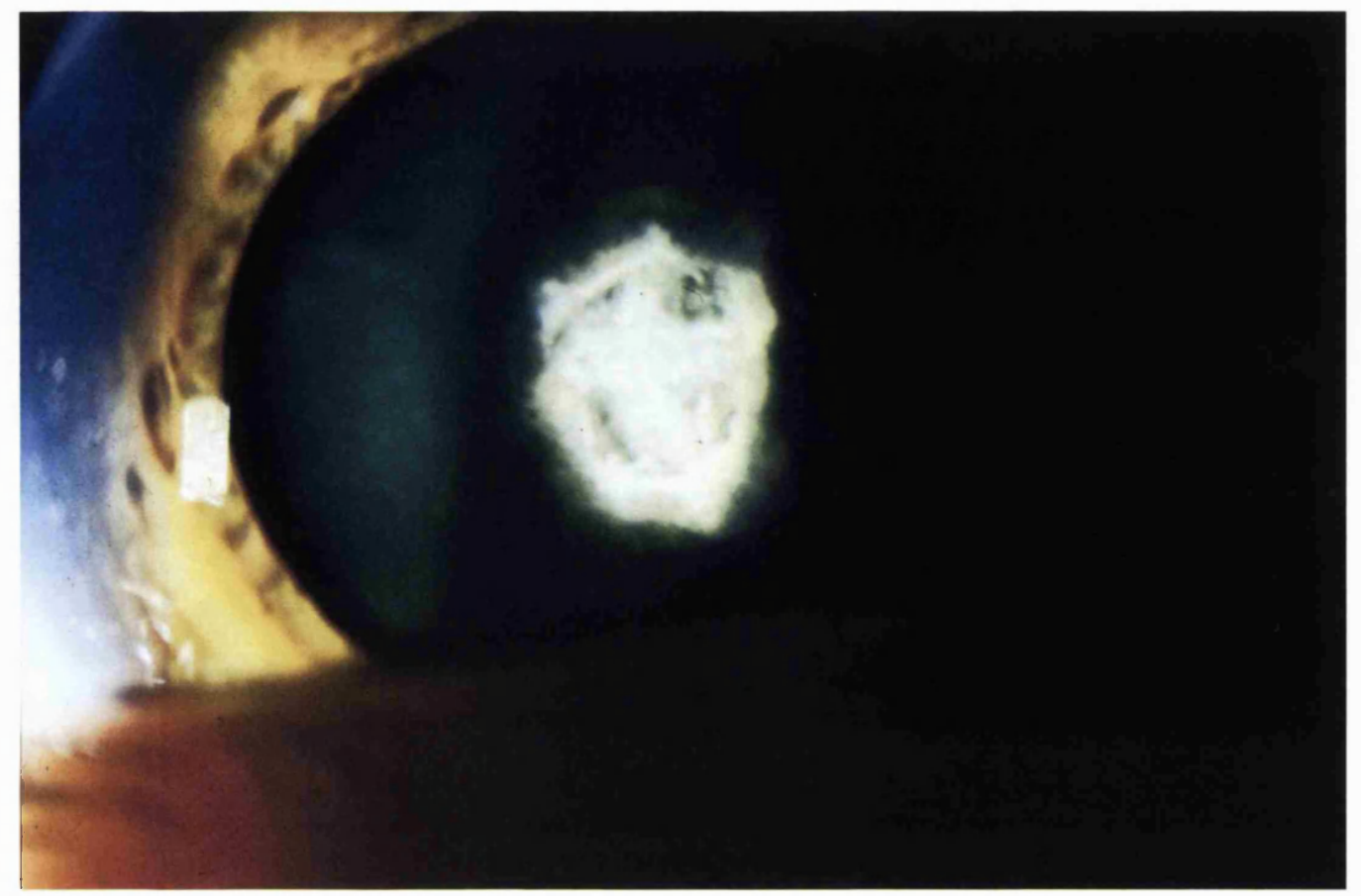

Figure 14. Posterior polar cataract. Progressive.

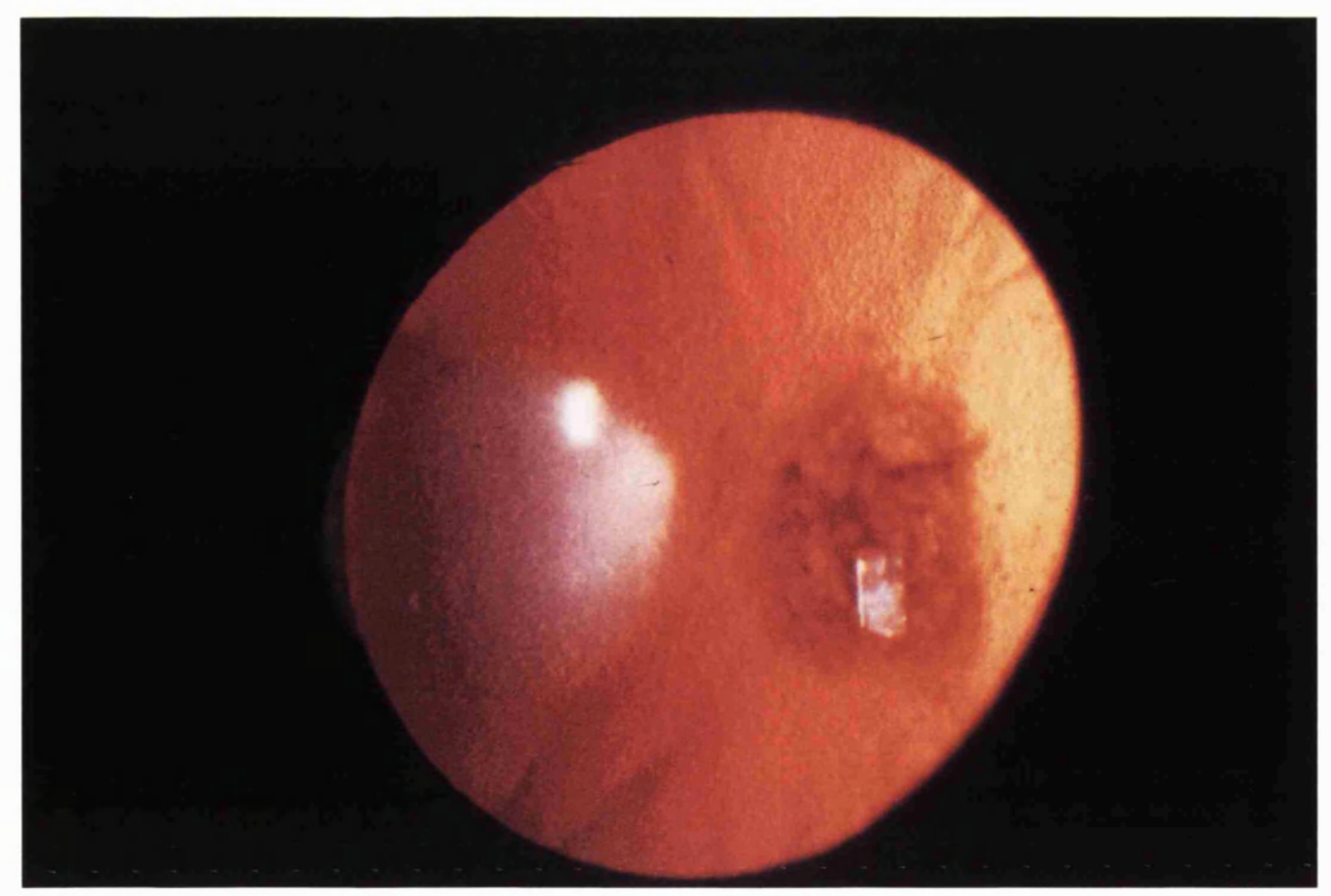

Figure 15. Progressive posterior polar cataract. Retroillumination. 


\section{Nuclear}

Two pedigrees affected by nuclear cataract were examined. In the first family (Pedigree D) 16 individuals were found to be affected with the nuclear cataract. Of these, 6 had undergone surgery and the notes were available in two cases. Six of the remaining ten patients who had not undergone surgery were examined and the cataract varied such that some of the patients had dense central opacities surrounded by fine dots (Figures $16 \& 17$ ), whilst others had fine dot opacities distributed throughout the embryonic and fetal nuclei, with opacification of the anterior and posterior $Y$-sutures (Figures 18-21). There were never any opacities outside the fetal nucleus. In this family six out of twelve affected patients examined were operated on at a mean age of 21 years with a bimodal distribution. The younger age group were operated on at a mean of 10 years and the older group at a mean age of 45 years. The visual outcome for the younger group varied from $6 / 9$ to $6 / 12$ in the better eye, and from $6 / 12$ to $6 / 60$ in the worse eye. The vision in the older group varied from $6 / 6$ to $6 / 12$.

In the other family affected by nuclear cataract (Pedigree E) 9 affected members were examined and 8 had undergone surgery (one patients had unilateral surgery) and in 7 of these the clinical notes gave accurate description of the cataract morphology. The cataracts in the three unoperated eyes were examined. Two lenses had dust-like opacities throughout the embryonic and fetal nuclei (Figures 22-25) and the third eye was more severely affected by a dense central opacity surrounded by a haze of fine powdery opacities (Figure 26-27). The operations in this family were performed at a mean age of 31 years (range 6-64, median 35) with a visual outcome that varied from $6 / 5$ to $6 / 60$ (median of $6 / 9$ ).

In a smaller pedigree affected by nuclear cataracts the central opacities were coarse and have been included here to show the wide spectrum of nuclear cataracts (Figures 28 \& 29). 


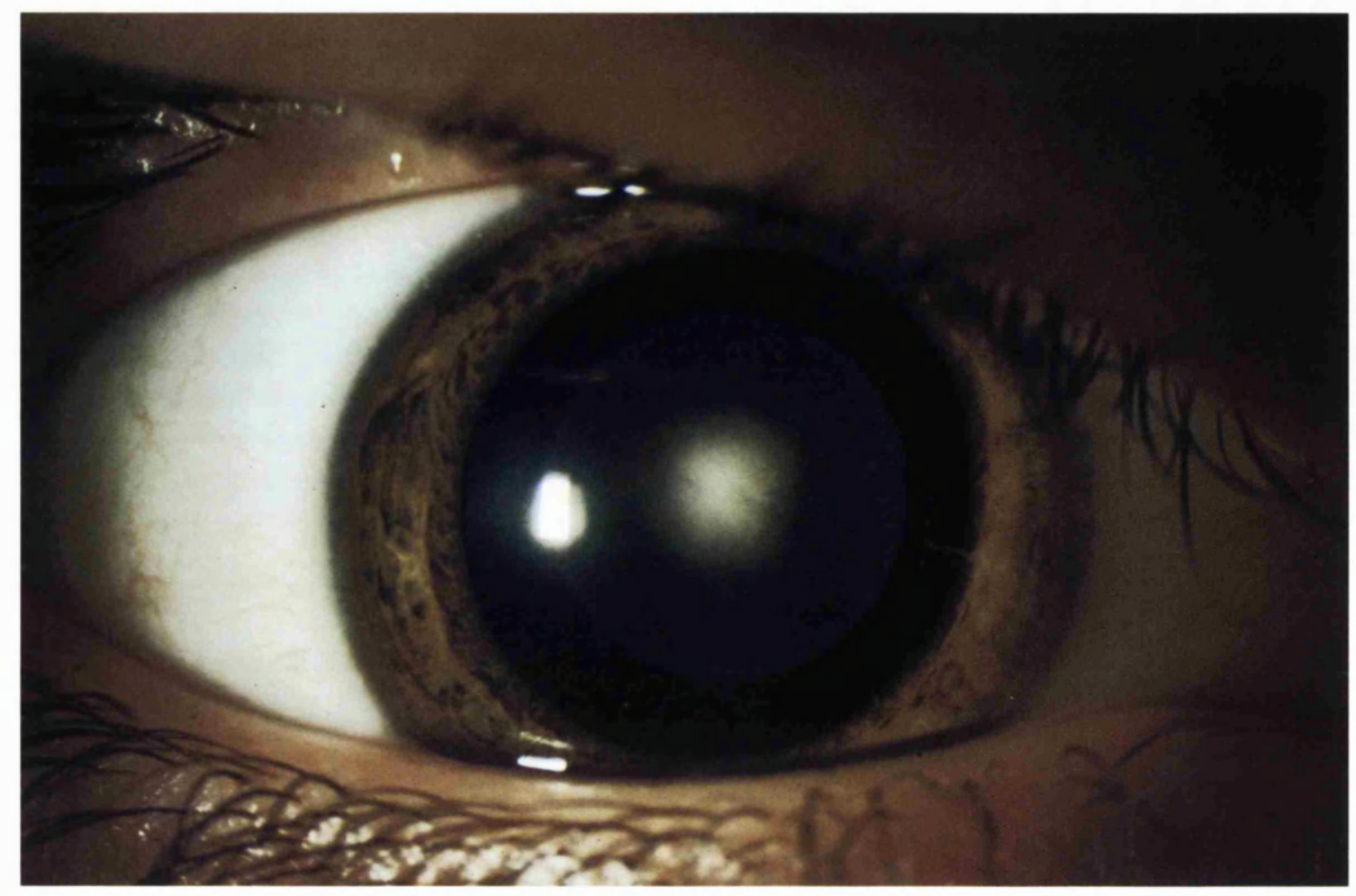

Figure 16 Nuclear cataract, dense central opacities. Ped D Individ 5.2

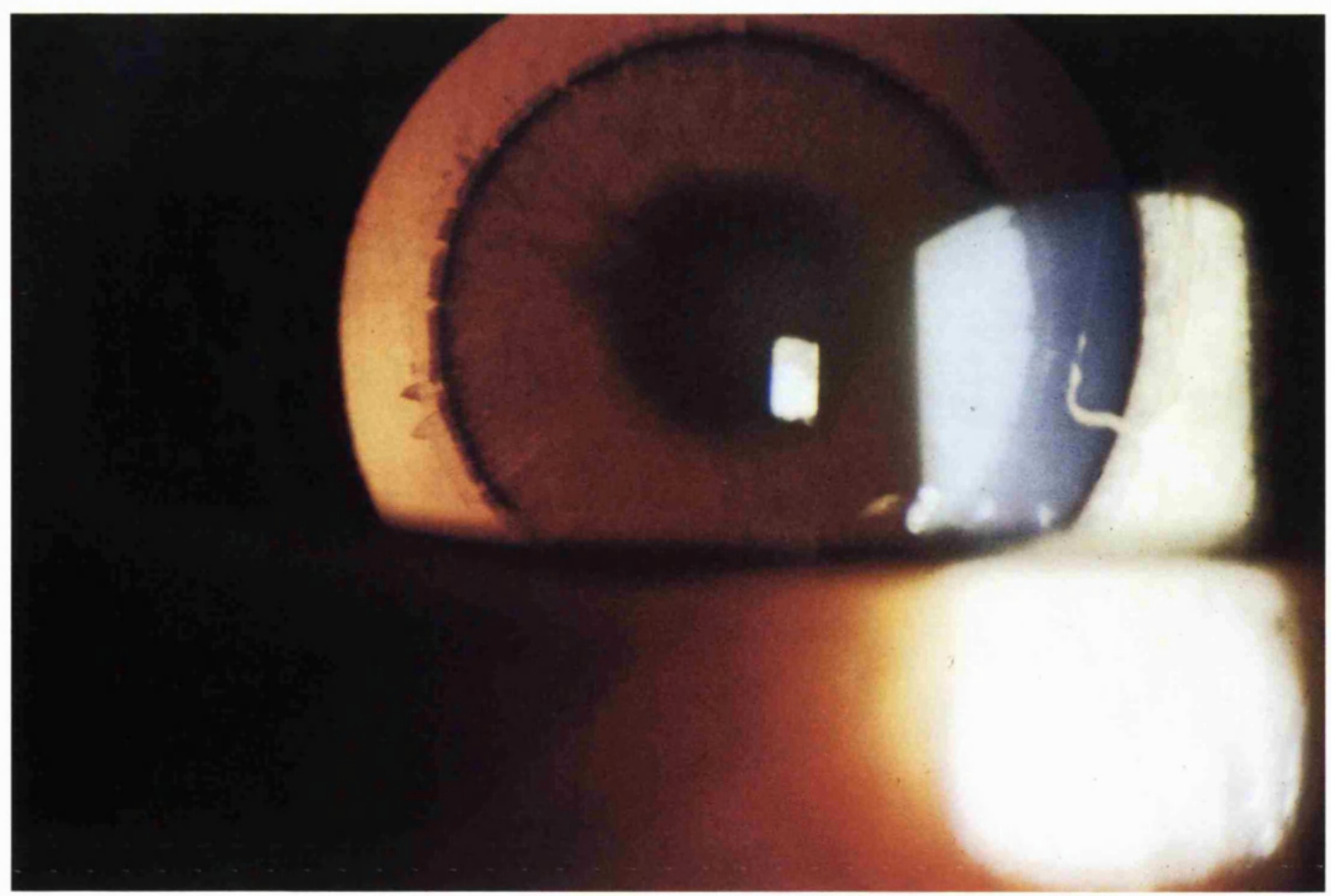

Figure 17. Nuclear cataract: Retroillumination. Ped D Individ 5.2 


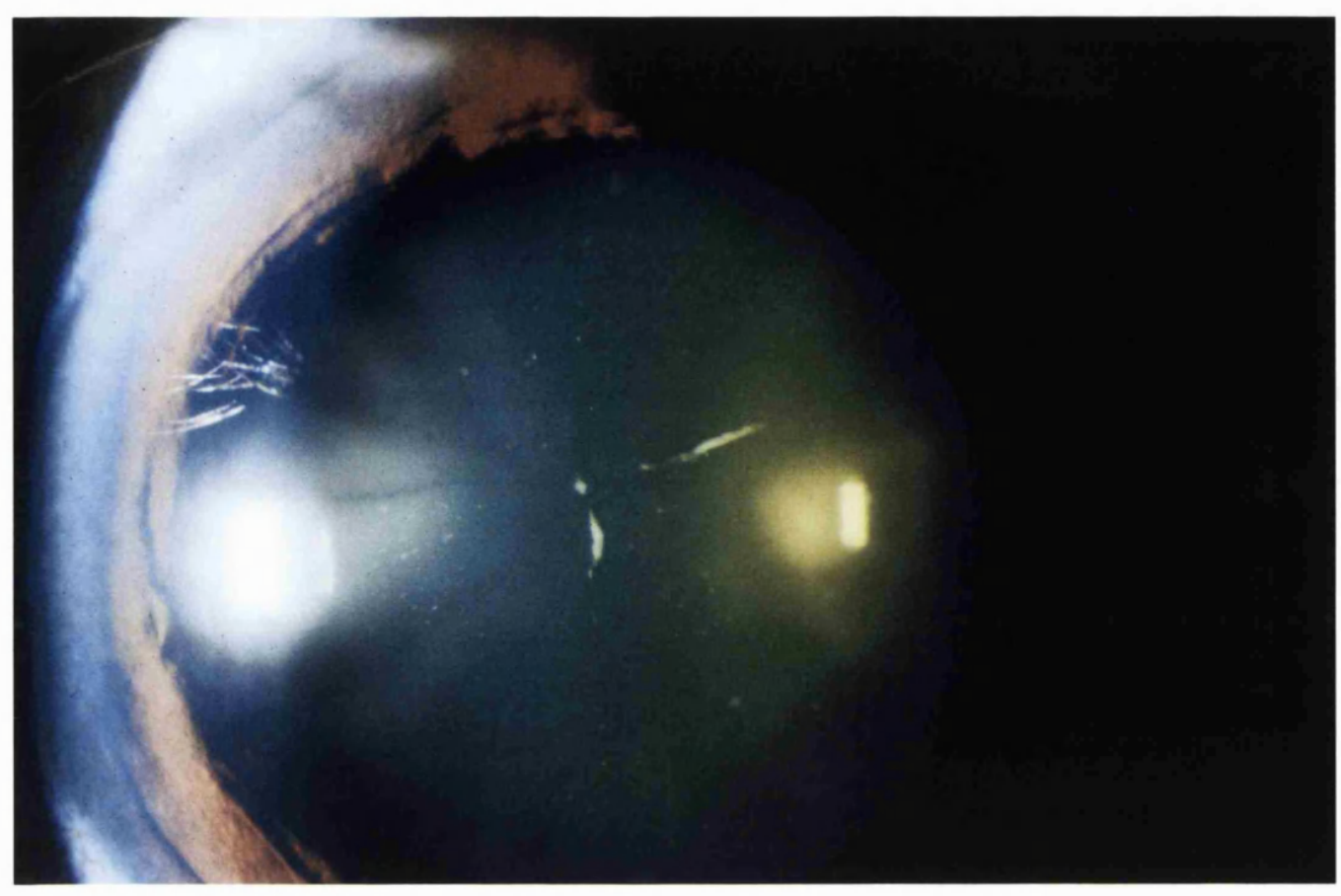

Figure 18. Nuclear cataract: Fine central opacities, including Y-sutures. $\quad$ Ped D Individ 4.4

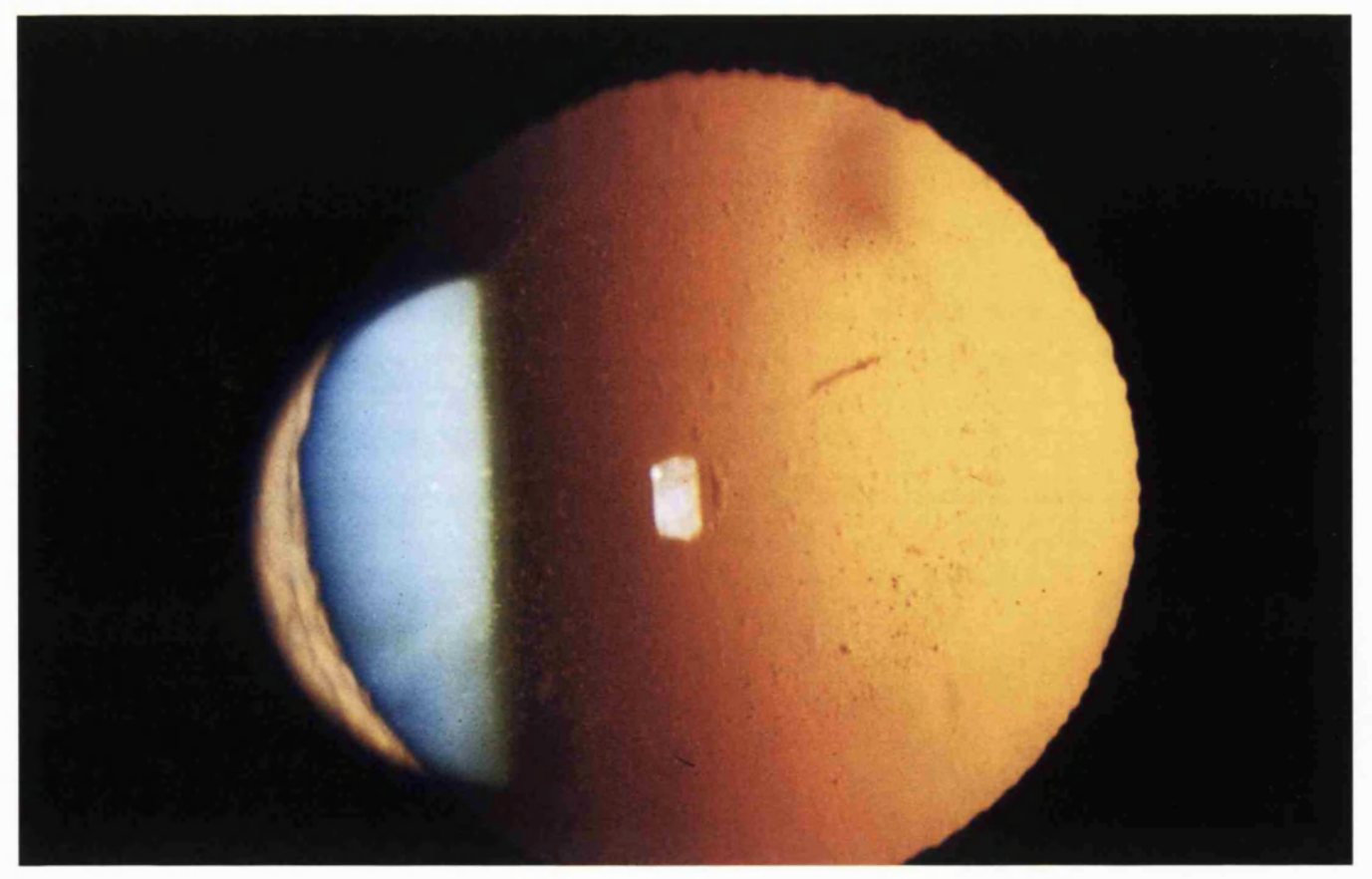

Figure 19. Nuclear cataract: Retroillumination. Ped D Individ 4.4 


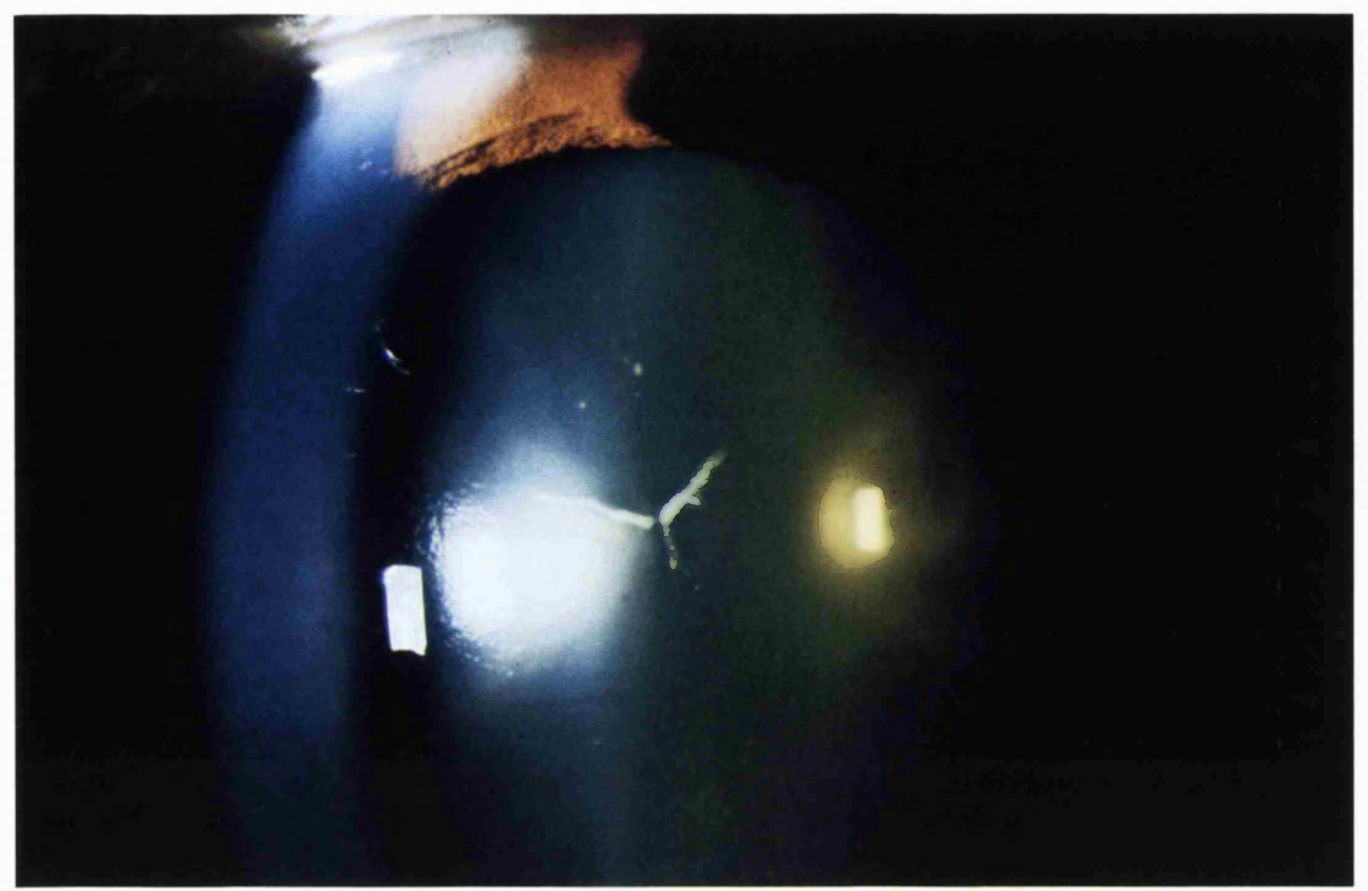

Figure 20. Nuclear cataract: Fine central opacities. Ped D Individ 4.4

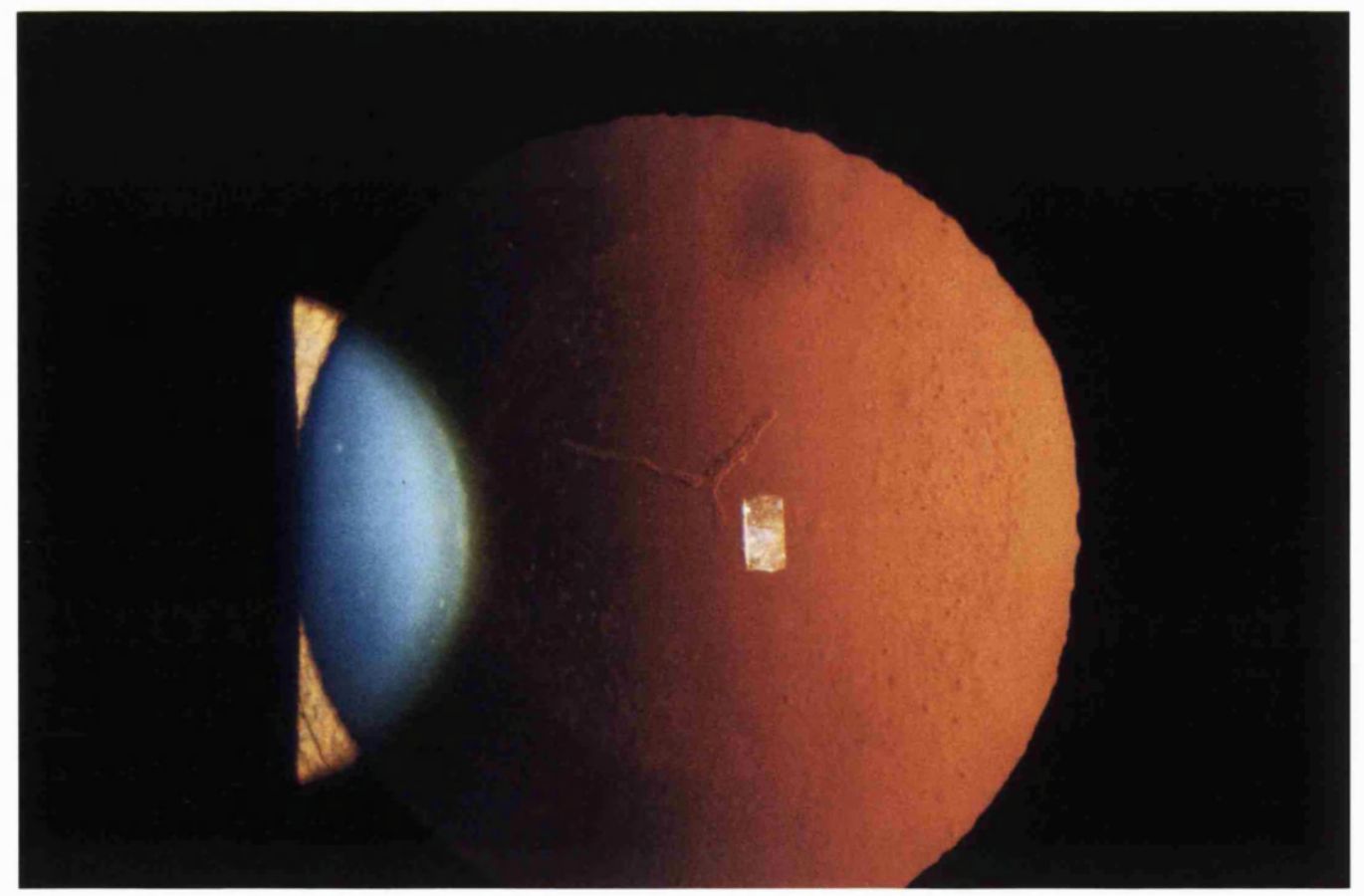

Figure 21. Nuclear cataract: Retroillumination. $\quad$ Ped D Individ 4.4 


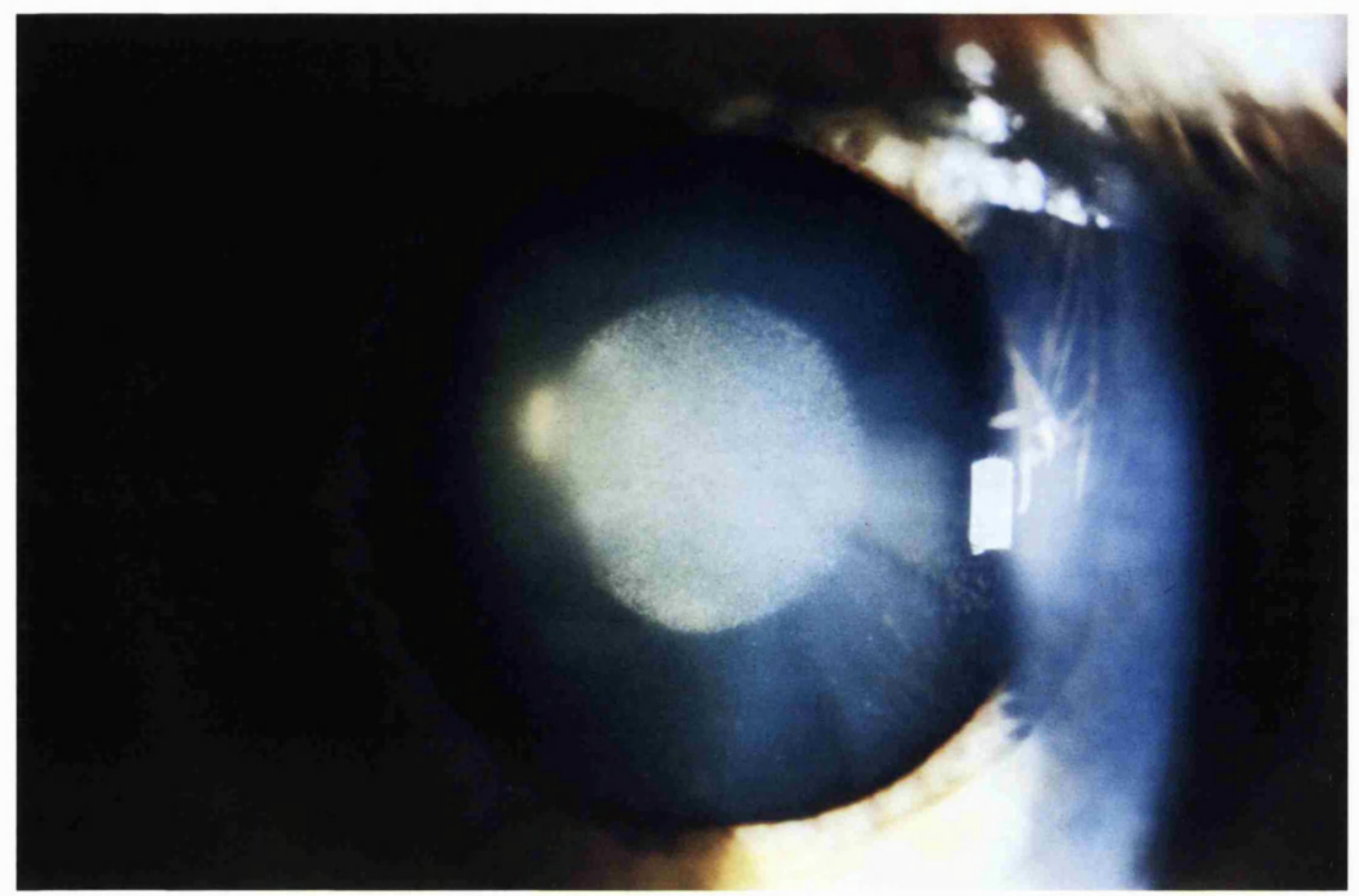

Figure 22. Nuclear cataract: Pedigree E. CCL Fine central opacities. Ped E Individ 5.1

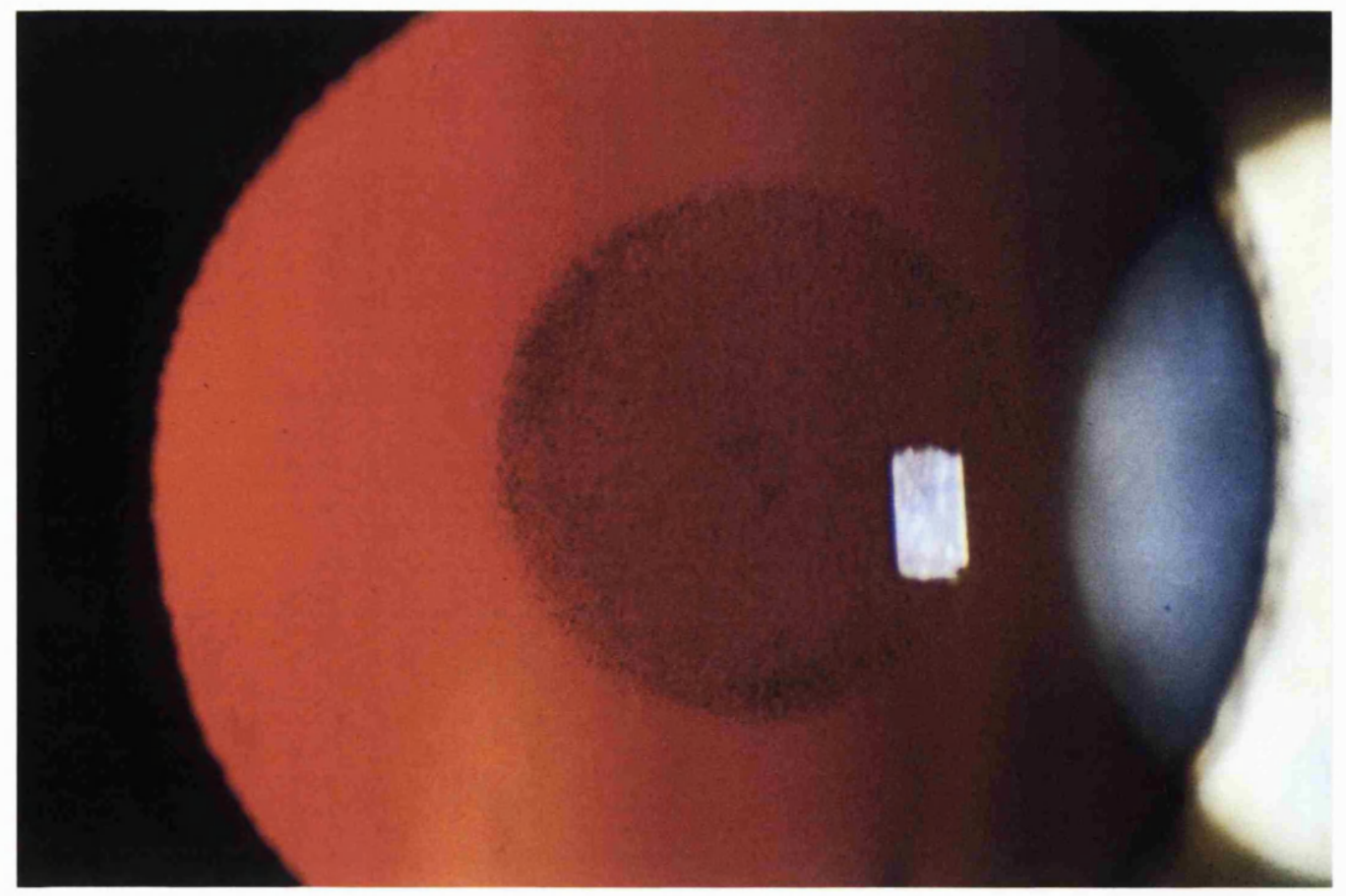

Figure 23. Nuclear cataract: CCL Retroillumination. Ped E Individ 5.1 


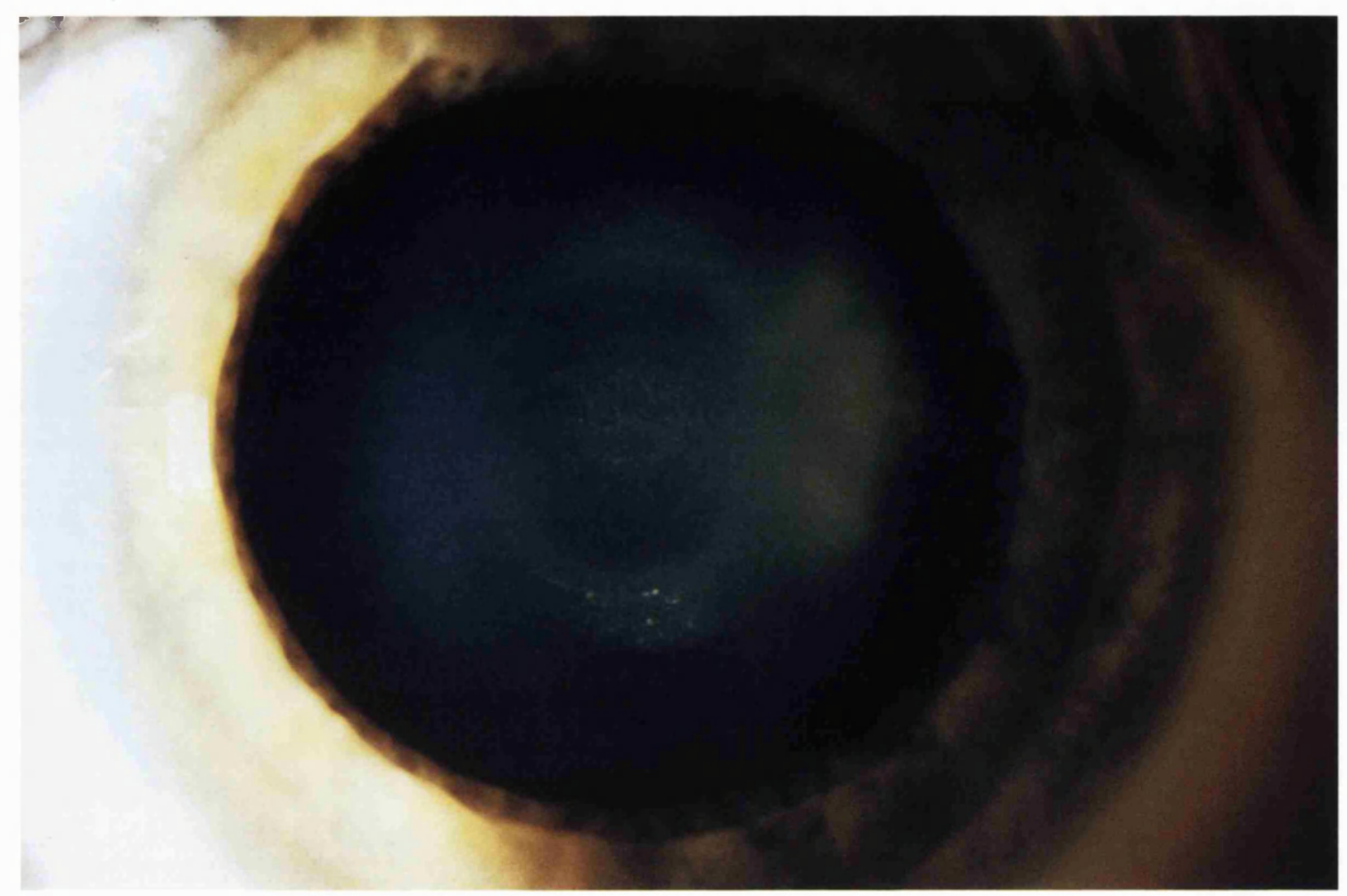

Figure 24. Nuclear cataract: Pedigree E. CCL Fine opacities. Ped E Individ 5.1

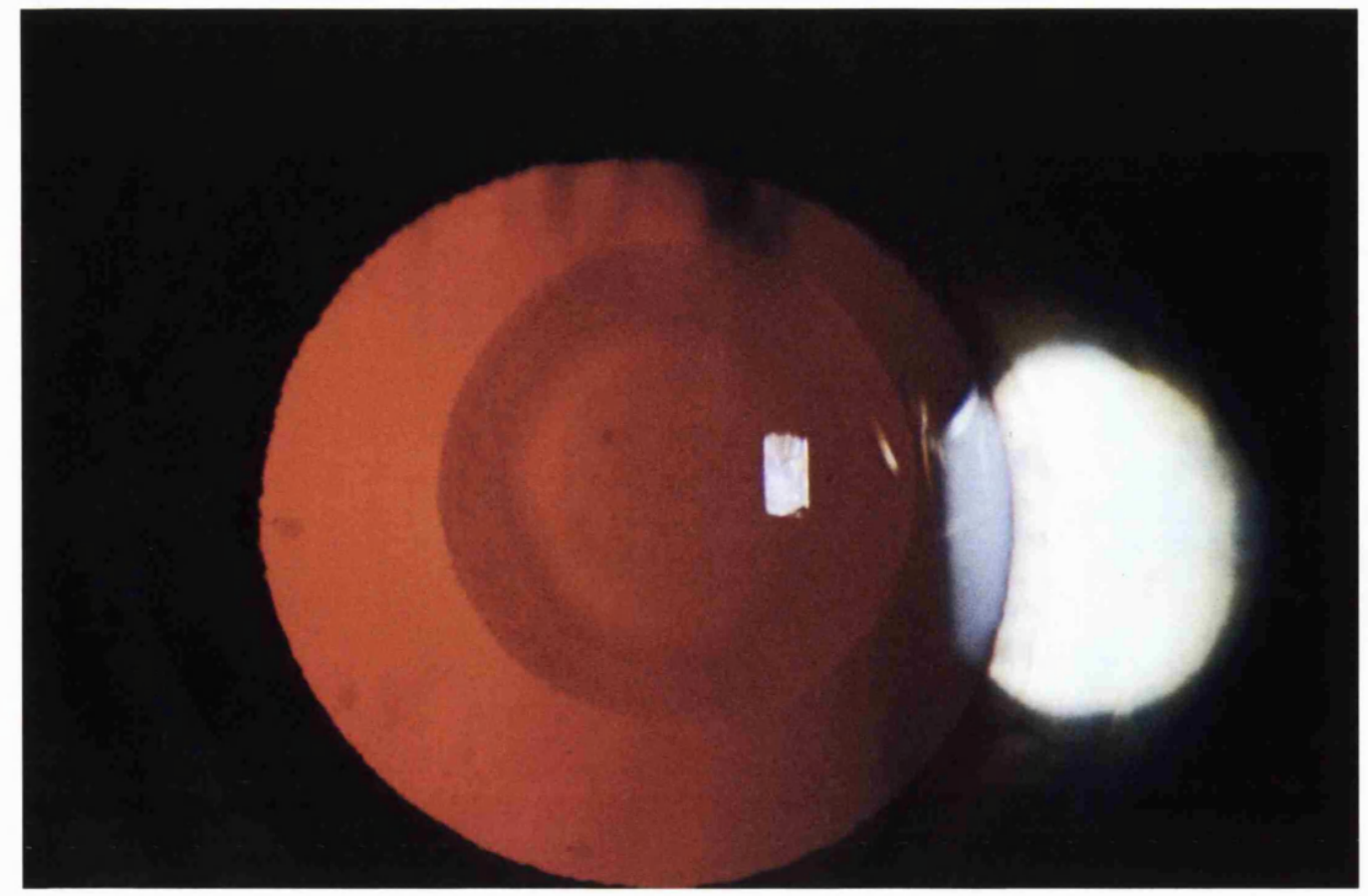

Figure 25. Nuclear cataract: CCL Retroillumination. Ped E Individ 5.1 


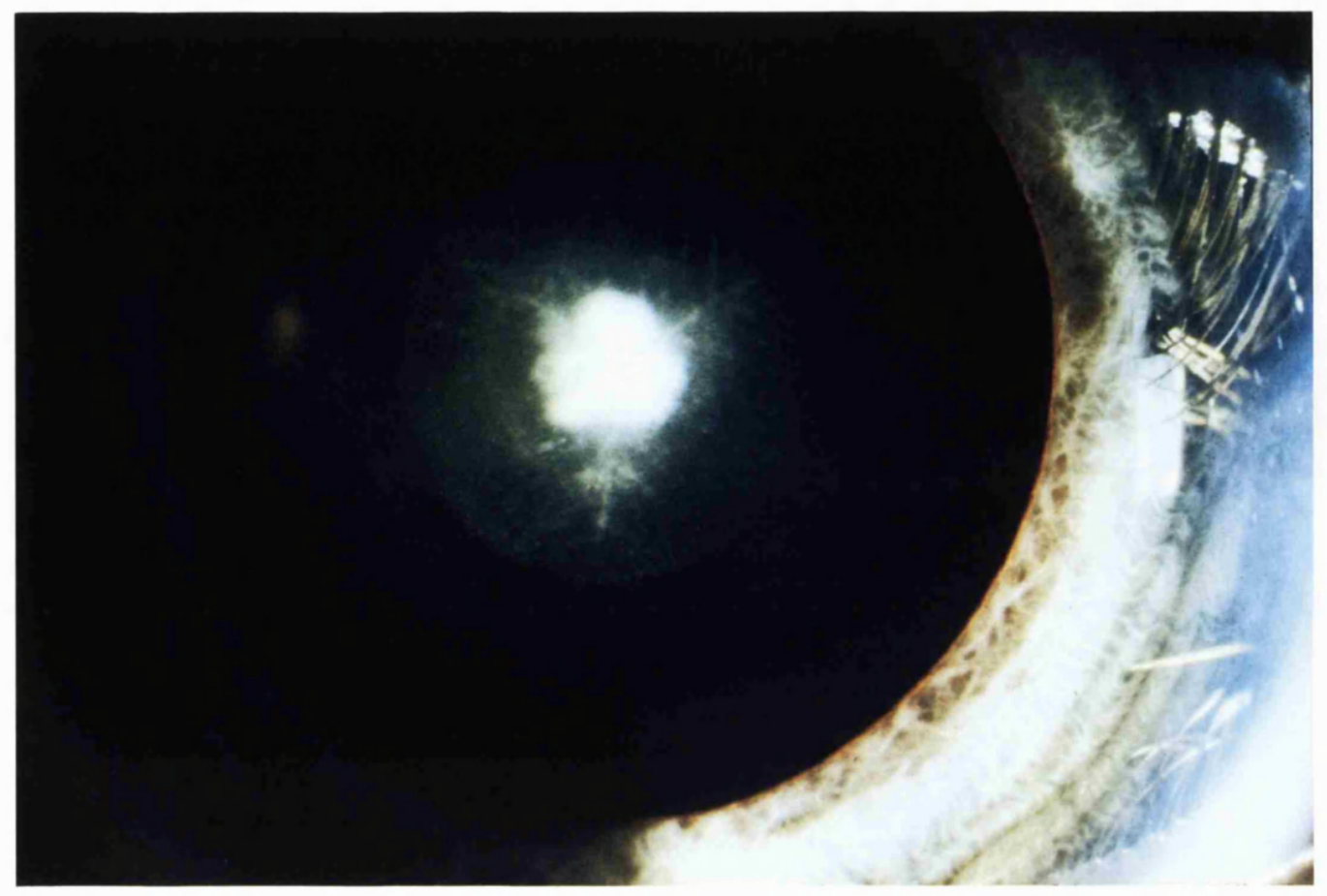

Figure 26. Nuclear cataract: CCL Dense central opacities. Ped E Individ 4.5

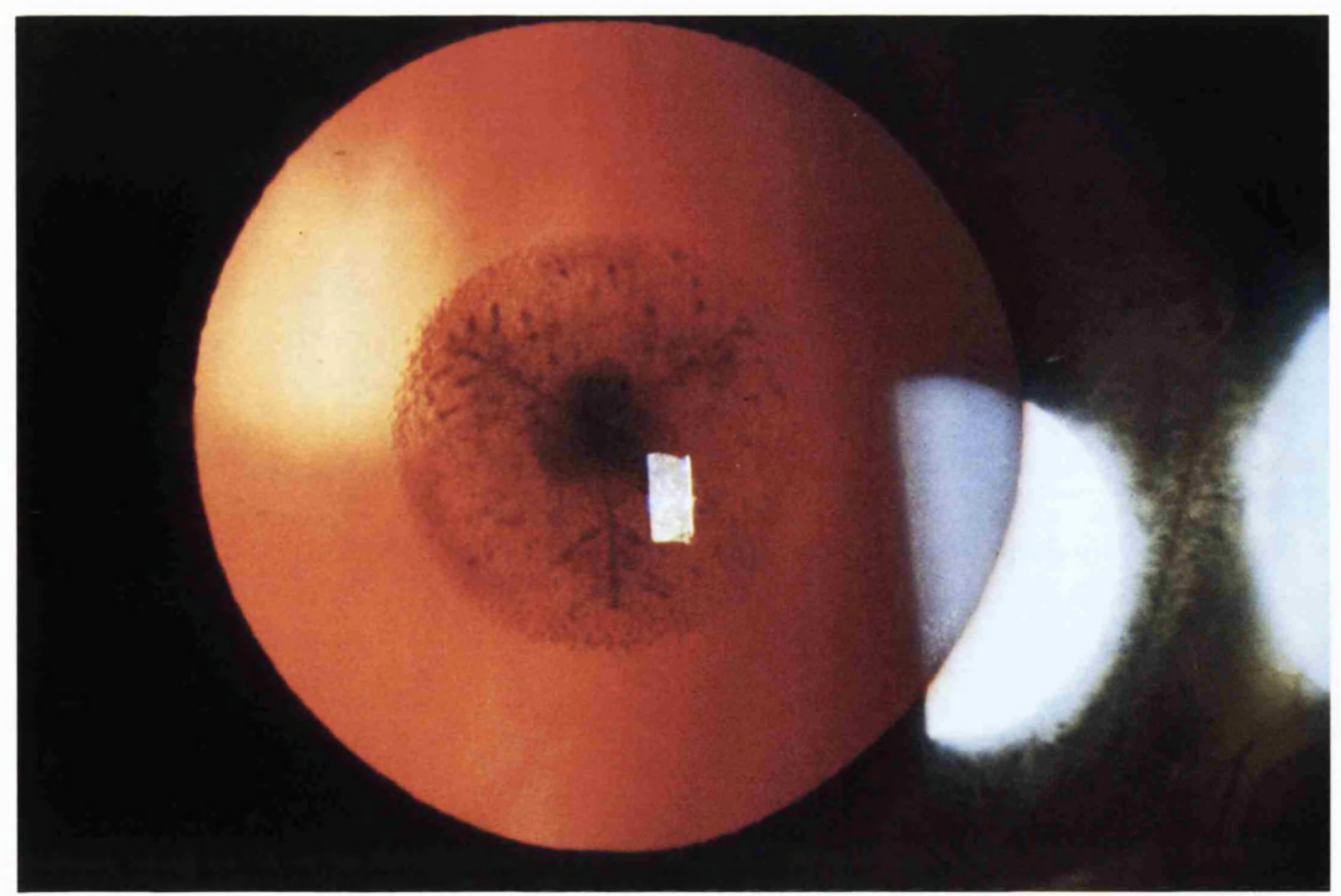

Figure 27. Nuclear cataract: CCL Retroillumination. Ped E Individ 4.5 


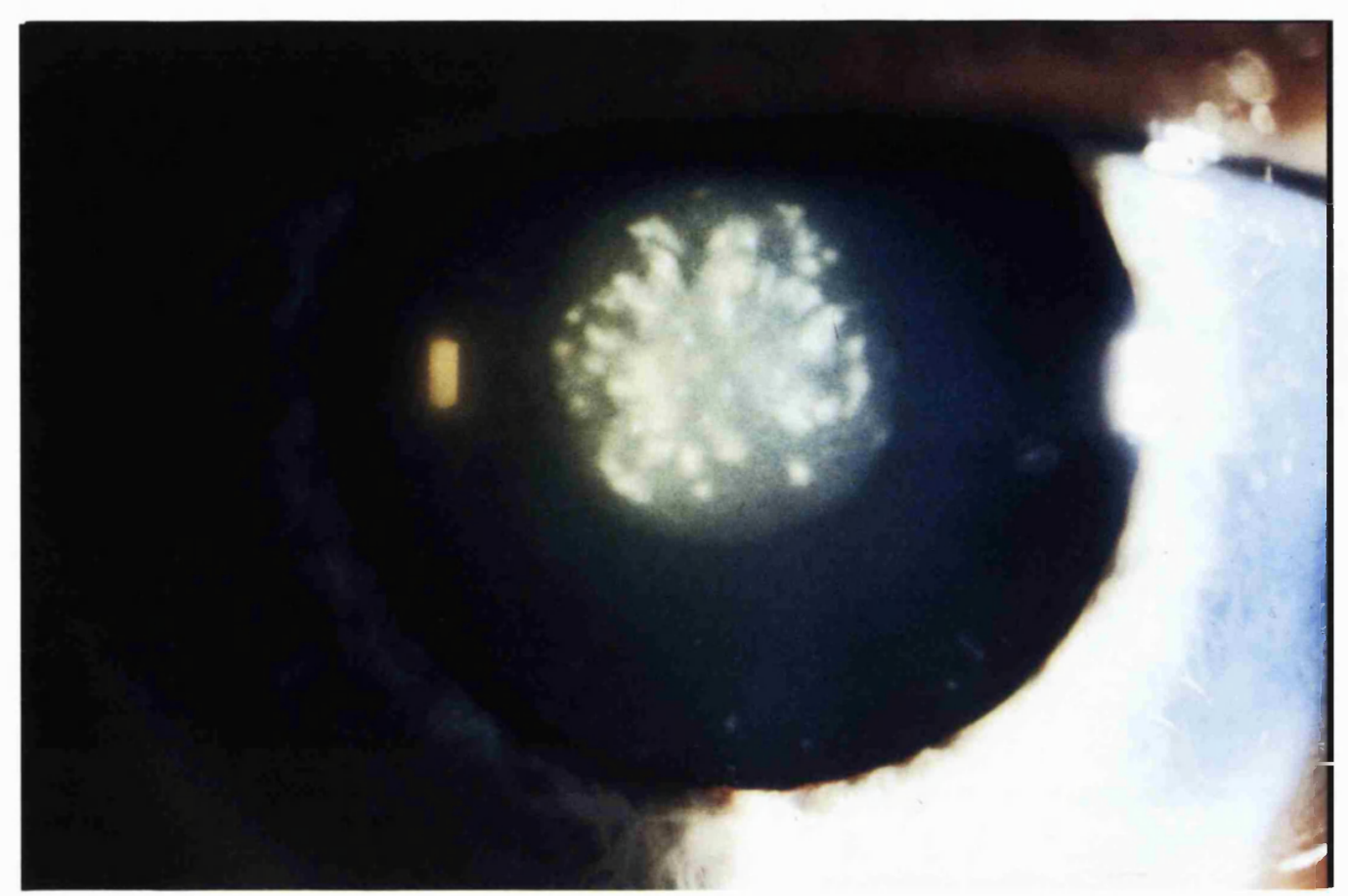

Figure 28. Nuclear cataract. Coarse central opacities.

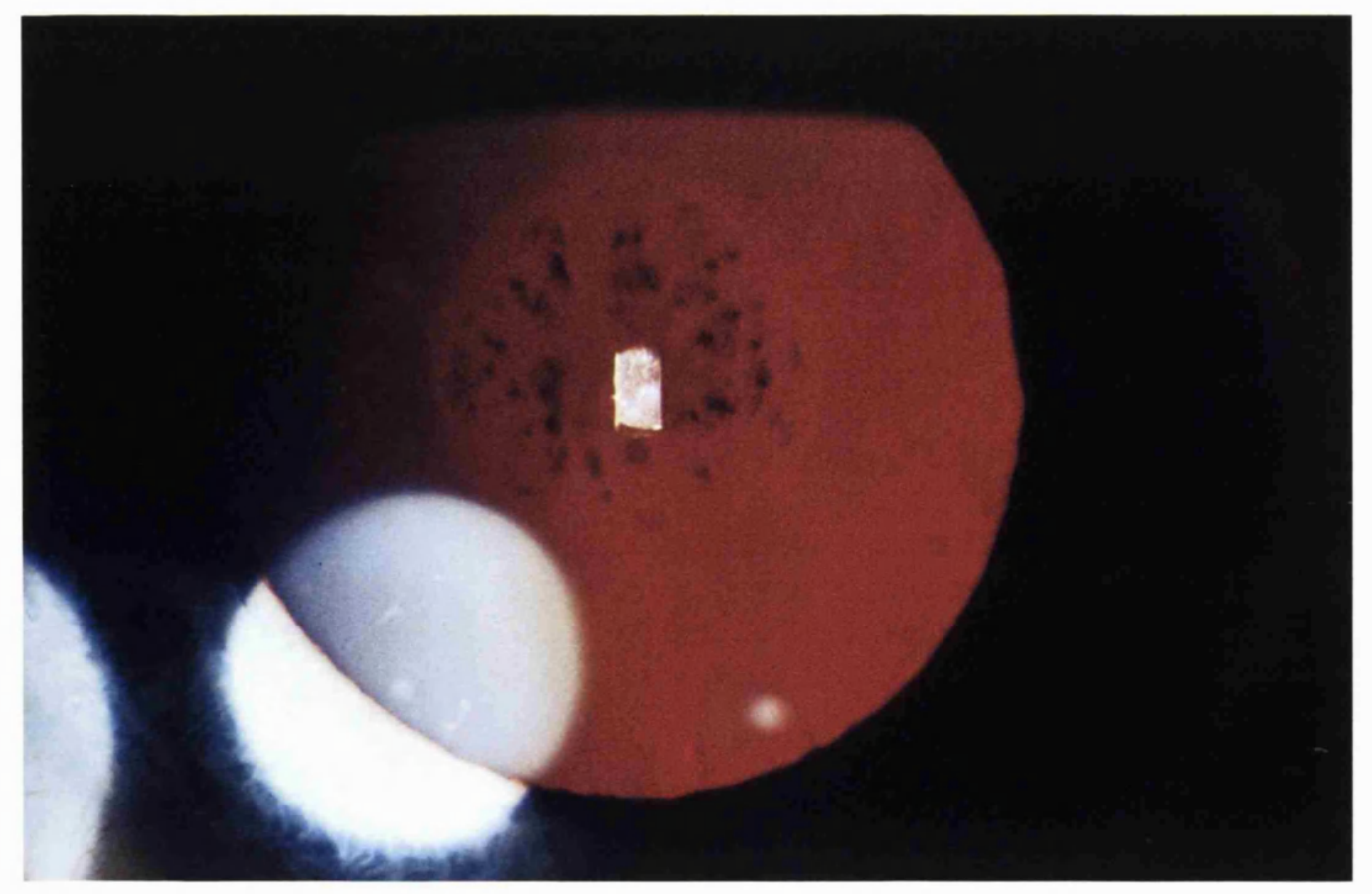

Figure 29. Nuclear cataract. Coarse central opacities. Retroillumination. 


\section{Lamellar cataract.}

Lamellar cataract, often referred to as zonular cataract, is one of the commonest phenotypes. The inner fetal nucleus is made up of clear lens surrounded by an opacified shell which is surrounded by clear cortex (Figure 30). This opacification represents a disturbance in the lens development at a particular time and the cataractous 'shell' varies in size according to the stage of fetal development at which the disturbance occurs. The cortex contains clear lens with a variable amount of opacification usually in the form of cortical spokes. The cataract may be mild and the visual acuity may be well preserved as illustrated in Figures 31-34. In other families the cataract may need operating on in childhood. Three families affected by lamellar cataract were studied. One of the families consisted of 14 members of whom 8 were affected (Pedigree F). All underwent surgery although one patient had unilateral cataract extraction. The surgery was carried out at a mean age of 7 months (range 2-36, mode 2, median 2), with a final V/A range of $6 / 12$ to NPL ( 7 of 15 eyes being NPL). The individual who still had a cataract in one eye has a lamellar cataract with a visual acuity of 6/60 but has refused surgery. In the rest of the family details of the phenotype were restricted to clinical records which were available in 4 cases. In the other two families all the affected individuals had undergone surgery. In one family (Pedigree G) of 14 people there were 9 affected individuals and the notes were available in 2 cases. In the third family (Pedigree $H$ ) there were also 14 members but with 8 affected individuals and notes available in three cases. All were described as having lamellar cataract. 


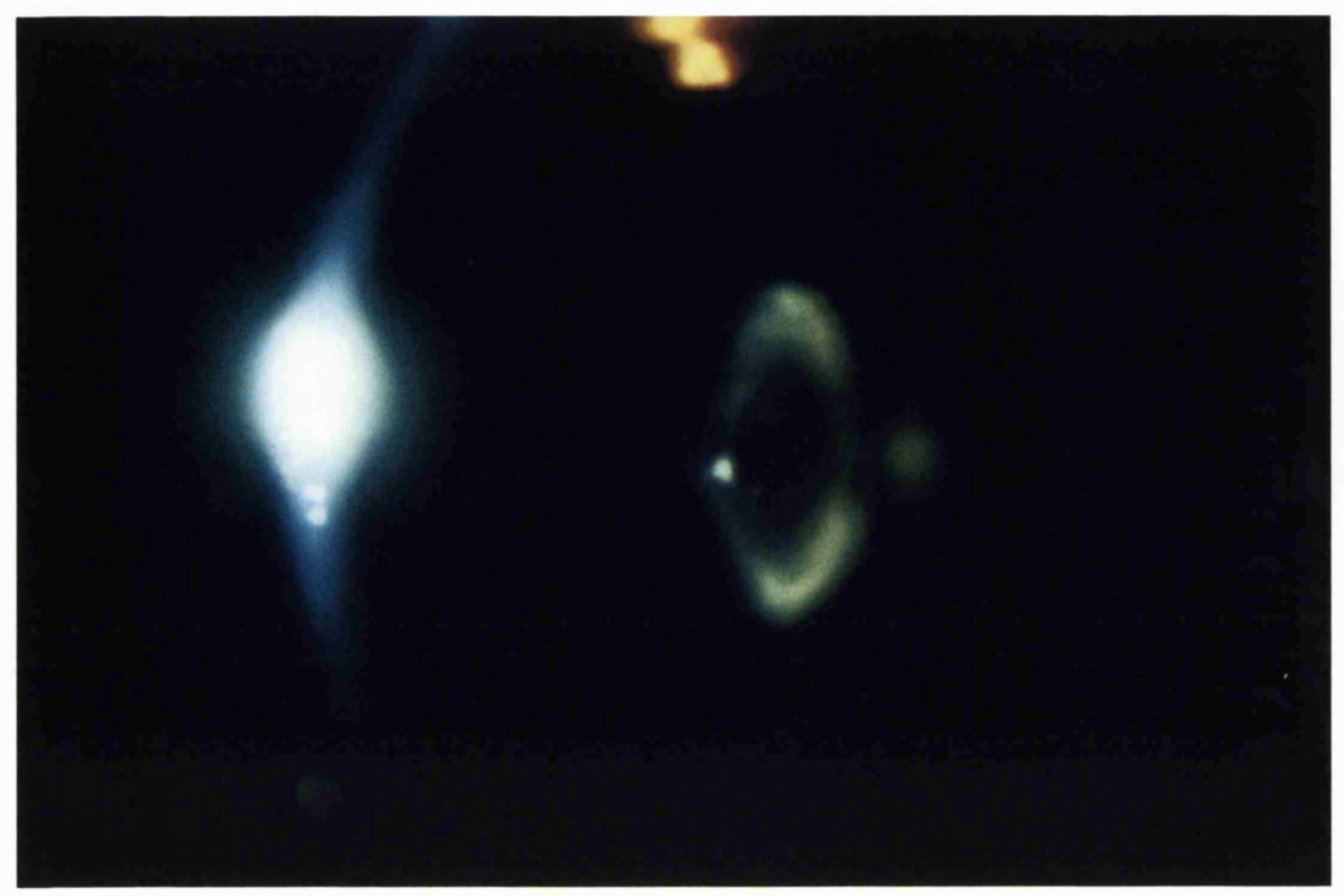

Figure 30. Lamellar cataract. 


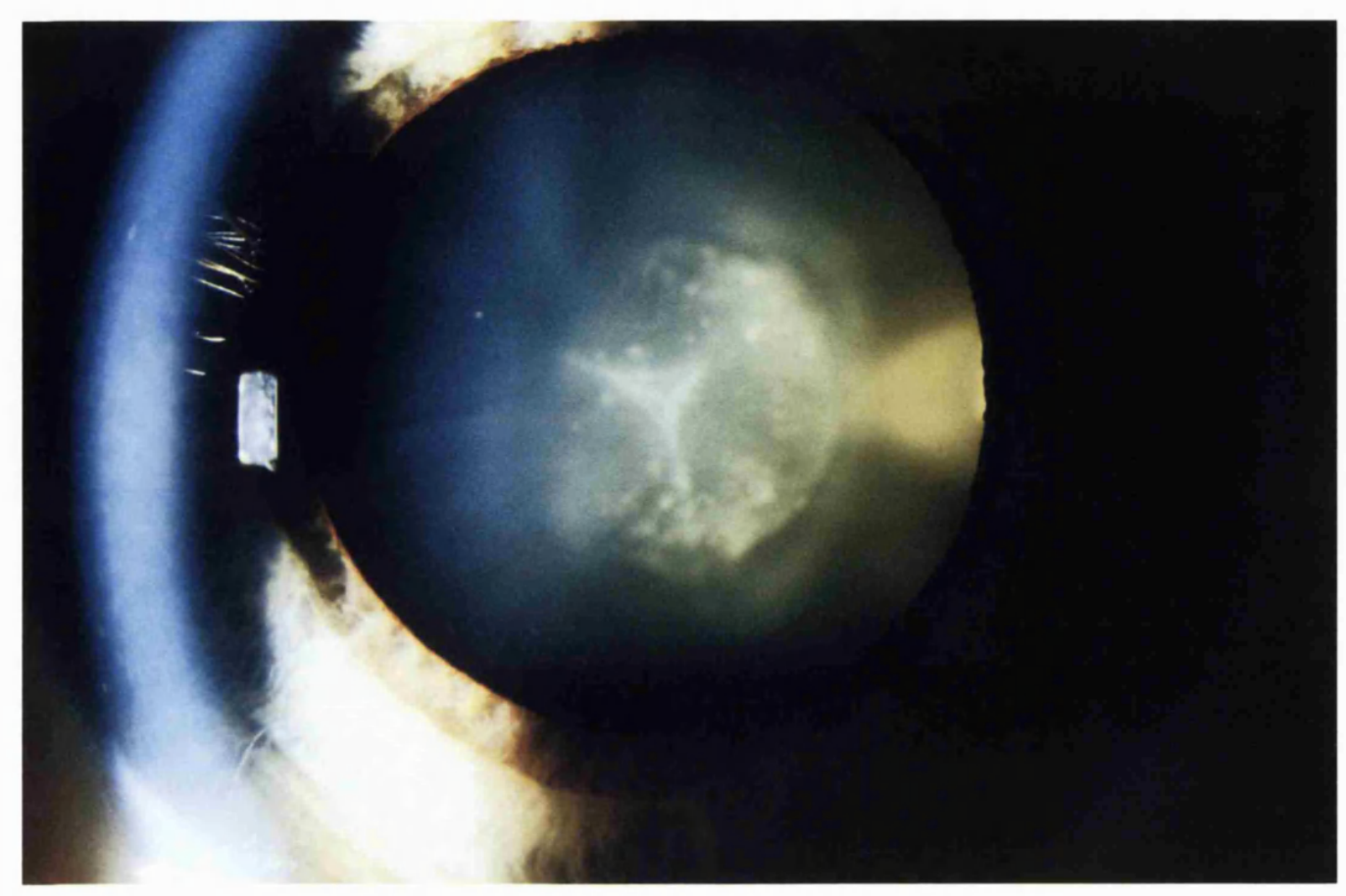

Figure 31. Lamellar cataract. Ped F Individ 3.10

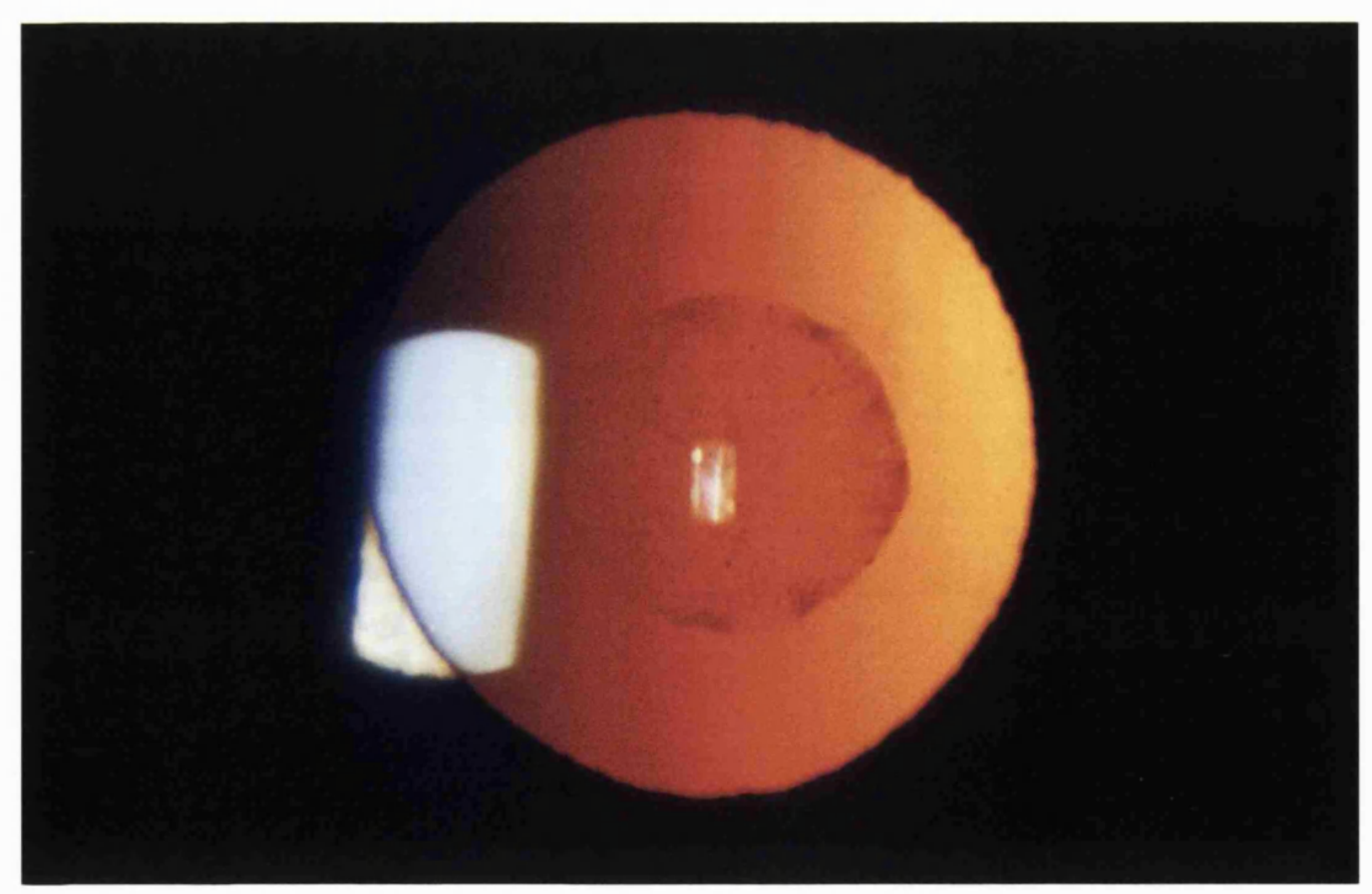

Figure 32. Lamellar cataract: Retroillumination. Ped F Individ 3.10 


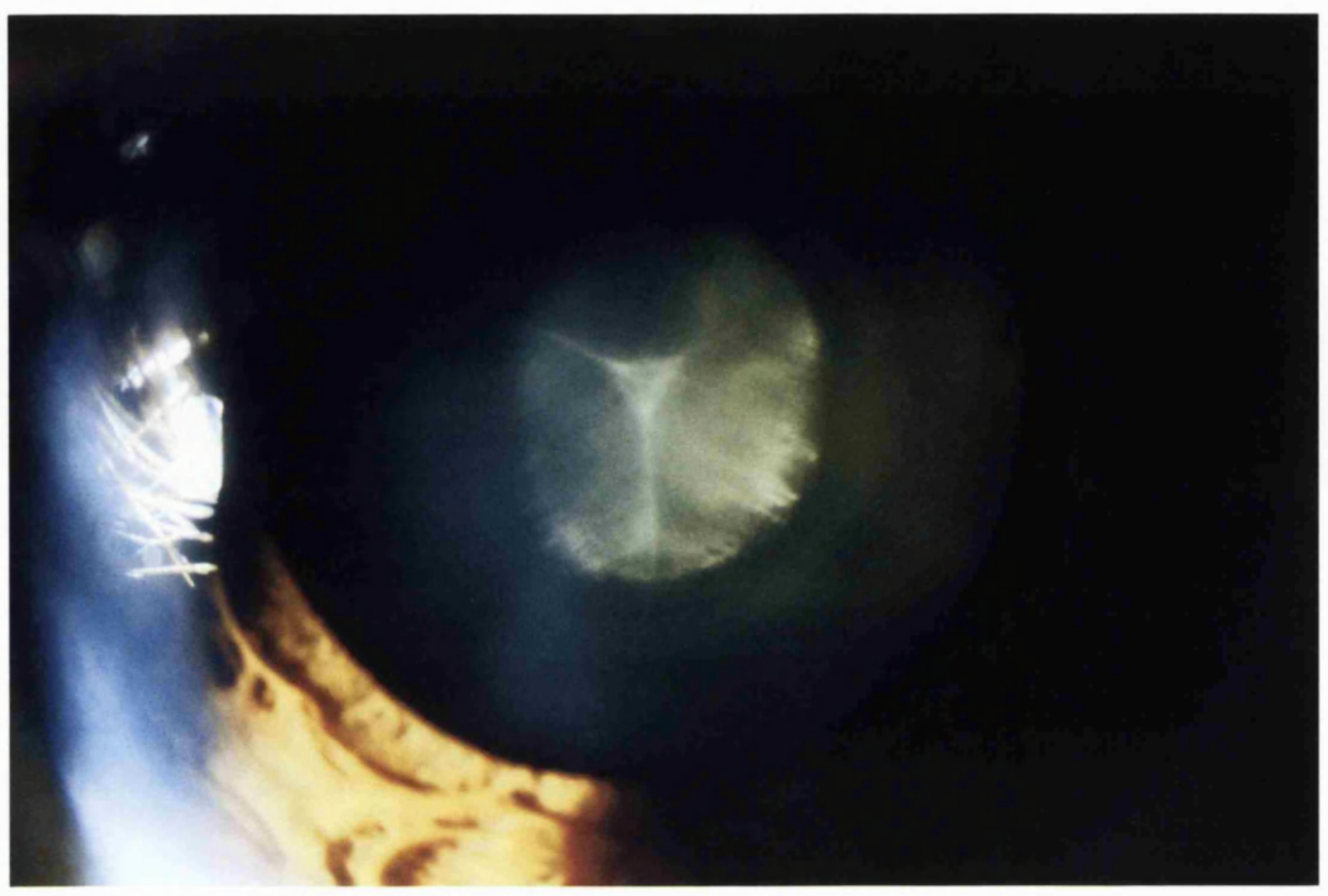

Figure 33. Lamellar cataract. Ped F Individ 4.6

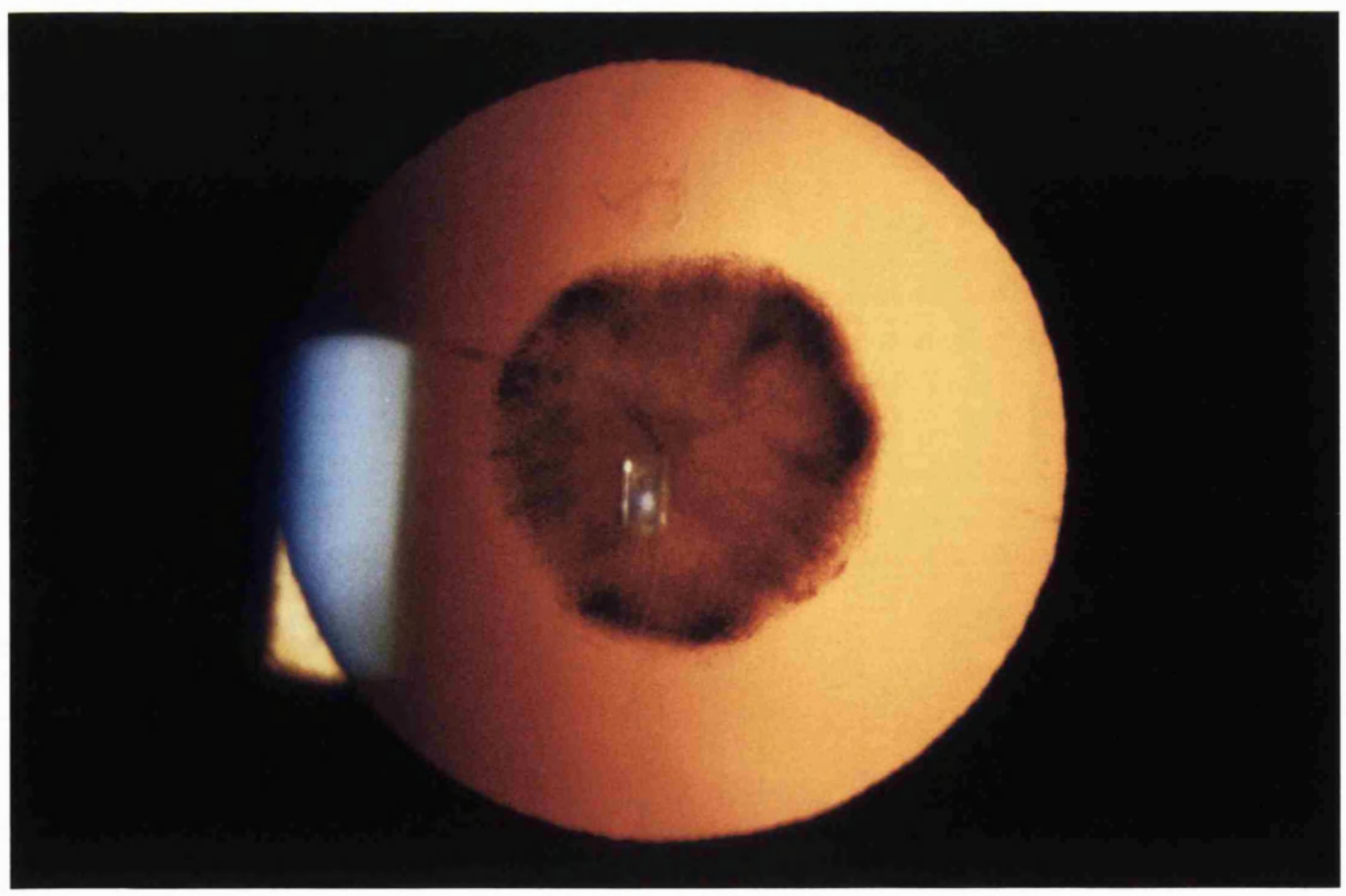

Figure 34. Lamellar cataract. Retroillumination. $\quad$ Ped F Individ 4.6 


\section{Coralliform}

The single pedigree of this phenotype (Pedigree I) from the Moorfields genetic data base is descended from a family originally described by Nettleship (Nettleship E, 1906) and illustrated in Figure 35. The name is derived from the resemblance of the cataract to sea coral, having finger-like tubular protuberances extending from the nucleus. All affected members of this pedigree had been operated on and none were available for slit lamp photography. The description of the cataract was taken from the clinical notes. The mean age at operation was 5 years (range 1-12 years, median 5 , mode 7 years). The visual outcome was $6 / 6$ to 6/36 (median 6/9, mode 6/9).
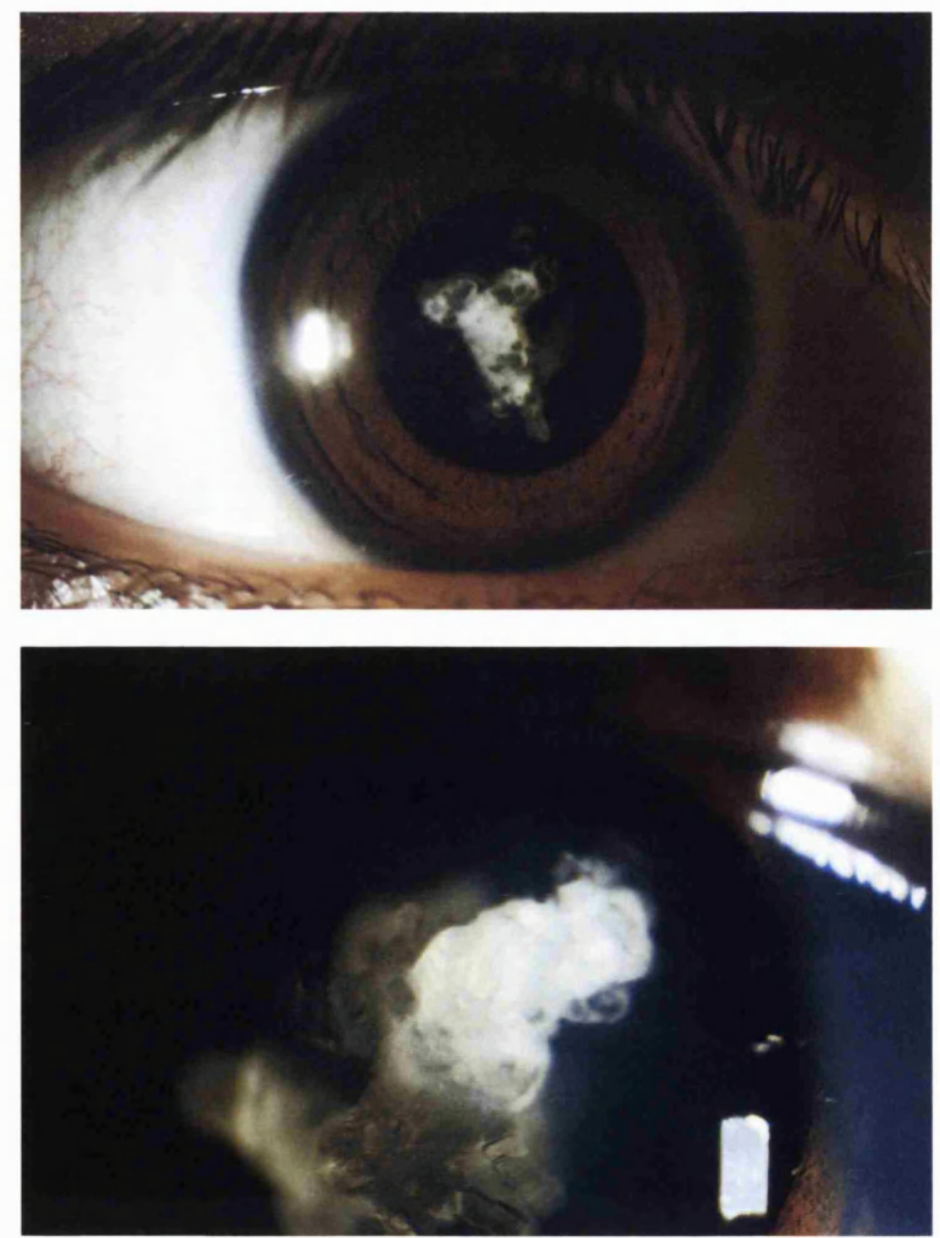

Figure 35. Coralliform cataract. 


\section{Blue-dot.}

The blue-dot, or cerulean cataract is not congenital but develops in childhood, progresses slowly and does not require surgery until adulthood. The opacities are distributed throughout the lens, with the nucleus containing blue-white dots but becoming more numerous in the cortex where they may form large cuneiform (wedge-like) shapes in the mid-periphery (Figures $36 \&$ 37). The phenotype is once again consistent throughout the pedigree varying in severity. The pedigree involved in this study consisted of 7 affected and 6 unaffected members. Inheritance of the cataract was autosomal dominant and showed clear male to male inheritance with five affected males and two affected females. Mean age at presentation was 11 years and all affected individuals underwent surgery which was performed at an average age of 27 years (range 10-47, mode 25, median 25). Final visual acuity in the affected members was good, measuring 6/12 or better. All unaffected members and six of the seven affected individuals underwent slit lamp examination and the cataract morphology was characteristic of the blue-dot phenotype. 


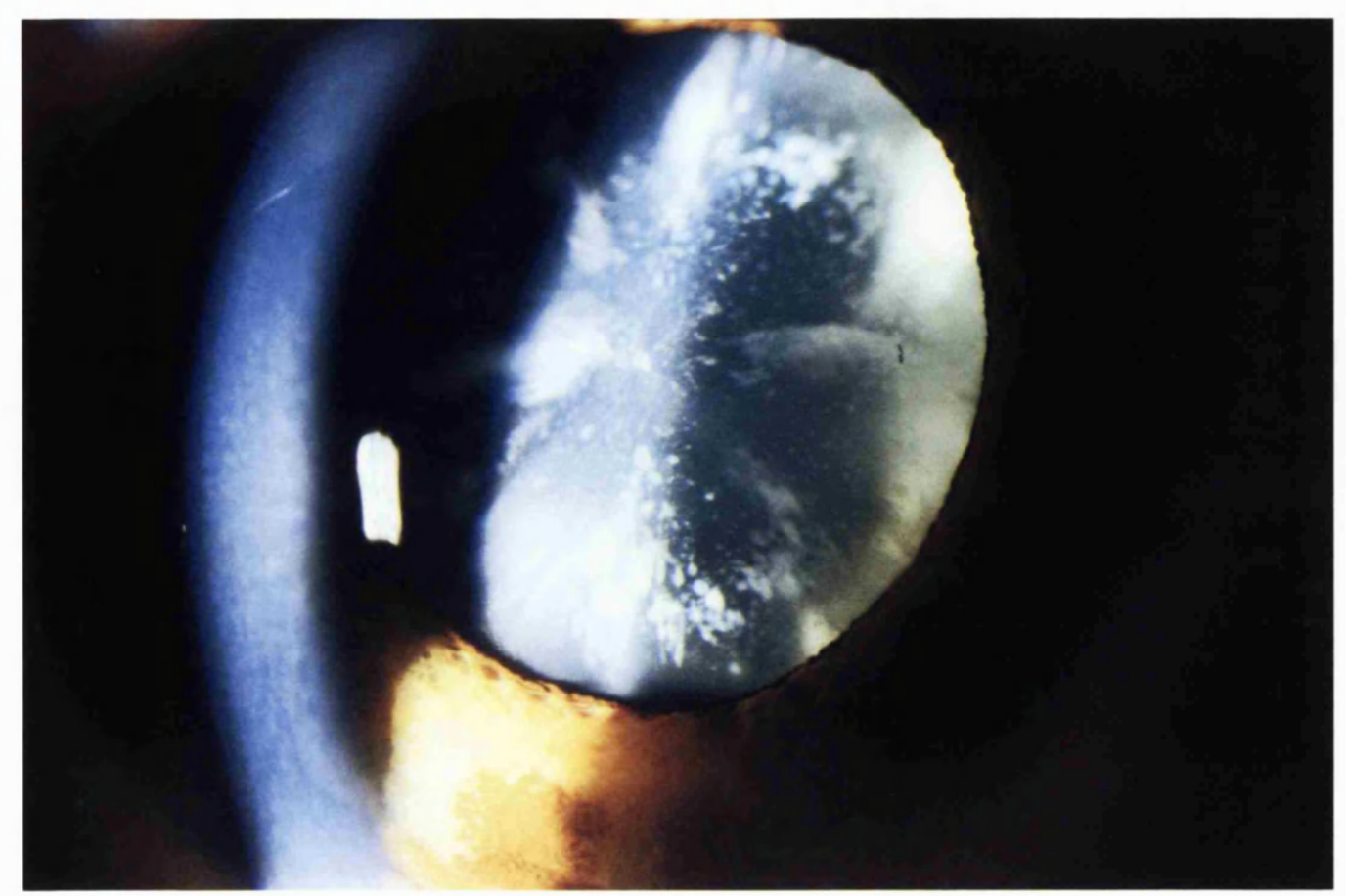

Figure 36. Blue-dot cataract. Ped J Individ 4.6

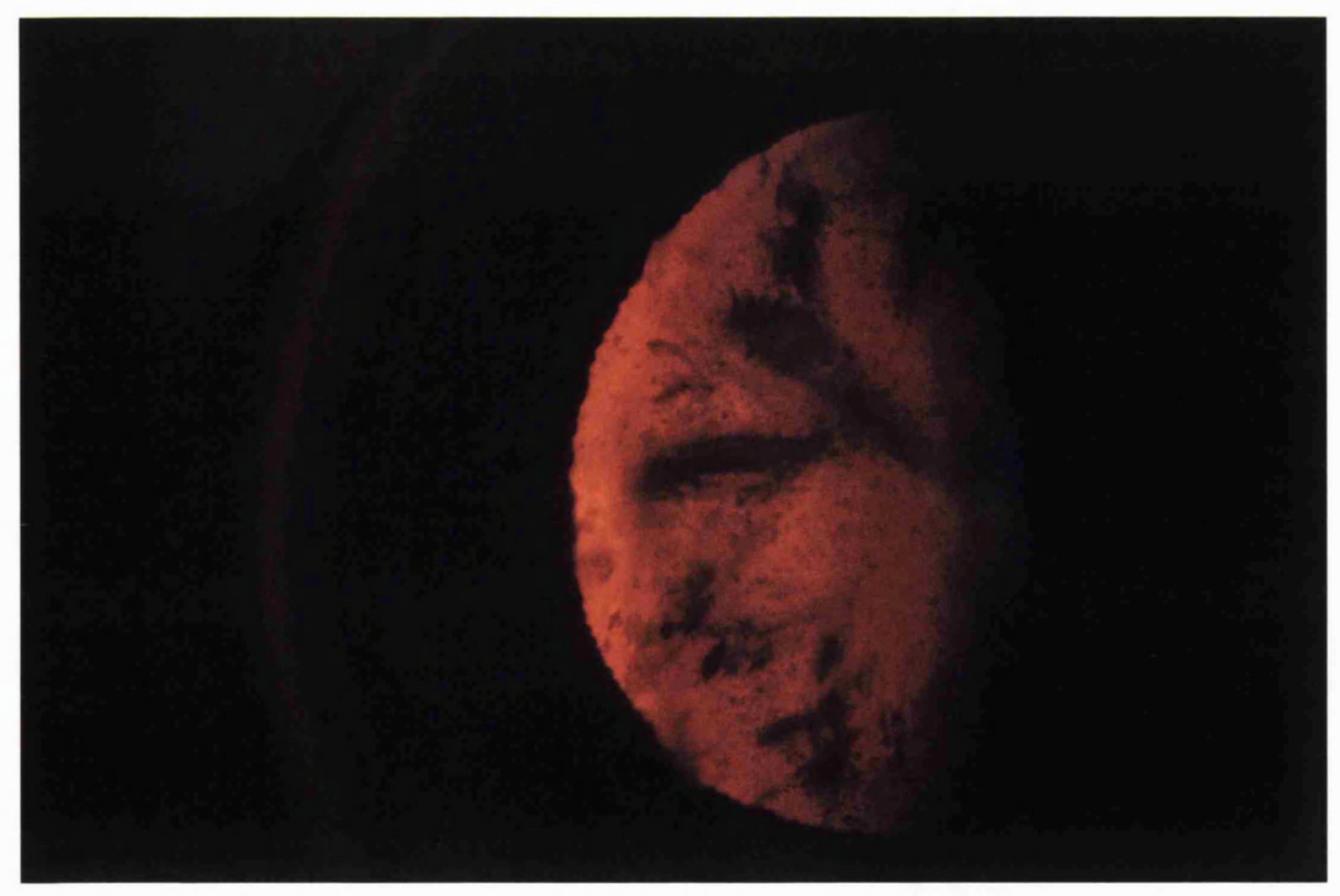

Figure 37. Blue-dot cataract: Retroillumination. Ped J Individ 4.6 


\section{Cortical cataract.}

Cortical cataract is rarely described as an autosomal dominant trait, but in the family described here the cataract had a late onset in childhood or early adult life and varied in severity but not in morphology (Figures 38-41). Cortical fibres are laid down after birth and the cortex does not begin to develop until childhood. The delayed onset of the cataract suggests an abnormality at this later stage of lens development. The pedigree we studied (Pedigree K) had only the superior cortex involved in the three affected patients examined that had not undergone bilateral surgery. The nucleus remained unaffected and there was no opacity elsewhere in the lens. Surgery was performed at a mean age of 23 (range 7-43), with a final visual acuity ranging from $6 / 6$ to $6 / 60$. 


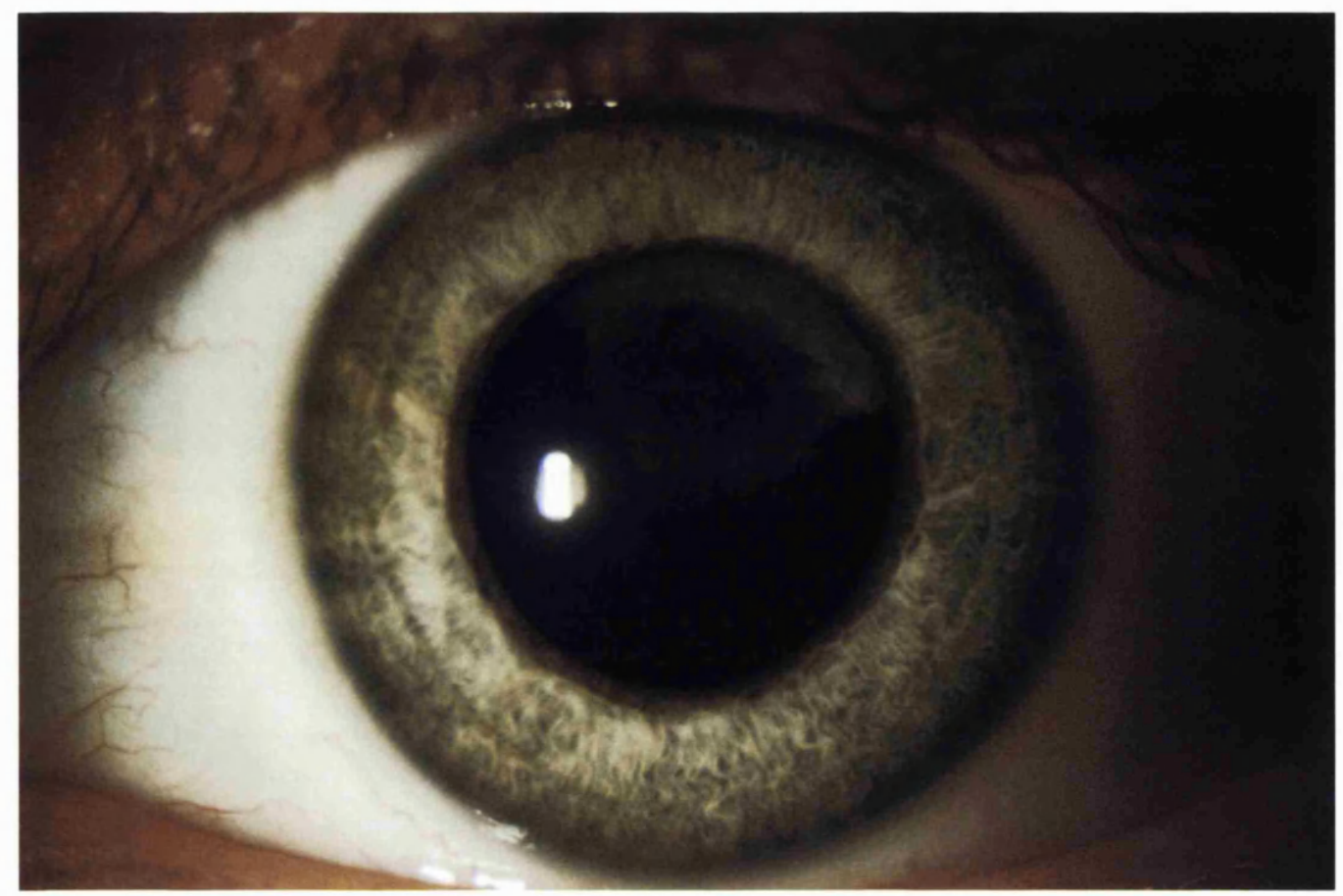

Figure 38. Cortical cataract. $\quad$ Ped K Individ 3.7

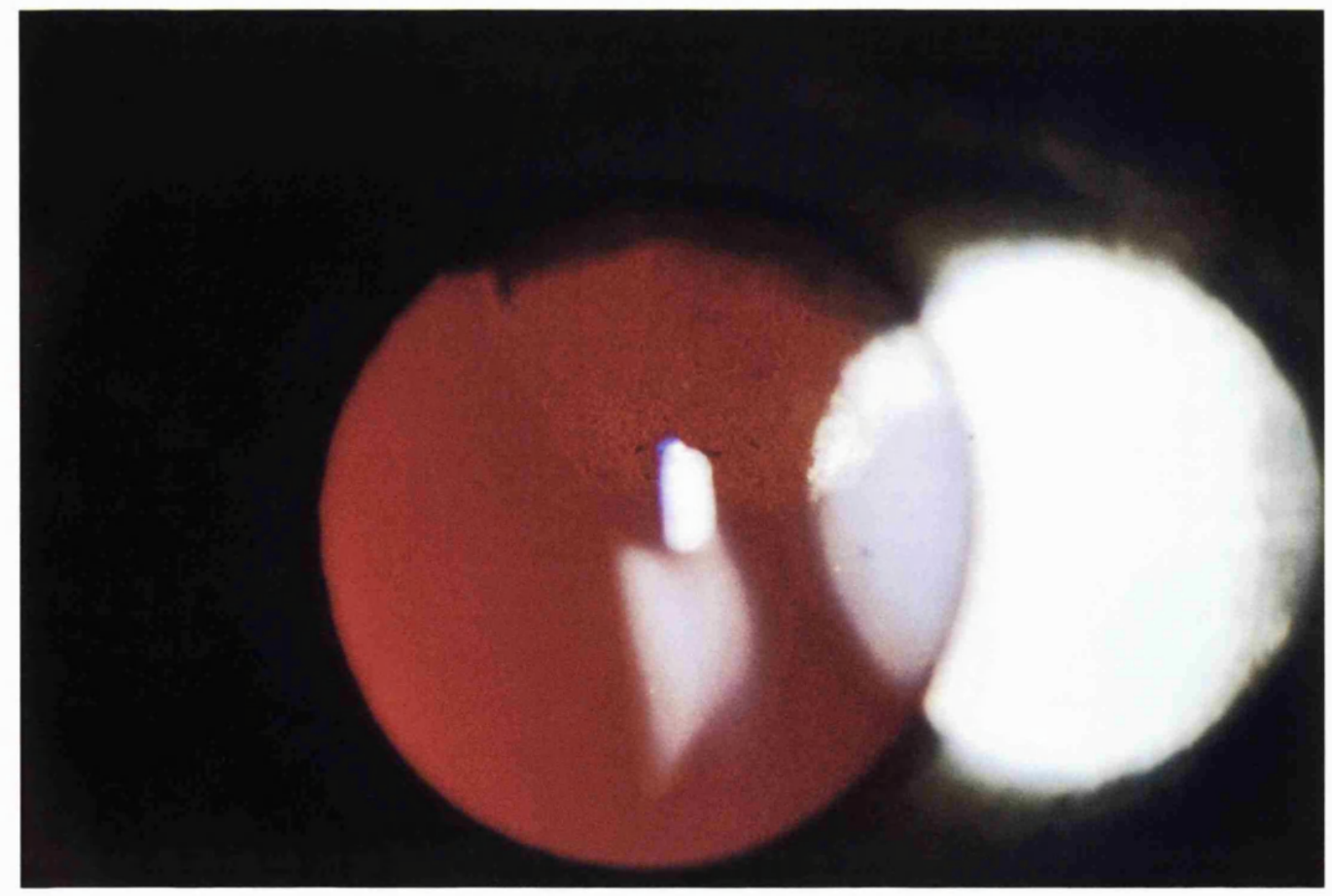

Figure 39. Cortical cataract. Retroillumination. $\quad$ Ped K Individ 3.7 


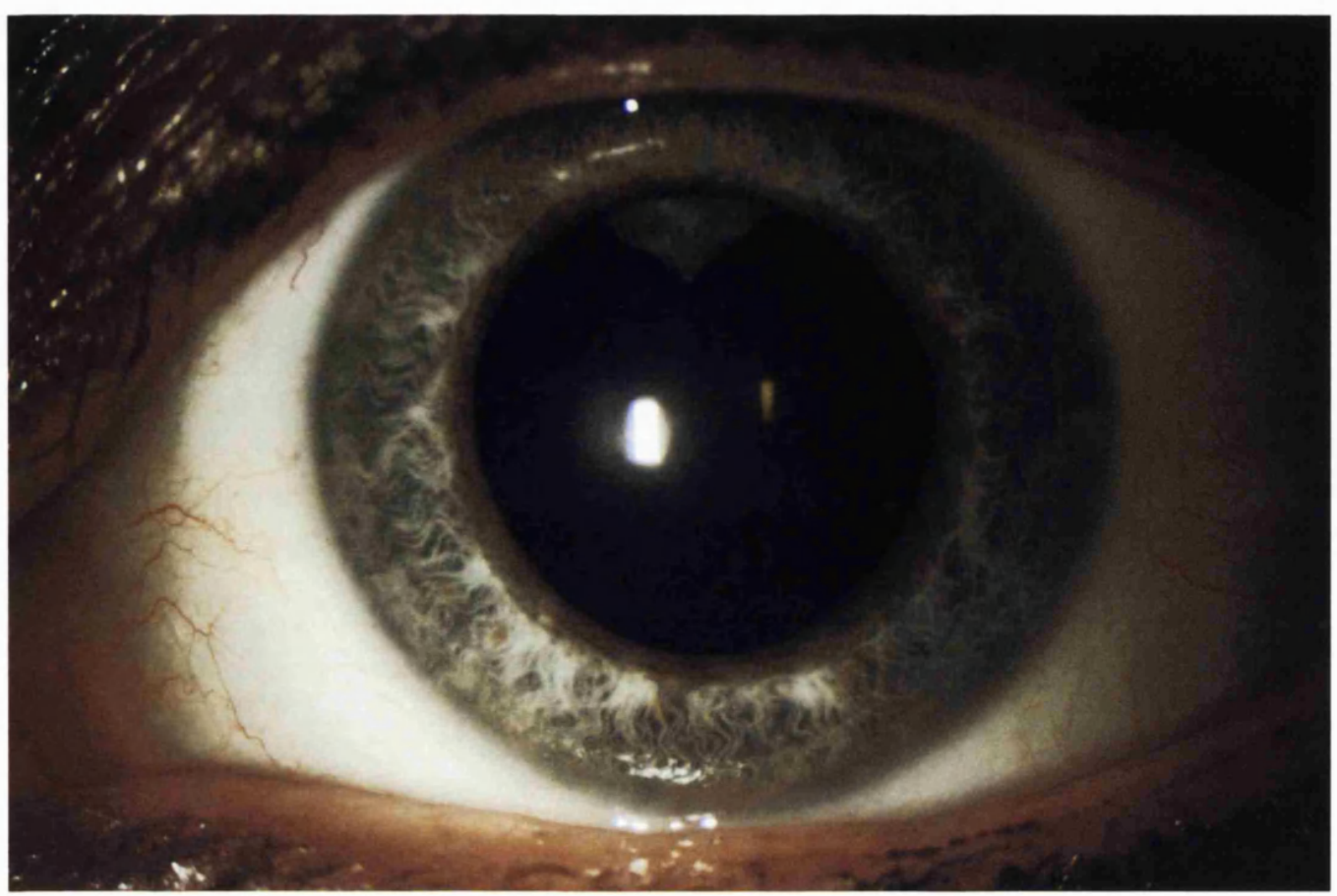

Figure 40. Cortical cataract. Ped K Individ 4.7

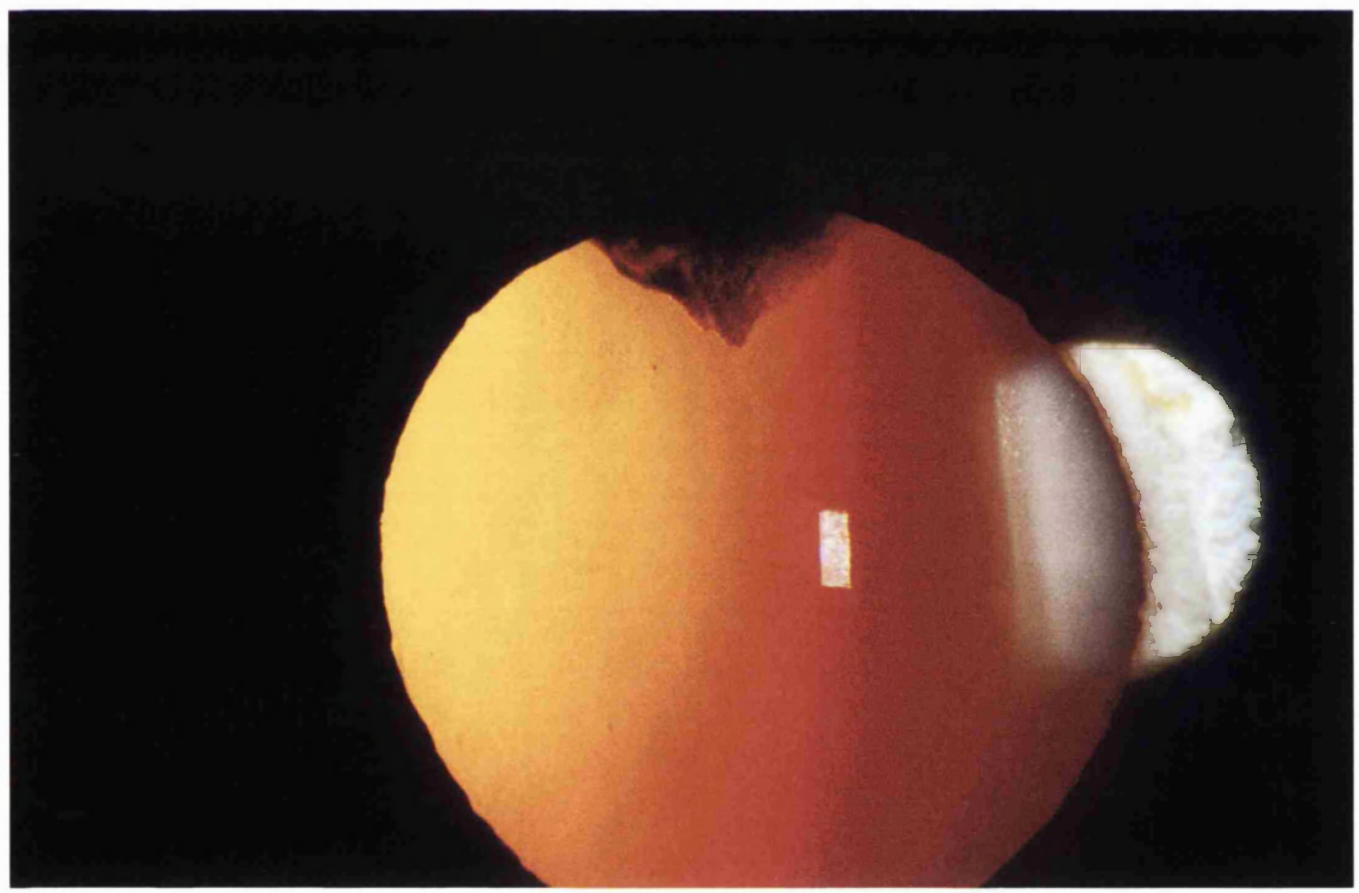

Figure 41. Cortical cataract. Retroillumination. $\quad P e d K$ Individ 4.7 


\section{Pulverulent.}

Pulverulent cataracts are powdery ('pulverised') opacities and although there is great intra-familial variety in pulverulent pedigrees, most of the affected patients had these fine, powdery opacities. Some individuals had sparse, fine opacities throughout the lens (Figure $42 \& 43$ ), others have dot-like sutural cataract (Figures 44-47), some have pulverised opacities in the posterior cortex (Figures $48 \& 49$ ) and others can have a dense central cataract (Figures 50-53). It is important to examine as many affected members of a family with pulverulent cataract as possible, as it can be difficult to diagnose this phenotype in a pedigree after examining only a few members. The main feature is the pulverulent nature of the opacities in several affected family members and the features that distinguish a pulverulent from a nuclear pedigree include the wide variation in morphology within a pulverulent pedigree as well as the involvement of the lens outside the embryonic and fetal nuclei.

Four families involved in this study had pulverulent cataract. In one of the families (Pedigree $\mathbf{L}$ ) affected by pulverulent cataract 18 patients were found to be affected. The cataract varied between affected individuals. In some the fine opacities formed a lamellar distribution with a clear cortex (Figure 44) and minimal inner fetal nuclear involvement. Others had more widely spread pulverised opacities (Figures 42 \& 43) extending into the cortex with no demarcation of the fetal nucleus (Figure 46). In some the cataract was mild and the fine dust-like opacities were clustered only around the anterior and posterior Y-sutures (Figure 47). Nine had undergone surgery at a mean age of 17 years (382 , median 8 , mode 11 ) with a final visual acuity that varied from $6 / 4$ to NPL. If the operation was performed under 8 years of age, the visual acuity was $6 / 9$ to NPL. If performed after the age of 20 years the range improved to 6/4 -6/12.

In a second family (Pedigree $\mathbf{M}$ ) with pulverulent cataract 15 members were examined and 10 were affected. Four had undergone bilateral cataract surgery, two unilateral and four had not had surgery. The mean age at surgery was 14 years (range 5-22 years, median 17 ) with a final visual acuity of $6 / 6-6 / 18$. The 
cataract had powdery opacities throughout the lens although they were more abundent in the fetal nucleus. In some the opacities were large and coarse (figure $56 \& 57)$ and in others finer and dust-like.

A third family affected by pulverulent cataract (Pedigree $\mathbf{N}$ ) consisted of 15 family members of whom 8 were affected by the cataract. Only two patients had undergone surgery and examination of the remaining six revealed fine dust-like opacities predominately in the fetal nucleus but also in the cortex, with moderate opacification of the Y-sutures.

The fourth family affected by pulverulent cataract (Pedigree $\mathbf{0}$ ) consisted of 21 family members with 8 affected individuals. The phenotype in this family showed great intra-familial variation, some had the typical fine dots throughout the lens (Figures $54 \& 55$ ), others had posterior opacities with the rest of the lens unaffected and one individual had dense bilateral nuclear cataracts (Figures 5053).

The fifth pedigree affected by a pulverulent cataract (Pedrigree P) was previously studied by Nettleship at the end of the $19^{\text {th }}$ century and had been the subject of a linkage study by Renwick published in 1963. All the affected individuals had been operated on and it was not possible to obtain any photographs of the cataract but descriptions of the phenotype (a 'zonular pulverulent cataract) have been published by Nettleship and then later by Renwick. 


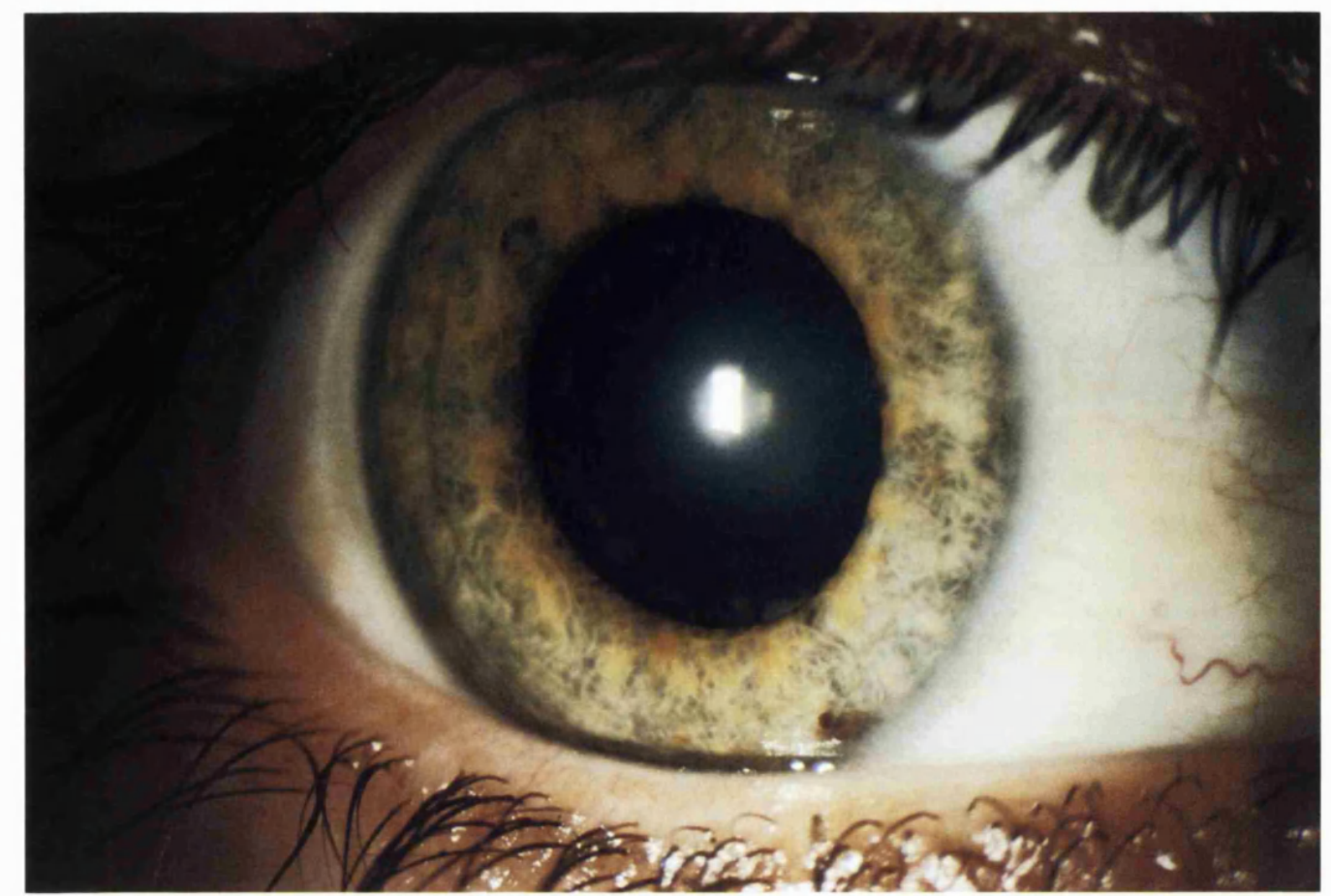

Figure 42. Pulverulent cataract. Pedigree L Fine opacities. Individ 2.4

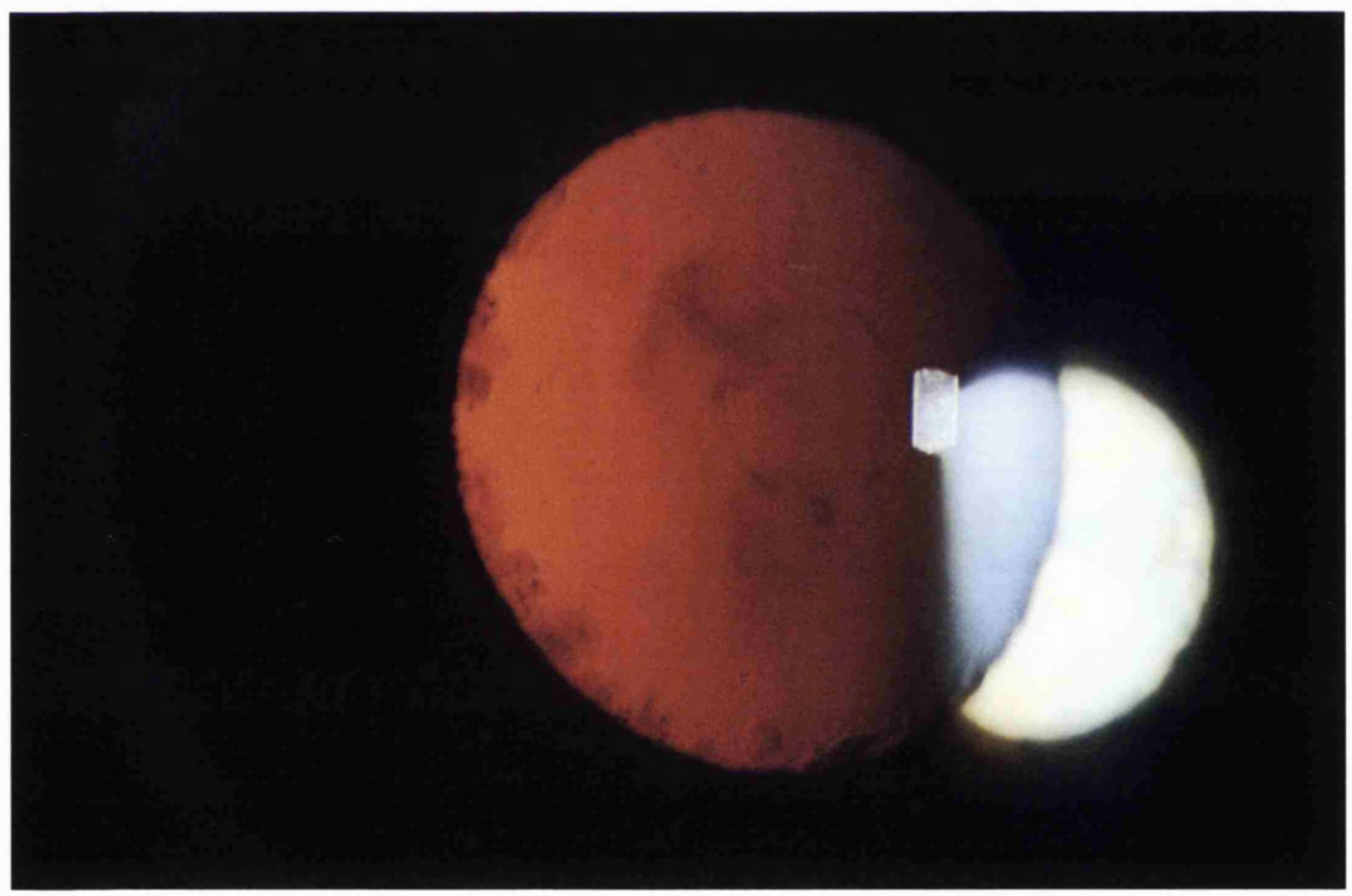

Figure 43. Pulverulent cataract. Pedigree L Fine opacities. Retroillumination. Individ 2.4 


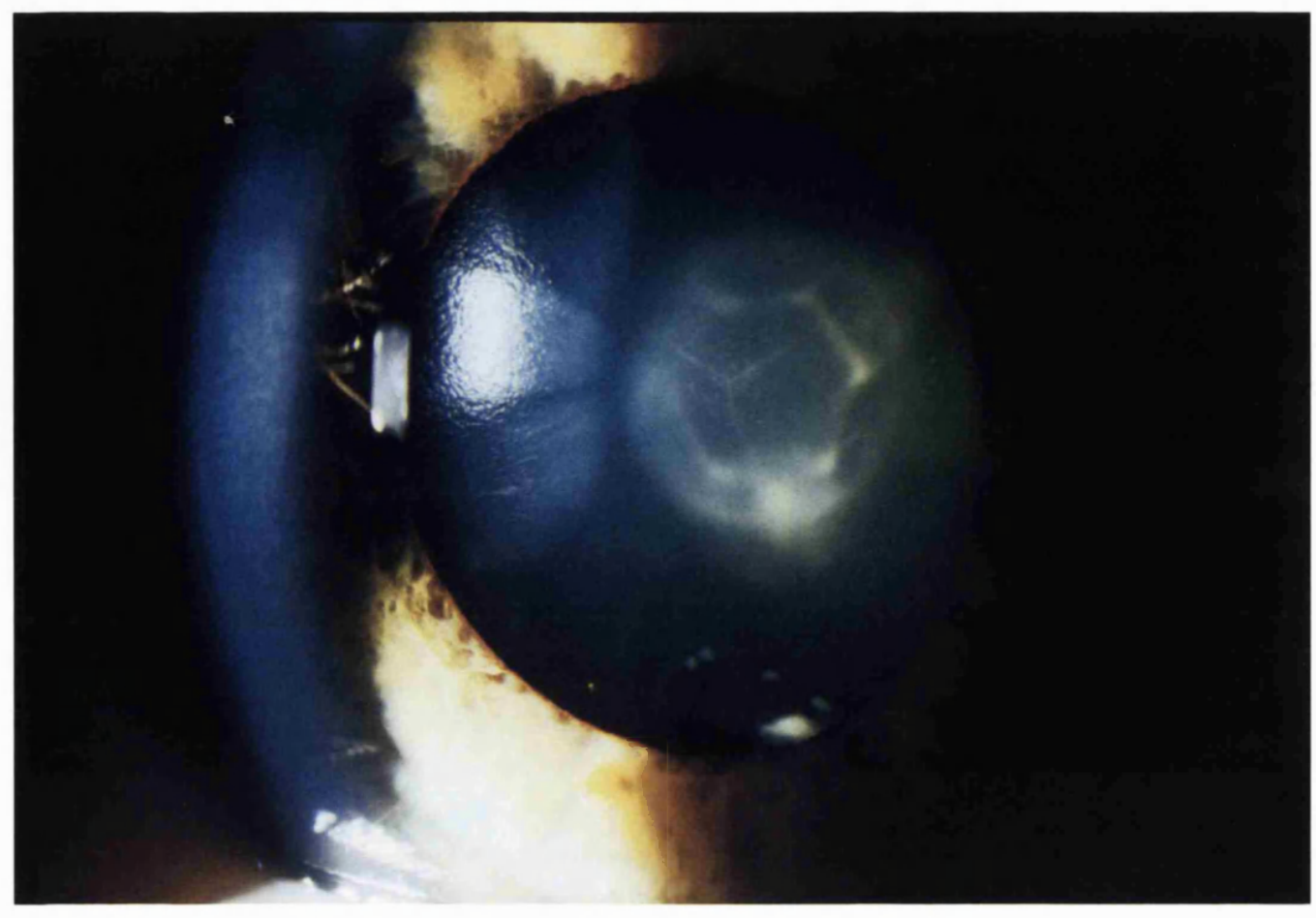

Figure 44. Pulverulent cataract. Pedigree L. Sutural opacities. Individ 2.4

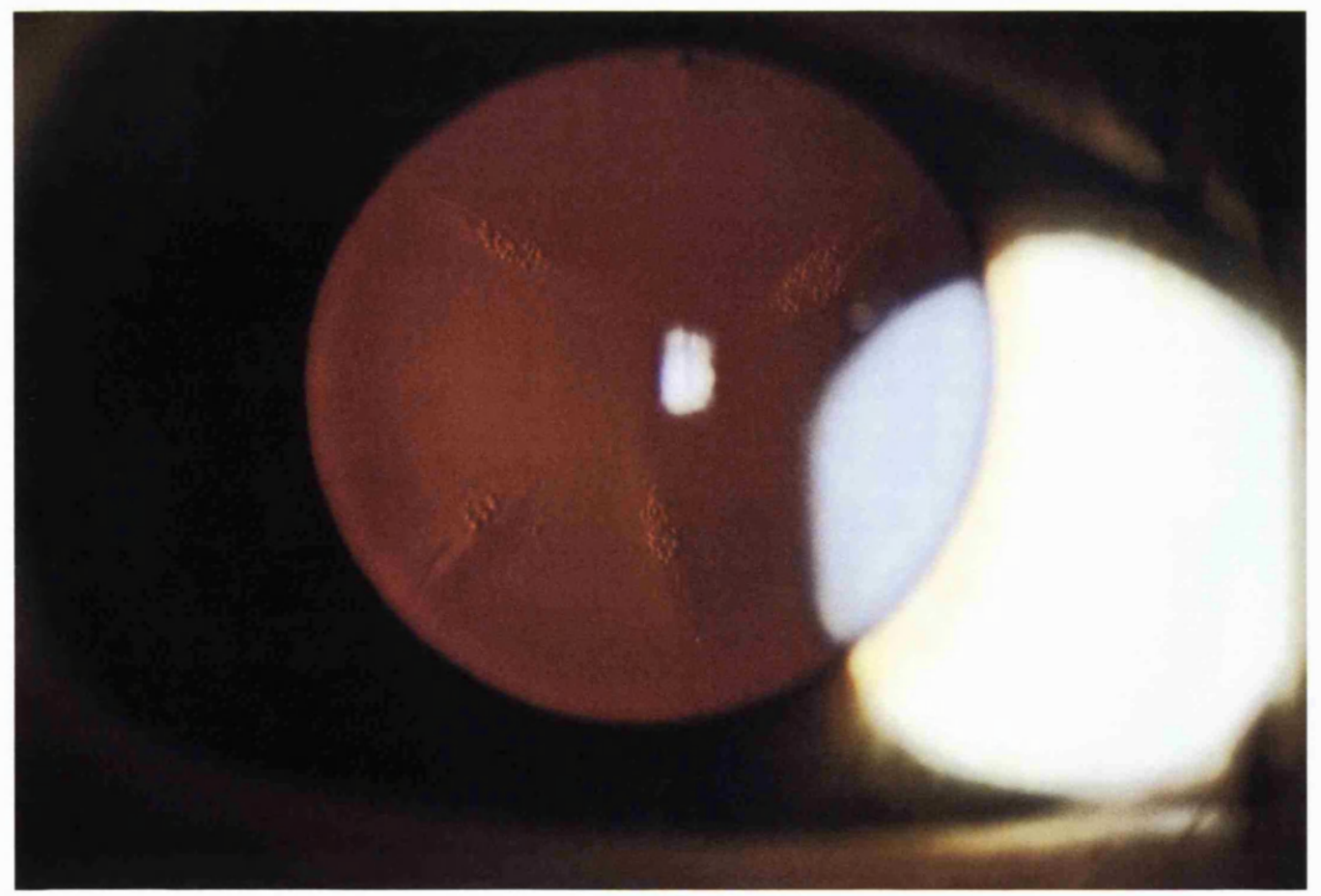

Figure 45. Pulverulent cataract.Pedigree L. Retroillumination. Individ 2.4 


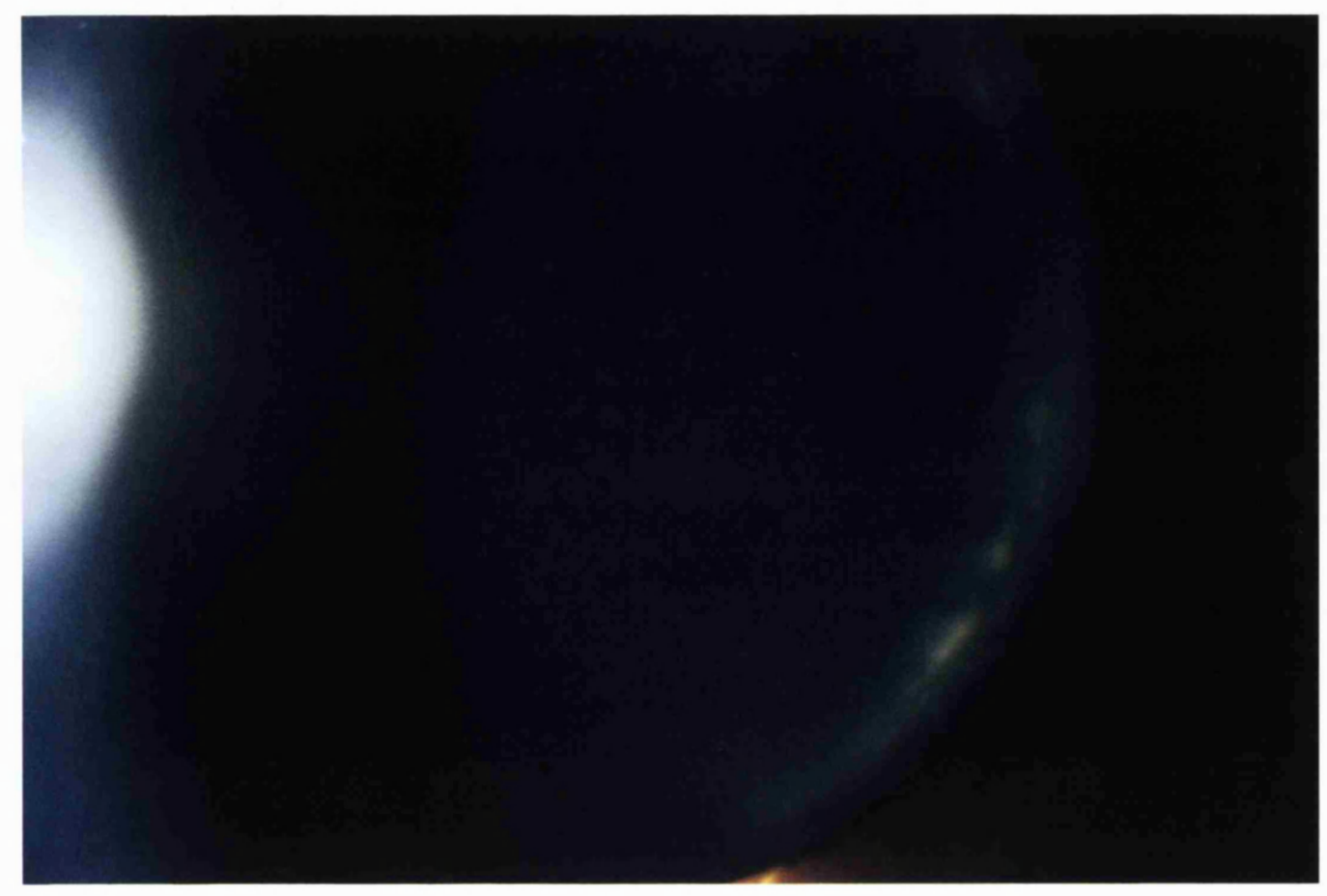

Figure 46. Pulverulent cataract:Pedigree L. Fine opacities.

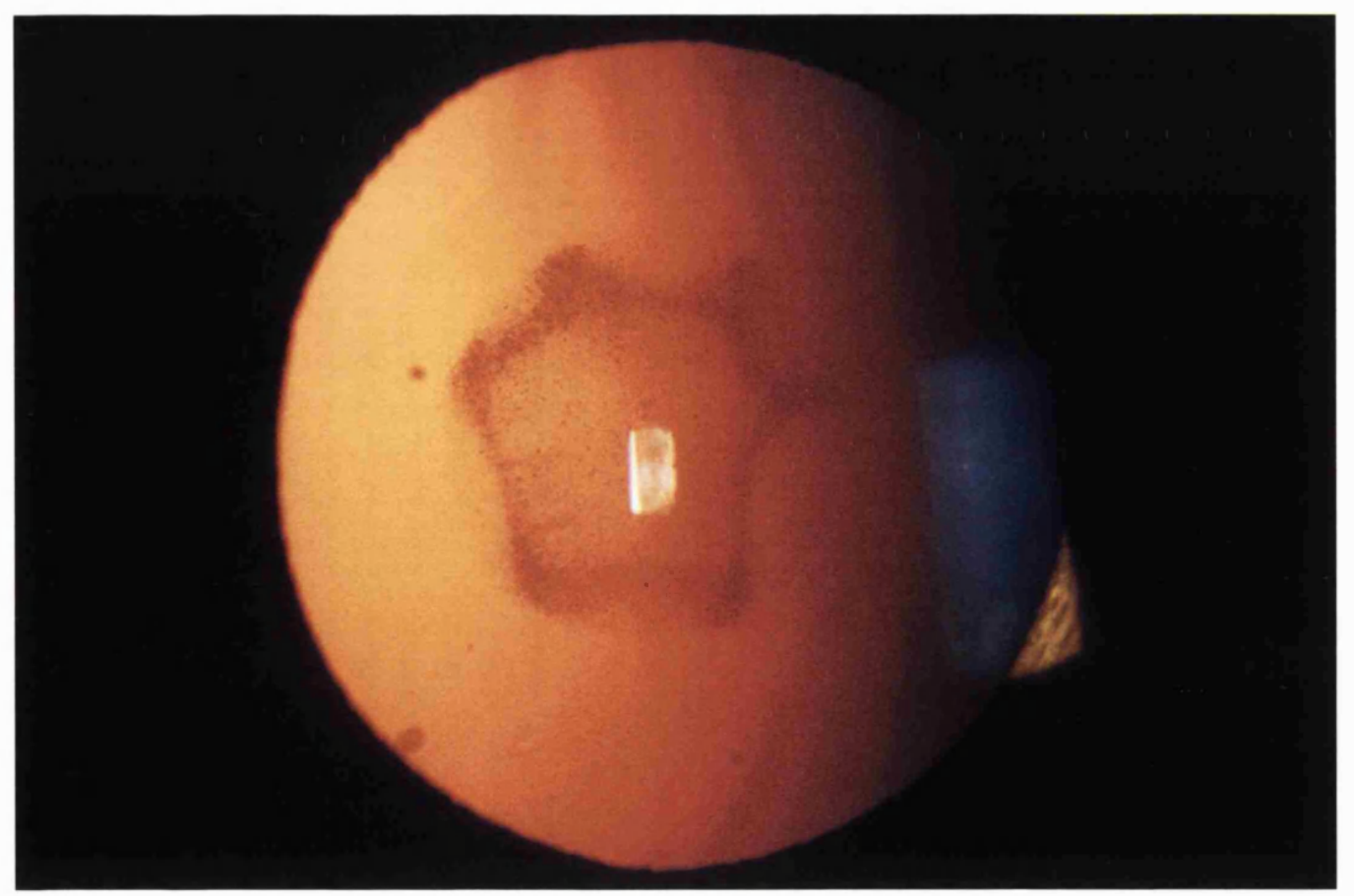

Figure 47. Pulverulent cataract: Pedigree L. Retroillumination 


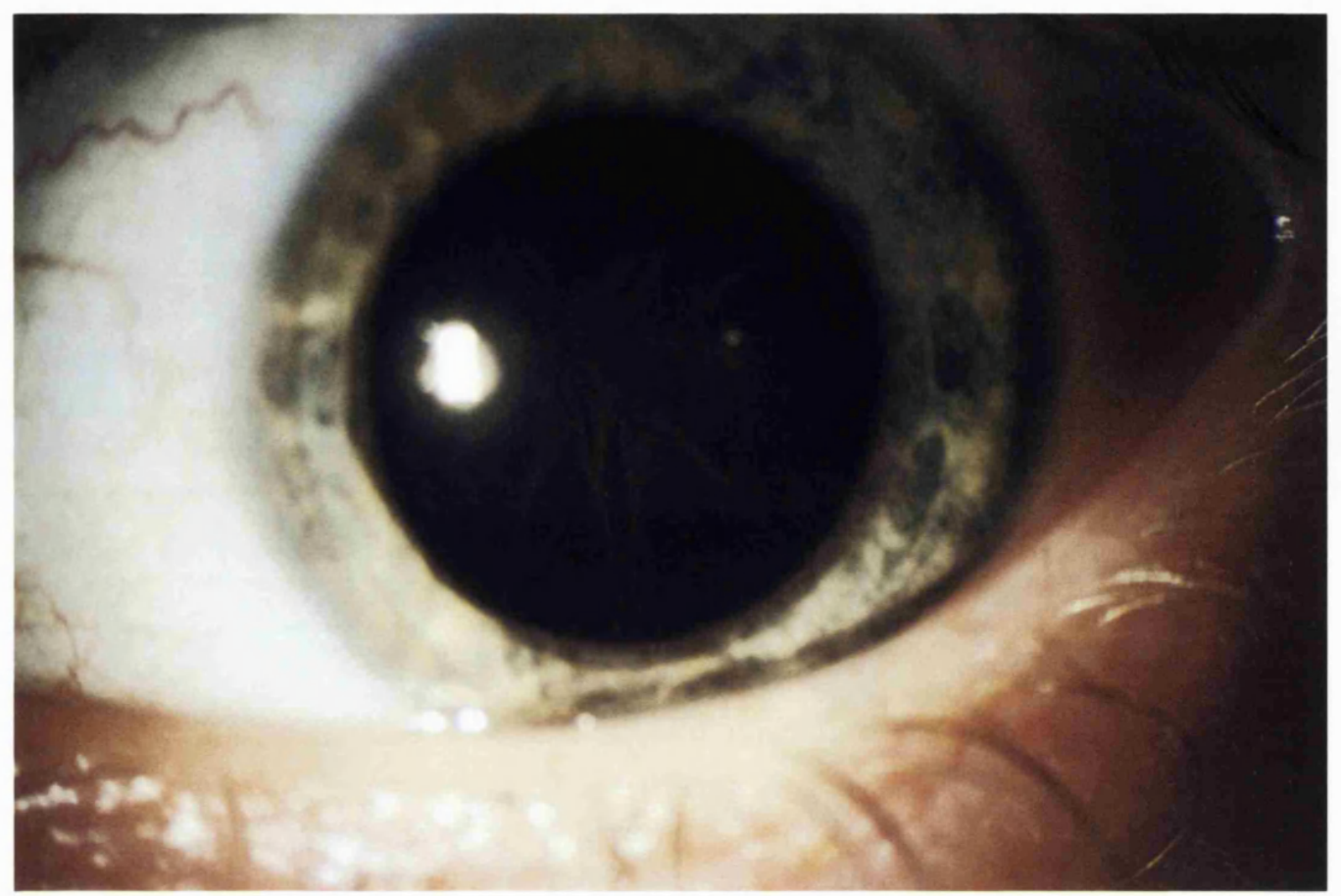

Figure 48. Pulverulent cataract. Posterior cortical opacities.

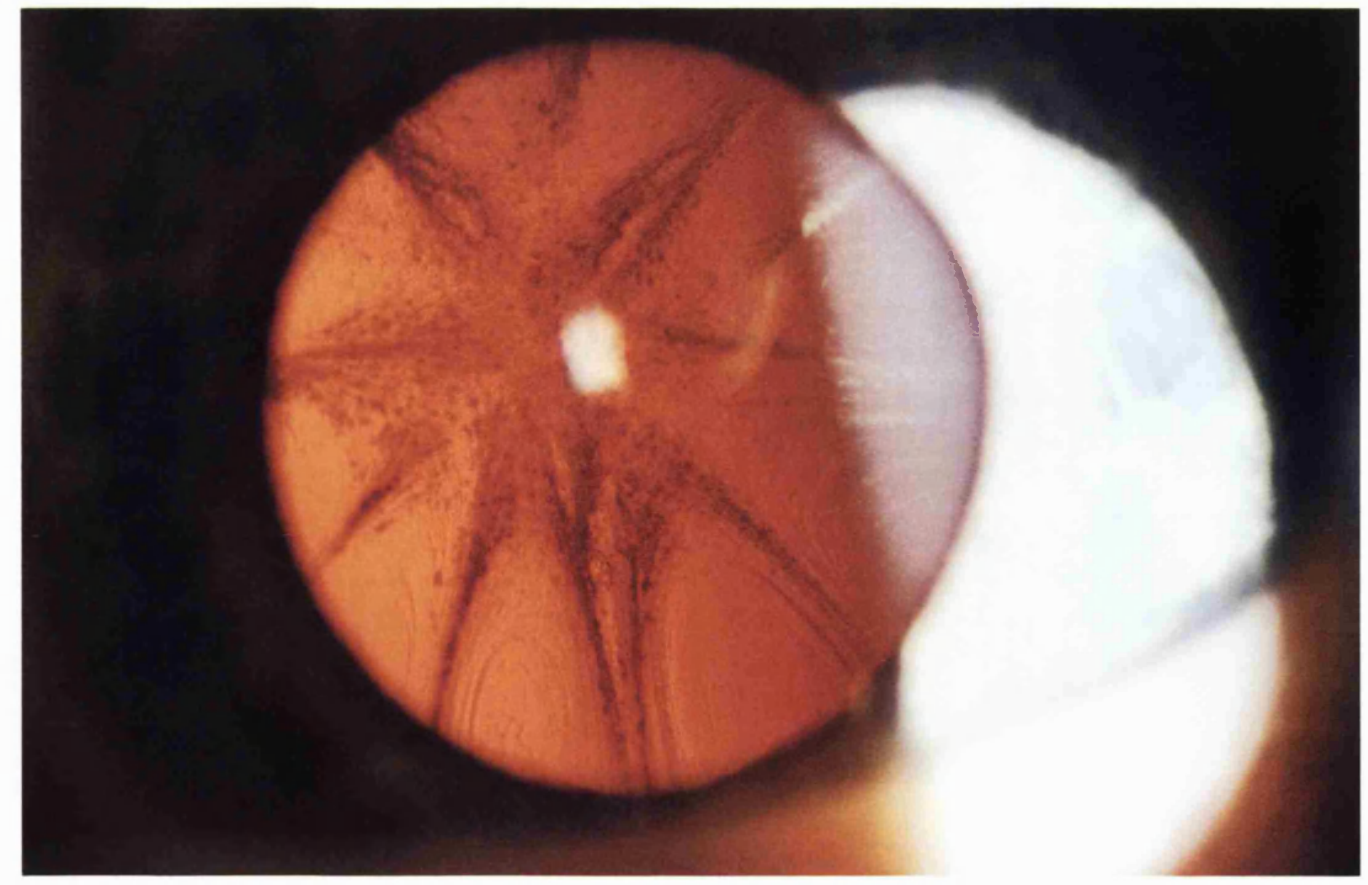

Figure 49. Pulverulent cataract. Retroillumination. 


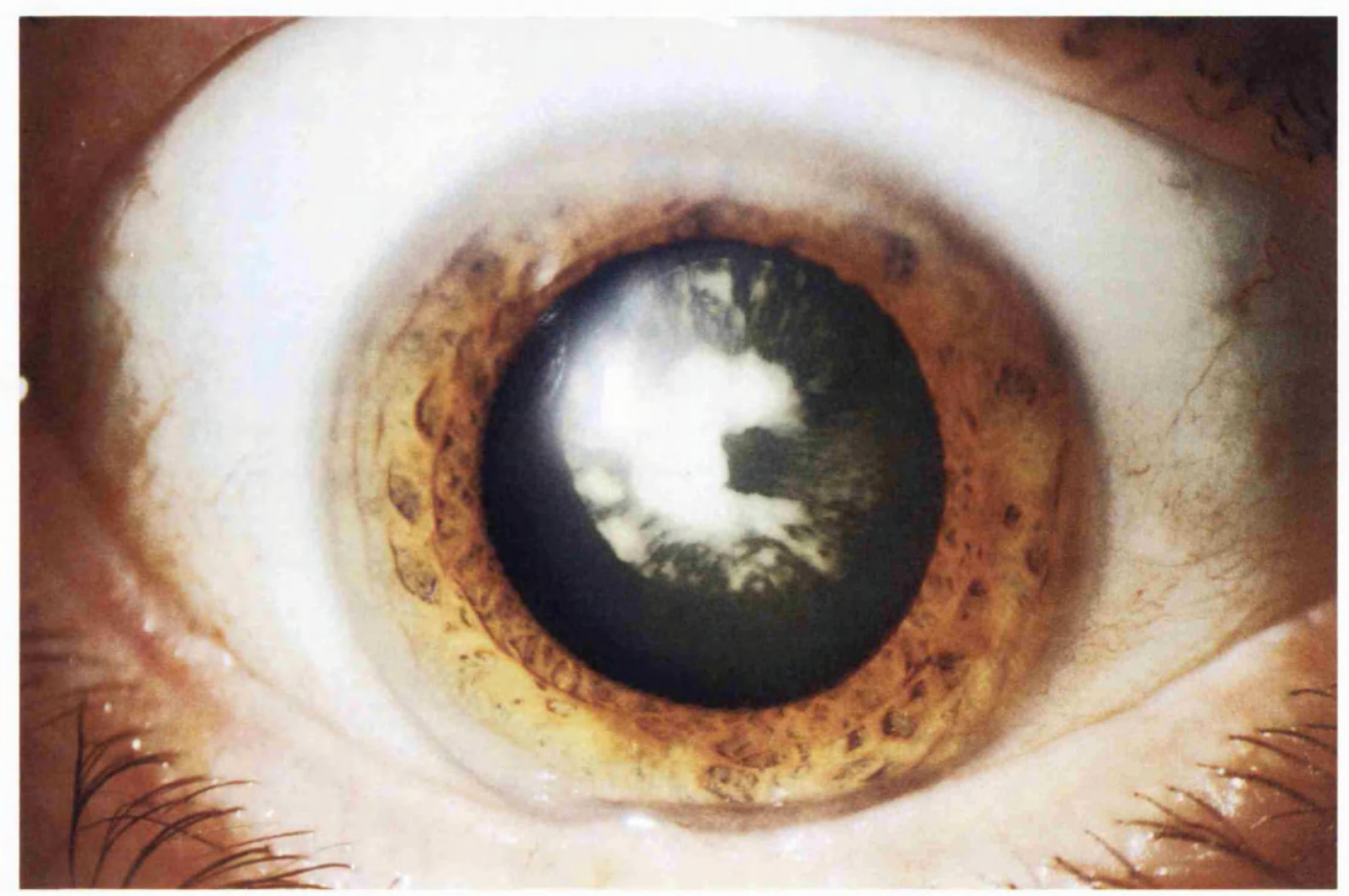

Figure 50. Pulverulent cataract. Pedigree O. Dense central opacities.

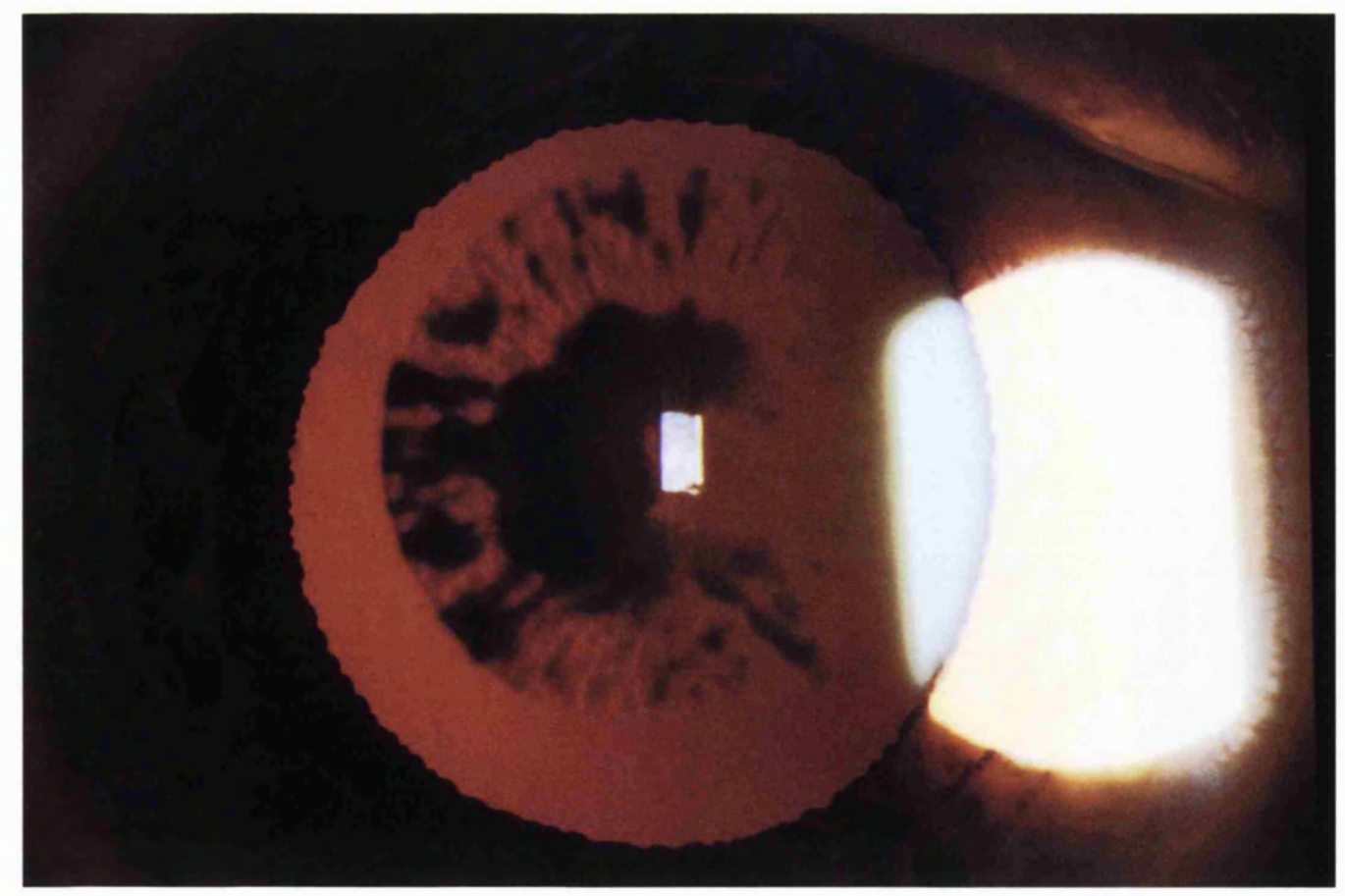

Figure 51. Pulverulent cataract. Pedigree O. Retroillumination. 


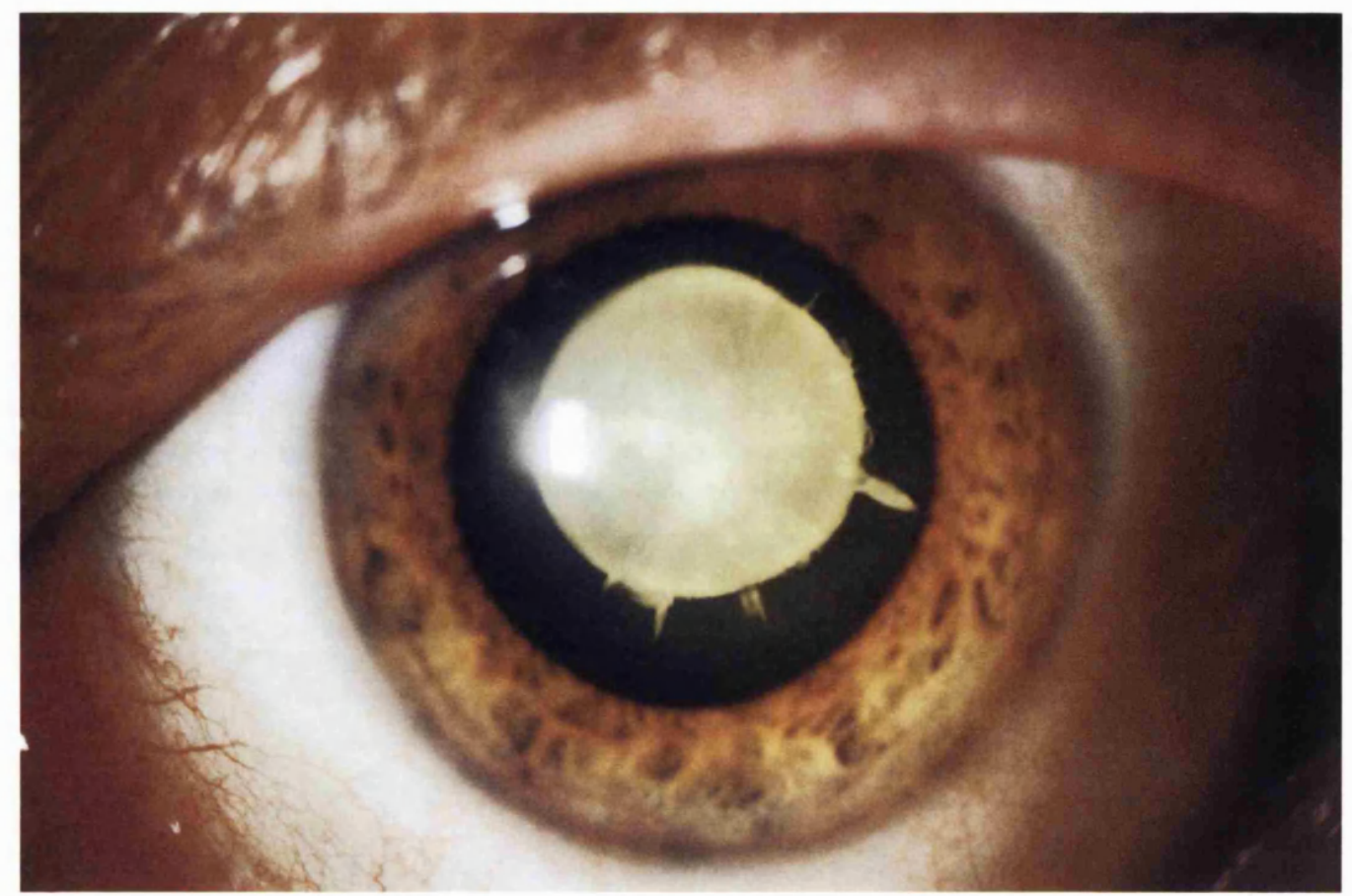

Figure 52. Pulverulent cataract. Pedigree O. Dense central opacities.

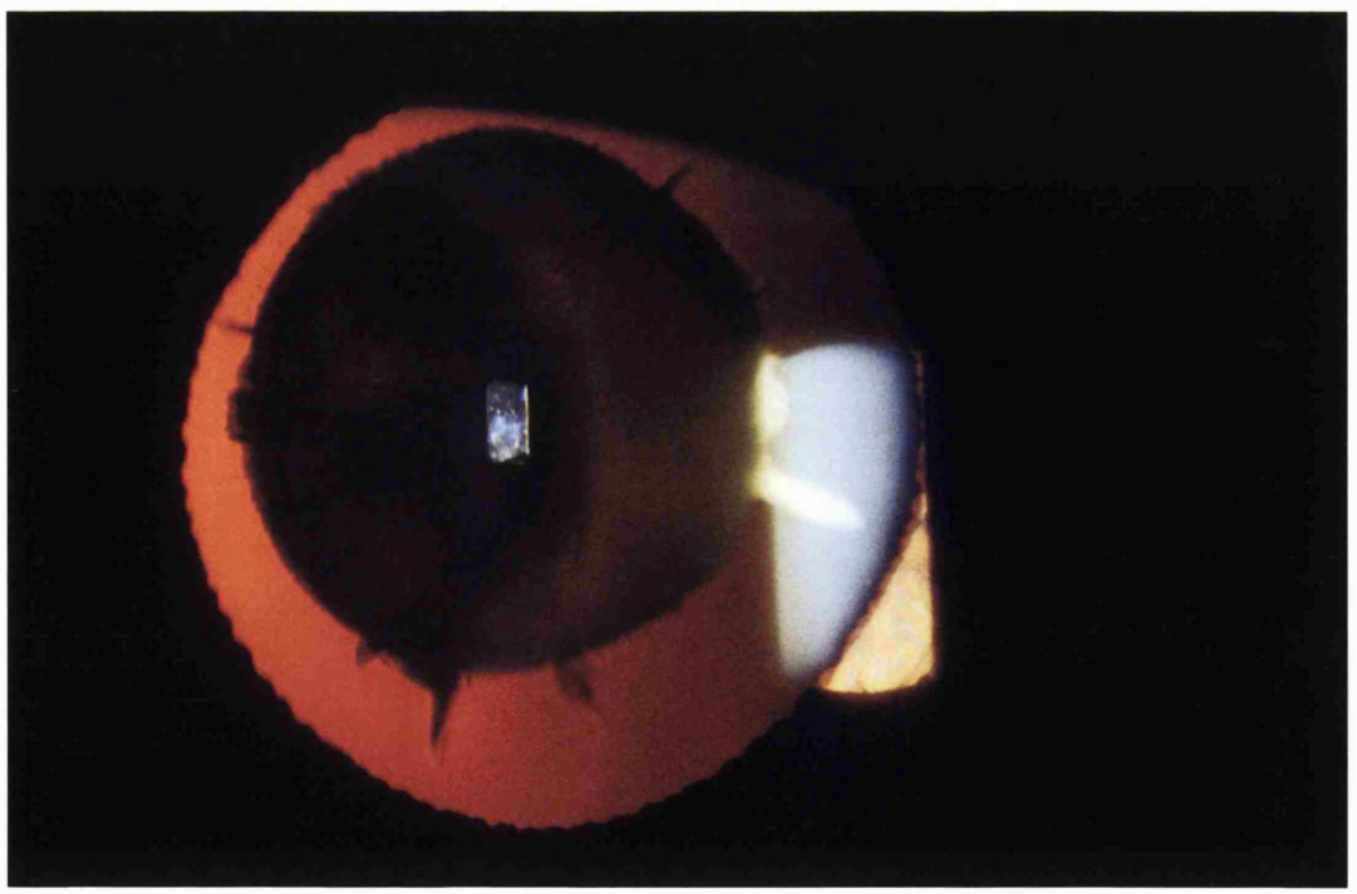

Figure 53. Pulverulent cataract.Pedigree O. Retroillumination. 


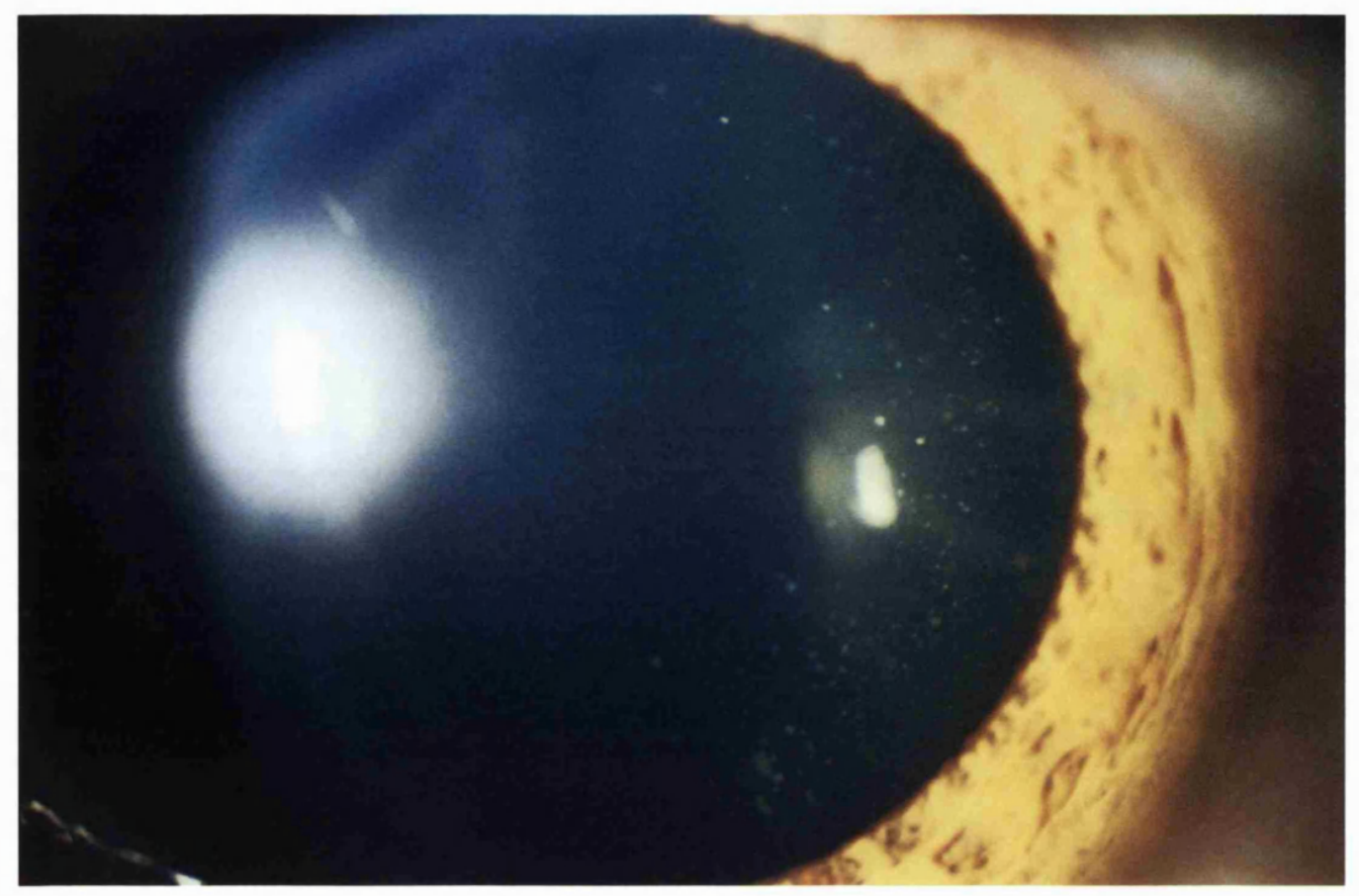

Figure 54. Pulverulent cataract. Pedigree O. Fine opacities.

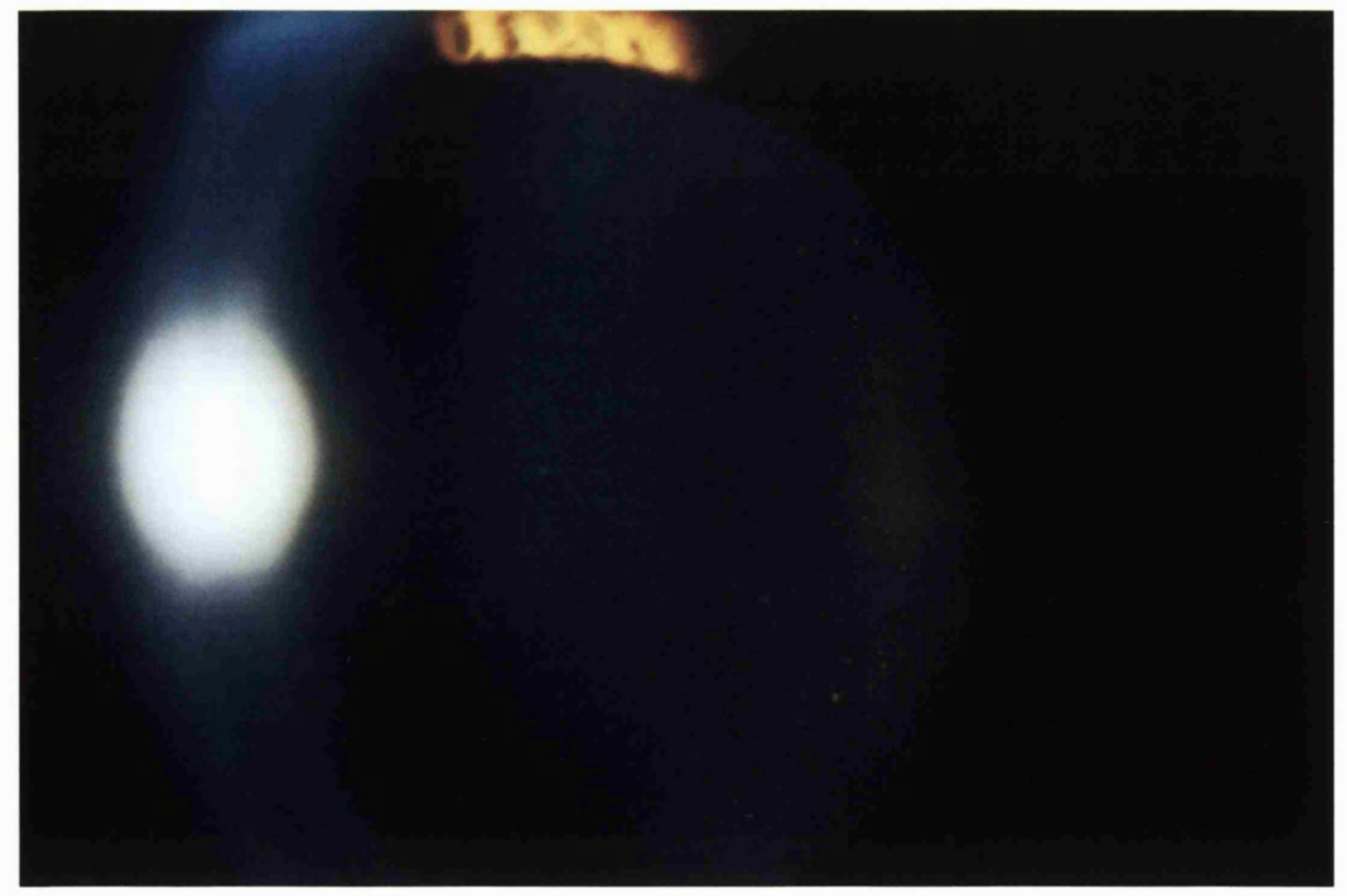

Figure 55. Pulverulent cataract. Pedigree O. Fine opacities. 


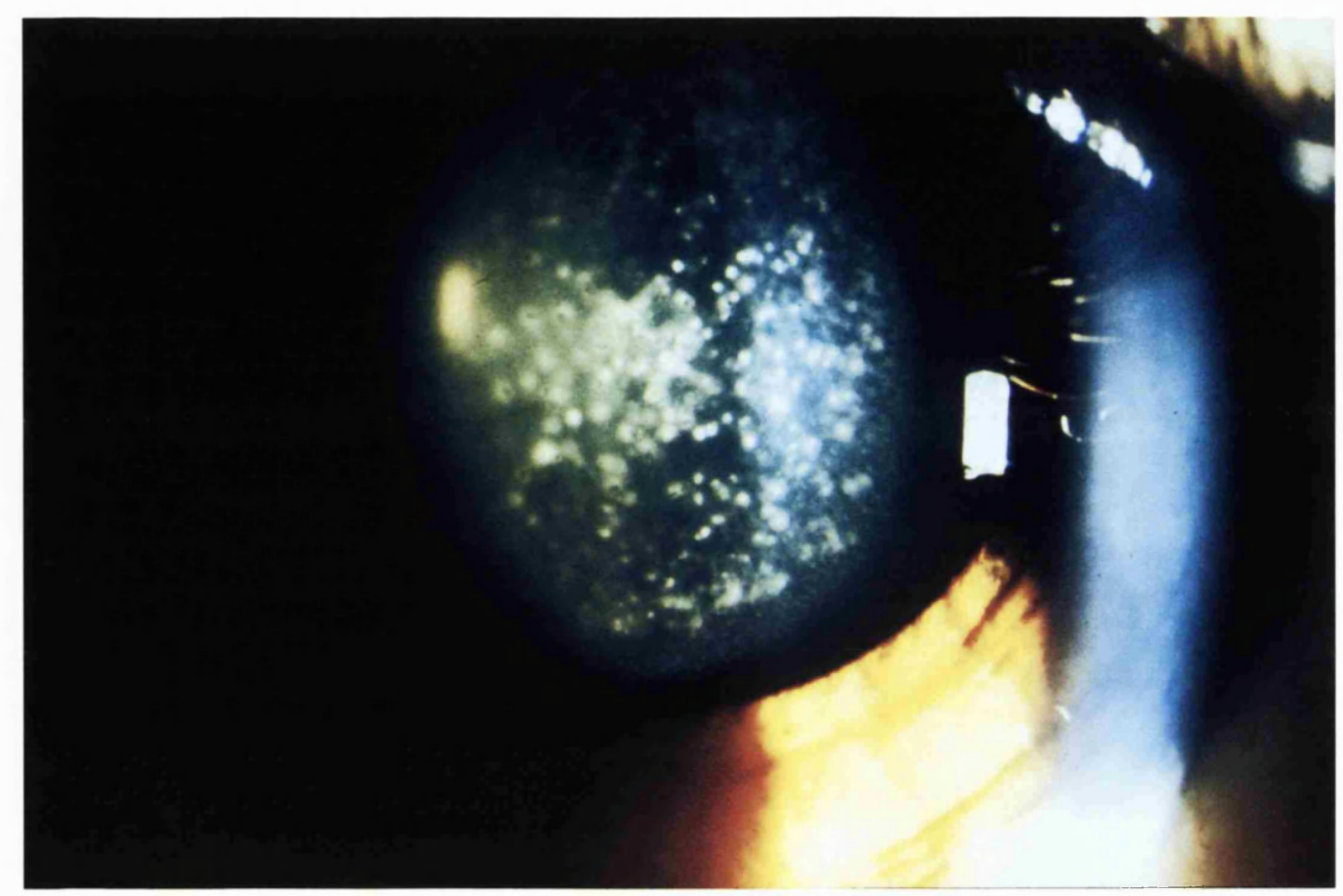

Figure 56. Pulverulent cataract. Pedigree M.Coarse opacities.

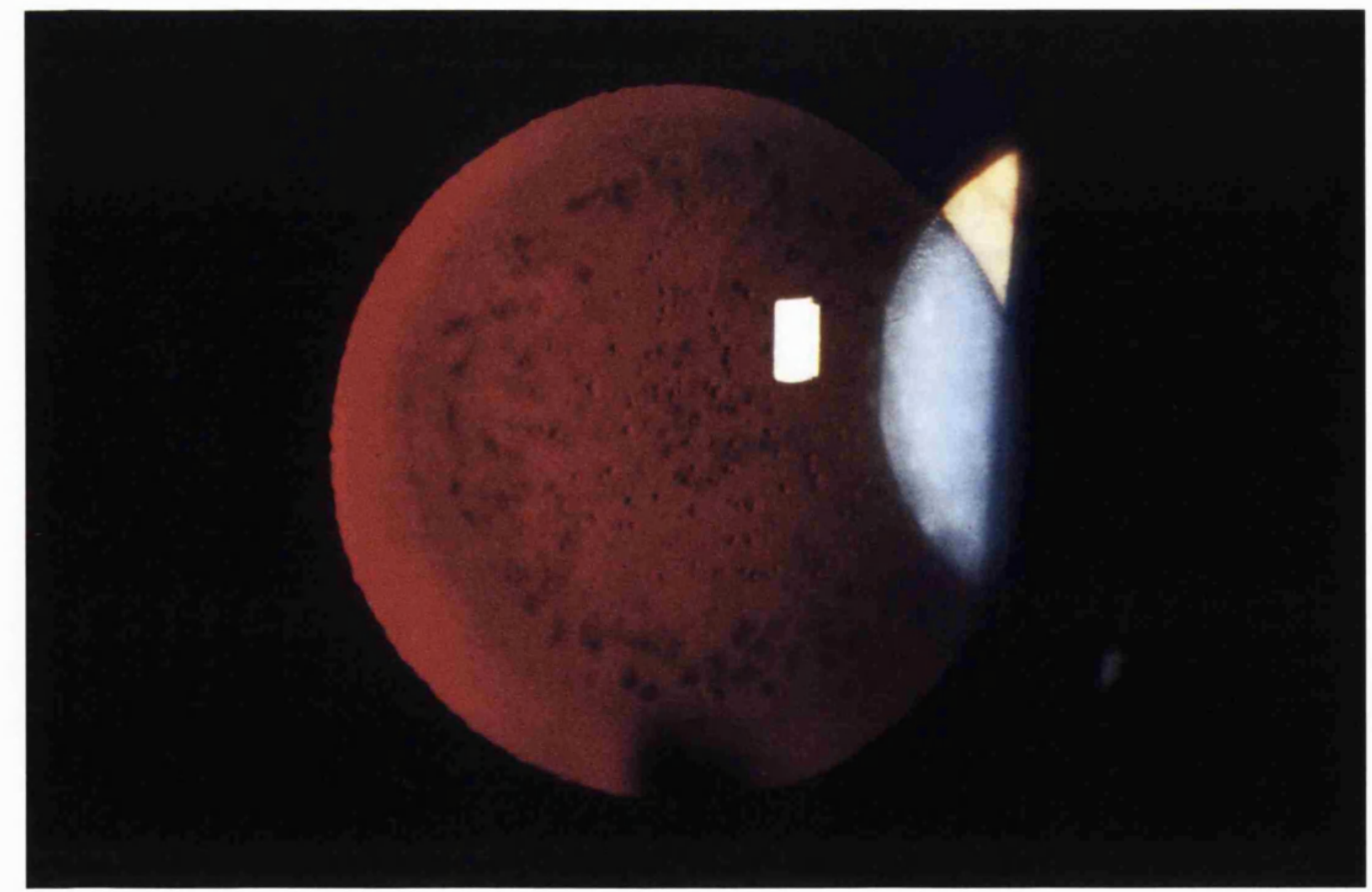

Figure 57. Pulverulent cataract. Pedigree M. Coarse opacities.

Retroillumination. 


\section{Summary}

We found that all the pedigrees could be classified as one of the eight following phenotypes; anterior polar, posterior polar, blue-dot (cerulean), cortical, lamellar (zonular), coralliform, nuclear and pulverulent (see table 1). Individuals within a pedigree all share the same phenotype which varies only in severity. The families affected by the 'pulverulent' cataract phenotype showed great intra-familial variation. 
Visual Outcome \& complications of surgery

Page no.

Age at diagnosis

96

Age at surgery and visual outcome.

99

Number of surgical interventions and visual

104

outcome.

Visual outcome for the different phenotypes.

106

Complications.

112 


\section{Age at diagnosis}

180 affected patients were examined of whom 96 were female and 84 male. The age at diagnosis was available on 136/180 affected patients of whom 101 had undergone surgery (figure 58). The mean age at diagnosis of cataract in all affected individuals was 5.2 years ranging from birth to 71 years. The age at diagnosis of the cataract in those who required surgery was 4.5 years, ranging from birth to 41 years. As part of the study asymptomatic relatives of affected

Figure 58 Age at diagnosis of inherited cataract.

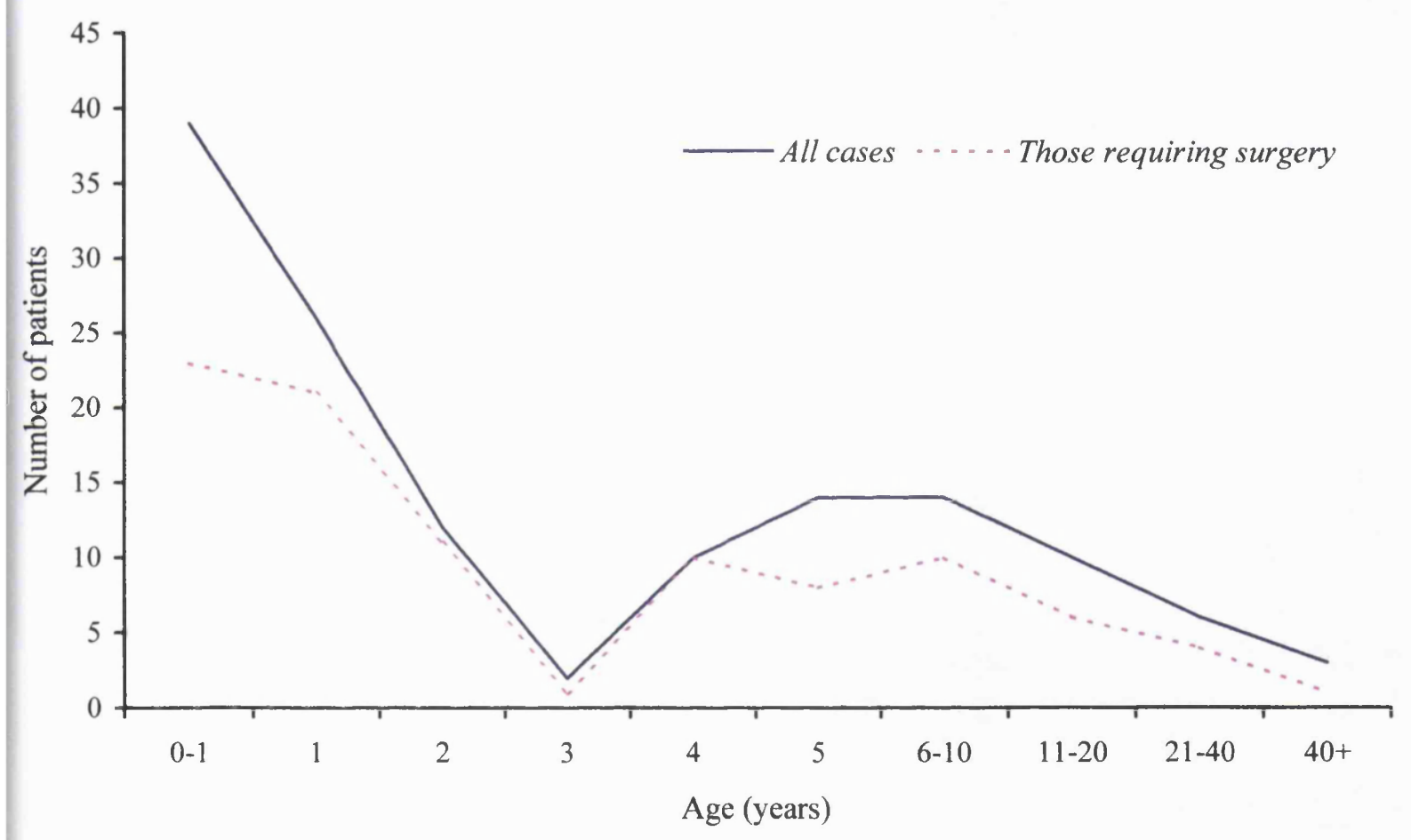

Table to accompany figure 58. Age at diagnosis of inherited cataract.

\begin{tabular}{l|llllllllll} 
Age & $\mathrm{x}<1$ & 1 & 2 & 3 & 4 & 5 & $6-10$ & $11-20$ & $21-40$ & $40+$ \\
\hline & 39 & 26 & 12 & 2 & 10 & 14 & 14 & 10 & 6 & 3 \\
$\ldots \ldots .$. & 23 & 21 & 11 & 1 & 10 & 8 & 10 & 6 & 4 & 1
\end{tabular}

patients were examined and some found to have cataracts. The age at diagnosis in these individuals was therefore not directly related to the clinical course of the disease as they remained asymptomatic and did not require clinical intervention. 
As can be seen in figure $\mathbf{5 8}$ the age at diagnosis follows a bimodal pattern. Most cases were diagnosed either at birth or in late childhood.

The age at diagnosis of the different phenotypes of cataract in those patients who underwent surgery is shown in table 5.

Table 5. Age at diagnosis for different phenotypes in those patients who had undergone surgery.

\begin{tabular}{llll}
\hline Phenotype & $\begin{array}{c}\text { Average } \\
\text { age at diagnosis } \\
\text { (years) }\end{array}$ & $\begin{array}{c}\text { Age Range } \\
\text { (years) }\end{array}$ & $\begin{array}{c}\text { n } \\
\text { (total 101) }\end{array}$ \\
\hline Anterior polar & $<1$ & $0-1$ & 8 \\
Posterior polar- Stationary & 1.25 & $0-8$ & 8 \\
Lamellar & 2.53 & $1-8$ & 15 \\
Nuclear & 3.0 & $0-30$ & 22 \\
Coralliform & 3.1 & $1-6$ & 8 \\
Pulverulent & 5.05 & $0-22$ & 19 \\
Posterior polar- Progressive & 5.9 & $0-25$ & 8 \\
Blue-dot & 11.6 & $1-16$ & 7 \\
Cortical & 18.8 & $5-41$ & 6 \\
\hline
\end{tabular}

The phenotypes that are diagnosed early are the anterior polar and stationary posterior cataracts.

The progressive posterior polar cataract was picked up later in life. The centrally placed lamellar, nuclear and coralliform cataract were generally diagnosed before the age of four although the milder opacities were not diagnosed until adulthood. The affected lens fibres were laid down in utero and were therefore present at birth, but the delayed diagnosis may suggest that these phenotypes are not always congenital. 
The opacities that did not tend to obscure the visual axis until later in life were the phenotypes that also presented later in life. As can be seen in figures 42-57 pulverulent opacities are very heterogeneous and whilst some are dense others are very mild. The age range at diagnosis is also very variable. The blue-dot cataract is recognised as having a late presentation and the cortical cataract affects the outer zone of the lens and does not affect the vision until much later in life. 


\section{Age at surgery and visual outcome.}

Of the 180 affected patients 123 underwent surgery. The visual outcome and age at surgery for 164 eyes in those who had the cataracts operated on is shown in Table 6. Although there was considerable asymmetry in severity between the two eyes of an affected person, there were only three cases of unilateral cataract. Two ocurred in pedigree $A$ affected by anterior polar cataract and one in pedigree $C$ affected by a progressive posterior polar cataract (see appendix 1).

Table 6. Final visual acuity and age at time of surgery for 164 eyes.

\begin{tabular}{lllllllllllll}
\hline Age (yrs) & $\mathbf{6 / 5}$ & $\mathbf{6 / 6}$ & $\mathbf{6 / 9}$ & $\mathbf{6 / 1 2}$ & $\mathbf{6 / 1 8}$ & $\mathbf{6 / 2 4}$ & $\mathbf{6 / 3 6}$ & $\mathbf{6 / 6 0}$ & $\mathbf{C F}$ & $\mathbf{H M}$ & PL & NPL \\
Under 1 & - & - & 4 & 1 & - & 2 & 3 & 1 & - & 2 & - & 2 \\
$1-2$ & - & 1 & 1 & 4 & 2 & 3 & - & 1 & 1 & 1 & - & 1 \\
$3-5$ & 1 & 3 & 9 & 6 & 1 & - & 2 & 3 & 1 & 4 & 2 & 5 \\
$6-10$ & 1 & 6 & 5 & 3 & - & 1 & - & 1 & - & - & 1 & - \\
$11-20$ & 4 & 5 & 7 & 4 & 3 & - & - & 1 & - & - & - & - \\
Over 20 & 4 & 11 & 22 & 7 & 3 & 4 & - & 2 & - & 1 & - & 1 \\
\hline
\end{tabular}

There is a definite improvement in the visual outcome the later the surgery is performed. As can be seen in Table 6, 53\% (8/15) of children operated on within the first year of life failed to reach a visual acuity better than 6/36. Alternatively $67 \%(37 / 55)$ of those operated on after the age of 20 reached a visual acuity of $6 / 9$ or better. 
The visual outcome for those patients undergoing surgery under 2 years of age is shown in Figure 59 below.

Figure 59. Visual outcome for those undergoing surgery under 2 years of age.

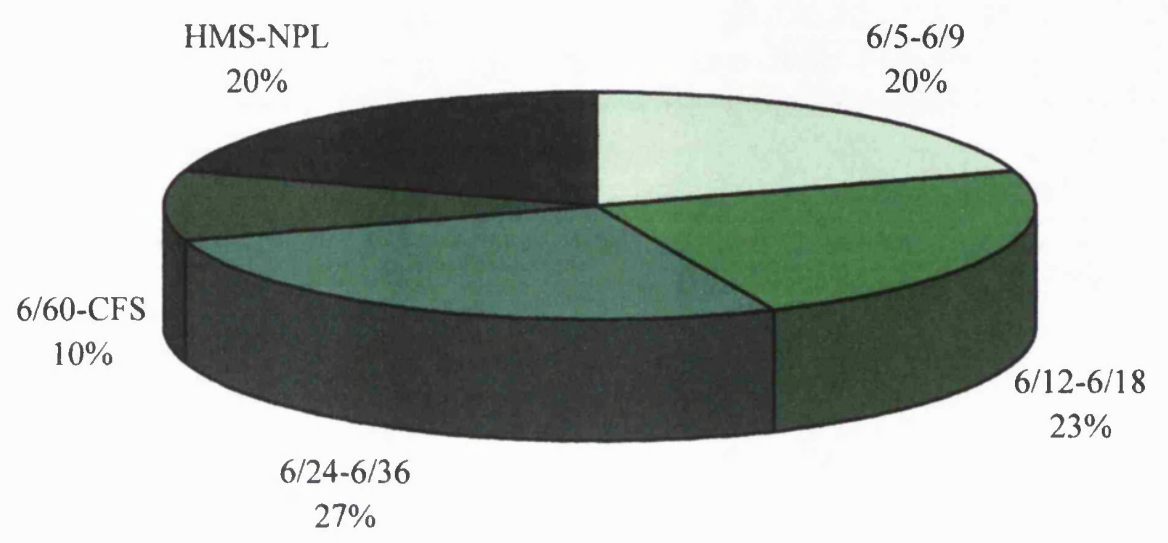

$\square 6 / 5-6 / 9 \square 6 / 12-6 / 18 \square 6 / 24-6 / 36 \square 6 / 60-C F S \square H M S-N P L$

The majority of patients had a visual acuity of $6 / 24$ or worse. As the age of

Figure 60. Visual outcome for those undergoing surgery aged 3-5 years of age.

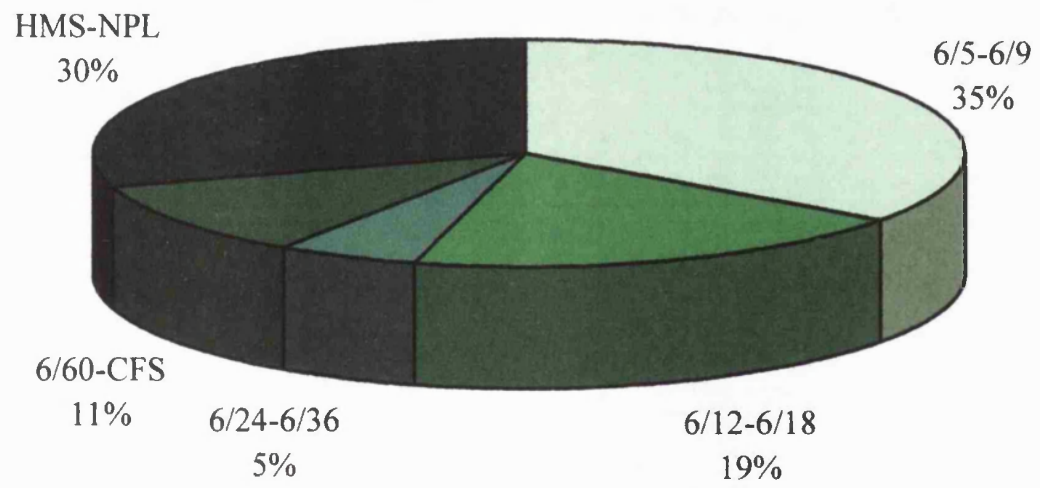

$\square 6 / 5-6 / 9 \square 6 / 12-6 / 18 \square 6 / 24-6 / 36 \square 6 / 60-C F S \square H M S-N P L$

surgery increases, the final visual acuity improves as shown in Figure 60 showing the visual acuity for those operated on in the age group 3-5 years old. In this age group $54 \%$ of patients achieved a visual acuity better than $6 / 24$. 
Figure 61. Visual outcome for those undergoing surgery between the ages of 6-10 years.

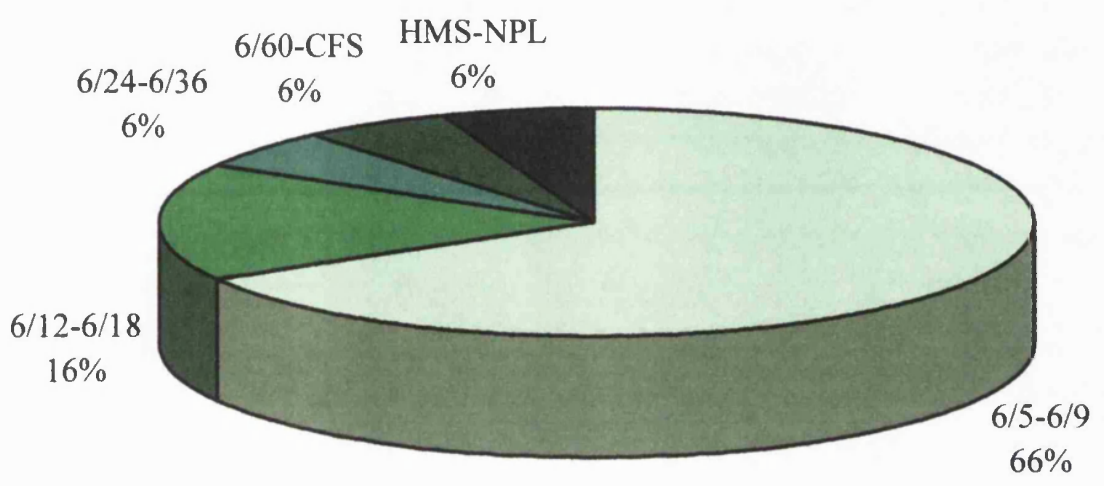

$\square 6 / 5-6 / 9 \square 6 / 12-6 / 18 \square 6 / 24-6 / 36 \square 6 / 60-C F S \square H M S-N P L$

Figure 62. Visual outcome for those undergoing surgery between the

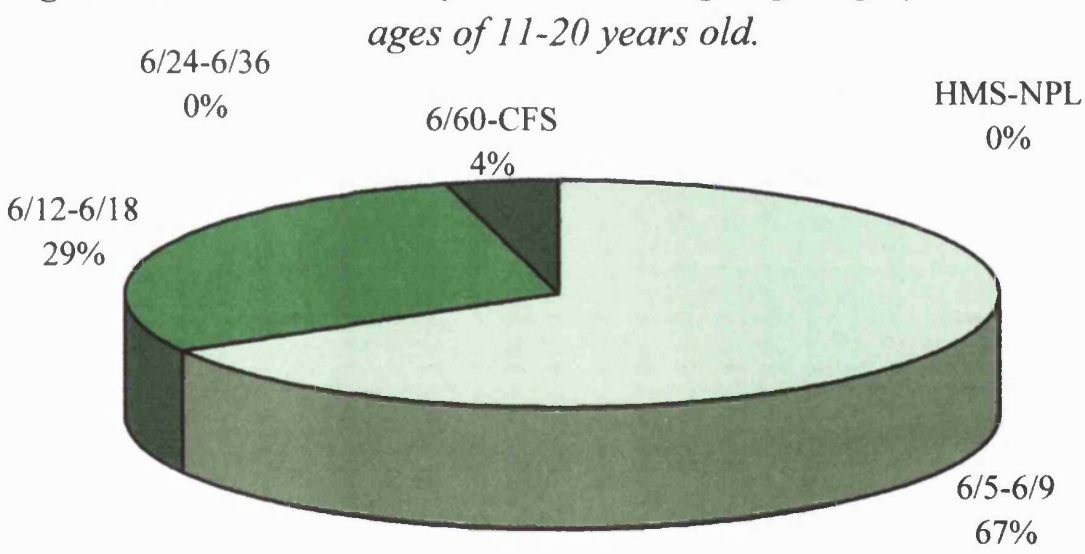

$\square 6 / 5-6 / 9 \square 6 / 12-6 / 18 \square 6 / 24-6 / 36 \square 6 / 60-C F S \square H M S-N P L$

The improved visual acuity with an older age of surgery is further illustrated in

figures 61-63 for the remaining age groups. 
Figure 63. Visual outcome for those undergoing surgery after the age of 20 years old.

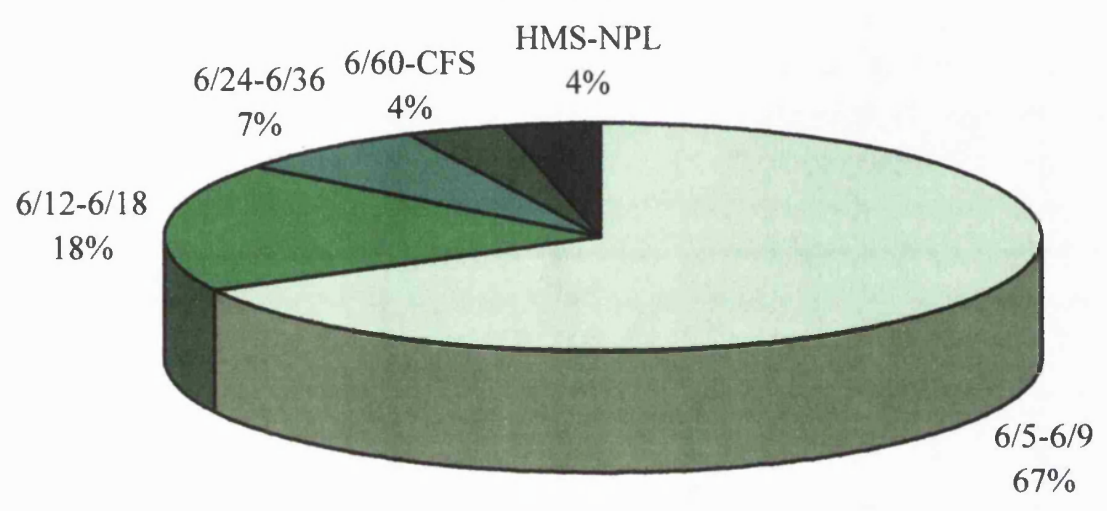

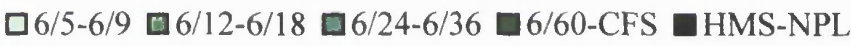


The final visual acuity according to the age at which surgery was first undertaken is shown below. (Figure 64).

Table to accompany Figure 64. Final visual acuity and average age at time of surgery.

\begin{tabular}{llllllllllll}
\hline Visual acuity & $6 / 5$ & $6 / 6$ & $6 / 9$ & $6 / 12$ & $6 / 18$ & $6 / 24$ & $6 / 36$ & $6 / 60$ & CF & HM & PL \\
\hline Average age & 21.5 & 21.96 & 20.73 & 15.8 & 15.4 & 13.6 & 2.4 & 15.7 & 3.5 & 3.87 & 8.5 \\
\hline
\end{tabular}

Figure 64. Final visual acuity and mean age at time of surgery.

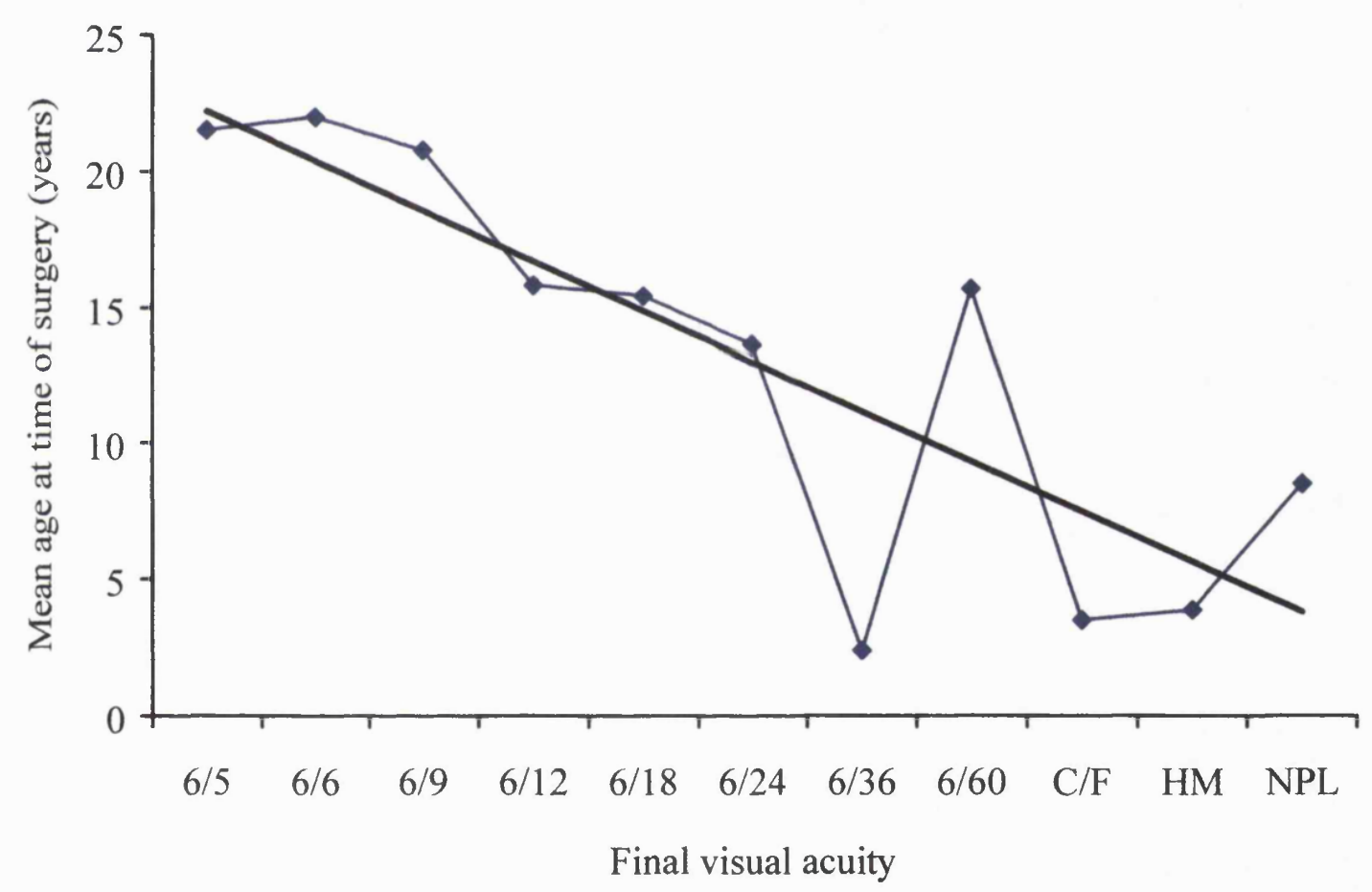

Patients that underwent surgery after the age of twenty years had a much better visual outcome than the younger patients. 


\section{Number of surgical interventions and visual outcome.}

Operative details were available on 86 patients who underwent surgery under the age of 16 years. The visual outcome for those who had a single procedure and those who underwent multiple procedures (needlings) is shown in Table 7 and

\section{Figure 65.}

Table 7. Visual outcome for those patients aged under 16 yrs who underwent single or multiple procedures.

\begin{tabular}{llllllllllll}
\hline No of procedures & $\mathbf{6 / 5}$ & $\mathbf{6 / 6}$ & $\mathbf{6 / 9}$ & $\mathbf{6 / 1 2}$ & $\mathbf{6 / 1 8}$ & $\mathbf{6 / 2 4}$ & $\mathbf{6 / 3 6}$ & $\mathbf{6 / 6 0}$ & $\mathbf{C F}$ & $\mathbf{H M}$ & NPL \\
\hline Multiple & 2 & 1 & 4 & 6 & 3 & 4 & 4 & 3 & 4 & 2 & 5 \\
Single & 3 & 9 & 19 & 8 & 3 & 3 & 1 & 4 & 2 & 1 & 3 \\
\hline
\end{tabular}

Figure 65. Visual outcome for those patients aged under l6yrs who underwent single or multiple surgical procedures

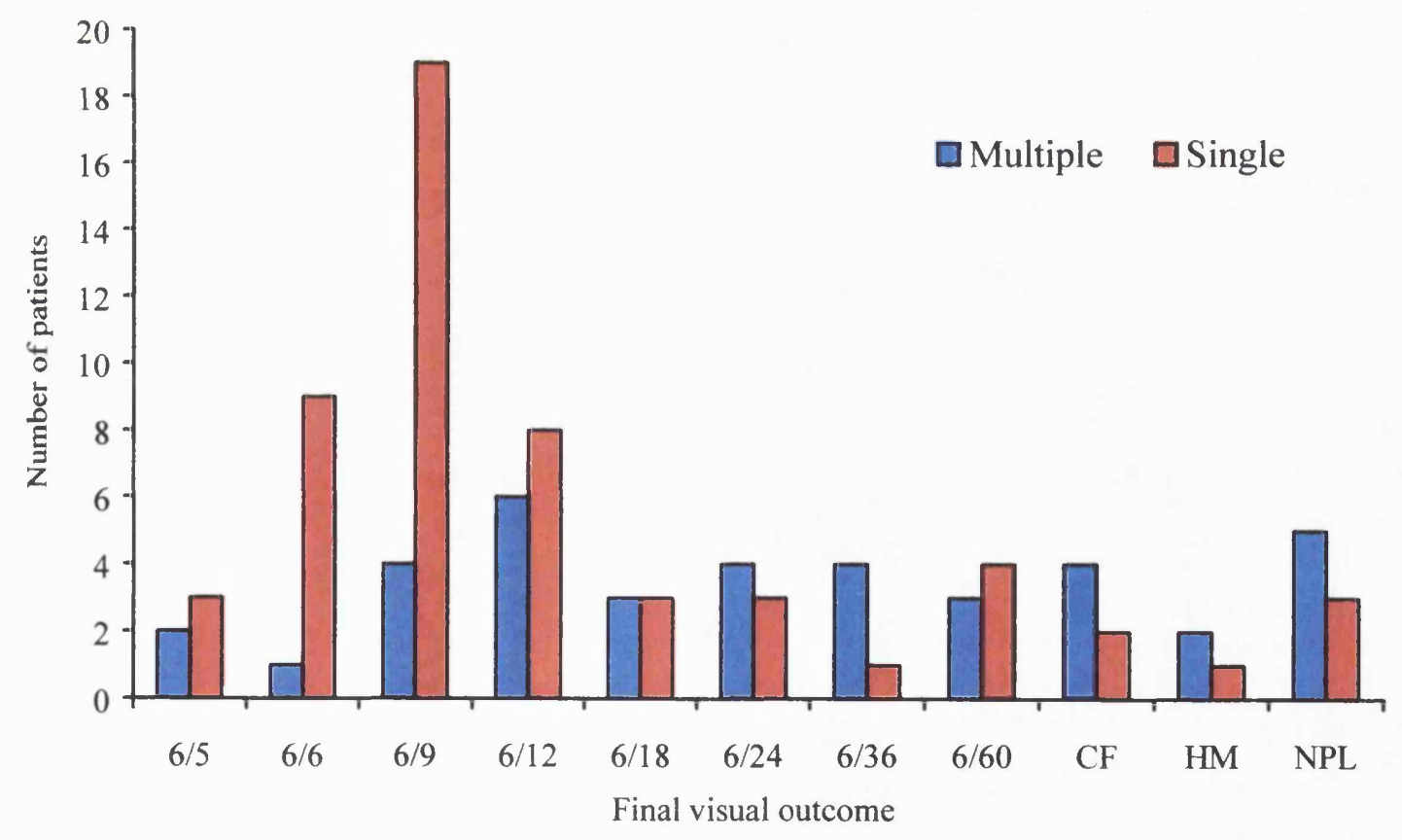

Patients that underwent a single surgical intervention were more likely to achieve a visual acuity of $6 / 12$ or better, as compared to those patients that had undergone multiple (more than one) surgical interventions. 
The results are shown in pie-chart form below (figures 66-67) to show more clearly the improved visual outcome with a single surgical episode.

Figure 66. Visual outcome for those patients under the age of 16 years who underwent multiple surgical procedures.

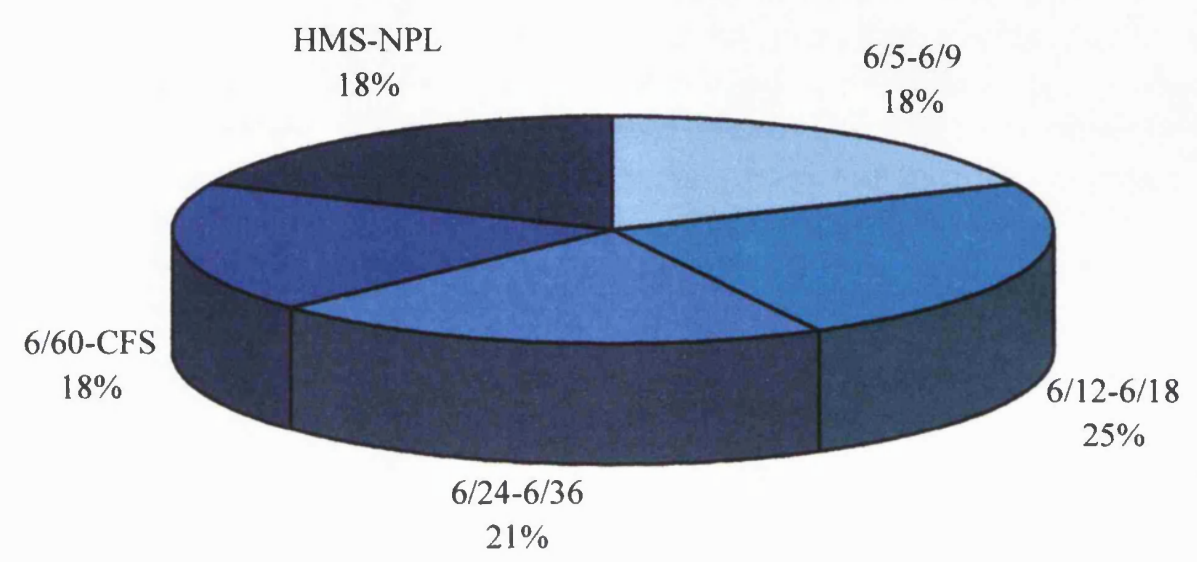

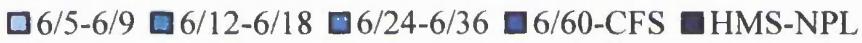

Figure 67. Visual outcome for those patients aged under 16 years of age who underwent a single surgical procedure.

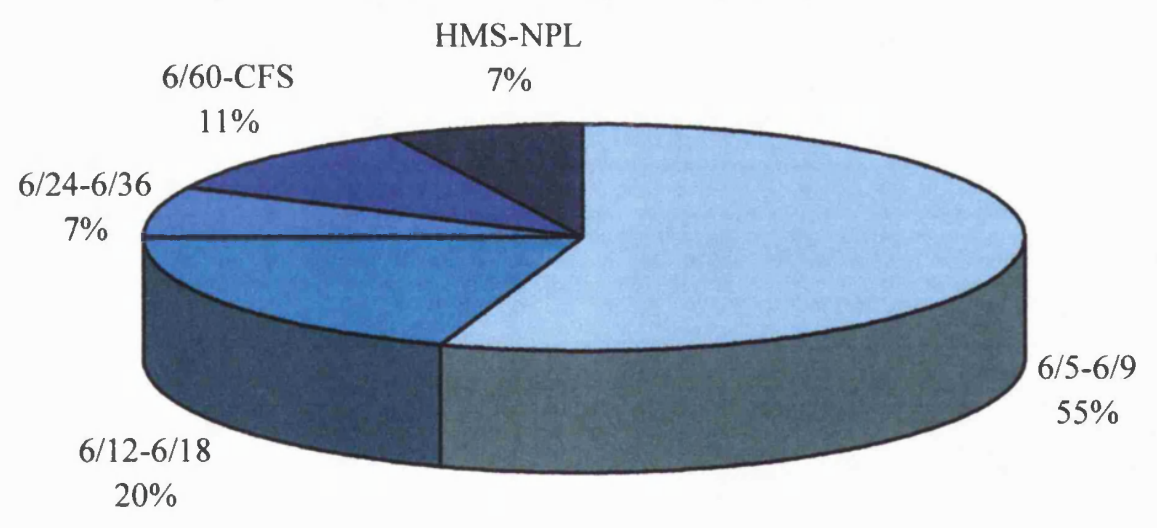

$\square 6 / 5-6 / 9 \square 6 / 12-6 / 18 \square 6 / 24-6 / 36 \square 6 / 60-C F S \square H M S-N P L$ 


\section{Visual outcome for the different phenotypes.}

The visual outcome for the different phenotypes is shown in table 8. Data were available on 264 eyes of which 180 had undergone surgery.

Table 8. Visual outcome for the different phenotypes. Number of eyes that underwent surgery in brackets.

\begin{tabular}{lcccc}
\hline Phenotype & $\mathbf{6 / 5 - 6 / 9}$ & $\mathbf{6 / 1 2 - 6 / 2 4}$ & $\mathbf{6 / 3 6 - 6 / 6 0}$ & CF-NPL \\
\hline Anterior polar & $4(0)$ & $15(3)$ & $3(2)$ & $10(7)$ \\
Posterior polar & & & & \\
- Stationary & $10(6)$ & $3(3)$ & $3(2)$ & $2(2)$ \\
- Progressive & $13(13)$ & $1(1)$ & $3(3)$ & $1(0)$ \\
Nuclear & $20(18)$ & $15(10)$ & $4(4)$ & $4(4)$ \\
Lamellar & $18(15)$ & $19(11)$ & $5(5)$ & $9(8)$ \\
Coralliform & $7(7)$ & $6(6)$ & $1(1)$ & 0 \\
Blue-dot & $5(5)$ & $2(2)$ & 0 & 0 \\
Cortical & $5(3)$ & $2(1)$ & $1(1)$ & 0 \\
Pulverulent & $42(21)$ & $17(6)$ & $4(2)$ & $8(8)$ \\
\hline Total & $126(88)$ & $82(43)$ & $24(20)$ & $34(29)$ \\
\hline
\end{tabular}

The visual outcome for the different phenotypes is shown graphically below (figures 68-76) and compares the outcome for those that underwent surgery to those that did not require surgery. 
Figure 68. Anterior polar cataract. Visual outcome in operated and unoperated eyes.

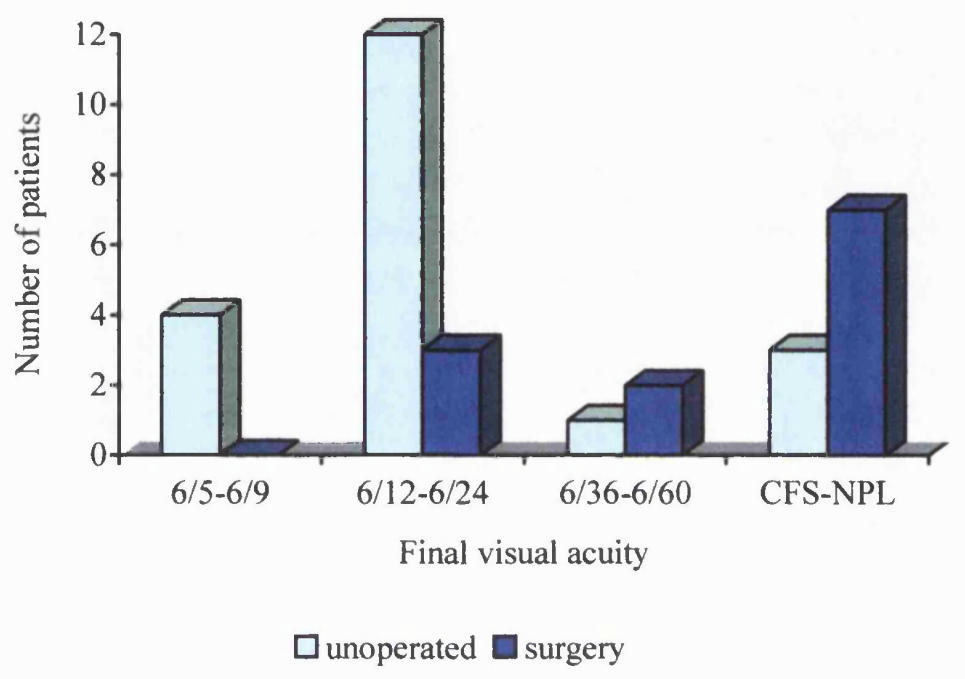

Figure 69. Posterior polar (stationary) cataract. Visual outcome in operated and unoperated eyes.

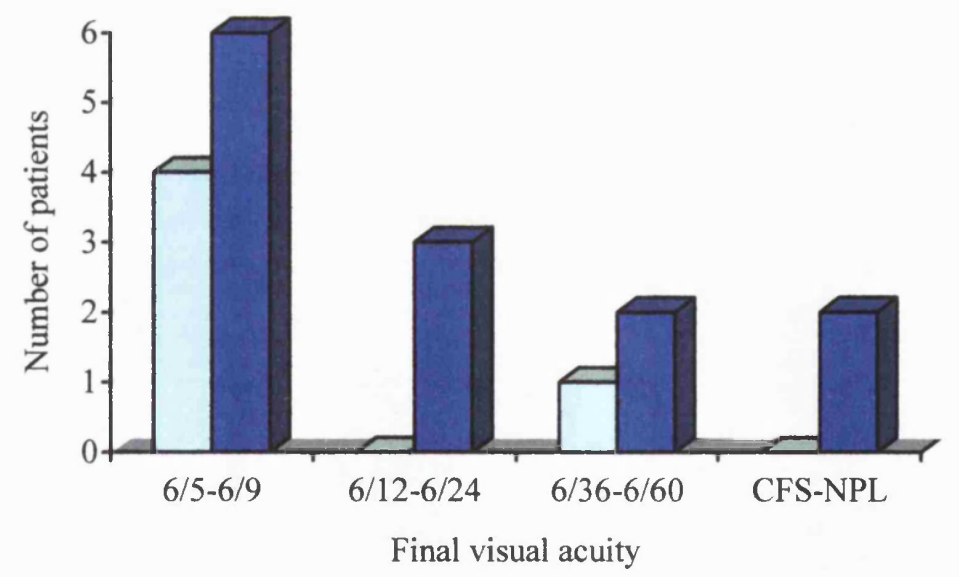

口unoperated $\boldsymbol{G}$ surgery 
Figure 70. Posterior polar (progressive) cataract. Visual outcome in operated and unoperated eyes.

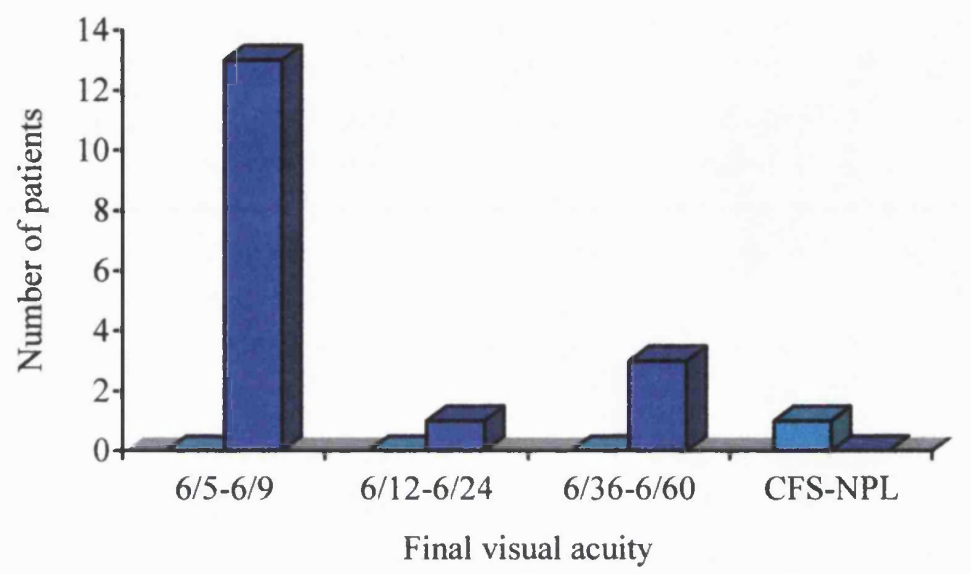

凹unoperated $\square$ surgery

Figure 71. Nuclear cataract. Visual outcome in operated and unoperated eyes.

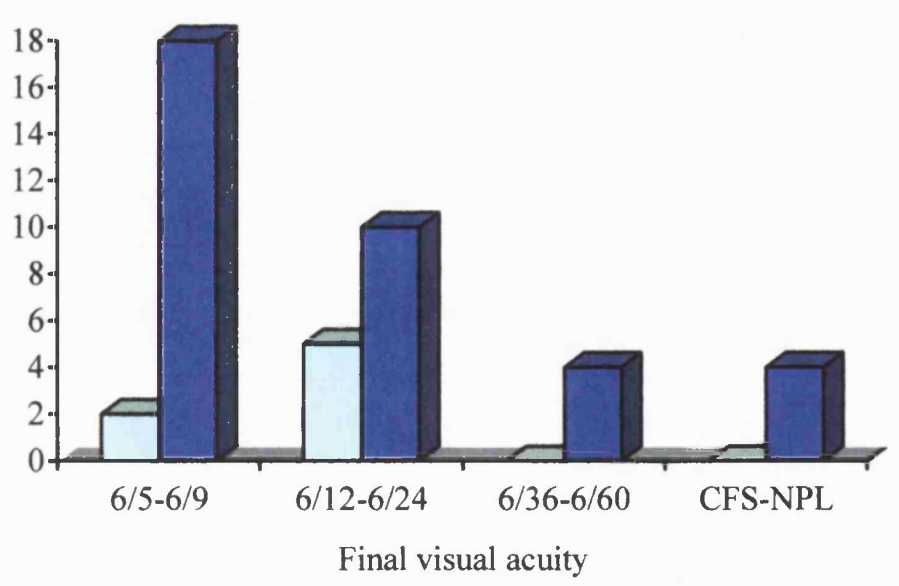

$\square$ unoperated $\square$ surgery 
Figure 72. Lamellar cataract. Visual outcome in operated and unoperated eyes.

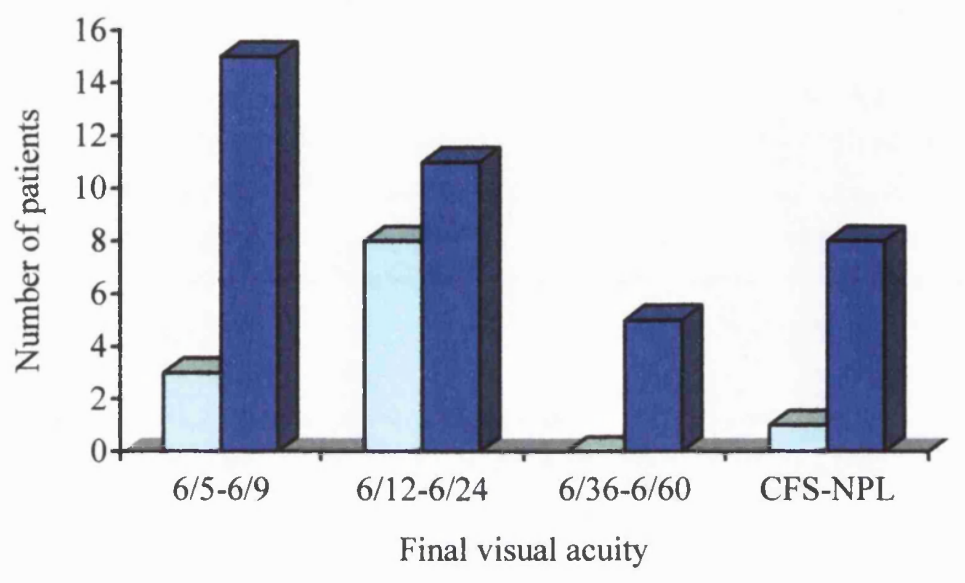

$\square$ unoperated $\boldsymbol{\square}$ surgery

Figure 73. Coralliform cataract. Visual outcome in operated and unoperated eyes.

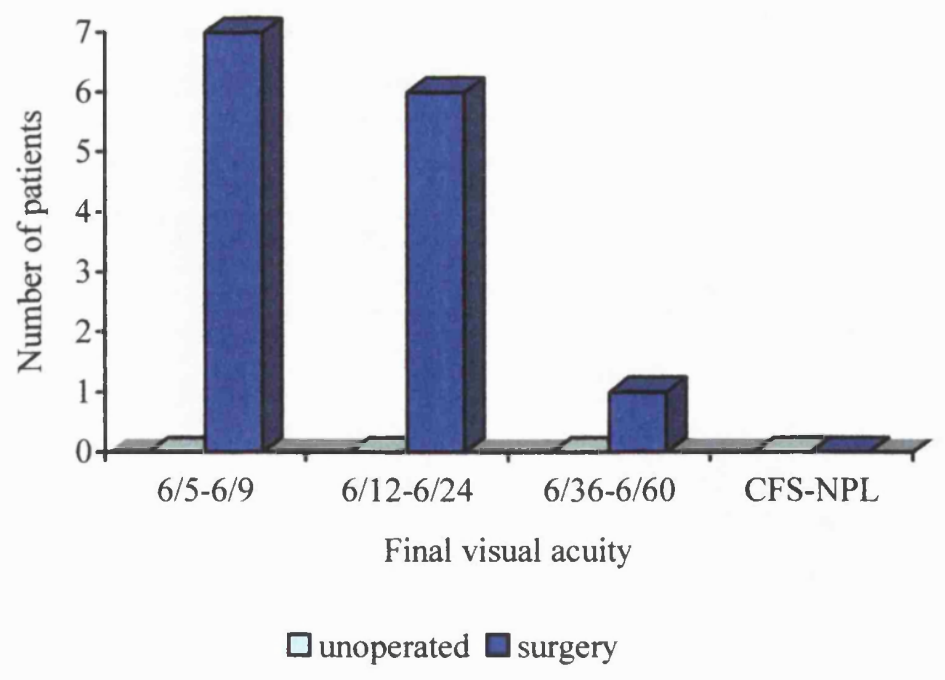


Figure 74. Blue-dot (cerulean) cataract. Visual outcome in operated and unoperated eyes.

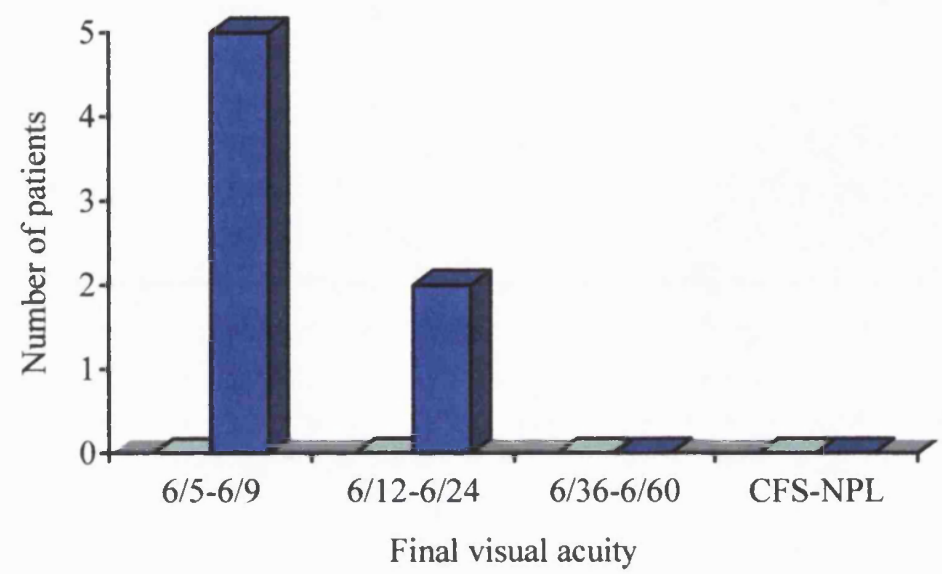

$\square$ unoperated $\square$ surgery

Figure 75. Cortical cataract. Visual outcome in operated and unoperated eyes.

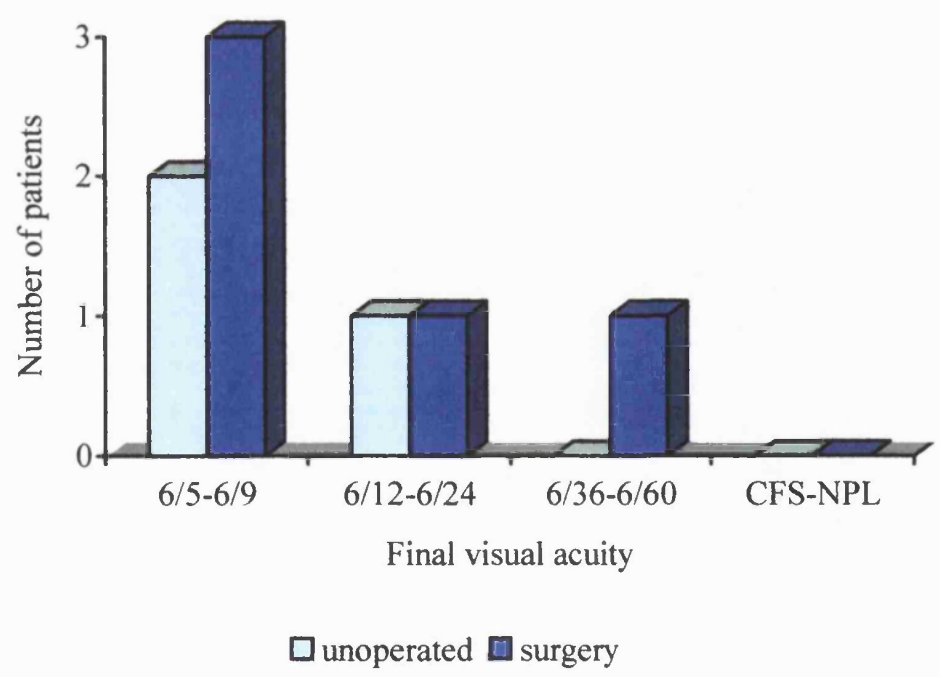


Figure 76. Pulverulent cataract. Visual outcome in operated and unoperated eyes.

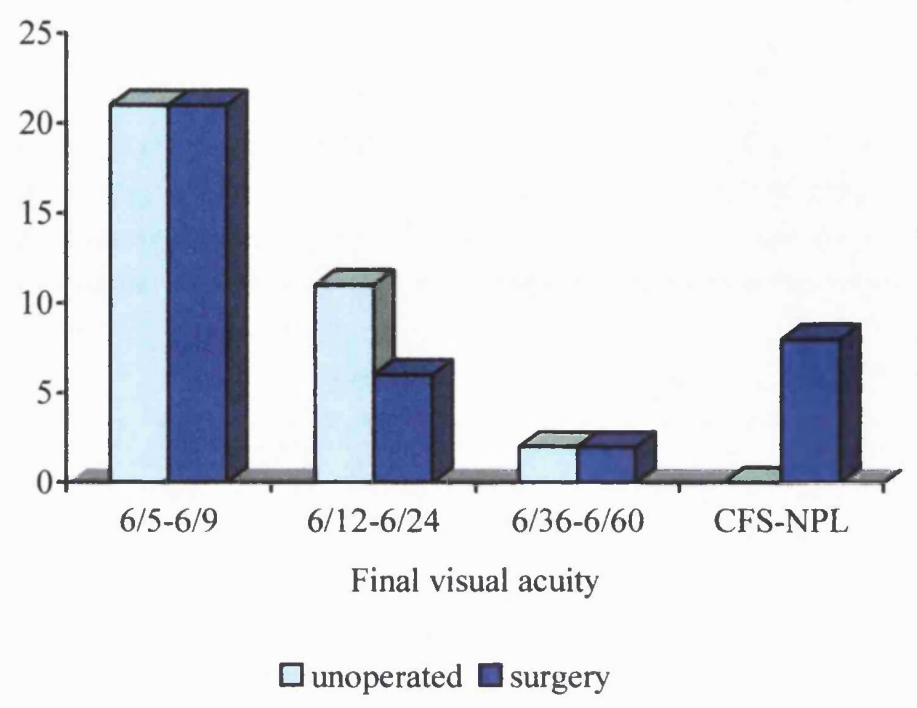

Seven of the patients affected with anterior polar cataract underwent surgery

(figure 68), all between the ages of 1-6 years, with a final V/A of 6/18 to NPL.

Three affected patients who had not undergone surgery had a visual acuity of $6 / 6$ in both eyes. Of the ten patients affected by stationary posterior polar cataract (figure 69) the visual acuity details were not available in one case and in the eighteen eyes of the remaining nine affected patients, ten eyes had a V/A of 6/9 or better. The patients who underwent surgery were all operated on between the ages of six weeks and six years. The visual outcome for the remaining phenotypes (figures 70-76) improved with the increasing age at which the surgery was performed.

As can be seen in Table 9 (p1 12), the phenotypes that had the better visual outcome were those that were operated on at an older age. The best example of this is the blue-dot (cerulean) cataract. All affected individuals were operated on after the age of 11 years with most being operated on after 20 years of age (table 9). All patients achieved a V/A of 6/24 or better (figure 74, p110). 
Table 9. Age at time of surgery for individual eyes of different phenotypes.

\begin{tabular}{lcccccc}
\hline & $\begin{array}{l}\text { Total no. of eyes that } \\
\text { underwent surgery }\end{array}$ & \multicolumn{5}{c}{ Age at surgery (years) } \\
Phenotype & 17 & $\mathbf{x}$ & $\mathbf{1 - 5}$ & $\mathbf{6 - 1 0}$ & $\mathbf{1 1 - 2 0}$ & $\mathbf{x}>\mathbf{2 0}$ \\
\hline $\begin{array}{l}\text { Anterior polar } \\
\text { Posterior polar }\end{array}$ & 15 & 6 & 6 & 5 & 2 & - \\
- Stationary & 18 & - & 2 & 3 & 5 & 8 \\
- Progressive & 39 & - & 8 & 8 & 3 & 20 \\
Nuclear & 44 & 8 & 19 & 7 & 2 & 8 \\
Lamellar & 18 & - & 8 & 8 & 2 & - \\
Coralliform & 14 & - & - & - & 6 & 8 \\
Blue-dot & 10 & - & - & 3 & 4 & 3 \\
Cortical & 37 & - & 8 & 6 & 7 & 16 \\
Pulverulent & $\mathbf{2 1 2}$ & $\mathbf{1 8}$ & $\mathbf{6 0}$ & $\mathbf{4 0}$ & $\mathbf{3 1}$ & $\mathbf{6 3}$ \\
\hline Total & & & & & & - \\
\end{tabular}




\section{Complications.}

The complications of glaucoma and retinal detachment are shown below. Out of the 180 patients affected with ADC, 8 developed glaucoma and 9 had retinal detachments.

Glaucoma.

Table 10. Complications; glaucoma.

\begin{tabular}{lllccccl}
\hline & Phenotype & $\begin{array}{c}\text { Affected } \\
\text { eye }\end{array}$ & \multicolumn{2}{c}{$\begin{array}{c}\text { Age at surgery } \\
\text { (years) }\end{array}$} & $\begin{array}{c}\text { Visual acuity } \\
\text { Right }\end{array}$ & $\begin{array}{c}\text { No. of } \\
\text { Left } \\
\text { procedures }\end{array}$ \\
& & Right & Left & & & \\
\hline 1. & Posterior polar & L & 1 & 3 & NPL & $6 / 12$ & Multiple \\
2. & Lamellar & R\&L & 1 & 1 & NPL & NPL & Multiple \\
3. & Lamellar & R\&L & 3 & 5 & NPL & $6 / 12$ & Single \\
4. & Lamellar & R\&L & 1 & 1 & $6 / 24$ & HM & Single \\
5. & Coralliform & R & 7 & 7 & $6 / 24$ & $6 / 9$ & Multiple \\
6. & Coralliform & R & 3 & 3 & $6 / 12$ & $6 / 9$ & Multiple \\
7. & Anterior polar & R\&L & 6 & 6 & NPL & NPL & Multiple \\
8. & Nuclear & R\&L & 8 & 8 & $6 / 9$ & $6 / 24$ & Single \\
\hline
\end{tabular}

Out of the 180 affected patients of whom 123 underwent surgery only 8 developed glaucoma. All the patients who developed glaucoma were aphakic and had been operated on under the age of nine. Of the eight patients with glaucoma, five had undergone multiple surgical procedures and three had only had one operation. 
Table 11. Complications; retinal detachment.

\begin{tabular}{lllll}
\hline & Phenotype & $\begin{array}{c}\text { Age at surgery (years) } \\
\text { Cat ext }\end{array}$ & $\begin{array}{c}\text { No. of } \\
\text { Procedures }\end{array}$ \\
\hline 1. & Posterior polar (stationary) & 3 & 13 & Single \\
2. & Pulverulent & 7 & 22 & Multiple \\
3. & Lamellar & 1 & 49 & Single \\
4. & Nuclear & 3 & 13 & Multiple \\
5. & Posterior polar (Progressive) & 40 & 51 & Single \\
6. & Posterior polar (Progressive) & 40 & 40 & Single \\
7. & Posterior polar (Progressive) & 21 & 39 & Single \\
8. & Anterior polar & 5 & 45 & Multiple \\
9. & Coralliform & 3 & 32 & Multiple \\
\hline
\end{tabular}

Of the 180 patients affected with cataract of whom 123 underwent surgery there were only nine patients who developed a retinal detachment.

\section{Summary.}

The main points regarding the visual outcome in patients affected with isolated ADC are that the overall results are very good and the incidence of adverse long term complications such as glaucoma and retinal detachment are rare when compared to patients affected by congenital cataract with additional ocular and systemic diseases. Furthermore the final visual acuity is much better in those patients that underwent a single surgical procedure and had the surgery performed later in life. 


\section{Linkage Analysis}

Ten pedigrees have been investigated as part of this linkage study. Linkage has been demonstrated in six pedigrees. Four pedigrees were new and two were found to be relatives of previously linked pedigrees. The four families that demonstrated linkage to new loci were affected with the following phenotypes; anterior polar, posterior polar and pulverulent cataracts (two pedigrees)(Table 12). Linkage was also confirmed in two pedigrees that were related to previously linked pedigrees; the CCL (Lubsen et al 1987) and the CAE (Renwick and Lawler 1963) pedigrees.

Table 12. Mapped Phenotypes.

\begin{tabular}{lcc}
\hline Phenotype & $\begin{array}{c}\text { Pedigree } \\
\text { (see Appendix 1) }\end{array}$ & Locus \\
\hline Posterior polar (CTPA) & $\mathrm{B}$ & $1 \mathrm{p}$ \\
Zonular pulverulent (CAE) & $\mathrm{P}$ & $1 \mathrm{q}$ \\
Coppock-like (CCL) & $\mathrm{E}$ & $2 \mathrm{q}$ \\
Pulverulent (CZP2) & $\mathrm{L}$ & $13 \mathrm{q}$ \\
Pulverulent & $\mathrm{M}$ & $13 \mathrm{q}$ \\
Anterior polar (CCTA2) & $\mathrm{A}$ & $17 \mathrm{p}$ \\
\hline
\end{tabular}

In four further families we have excluded all candidate loci. The phenotypes of these families are; progressive posterior polar cataract, a blue-dot cataract and two further pulverulent phenotypes. 


\section{Posterior polar cataract: $1 \mathrm{p}$ (Pedigree B).}

Patients and methods: Nineteen family members from the pedigree affected by the stationary posterior polar cataract (see Figures 7-12, pp53-55), including 10 affected individuals, 5 unaffected and 4 spouses (pedigree B, Appx 1, p122) were genotyped with microsatellite markers from the Généthon $(\mathrm{AC})_{\mathrm{n}}$ map. We first excluded linkage of the cataract with the HP locus on chromosome 16q using markers D16S515 $(Z=-3.31, \theta=0.05)$ and $\operatorname{D16S503}(Z=-1.76, \theta=0.05)$ and then excluded eleven other known loci and candidate genes for ADC (see table 2). Following exclusion of the $\zeta$-crystallin gene (CRYZ) on 1p with marker D1S201 $(Z=2.71, \theta=0.05)$ we detected positive LOD scores for markers $D 1 S 468(Z=2.71$, $\theta=0)$ and $D 1 S 243(Z=1.51, \theta=0)$. These markers flank a $6 \mathrm{cM}$ interval close to the CCV locus at the telomeric end of $1 p$ (Eiberg $\mathrm{H}$ et al, 1995). Ten other Généthon markers in this region of chromosome $1 p$ were genotyped in the family and the two-point LOD scores of all twelve marker loci are summarised in Table 13.

Table 13. Two point lod scores (Z) for linkage between the CTPA locus and chromosome lp markers.

\begin{tabular}{|c|c|c|c|c|c|c|c|c|c|c|}
\hline \multirow[b]{2}{*}{ Marker } & \multirow[b]{2}{*}{$\mathbf{c M}$} & \multicolumn{7}{|c|}{ Recombination fraction $(\theta)$} & \multirow[t]{2}{*}{$\mathbf{Z}_{\max }$} & \multirow[t]{2}{*}{$\theta_{\max }$} \\
\hline & & 0.00 & 0.01 & 0.05 & 0.10 & 0.20 & 0.30 & 0.40 & & \\
\hline$D 1 S 243$ & 6.2 & 1.51 & 1.47 & 1.35 & 1.19 & 0.83 & 0.46 & 0.13 & 1.50 & 0.00 \\
\hline$D 1 S 468$ & 4.9 & 2.71 & 2.66 & 2.46 & 2.21 & 1.64 & 1.01 & 0.35 & 2.70 & 0.00 \\
\hline$D 1 S 2845$ & 1.8 & $-\infty$ & 1.85 & 2.30 & 2.27 & 1.86 & 1.23 & 0.48 & 2.31 & 0.07 \\
\hline$D 1 S 2660$ & 3.5 & $-\infty$ & 1.85 & 2.30 & 2.27 & 1.86 & 1.23 & 0.48 & 2.31 & 0.07 \\
\hline$D 1 S 214$ & 0.0 & 0.57 & 0.56 & 0.51 & 0.44 & 0.33 & 0.22 & 0.10 & 0.57 & 0.00 \\
\hline$D 1 S 2870$ & 0.5 & $-\infty$ & 0.22 & 0.35 & 0.49 & 0.44 & 0.24 & 0.04 & 0.49 & 0.13 \\
\hline$D 1 S 2663$ & 1.2 & $-\infty$ & 1.26 & 1.74 & 1.76 & 1.45 & 0.94 & 0.33 & 1.78 & 0.08 \\
\hline$D 1 S 508$ & 4.8 & 3.14 & 3.08 & 2.85 & 2.54 & 1.88 & 1.15 & 0.39 & 3.14 & 0.00 \\
\hline$D 1 S 450$ & 4.0 & $-\infty$ & 1.55 & 2.00 & 1.98 & 1.58 & 1.00 & 0.35 & 2.01 & 0.07 \\
\hline$D 1 S 2667$ & 5.5 & $-\infty$ & 1.85 & 2.30 & 2.27 & 1.86 & 1.23 & 0.48 & 2.31 & 0.07 \\
\hline$D 1 S 228$ & 15.3 & 1.03 & 1.01 & 0.91 & 0.78 & 0.53 & 0.30 & 0.11 & 1.03 & 0.00 \\
\hline D1S199 & 8.9 & $-\infty$ & 1.34 & 1.79 & 1.78 & 1.41 & 0.87 & 0.30 & 1.81 & 0.07 \\
\hline$D 1 S 234$ & & $-\infty$ & -1.56 & -0.39 & -0.07 & 0.06 & 0.11 & 0.11 & 0.12 & 0.35 \\
\hline
\end{tabular}

The maximum two-point LOD score was obtained with marker D1S508 $\left(\mathrm{Z}_{\max }=3.14, \theta=0\right)$. Multipoint linkage analysis using ten markers produced a significant LOD score value of $3.48(\theta=0.07)$. 
Results: Haplotype analysis (see Appx 2, publications) detected three affected individuals $(3-6,3-7,3-8)$ that were recombinant with the most centromeric marker used in the region, D1S234. Only one unaffected individual (4-1) was recombinant for markers D1S2667, D1S450, D1S2663, D1S468 and D1S243. The informative haplotype data for individual 4-1 indicated that the cataract locus probably lies in the interval between D1S2845 and the telomere on chromosome 1p. For a copy of the published results see Appendix 2; publications (Ionides et al 1997). 


\section{Zonular pulverulent cataract (CAE) 1q (pedigree $\mathrm{P}$ )}

Patients and methods: Descendents of the family Ev (see Introduction page ) originally described by Nettleship in 1909 and later investigated by Renwick and Lawler in 1963 were traced using the records at Great Ormond Street Hospital for Sick Children and those at Moorfields Eye Hospital, both in London. The pedigree is illustrated in appendix 1, pedigree X. All affected individuals had been operated on and it was not possible to get a good description of the phenotype. It had previously been described as 'lamellar' (Nettleship 1909) and 'zonular pulverulent' (Renwick and Lawler 1963). Although assumed to be identical to the Coppock cataract and often called the Coppock cataract, there is no kinship between the Everett and Coppock pedigrees and the Coppock cataract has never been the subject of a published linkage study.

Eighteen members of the family were genotyped using microsatellite markers from the Généthon map (Dibb et al 1996), including 10 affected individuals, 6 unaffected and 2 spouses. The two-point maximum lod scores for the markers are shown in Table 14 below.

Table 14. Two point $Z$ values for linkage between CZPI and chromosome 19 markers.

\begin{tabular}{|c|c|c|c|c|c|c|c|c|c|c|}
\hline \multirow[b]{2}{*}{ Marker } & \multirow[b]{2}{*}{$\mathrm{cM}$} & \multicolumn{9}{|c|}{ Recombination fraction $(\theta)$} \\
\hline & & 0.00 & 0.01 & 0.05 & 0.10 & 0.20 & 0.30 & 0.40 & $\mathbf{Z}_{\max }$ & $\theta_{\max }$ \\
\hline$D 1 S 2746$ & 1.1 & $-\infty$ & 1.19 & 1.66 & 1.65 & 1.31 & 0.84 & 0.34 & 1.68 & .07 \\
\hline$D 1 S 250$ & 0.6 & 3.52 & 3.46 & 3.19 & 2.84 & 2.10 & 1.31 & 0.52 & 3.52 & .00 \\
\hline$D 1 S 189$ & 2.2 & 3.34 & 3.27 & 3.02 & 2.69 & 2.00 & 1.27 & 0.52 & 3.34 & .00 \\
\hline$D 1 S 2669$ & 1.3 & 4.52 & 4.43 & 4.09 & 3.65 & 2.72 & 2.24 & 0.76 & 4.52 & .00 \\
\hline D1S514 & 1.1 & 4.48 & 4.40 & 4.07 & 3.64 & 2.73 & 1.77 & 0.77 & 4.48 & .00 \\
\hline$D 1 S 2696$ & 1.1 & 3.49 & 3.44 & 3.22 & 2.91 & 2.21 & 1.44 & 0.65 & 3.49 & .00 \\
\hline$D 1 S 442$ & 1.2 & 1.07 & 1.04 & 0.95 & 0.84 & 0.62 & 0.41 & 0.20 & 1.07 & .00 \\
\hline$D 1 S 2345$ & 3.3 & 2.23 & 2.16 & 1.90 & 1.57 & 0.90 & 0.30 & 0.00 & 2.23 & .00 \\
\hline$D 1 S 305$ & 1.6 & 2.34 & 2.28 & 2.05 & 1.76 & 1.17 & 0.62 & 0.20 & 2.34 & .00 \\
\hline$D 1 S 2721$ & 1.7 & 3.83 & 3.75 & 3.42 & 2.99 & 2.08 & 1.15 & 0.35 & 3.83 & .00 \\
\hline$D 1 S 506$ & 2.7 & 1.11 & 1.09 & 0.99 & 0.86 & 0.59 & 0.33 & 0.11 & 1.11 & .00 \\
\hline$D 1 S 2635$ & 2.7 & 0.93 & 0.92 & 0.86 & 0.76 & 0.53 & 0.31 & 0.13 & 0.93 & .00 \\
\hline$D 1 S 2771$ & & $-\infty$ & -1.84 & -0.57 & -0.14 & 0.11 & 0.12 & 0.07 & 0.13 & .25 \\
\hline
\end{tabular}


Results. The maximum two point lod score was obtained with marker D1S2669. Multipoint analysis using markers D1S2746, D1S2669, D1S442 and D1S2771 gave a maximum lod score of $5.22(\theta=0)$ at D1S2669 (see Shiels et al 1998, Appendix 2; publications) and this information combined with haplotype analysis suggested that the gene for the cataract lies in the genetic distance D1S2746-D1S2771. A missense mutation in the gene that codes for connexin 50 (GJA8) has been found to be the cause of the cataract (Shiels et al 1998). 


\section{Coppock-like cataract: $2 q$ (Pedigree E).}

Patients and methods: During the collection of this family it became apparent that some members had already been visited by geneticists and further investigations revealed that they were descended from the Forman family, first described by Nettleship and then studied by Lubsen who demonstrated linkage to chromosome 2q (Lubsen et al 1987). The phenotype is illustrated in Figures 2025 and the locus has been refined to the microsatellite region shown below in

Table 15. The original linkage was performed using RFLPs. The genetic mutation found by Brackenhoff et al 1994, has yet to be confirmed.

The linkage analysis was performed on 27 DNA samples comprising 18 affected individuals, 5 unaffected and 4 spouses.

\section{Results:}

The highest two-point lod scores as shown in Table 15 was found at marker D2S157. Multipoint linkage analysis was undertaken with markers D2S72, D2S157, D2S371 and D2S126 and gave a maximum lod score of 5.66 in the interval between D2S157 and D2S371.

Table 15. Two point LOD scores (Z) for linkage between CCL and chromosome $2 q$ markers. Genetic distances between markers are shown in $\mathrm{cM}$.

\begin{tabular}{lrlllllllll}
\hline \multicolumn{10}{c}{ Recombination fraction $(\theta)$} \\
\cline { 3 - 12 } Marker & CM & 0.00 & 0.01 & 0.05 & 0.10 & 0.20 & 0.30 & 0.40 & $\mathbf{Z}_{\max }$ & $\theta_{\max }$ \\
\hline$D 2 S 72$ & 6.0 & $-\infty$ & -3.09 & -0.18 & -0.51 & -0.06 & 0.06 & 0.06 & $\mathbf{0 . 0 7}$ & 0.35 \\
$D 2 S 325$ & 0.5 & 3.34 & 3.26 & 2.90 & 2.44 & 1.56 & 0.87 & 0.40 & $\mathbf{3 . 3 4}$ & 0.00 \\
$D 2 S 2242$ & 0.1 & 2.76 & 2.71 & 2.49 & 2.22 & 1.76 & 1.08 & 0.51 & $\mathbf{2 . 7 6}$ & 0.00 \\
$D 2 S 2208$ & 1.1 & 1.65 & 3.00 & 3.36 & 3.25 & 2.65 & 1.83 & 0.90 & $\mathbf{3 . 3 7}$ & 0.05 \\
$D 2 S 157$ & 0.1 & 5.28 & 5.19 & 4.28 & 4.34 & 3.31 & 2.19 & 1.01 & $\mathbf{5 . 2 8}$ & 0.00 \\
$D 2 S 2321$ & 0.8 & 2.41 & 2.33 & 2.01 & 1.61 & 0.81 & 0.27 & 0.01 & $\mathbf{2 . 4 1}$ & 0.00 \\
$D 2 S 371$ & 3.6 & 5.12 & 5.03 & 4.67 & 4.20 & 3.18 & 2.08 & 0.93 & $\mathbf{5 . 1 2}$ & 0.00 \\
$D 2 S 128$ & 10.0 & 2.83 & 2.75 & 2.42 & 2.00 & 1.17 & 0.46 & 0.09 & $\mathbf{2 . 8 3}$ & 0.00 \\
$D 2 S 126$ & & $-\infty$ & -0.60 & 0.62 & 0.98 & 1.04 & 0.80 & 0.44 & $\mathbf{1 . 0 7}$ & 0.16 \\
\hline
\end{tabular}




\section{Pulverulent cataract: 13 (Pedigree L).}

Patients and methods: Twenty-seven members of the pedigree were genotyped including 16 affected, 7 unaffected and 4 spouses. The candidate regions were excluded according to the approach described earlier.

Results: The two point lod scores for the markers in the relevant area on chromosome 13q are shown in Table 16. The highest lod score was obtained with marker D13S1236. Mutipoint analysis using markers D13S1236, D13S175, D13S1243 gave a maximum lod score of $6.62\left(\theta_{\max }=0\right)$ at D13S175 (See Appendix 2; publications Mackay et al 1998).

Table 16. Two point LOD scores (Z) for linkage between pulverulent cataract (pedigreeL) and chromosome 13q markers.

\begin{tabular}{|c|c|c|c|c|c|c|c|c|c|c|}
\hline \multirow[b]{2}{*}{ Marker } & \multirow[b]{2}{*}{$\mathrm{cM}$} & \multicolumn{9}{|c|}{ Recombination fraction $(\theta)$} \\
\hline & & 0.00 & 0.01 & 0.05 & 0.10 & 0.20 & 0.30 & 0.40 & $\mathbf{Z}_{\max }$ & $\theta_{\max }$ \\
\hline$D 13 S 1316$ & 4.2 & 2.39 & 2.33 & 2.10 & 1.80 & 1.19 & 0.60 & 0.15 & 2.39 & 0.00 \\
\hline$D 13 S 1236$ & 3.2 & $-\infty$ & 3.66 & 3.98 & 3.79 & 3.04 & 2.03 & 0.83 & 3.98 & 0.05 \\
\hline$D 13 S 175$ & 1.4 & 4.06 & 3.97 & 3.64 & 3.21 & 2.28 & 1.55 & 0.61 & 4.06 & 0.00 \\
\hline D13S1275 & 2.6 & $-\infty$ & 1.02 & 1.52 & 1.55 & 1.26 & 0.82 & 0.37 & 1.56 & 0.08 \\
\hline$D 13 S 292$ & 0.1 & 2.17 & 2.14 & 1.99 & 1.80 & 1.37 & 0.89 & 0.40 & 2.17 & 0.00 \\
\hline$D 13 S 1243$ & 0.1 & $-\infty$ & -0.97 & 0.67 & 1.19 & 1.31 & 0.99 & 0.48 & 1.34 & 0.17 \\
\hline$D 13 S 283$ & 7.5 & $-\infty$ & 1.64 & 2.69 & 2.85 & 2.48 & 1.73 & 0.75 & 2.85 & 0.10 \\
\hline$D 13 S 217$ & & $-\infty$ & -7.12 & -3.15 & -1.63 & -0.43 & -0.03 & 0.04 & 0.04 & 0.39 \\
\hline
\end{tabular}




\section{Pulverulent Cataract: 13q (Pedigree M).}

Patients and methods: Eighteen family members were genotyped including 10 affected, 5 unaffected and 3 spouses (see Appendix 1; pedigree M). The genome was ranked into the candidate regions described above, although the candidate cataract loci now included the 13q site.

Results: A maximum lod score of 3.91 was obtained with markers D13S175, D13S1275 and D13S292 as shown in Table 17.

Table 17. Two point LOD scores (Z) for linkage between pulverulent cataract (pedigree $M$ ) and chromosome $13 q$ markers.

\section{Recombination fraction $(\theta)$}

\begin{tabular}{lrrrrrrrrrr} 
Marker & $\mathrm{cM}$ & 0.00 & 0.01 & 0.05 & 0.10 & 0.20 & 0.30 & 0.40 & $\mathbf{Z}_{\max }$ & $\theta_{\max }$ \\
\hline n13S1316 & 4.2 & 3.37 & 3.31 & 3.06 & 2.73 & 2.02 & 1.23 & 0.49 & $\mathbf{3 . 3 7}$ & 0.00 \\
$D 13 S 1236$ & 3.2 & 0.90 & 0.89 & 0.84 & 0.77 & 0.61 & 0.44 & 0.24 & $\mathbf{0 . 9 0}$ & 0.00 \\
$D 13 S 175$ & 1.4 & 3.91 & 3.85 & 3.60 & 3.27 & 2.56 & 1.76 & 0.89 & $\mathbf{3 . 9 1}$ & 0.00 \\
$D 13 S 1275$ & 2.6 & 3.91 & 3.85 & 3.60 & 3.27 & 2.56 & 1.76 & 0.89 & $\mathbf{3 . 9 1}$ & 0.00 \\
$D 13 S 292$ & 0.1 & 3.91 & 3.85 & 3.60 & 3.27 & 2.56 & 1.76 & 0.89 & $\mathbf{3 . 9 1}$ & 0.00 \\
$D 13 S 1243$ & 0.1 & 2.91 & 2.07 & 1.93 & 1.74 & 1.33 & 0.88 & 0.41 & $\mathbf{2 . 1 1}$ & 0.00 \\
$D 13 S 283$ & 7.5 & 3.61 & 3.55 & 3.30 & 2.97 & 2.26 & 1.47 & 0.65 & $\mathbf{3 . 6 1}$ & 0.00 \\
$D 13 S 217$ & & $-\infty$ & -1.62 & -0.33 & 0.13 & 0.43 & 0.43 & 0.27 & $\mathbf{0 . 4 5}$ & 0.25 \\
\hline
\end{tabular}

Both these two families affected by pulverulent cataract map to the same region on chromosome on $13 \mathrm{q}$ and a candidate gene that codes for connexin46 lies in this region. Further studies have now isolated different muations in this gene in the two families that gives rise to the cataract. 


\section{Anterior polar cataract: $17 \mathrm{p}$ (Pedigree A).}

Patients and methods: Twenty-eight family members, of whom 16 were affected (see Figures 2-6), 8 unaffected and 4 spouses were genotyped using microsatellite markers from the Genethon poly-CA map (Gyapay G et al, 1994). Candidate loci for anterior polar cataract were excluded before excluding the known loci for $\mathrm{ADC}$ and the crystallin genes. Aniridia is associated with anterior polar cataract and is caused by a mutation on the PAX6 gene on chromosome $11 \mathrm{p} 13$ (Riccardi VM et al, 1978) a translocation $(2 ; 14)(\mathrm{p} 25 ; \mathrm{q} 24)$ (Moross T et al, 1984) has also been associated with anterior polar cataract. Both these regions were excluded by linkage analysis to contain the relevant gene in this pedigree.

Results: Positive lod scores were obtained for markers D17S799 ( $Z=0.74 @$ $\theta=0.30)$ and D17S798 $(Z=0.45 @ \theta=0.30)$. These markers flank the zonular sutural cataract locus and the $\beta$ A3/A1-crystallin gene. Linkage to these loci were excluded with marker D17S805 ( $\mathrm{Z}=-3.93 @ \theta=0.05)$. The cerulean cataract locus on 17q24 was also excluded with marker D17S802 ( $Z=-3.27 @ \theta=0.05)$, thus excluding the known cataract and crystallin loci on 17q. Chromosome 17 is rich in genes and contains many loci important in eye diseases so it was felt that the entire chromosome should be excluded. During this exclusion significant lod scores were obtained for the following markers on $17 \mathrm{p}$ (see Table 18, below), marker D17S786 ( $Z=3.61 @ \theta=0.10), D 17 S 796(Z=4.17 @ \theta=0.05)$ and $\operatorname{D17S849}(Z=4.01 @ \theta=0.05)$. 
Table 18. Two-point lod scores (Z) for linkage between the anterior polar cataract locus and chromosome 17 markers.

\begin{tabular}{|c|c|c|c|c|c|c|c|c|c|}
\hline \multirow[b]{2}{*}{ Marker } & \multicolumn{7}{|c|}{ Recombination fraction $(\theta)$} & \multirow[t]{2}{*}{$Z_{\max }$} & \multirow[t]{2}{*}{$\theta_{\max }$} \\
\hline & 0.00 & 0.01 & 0.05 & 0.10 & 0.20 & 0.30 & 0.40 & & \\
\hline D17S849 & $-\infty$ & 3.68 & 4.01 & 3.83 & 3.10 & 2.14 & 1.05 & 4.01 & 0.05 \\
\hline D17S796 & $-\infty$ & 3.84 & 4.17 & 3.99 & 3.26 & 2.30 & 1.17 & 4.17 & 0.05 \\
\hline D17S786 & $-\infty$ & 2.51 & 3.52 & 3.61 & 3.11 & 2.24 & 1.16 & 3.61 & 0.08 \\
\hline Centromere & & & & & & & & & \\
\hline D17S799 & $-\infty$ & -3.39 & -0.81 & 0.11 & 0.71 & 0.74 & 0.49 & - & - \\
\hline D17S805 & $-\infty$ & -8.01 & -3.93 & -2.27 & -0.82 & -0.19 & 0.05 & - & - \\
\hline D17S798 & $-\infty$ & -2.73 & -0.78 & -0.80 & 0.39 & 0.45 & 0.30 & - & - \\
\hline D17S802 & $-\infty$ & -7.19 & -3.27 & -1.83 & -0.73 & -0.28 & -0.04 & - & - \\
\hline
\end{tabular}

Maximum lod scores and corresponding recombination fractions are shown (in bold) only for the $17 \mathrm{p}$ markers.

The maximum lod score of 4.17 was obtained with D17S796. Multipoint analysis using markers D17S849, D17S796 and D17S786 gave a maximum lod score of $5.2 @ \theta_{\max }=0.06$. This placed the anterior polar cataract locus in a $13 \mathrm{cM}$ interval between the markers D17S849 and D17S796 at the telomeric end of chromosome $17 \mathrm{p}$. Assignment to this genetic locus is supported by fully informative haplotype analysis (see Appx 2, publications) which detected four recombinant individuals with D17S799; 4-2, 4-6, 4-9 and 4-11, two recombinant individuals with D17S786; 4-6 and 4-9, and one recombinant individual with D17S796; 4-6. This means that the cataract locus cannot lie centromeric to D17S796. Work is continuing on this family to try and find the underlying mutation.

\section{Exclusion data:}

In five further pedigrees exclusion of various loci has been undertaken. All the studies were subject to a candidate gene approach to exclude the known relevant loci for the particular phenotype and positive linkage has yet to be demonstrated. 


\section{Discussion}

Clinical heterogeneity

Visual Outcome \& Complications of surgery

Age at diagnosis 130

Age at surgery and visual outcome 131

Number of surgical interventions and visual $\quad 132$ outcome

Visual outcome for the different phenotypes

Complications

Genetic heterogeneity 


\section{Clinical Heterogeneity.}

In this study of $\mathrm{ADC}$ we have demonstrated that all the phenotypes of the pedigrees encountered could be classified as one of the eight following types; anterior polar, posterior polar, nuclear, lamellar, coralliform, blue-dot (cerulean), cortical and pulverulent. This study was limited to large families that were suitable for linkage studies but this was thought not to affect the distribution of the affected phenotypes. Other phenotypes not included in this study have been reported but they have either been described in individual cases or are very uncommon. Although an attempt was made to examine the phenotypes of all family members at risk of inheriting the affected gene, the description of intrafamilial variation in the phenotypes was limited by the number of patients who had already undergone surgery. This is a limitation inherent in all studies of early onset inherited cataract and we attempted to obtain as detailed a description as possible from the hospital records in such cases.

The eight phenotypes described here are all recognised and previously described. Cortical cataract however, is the least well recognised of the eight phenotypes. Jaafar and Robb (1984) list the types of cataract seen in 463 patients diagnosed as having congenital cataract of all aetiologies in a paediatric eye department, 37 patients were described as having 'cortical' cataracts. There is no description nor photograph of the cortical cataracts and the paper concentrates on the clinical course and visual outcome of those affected by anterior polar cataract, not cortical cataract. Lamellar cataracts are also listed amongst the phenotypes by Jaafar and Robb indicating that cortical and lamellar are distinct phenotypes in their classification. Cortical cataract is a description more usually applied to adult 'age-related' cataract. There is evidence for a single gene to be involved in a large proportion of adult cortical cataract (Heiba et al 1995) and the identification of the gene for the cortical cataract in pedigree $\mathbf{K}$ will allow us to test the hypothesis that mutations in this gene may influence cortical cataract in the elderly. 
There is also evidence for a single gene for age related nuclear cataract (Heiba et al 1993). In a study analysing data from the Beaver Dam Eye Study Heiba et al found that a single major gene can account for $35 \%$ of the total variability of agesex-adjusted measures of nuclear sclerosis. Although it is unlikely that a mutation in a gene for autosomal dominant nuclear cataract may also give rise to the nuclear sclerosis seen in the elderly population, there may be other mutations or a series of mutations that may have a role to play in age-related cataract (Kantorow et al 1998).

Lamellar cataract is occasionally referred to as 'zonular', although this term is not used here as zonular describes a variety of different morphologies. Duke-Elder uses the term zonular for an opacity limited to a specific zone of the lens due to a temporary disturbance of development at a particular period. This definition includes almost every form of inherited cataract. Posterior polar cataract only affects the posterior zone of the lens, anterior cataracts affect the anterior zone of the lens and so on. Vogt defines zonular cataract as having a layer of opacities surrounding a clear nucleus and describes an infinite variety of zonular cataracts. It is this wide clinical spectrum that makes 'zonular' a confusing term. DukeElder includes central pulverulent, nuclear and lamellar cataracts as being zonular. The zonular pulverulent cataract linked to 1q by Renwick and Lawler is probably a nuclear cataract, as the opacity is 'always in the centre of the lens.' The term zonular in this instance is not used according to Vogt's definition but follows Duke-Elder's interpretation of the opacity being in a specific zone of the lens, which in this case is the nucleus. Padma et al demonstrated linkage of a zonular-sutural cataract. Although most affected individuals had a clear embryonic and fetal nucleus, fulfilling Vogt's description of a zonular cataract, some opacities were described as varying from a uniform dense opacity to a collection of fine dots forming a hazy cloud. This description suggests that this pedigree may be affected by the pulverulent phenotype. For these reasons we have avoided the term 'zonular' cataract and used 'lamellar' to describe a cataract that forms a shell around a clear inner nuclear area as described and illustrataed in Figures 30-34 pp75-77. 
The distinction between stationary and progressive posterior polar cataract has been previously documented. Tulloh (1955) describes the progressive posterior polar cataract in a five generation family that had "a peculiar discoid posterior polar cataract, with fluffy white extensions through the posterior cortex towards the equator. There were a few anterior cortical punctate opacities." Tulloh goes on to state that the initial opacity was the circular posterior polar cataract, but the progression of the cortical opacities occurred later. In the family he describes subsequent generations developed the extensions at progressively earlier ages. This phenomenon of 'anticipation' was not seen in the family examined in this study (Pedigree C). However the phenotype is very similar in the description and the progression as that seen in this study and illustrated in Figure 13, page 62.

In all the pedigrees apart from the pulverulent pedigrees the morphology was the same but varied in severity. In the pulverulent pedigrees the phenotype varied amongst affected individuals from the same family. Intra-familial clinical heterogeneity in ADC has been described by many authors including interocular variability in individuals affected by ADC (Scott et al 1994). The pedigrees described as having this wide variation in morphology are characteristic of the pulverulent type described in this study and the cataract pedigree described by Scott et al that shows inter-individual variability is referred to in that paper as the 'pulverulent' type of cataract.

There was no evidence of a gradual worsening nor improvement in the severity of the cataract with subsequent generations. Only the phenotype could be predicted, in all but the families affected by pulverulent cataract.

The phenotype of the cataract remains consistent throughout the affected individuals in all but the families affected by pulverulent cataract. For all the other families the cataract does not alter according to the part of the lens that is affected by cataract, although it will vary in severity. A parent affected by a posterior polar cataract has a $50 \%$ chance of passing the gene on to their 
offspring, and any affected children will therefore be affected by a posterior polar cataract. The only way the cataract may vary, is in its severity, as clearly shown in the photographs in the illustrations of the opacities earlier in this thesis. This is true for all the phenotypes except those pedigrees affected by the pulverulent phenotype and Figures 42-55 show the wide scope for phenotypic variability in these pedigrees.

This study of the lens morphology in ADC has demonstrated wide clinical heterogeneity and had initially set out to suggest a clinical classification. Most of the phenotypes can be classified according to a few of the different types. Almost $25 \%$ of all affected patients had lamellar cataracts and over $28 \%$ had pulverulent cataracts. This means that over $50 \%$ of affected individuals could be classified as one of two phenotypes. For this reason it is tempting to try and create a clinical classification but no clinical clasification can include the rare and unusual phenotypes that make up a significant number of those affected by ADC. Inherited cataract has been a topic of study by many ophthalmologists in the past including Doyne, Nettleship, Vogt, Duke-Elder and François. None have suggested a clinical classification for the opacities. This thesis has attempted to classify the opacities according to the position in the lens and the cataract morphology and has therefore suggested the eight phenotypes as a basic approach to creating some form of unified approach in dealing with the clinical aspects of $\mathrm{ADC}$.

There is clearly considerable genetic heterogeneity and further advances in the genetic aetiology will allow for a more detailed comparison between the genetic mutation and the clinical phenotype as well as offering the potential for a genetic classification of ADC. Already it is possible to see a correlation between the phenotype and the underlying genetic mutation and further evaluation of the molecular genetics of ADC will undoubtedly provide a genetic classification. 


\section{$\underline{\text { Visual Outcome and Complications of surgery }}$}

\section{Age at diagnosis.}

The age at diagnosis of those affected by ADC is illustrated in Figure 58 on page 96 and shows a bimodal distribution. The peaks are at birth and then during late infancy (aged 5-19 years). These ages probably reflect the ages at which visual screening is most likely to take place. Following birth all babies are given a general examination by a paediatrician prior to discharge from the hospital that includes examining the eyes and the 'red reflex' with a direct ophthalmoscope. Whilst it is unlikely that they will diagnose the mild and more diffuse cataracts, this technique will pick up the central dense opacities. The second peak of the bimodal distribution, which occurs in late infancy, is during early school age when visual problems are more likely to be recognised either by routine screening or by teachers noticing children with visual problems.

The phenotypes that are diagnosed early (Table 5, page 97) are the anterior polar (mean age at presentation under 1 year old) and stationary posterior polar cataracts (mean age at presentation 1.25 years). These are more clearly visible as a white dot in the pupil and will also be more visible as a central shadow against the 'red reflex' on direct ophthalmoscopy. Table 5 only shows the age at diagnosis for the cataracts that underwent surgery. The milder polar opacities that never required surgery have not been included.

The other phenotypes that involve the visual axis early in their development; lamellar, nuclear and coralliform, were the next to present at a mean age of; 2.5, 3.0 and 3.1 years respectively. The opacities that predominately affect the lens cortex presented last. The blue-dot cataract presented at a mean age of 11.6 years and the cortical cataract at a mean age of 18.8 years. The wide clinical heterogeneity of the pulverulent cataracts is reflected in the age at presentation. Whilst some are dense and present early others are mild and require surgery at a much later date. The mean age at presentation is therefore later than the polar cataracts but earlier than the blue-dot and cortical cataracts. The late age at presentation of the progressive posterior polar cataract is surprising. It may be that this phenotype is not congenital but develops later in life. 
Very few of the affected patients from all the phenotypes had received regular examinations by an ophthalmologist or optician in early childhood, despite the strong family history of cataracts.

\section{Age at surgery and visual outcome.}

The age at surgery had a significant effect on the final visual outcome. Table 6 (page 99) shows the final visual outcome and time of surgery for 164 eyes.

Figures 59-63 (pp100-102) show in pie-chart form the final visual outcome for the different age groups. The percentage of eyes achieving a visual acuity of 6/9 or better increases as the age at time of surgery gets older. For those operated on under the age of 2 years, $20 \%$ achieve a V/A better than $6 / 9$, whilst $67 \%$ of those operated on after the age of 20 years achieve a V/A of $6 / 9$ or better. There is a gradual increase in the percentage of patients achieving a visual acuity of $6 / 9$ or better. In the intervening years, $35 \%$ of the $3-5$ year group, $66 \%$ if the $6-10$ year olds and $67 \%$ of the $11-20$ have a final visual acuity of $6 / 9$ or better.

On page 103 Figure 64 shows the mean age at time of surgery for those achieving a V/A of $6 / 5$ through to non-perception of light (NPL). The 'trend line' clearly shows that those achieving a better V/A were operated on later in life. What this cannot take into account is the severity of the opacities and the age at presentation to an ophthalmologist. The issue of when to operate on bilateral infantile cataracts has received considerable attention over the years and early intervention is recommended (Rice \& Taylor 1982). This is supported by recent improvements in visual acuity testing, surgical techniques, instruments and contact lens management. Although this study shows the benefits of late surgery, it is only possible to delay surgery for the milder cataracts. The dense opacities have to be operated on earlier in life and there are many guidelines to help in the decision of when to operate. These include the ability to visualise the fundus (Stark et al 1979), whether the opacity is greater than $3 \mathrm{~mm}$ in diameter (Hiles DA 191983), or how dense the cataract is (Arkin et al 1992). In the individuals with more dense cataracts that require earlier surgery there may well be a more advanced degree of amblyopia. Whilst there are reports of good visual results in patients with dense cataracts who have had surgery late or not at all (Freeman \& 
Rovick 1994), these are the exceptions and many studies have shown the benefits of early surgery. What this study shows is that with the partial cataracts, where possible, delayed surgery is associated with a better final visual acuity. This study has not investigated the effect of amblyopia on the final visual outcome.

\section{Number of surgical interventions and visual outcome.}

In order to assess the number of surgical interventions and the effect this may have had on the final visual acuity, only patients operated on under the age of 16 years were included. The overall results are shown graphically in Figure 65 (page 104) and also in the pie charts in Figures 66 and 67 (page 105).

The visual results are better for those patients who underwent a single surgical procedure. $55 \%$ of patients who underwent a single procedure achieved a V/A of $6 / 9$ or better compared to only $18 \%$ of those who had multiple surgical procedures. A number of factors probably underlie these figures. The patients who had the multiple procedures may well have had earlier surgery for dense opacities in an era before the advent of improved methods of visual acuity testing, surgical techniques and contact lens management. These patients are also more likely to have had periods of poor vision prior to repeated surgery owing to the visual axis being obscured by the re-growth of lens fibres. This would leave them at a greater risk of developing amblyopia.

\section{Visual outcome for different phenotypes.}

The visual outcome for the different phenotypes is shown in Table 8 on page 104. This information is shown graphically for the different phenotypes in Figures 68-76 (pp107-111). Data was not available on all the operated eyes. There is a close association between those phenotypes that have a good visual outcome and those that are operated on at an older age (ie cortical and blue-dot). Alternatively, those with a poorer visual outcome are the phenotypes that underwent surgery in early infancy (the polar cataracts). Table 9 on page 112 illustrates this by showing the age at time of surgery for the different phenotypes.

\section{Anterior polar cataract.}

Those patients affected by anterior polar cataract that underwent surgery (Table 7 [page 104] \& Figure 66 [page 105]) had a poorer final visual outcome than those that did not have surgery (Ionides et al 2000).Most of the un-operated cases 
had mild opacities but the patient illustrated in Figures 2 and 3 (p57) with pyramidal anterior cataracts had refused surgery and had 6/18 vision in each eye. It is not possible to assess the density of the cataracts in the patients who had already been operated on but it is likely that they had large and dense cataracts that completely occluded the visual axis. The better visual results for those that did not have surgery may suggest that in some cases there is an argument for postponing surgery to an older age so as to increase the chances of obtaining an improved final visual acuity. The three unoperated eyes with visual acuities of CFS-NPL were in two elderly patients who had refused surgery. In Table 9 (page 112) it can be seen that patients affected by the anterior polar cataract tended to be operated on in early infancy and this may account for the poor visual results. Only one patient developed glaucoma and one patient had a retinal detachment that occurred forty years following the original cataract surgery. This had been performed at the age of three years.

\section{Stationary posterior polar cataract.}

The visual results for this phenotype are illustrated in Figure 69 (page 107). The affected patients were operated on early in life, as shown in Table 9 (112) with all of the operations occurring within the first five years of life. The visual results are better than was the case with the anterior polar cataracts that also tended to be operated on early in life. A final visual acuity of $6 / 9$ or better was achieved in $10 / 18$ affected patients and six of these ten patients had undergone surgery for their cataracts. Posterior polar cataracts affect the optical nodal point of the lens and therefore even small opacities can theoretically have a profound impact on visual symptoms. However in some cases large, dense opacities as illustrated in Figure 7 and 8 on page 61 resulted in a relatively small drop in visual acuity. This patient had a V/A of 6/24. Although individual cases cannot create guidelines for the management of cataract, it may again suggest that some cases of moderately severe opacities may benefit from delayed surgery. The two patients with V/A of CFS-NPL consisted of one eye that had a retinal detachment and the other eye was densely amblyopic in a patient who had undergone unilateral surgery. The patient who developed a retinal detachment had undergone surgery on the affected eye at the age of 3 years and had been kicked in that eye at the age of 13 years. This caused a complete retinal detachment for 
which he underwent vitreo-retinal surgery but this failed to re-attach the retina and the eye is now phthisical. This patient has developed glaucoma in his other eye.

Progressive posterior polar cataract.

All but one case underwent surgery in the single pedigree affected with progressive posterior polar cataract (Figure 70 page 108). The single unoperated eye was in a ten year old girl with a dense unilateral cataract and profound amblyopia, illustrated in Figure 13 page 64. Of the 18 affected patients 13 underwent surgery after the age of 11 years and 8 after the age of 20 years. The good visual outcome, with 13 out of 18 eyes seeing 6/9 or better is largely due to the late stage at which their cataracts caused visual symptoms, allowing for the later surgery and the good final visual outcome. However, three patients developed retinal detachments as will be discussed under the complications section, but all had good outcomes from the retinal surgery.

\section{Nuclear cataract.}

Nuclear cataract affects the visual axis early in its development and would be expected to have a poor visual outcome with surgery performed early in life. The visual outcome was surprisingly good. Despite the relatively early age at diagnosis of the cataracts (Table 5, p97) they were operated on relatively late in life (Table 9, p112) suggesting slow progression. As can be seen in Figure 71 page 108 , the majority of patients $(18 / 43 ; 41.8 \%)$ achieved a V/A of 6/5-6/9. Although previously associated with glaucoma (Barkhash et al 1975) this study found only one patient to develop glaucoma.

\section{Lamellar cataract.}

Lamellar cataract was one of the commonest phenotypes seen in this study and most affected patients $(39 / 51 ; 76 \%$, Figure 72 , p109) underwent surgery. The majority of patients had the surgery performed before the age of 5 years old (27/44; 61\%, Table 9, p112). Despite the young age at the time of surgery, 35\% $(18 / 51)$ had a final visual acuity of $6 / 9$ of better. Seven of the eight patients with a final visual acuity of CFS-NPL underwent surgery within the first year of life. Previous studies have linked lamellar cataract to the development of glaucoma 
and of the eight patients found to have developed glaucoma in this study three of them had lamellar cataract. However, lamellar cataract was the commonest phenotype encountered (38/180 patients) in this study and the incomplete clinical data as well as the small number of patients developing glaucoma make any interpretation unreliable.

\section{Coralliform cataract.}

In the single family affected by coralliform cataract all affected individuals had undergone surgery. The majority of eyes had a good visual outcome with 7/14 patients seeing $6 / 9$ or better. All affected patients had surgery performed by the age of 20 years with $16 / 18$ eyes having been operated on by the age of 10 years. Two patients developed glaucoma, both in their right eye and one patient developed the raised intra-ocular pressure following repeated retinal detachment surgery involving silcone oil.

\section{Blue-dot cataract.}

The blue-dot cataract presented later than the other phenotypes and once again all the affected patients in this study were operated on. The surgery was performed after the age of 11 years old in all cases with $8 / 14$ patients being operated on after 20 years old. The visual results were very good with $5 / 7$ patients on whom it was possible to get visual details having a final visual outcome of $6 / 9$ or better. No patient developed glaucoma nor retinal detachment.

\section{Cortical cataract.}

The cortical phenotype had not been described before as an autosomal dominant trait and is therefore rare. There were visual details on only eight affected eyes and therefore it is difficult to draw any real conclusions. However, as would be expected with a phenotype that does not affect the visual axis until late in its pathogenesis the affected eyes underwent surgery late in life, with $7 / 10$ eyes being operated on after the age of 11 years. $5 / 8$ eyes had a final visual acuity of $6 / 9$ or better with only one patient having a V/A worse than $6 / 12$. 


\section{Pulverulent cataract.}

Despite the wide clinical heterogeneity of this phenotype no patients were operated on under the age of 1year old. The majority of patients were operated on after the age of 11 years with $43 \%$ (16/37) having surgery after the age of 20 years. $42 / 71$ of all affected eyes had a V/A of $6 / 9$ or better.

\section{Complications}

\section{Glaucoma.}

The incidence of glaucoma following surgery for congenital cataract (RussellEggitt et al 1997) varies from 2.9\% (Barkhash et al 1975) to 32\% (Parks et al 1993). This study found that eight patients developed glaucoma, from a total of 180 affected patients of whom 123 had undergone surgery. This is an incidence of $6.5 \%$. Previous studies have reviewed cases affected by cataracts of all aetiologies including microphthalmia and persistent primary hyperplastic vitreous (PHPV). The most important factor affecting the onset of glaucoma is a corneal diameter less than 10mm (Parks et al 1993, Robb and Petersen 1992, Wallace and Plager 1996). Other factors such as the surgical technique at time of surgery (Chrousos et al 1984), surgery performed in early infancy (Phelps and Arafat 1977) and cataract phenotype have not been shown to be as important. However, Robb and Petersen (1992) found glaucoma to be more common in lamellar cataract, and Barkhash et al (1975) et al found glaucoma in eyes affected by nuclear or lamellar cataract.

In this study the patients who had poorer vision were less likely to attend the hospital for an eye examination and therefore the incomplete clinical data may favour a low pick-up rate for the patients affected by complications such as glaucoma. This study only recruited patients affected by ADC, therefore patients affected by microphthalmia and small corneal diameter were not encountered although the corneal diameters were not measured. This would also help to explain the low incidence of glaucoma in this study. The average age at surgery 
for those patients that went on to develop glaucoma was 4 years old and this is not that different from the average age of all the patients that underwent surgery for their cataracts which was 4.5 years.

\section{Retinal detachment.}

This study found 9/164 (5.49\%) patients to have a retinal detachment. Parks et al (1993) had one retinal detachment out of 174 paediatric cataract extractions and notes that the type of surgery employed in cataract extraction affects the incidence. Prior to aspiration techniques $3 \%$ to $10 \%$ of cases had retinal detachment, but following its introduction this reduced to under 3\% (Francois 1979, Ryan et al 1965). Retinal detachments can occur up to 30 years following surgery (Lloyd et al 1992) and this makes analysis of the true incidence difficult.

In Table 11 (page 114) it can be seen that the age at surgery was not related to the development of a retinal detachment, nor was the number of surgical procedures. The posterior polar cataracts have a much higher rate of detachment than would be expected, despite the older age at time of cataract surgery in three of the four patients with posterior polar cataract who developed a retinal detachment. These three cases occurred in patients with progressive posterior polar cataracts and all retinas underwent successful retinal surgery with a visual outcome of 6/9 in two cases and 6/18 in the last. The case of retinal detachment in the patient with a stationary posterior polar cataract followed a kick in the affected eye resulting in a total retinal detachment. Retinal surgery failed and the eye is now phthisical.

\section{Conclusion}

This study was designed primarily to examine the molecular genetics of autosomal dominant cataract and insufficient data were available on the clinical aspects of the affected patients to draw strong conclusions regarding the visual outcomes and complications of surgery. The patients of any one pedigree tended to have received their eye care at hospitals across the United Kingdom and in a few cases in Europe and the United States. The medical histories spanned the past 70 years so that full medical notes were not usually available. The more severely affected patients were often unwilling to attend the hospital for a clinical 
examination and also preferred not to receive a 'home visit'. They would usually allow a blood sample to be taken at their local health centre or General Practitioners surgery and have it sent in for molecular analysis. It may be that if all patients had undergone a full ophthalmological examination with complete eye histories, the incidence of complications would be higher and the visual outcome for $\mathrm{ADC}$ in this study would not be as good. The incomplete clinical data meant that it was sometimes possible to get the age at surgery but not the final visual outcome, and without examining the patients the incidence of nystagmus, strabismus, amblyopia and additional problems could not be properly addressed.

However, on the results obtained in this study, it appears that the visual outcome is largely dictated by the phenotype. Although the complications of glaucoma and retinal detachment are probably not phenotype related, the overall visual results are better for those that underwent delayed surgery. The phenotypes that had surgery performed in early infancy (anterior and posterior polar opacities) tended to have a poor visual outcome, whilst those that were milder could be left until late childhood before having surgery with an improved visual outcome. The phenotypes that presented the latest and had surgery performed in adulthood (blue-dot cataract) had the best visual outcome. 


\section{Genetic Heterogeneity.}

There are now ten loci known to contain genes giving rise to ADC and the underlying mutation has been identified at seven of these loci.

Table 19. Mutations giving rise to $A D C$.

$\begin{array}{lllll}\text { Locus } & \text { Gene } & \text { Protein } & \text { Phenotype } & \text { Reference } \\ 21 \mathrm{q} & \text { CRYAA } & \alpha \text { A-crystallin } & \text { Variable } & \text { Litt et al } 1998 \\ 22 \mathrm{q} & \text { CRYBB2 } & \beta B 2-\text { crystallin } & \text { Cerulean } & \text { Litt et al 1997 } \\ 17 \mathrm{q} & \text { CRYBA1 } & \beta \text { A3/A1-crystallin } & \text { Zonular } & \text { Kannabiran et al } 1999 \\ 2 \mathrm{q} & \text { CRYG } & \gamma \text { D-crystallin } & \text { Punctate } & \text { Stephan DA et al } 1999 \\ 2 \mathrm{q} & \text { CRYG } & \gamma \text { E-crystallin } & \text { Coppock-like } & \text { Brakenhoff et al } 1994 \\ 1 \mathrm{q} & \text { GJA8 } & \text { Connexin } 50 & \text { Pulverulent } & \text { Shiels } \text { et al } 1998 \\ 13 \mathrm{q} & \text { GJA3 } & \text { Connexin } 46 & \text { Pulverulent } & \text { Shiels } \text { et al } 1999\end{array}$

There is a close correlation between the phenotype and genotype. The $\alpha \mathrm{A}$ crystallin protein is found in other structures of the eye as well as the lens. It is also present outside the eye. A mutation in this protein would therefore affect other structures within the eye. The pedigree studied by Litt et al shown to have the mutation in the $\alpha \mathrm{A}$-crystallin gene were described as having congenital zonular central nuclear cataracts. Some affected patients also had microcornea, with the adults developing cortical and posterior sub-capsular cataracts and several patients had congenital microphthalmia. This wide clinical spectrum of ocular disease is consistent with the wide distribution of the mutated $\alpha \mathrm{A}$ crystallin.

The $\beta$-crystallin protein is predominately found in the outer part of the lens and a mutation in a gene encoding for one of the $\beta$-crystallins has been associated with a cerulean (blue-dot) cataract. This phenotype has opacities that predominate in the lens cortex. The genetic mutation is closely associated with the phenotype. A second mutation in a gene that also encodes for a $\beta$-crystallin protein has been 
more recently described. The phenotype is described as a zonular cataract with sutural opacities. Although there are no published photographs nor detailed descriptions of this phenotype it may that the opacities are located outside the nucleus and the cortical location of the opacities is consistent with the current theories on the location of the $\beta$-crystallin proteins.

The $\gamma$-crystallin mutation in the Coppock-like cataract pedigree also parallels the molecular biology of the lens. The cataract (Figures 22-27 pages 70-72) is a nuclear cataract and the $\gamma$-crystallin protein is found in greatest quantity in the lens nucleus. The mutation has recently been questioned as to whether it is the causative factor in the formation of cataract but no further details have been published to date. Another more recently described mutation in the $\gamma$-crystallin gene complex is in the $\gamma$-D-crystallin gene. This has been found in a family where the affected members have a progressive juvenile onset punctate cataract. Protein modelling has suggested that the effect of this mutation is subtle, affecting only the surface properties of the crystallin molecule which the authors suggest is consistent with the normal lens at birth (Stephan DA et el 1999).

The CAE cataract, a 'zonular pulverulent' cataract has been found to be caused by a mutation in a gap-junction protein. The gap junctions are cell-to-cell communication pores and are made up of various proteins that dictate the characteristics of the pores and the class of molecules that can pass through the channel. Connexin 50 is one of these gap junction proteins and a mutation would expect to give rise to widely distributed and discreetly localised opacities. The pulverulent cataract phenotype can therefore be explained by understanding the molecular biology of the lens, the gene mutation and the role of the connexin proteins in the formation of gap junctions. A mutation in the gene encoding connexin 46 has also been shown to cause a pulverulent cataract. Mutations at two different points in this gene causes two different phenotypes of pulverulent cataract (Pedigrees L and M, Figures 42-47, 56-57, pp86-88 and p93). 
When this study began only three loci had been identified as containing genes for ADC. The mutation had been isolated at one of these loci. There are now ten loci and the underlying gene mutation has been identified in seven of these cases. This study has contributed three new loci and two new mutations to the molecular genetics of ADC.

The study of genes for autosomal dominant cataract will shed new light on lens development. Sequence changes in the genes for autosomal dominant cataract could also offer information on the risks for age related cataract and would have far wider implications. 


\section{References}

Adams PH. Doyne's discoid cataract (Coppock). Trans Ophthalmol Soc UK 1942;62:152-153.

Amsbaugh DF, Stone SH. Autosomal dominant congenital nuclear cataracts in strain $13 / \mathrm{N}$ guinea pigs. J Hered 1984;75: 55-8.

Antonarakis SE. Genome linkage scanning: Systematic or intelligent? Nature Genet 1994;8:211-212.

Arkin M, Azar D, Fraioli A. Infantile cataracts. Int Ophthalmol clin 1992;32:107-120.

Armitage MM, Kivlin JD \& Ferrell RE. A progressive early onset cataract gene maps to human chromosome 17q24 Nature Genet 1995;9:37-40.

Attwood,J. and Bryant,SA. A computer program to make analysis with LIPED and LINKAGE easier to perform and less prone to input errors. Am. J. Hum. Genet., 1988;52, 259.

Barishak YR. Embryology of the eye and its adnexae. Dev Ophthalmol. 1992;24:

Barkhash SA, Pikalova LD, Grechko AS. Secondary glaucoma after extraction of congenital cataract in children. Oftalmol Zh 1975; 30:204-206.

Barrett DJ, Sparkes RS, Gorin MB. Genetic linkage analysis of autosomal dominant congenital cataracts with lens-specific DNA probes and polymorphic phenotypic markers. Ophthalmol 1988;95: 538-544.

Bassnett S, Beebe DC, Coincident loss of mitochondria and nuclei during lens fibre cell differentiatiòn. Dev Dyn 1992;19: 421-5.

Bassnett S, Kuszak JR, Reinisch L, et al. Intercellular communication between epithelial and fiber cells of the eye lens. J of Cell Science 1994;107:799-811.

Basti S, Hejtmancik JF, Padma T, et al. Autosomal dominant zonular cataract with sutural opacities in a four-generation family. Am J Ophthalmol 1996;121 (2): 162-8.

Batemen JB, Spence MA, Marazita ML, et al. Genetic linkage analysis of autosomal dominant cataracts. Am J Ophthalmol 1986;101: 218-225.

Beaumont C, Garrett C, Garner C, et al. Linkage data on dominant inherited congenital cataracts in families from the South West of England. Cytogenet Cell Genet 1989;51: 959.

Beebe DC, Johnson MC, Feagans DE, et al. In: Hilfer SR and Sheffield JB eds. Ocular size and shape regulation during development. The mechanism of cell elongation during lens fibre cell differentiation.1980:pp 79-98.

Berman ER. Biochemistry of the eye. New York: Plenium Press.1991:pp201-290.

Berry V, Ionides ACW, Moore AT, et al. A locus for anterior polar cataract on chromosome 17p. Hum Molec Genet 1996;5:415-419.

Birdwood SC, Garrett C, Garner C, et al. The locus causing a form of dominantly inherited congenital lamellar cataracts is not linked to the $\gamma$-crystallin gene cluster on chromosome 2q33-35. Cytogenet Cell Genet 1992;58:1968.

Bloemendal H. Lens research; From protein to gene. Exp Eye Res 1985;41: 429-448. 
Bloemendal H, Vermorken AJM, Kibbelaar M. Nomenclature for the polypeptide chains of lens plasma membranes (letter). Exp Eye Res 1977;24: 413.

Bloemendal H. Lens proteins as markers of terminal differentiation. Ophthalmic Res 1979;11: 243253.

Bloemendal H, Piatigorsky J, Spector A. Recommendations for crystallin nomenclature. Exp Eye Res 1989;48: 465-466.

Bodker FS, Lavery MA, Mitchell TN, et al. Microphthalmos in the presumed homozygous offspring of a first cousin and linkage analysis of a locus in a large family with autosomal dominant cerulean congenital cataracts. A J Med Genet 1992;37: 54-59.

Bonneau D, Winter-Fuseau I, Loiseau M-N, et al. Bilateral cataract and high serum ferritin: a new dominant genetic disorder? J Med Genet 1995;32: 778-779.

Brakenhoff RH, Henskens HAM, van Rossum MWPC, et al. Activation of the $\gamma \mathrm{E}$-crystallin pseudogene in the human hereditary Coppock-like cataract. Hum Mol Genet 1994;3: 270-283.

Brakenhoff RH, Aarts HJM, Reek FH, et al. The human $\gamma$-crystallin genes: a gene family on its way to extinction. J Mol Biol 1990;216: 519-532.

Brackenhoff RH, Aarts HJM, Schuren F, et al. The second human $\alpha \mathrm{B} 2$-crystallin is a psuedogene. Exp Eye Res 1992;54: 803-806.

Brown NAP, Bron AJ, Sparrow JM. Central compaction in the process of lens growth as indicated by lamellar cataract. Br J Ophthalmol 1988;72: 538-544.

Byers B, Porter K. Orientated microtubules in elongating cells of the developing lens rudiments after induction. Proc Acad Natl Sci USA 1964;52: 1091.

Carper D, Shinohara T, Piatigorsky J, et al. Deficiency of functional messenger RNA for a developmentally regulated beta-crystallin polypeptide in a hereditary cataract. Science 1982;217(4558): 463-465.

Carter JM, Hutcheson AM, Quinlan RA. In vitro studies on the assembly properties of the lens proteins CP49, CP115. Coassembly with $\alpha$-crystallin but not with vimentin. Exp Eye Res 1995;60: $181-192$.

Cartier M, Breitman ML, Tsui L-C. A frameshift mutation in the $\gamma \mathrm{E}$-crystallin gene of the Elo mouse. Nature Genet 1992;2:42-45.

Cartier M, Tsui L, Ball SP, et al. Crystallin genes and cataract. In; Molecular genetics of inherited eye disorders. eds. Wright AF, Jay B. Vol 2 Modern genetics Series ed. Evans HJ. Publ Harwood Acad Press. Switzerland. 1994

Cascio M, Kumar NM, Safarik R, et al. Physical characterisation of gap junction membrane connexons (hemi-channels) isolated from rat liver. J Biol Chem. 1995;270: 18643-18648.

Chambers C, Russell P. Deletion mutation in an eye lens $\beta$-crystallin. J Biol Chem 1991;266: 67426746.

Chrousos GA, Parks MM, O'Neil JF. Incidence of chronic glaucoma, retinal detachment and secondary membrane surgery in pediatric aphakic patients. Ophthalmol 1984;91:1238-1241.

Church RL, Wang J, Steele E. The human lens intrinsic membrane protein MP70 (Cx50) gene: clinal analysis and chromosome mapping. Curr Eye Res 1994;14: 215-221. 


\section{References}

Chylack LT Jr, Sugar Cataracts- possibly the beginning of medical anti-cataract therapy. Mechanisms of cataract formation in the human lens, G Duncan, ed. Academic press, London. pp237-252. (1981)

Clyde A Clapp, Cataract Its etiology and treatment. Henry Kimpton, London. 1934. pp86-90.

Conneally PM, Wison AF, Merritt AD, et al. Confirmation of genetic heterogeneity in autosomal dominant forms of congenital cataracts from linkage studies. Cytogenet Cell Genet 1978;22: 295-297.

Coulombre AJ. Cataractogensis: Developmental inputs and constraints. Ophthalmol 1979;86: 1559. 1570.

Coulombre J, Coulombre A. Regeneration of neural retina ffrom the pigmented epithelium in the chick embryo. Dev Biol 1965;12:79.

de Jong WW, Hendriks W, Mulders JWM, et al. Evolution of eye lens crystallins: the stress connection. TIBS 1989;14: 365-368.

Delaye M, Tardieu A. Short-range order of crystallin proteins accounts for eye lens transparency. Nature 1983;302: 415-417.

Dib C. et al. A comprhensive genetic map of the human genome based on 5,264 microsatellites. Nature 1996;380:152-154.

Donahue RP. Probable assignment of the Duffy blood group locus to chromosome 1 in man. Proc Natl Acad Sci USA 1968;61: 949-955.

Donaldson The Crystalline Lens.

Donis-Keller H, Green P, Helms C et al.A genetic linkage map of the human genome. Cell 1987;51:319-337.

Doolittle DP, Davisson MT, Guidi JN, et al. (1996). In Genetic variants and strains of the laboratory mouse (MF Lyon, S Rastan, SDM Brown, eds). 3rd ed pp17-854, Oxford Univ Press. London.

Doyne RW. A peculiar form of lens degeneration. Trans Ophth Soc UK. 1889;9: 113.

Dubin RA, Wawrousek EF, Piatigorsky J. Epression of the murine alpha B-crystallin gene is not restricted to the lens. Mol Cell Biol. 1989;9(3):1083-1091.

Duguid JR, Rohwer RG, Seed B. Isolation of cDNAs of scrapie modulated RNA by subtractive hybridisation of a cDNA library. Proc Natl Acad Sci USA 1988;85(15):5738-5742.

Duke-Elder S, Abrams D. 1970 The refraction of light. In 'Systems of Ophthalmology' Vol V. (Duke-Elder S. ed) pp74-78. CV Mosby Co. St Louis.

Duke-Elder S. In: A System of Ophthalmology. Henry Kimpton 1964: Vol III Part 2, The Lens, 715759.

Duke-Elder S. In: A System of Ophthalmology. Henry Kimpton 1964: Vol III Part 2, The Lens, 732

Duke-Elder S. System of Ophthalmology, Voume II pp320-321. The anatomy of the visual system. London Henry Kimpton. 1961

Eiberg H, Marner E, Rosenberg T, et al. Marner's cataract (CAM) assigned to chromosome 16: Linkage to Haptoglobin. Clin Genet 1988;34: 272-275.

Eiberg H, Lund AM, Warburg M, et al. Assignment of congenital cataract Volkmann type (CCV) to chromosome 1p36. Hum Genet 1995;96: 33-38. 
Elfgang C, Eckert R, Lichenberg-Fraté $\mathrm{H}$, et al. Specific permeability and selective formation of gap junction channels in connexin-transfected HeLa cells. J Cell Biol 1995;129: 805-817.

Evans J, Rooney C, Ashwood F, et al. Blindness and partial sight in England and Wales: April 1990 March 1991. Health Trends 1996; 28: 5-12.

Francis PJ, Berry V, Moore AT, et al. Lens biology, development and human cataractogenesis. Trends Genet 1999;15:191-6.

Francois J, Congenital Cataracts. Springfield, IL. Charles C Thomas 1963.

Francois J. Late results of congenital cataract surgery. Ophthalmology 1979;86:1586-1598.

Francois J. Genetics of cataract. Ophthalmologica 1982; 184:61-71.

Fraser FC, Schabtach G. 'Shrivelled': a hereditary degeneration of the lens in the house mouse. Genet Res 1962;3:383-7.

Freeman RS, Rovick LP. Cloudy lenses and Issues: A pedigree of unoperated congenital cataracts. $J$ Pediatr Ophthalmol Strabismus 1994;31:318-322.

Fukui HN, Merola LO, Kinoshita JH. A possible cataractogenic factor in the Nakano mouse lens. Exp Eye Res 1978;26: 477-485.

Galvan A, Lampe PD, Hur KC, et al. Structural organisation of the lens fiber cell plasma membrane protein MIP18. J Biol Chem 1989;264:19974-19978.

Gao Y, Spray DC. Structural changes in lenses of mice lacking the gap juncion protein connexin43. Invest Ophthalmol Vis Sci 1998;39:1198-1209.

Garber AT, Winkler C, Shinohara T, et al. Selective loss of a family of gene transcripts in a hereditary murine cataract. Science 1985;227(4682):74-77.

Garland DL, Duglas-Tabor Y, Jimenez-Assensio J, et al. The nucleus of the human lens: Demonstration of a highly characteristic protein pattern by two-dimensional electrophoresis and introduction of a new method of lens dissection. Exp Eye Res 1996;62: 285-291.

Garland D, Rao PV, Del Corso A, et al. $\zeta$-crystallin is a major protein in the lens of Camelus dromedarius. Arch Biochem Biophys. 1991;285: 134-136.

Gause GG, Tomarwv SI, Zinovieva RD, et al. (1985). in The Lens: Transparency and Cataract. (ed G Duncan). 171-179. Eurage.

Giersing OM. En kataraktøs Bondefamilie. Ugeskr Lager 1878;3.rk.XXXVI: 273-277.

Goldman. v Graefes Arc Ophthalmol. 1929;122:198.

Gonzalez P, Rao V, Zigler JS. Organisation of the human $\zeta$-crystallin/Quinone reductase gene (CRYZ). Genomics 1994;21: 317-324.

Goodenough DA. The crystalline lens: A system networked by gap junctional intercellular communication. Semin Cell Biol. 1992;3: 49-58.

Goulden and Harris. Koby's Slit lamp micros of the living eye, London 1925.

Griffen CS, Shiels A. Localisation of the gene for the major intrinsic protein of eye-lens fibre cell membranes to mouse chromosome 10 by in situ hybridisation. Cytogenet Cell Genet 1992;59(4):300-302. 
Gyapay G, Morisette J, Vignal, A, et al. The 1993-1994 Genethon human genetic linkage map. Nature Genet., 1994;7: 246-339.

Hammerstein W, Scholz W. Familiare form einer "cataracta centralis": Klinisch-genetische studie mit koppelungsdaten. Arch Klin Exp Ophthalmol 1974;189: 9-19.

Harding JJ, Crabbe MJC. (1984). in The Eye (Davson H ed) pp207-492, Academic Press.

Harding J. The Normal Lens. Pp22-25. In Cataract: Biochemistry, epidemiology, and pharmacology.(1991) Pub. Chapman and Hall. London.

Harman NB. Ten pedigrees of congenital and infantile cataract; lamellar, coralliform, discbid, and posterior polar with microphthalmia. Trans Ophthalmol Soc UK 1910;XXX: 251-274.

Harman NB. Congenital cataract; a pedigree of five generations. Trans Ophthalmol Soc UK 1909;29:101-108.

Harman NB. Treasury of Human Inheritance. Part 4. Section XIIIa, Congenital cataract. Eugenics Library Memoirs XI. London 1910.

Hearne CM, Ghosh S, Todd JA. Microsatellites for linkage of genetic traits. TIG 1992;8: 288-294.

Heiba IM, Elston RC, Klein BE, et al. Evidence for a major gene for cortical cataract. IOVS 1995;36(1):227-235.

Heinzmann C, Kojis TL, Gonzalez P, et al. Assignment of the zeta crystallin gene (CRYZ) to human chromosome $1 \mathrm{p} 22-1 \mathrm{p} 31$ and identification of restriction fragment length polymorphisms. Genomics. 1994;23: 403-407.

Hess JF, Casselman JT, FitzGerald PG. Chromosomal localisation of the genes for the beaded filaments. Curr Eye Res 1996;14: 11-18.

Hiles DA. Infantile cataracts. Pediatr Ann 1983;12:556-573.

Horwitz JN, Robertson NP, Wong MM, et al. Some properties of lens plasma membrane polypeptides isolated from normal human lenses. Exp Eye Res 1979;28:359-365.

Huang Q-L, Du XY, Stone SH, et al. Association of hereditary cataracts in strain 13/N guinea pigs with mutation of the gene for $\zeta$-crystallin. Exp Eye Res 1990;50:317-325.

Huang QL, Russell P, Stone SH, et al. Zeta crystallin, a novel lens protein from the guinea pig. Curr Eye Res 1987;6:725-732.

Hammerstein W, Scholz W. Familiare form einer "cataracta centralis": Klinisch-genetische studie mit koppelungsdaten. Arch Klin Exp Ophthalmol 1974;189: 9-19.

Huntzinger RS, Weitkamp LR, Roca PD. Linkage relationships of a locus for congenital total nuclear cataract. J Med Genet 1977;15:113-115.

Ionides ACW, Berry V, Mackay D, et al. Phenotypic variation in a single pedigree with anterior polar cataract. Eye 1998;12:234-236.

Ionides ACW, Berry V, Mackay D, et al. A posterior polar cataract maps to chromosome 1p. Hum Mol Genet 1997;6: 47-51.

Ingolia TD, Craig EA. Four small heat drosophila heat shock proteins are related to each other and to mammalian alpha-crystallin. Proc Natl Acad Sci USA 1982;79:2360-2364.

Iwaki T, Kume-Iwaki A, Liem RKH, et al. Alpha B-crystalin is expressed in non-lenticular tissues 


\section{References}

and accumulates in Alexander's disease brain. Cell 1989;57: 71-78.

Jahal C, Renkawek K, de Jong WW, et al. $\alpha \mathrm{B}$-crystallin is present in reactive glia in Creutzfeld-Jakob disease. Acta Neuropathol (Berl) 1992;83:324-7.

Jay M. Linkage and chromosomal studies on congenital cataract. Trans Ophthalmol Soc UK 1982;102:350-354.

Kannabiran C, Rogan PK, Olmos L, et al. Autosomal dominant zonular cataract with sutural opacities is associated with a splice mutation in the betaA3/A1-crystallin gene. Molecular Vision 1999;4:21

Kantorow M, Kays T, Horwitz J, et al. Differential display detects altered gene expression between cataractous and normal human lenses. Invest Ophthlamol Vis Sci 1998;39:2344-2354.

Kato $\mathrm{K}$, Shinohara $\mathrm{H}$, Kurobe $\mathrm{N}$, et al. Immunoreactive $\alpha \mathrm{A}$-crystallin in rat non-lenticular tissues detected with a sensitive immunoassay method. Biochem Biophys Acta. 1991;1080:173-180.

Kador PF, Fukui HN, Fukushi S, et al. Philly mouse; a new model of hereditary cataract. Exp Eye Res 1980;30:59-68.

Kerscher S, Glenister PH, Favor J, et al. Two new cataract loci, Ccw and To3, and further mapping of the Npp and Opj cataracts in the mouse. Genomics 1996;36: 17-21.

Kinsey VE, Reddy DVN. (1964) Studies on the crystalline lens, XI: The relative role of the epithelium and capsule in transport. Invest Opthalmol. 4: 104-116.

Kinoshita JH. Mechanisms initiating cataract formation. Proctor Lecture. Invest Ophthalmol 13: 713737 (1974)

Kramer P, Yount J, Mitchell T, et al. A second gene for cerulean cataracts maps to the $\beta$ crystallin region on chromosome 22. Genomics 1996;35: 539-542.

Koretz JF, Cook CA, Kusak JR. The zones of discintinuity in the human lens: development and distribution with age. Vision Res 1994;34: 2955-62.

Kuliszewski M, Rupert J, Golod R. The ontogeny of $\gamma$-crystallin mRNAs in Cat ${ }^{\text {FRASER }}$ mice. Genet Res Camb 1988;52: 45-9.

Kumar NM, Gilula NB. The gap junction communication channel. Cell 1997;84: 381-388.

Kumar NM, Gilula NB. Molecular biology and genetics of gap junction channels. Sem Cell Biol 1992;3: 3-16.

Kuszak J, Maisel H, Harding C. Gap junctions of chick lens fibre cells. Exp Eye Res 1978;27:495498.

Kuszak JR, Bertram BA, Macsai MS, et al. 1984. Sutures of the crystalline lens: A review. Scan Elec Micr 111: 1369-1378.

Kuszak JR, Bertram BA, Rae JL. The ordered structure of the crystalline lens. In Development of order in the visual system. eds SR Hilfer, JB Sheffield. Cell and developmental biology of the eye. Springer-Verlag New York. 1986.

Kuszak JR, Macsai MS, Rae JL. Stereo scaning electron microscopy of the crystalline lens. Scan Elec Micr 1983;111: 1415-1426.

Kuwabara T. (1975) The maturation of the lens cell: A morphologic study. Exp Eye Res 20:427-443. 


\section{References}

Lambert SL, Drack AV. Infantile Cataracts. Surv Ophthalmol 1996;40:427-458.

Lathrop G.M, Lalouel JM, Julier C, et al. Strategies for multipoint linkage analysis in humans. Proc. Natl. Acad. Sci. USA, 1984;81:3443-3446.

Litt M, Carrero-Valenzuela R, LaMorticella DM, et al. Autosomal dominant cerulean cataract is associated with a chain mutation in the haman beta-crystallin gene CRYBB2. Hum Mol Genet 1997;6(5): 665-8.

Litt M, Kramer P, LaMorticella DM, et al. Autosomal dominant congenital cataract associated with a missense mutation in the human alpha crystallin gene CRYAA. Hum Mol Genet 1998;\&:471-474.

Lloyd IC, Goss-Sampson M, Jeffrey BG, et al. Neonatal cataract; Aetiology, pathogenesis and management. Eye 1992;6:184-196.

Lund AM,Eiberg H, Rosenberg T, et al. Autosomal dominant congenital cataract; linkage relations; clinical and genetic heterogeneity. Clin. Genet. 1992;41:65-69.

Lubsen NH, Renwick JH, Tsui L-C, et al. A locus for a human hereditary locus is closely linked to the $\gamma$-crystallin gene family. Proc Natl Acad Sci USA 1987;84;489-492.

McAvoy JW. Developmental biology of the lens. In: Mechanisms of cataract formation in the human lens. G Duncan, ed. Academic press, London. pp7-46 (1981)

McAvoy JW. Cell division, cell elongation and distribution of $\alpha-, \beta-, \gamma$-crystallins in the rat lens. $J$ Embryol Exp Morph. 1978;44:140-165.

Mackay D. Ionides A. Kibar Z, et al. Connexin46 mutations in autosomal dominant congenital cataract. American Journal of Human Genetics. 64(5):1357-64, 1999 May.

Mackay DM, Ionides ACW, Berry V, et al. Autosomal dominant 'zonular pulverulent' cataract linked to human chromosome 13. Am J Hum Genet. 1997;60:1474-1478.

McGill JR, Yang F, Baldwin WD. Localisation of the haptoglobin alpha and beta genes (HPA and HPB) to human chromosome 16q22 by in situ hybridisation. Cytogenet Cell Genet 1984;38:155-157.

Maisel H. The lens Marcel Dekker, Publ New York. Now published. Find ref from library.

Mann IC. The development of the human eye. III The Lens 1928 Cambridge Univ Press, London.

Marner E. A family with eight generations of hereditary cataract. Acta Ophthalmol 1949;27: 537-551.

Marner E, Rosenberg T, Eiberg H. Autosomal dominant congenital cataract. Morphology and mapping. Acta Opthalmologica 1989;67: 151-158.

Marshall J, Beaconsfield M, Rottery S. The anatomy and development of the humen lens and zonules. Trans Ophthalmol Soc UK 1982;102: 423-439.

Mathias RT, Rae JL, Baldo GJ. Physiological properties of the normal lens. Physiol Rev 1997;77: 2150 .

Maumenee IH. Classification of hereditary cataracts in children by linkage analysis. Ophthalmol 1979;86: 1554-1558.

Merin S, Crawford JS. The etiology of congenital cataracts. Can J Ophthalmol 1971;1:1.

Mignon C, Fromaget C, Mattei M-G, et al. Assignment of connexin 26 (GJB20 and 46 (GJA3) genes to human chromosome 12q11-q12 and mouse chromosome 14D1-E1 by in situ hybridisation.

Cytogenet Cell Genet 1996;72: 185-186. 
Miller BA, Jaafar MS, Washington DC, et al. Chromosome 14- Terminal deletion and cataracts. Arch Ophthalmol 1992;110:1053.

Moross T, Vaithilingam SS, Styles S, et al. Autosomal dominant anterior polar cataracts associated with a familial 2;14 translocation. J Med Genet 1984;21: 52-53.

Muggleton-Harris A, Festing M, Hall M. A gene lcation for the ingeritance of the cataract Fraser (CatFr) mouse congenital cataract. Gen Res Camb 1987;49:235-239.

Mulders JWM, Hendriks W, Blankesteijn WM, et al. Lambda crystallin, a major rabbit lens protein is related to hydroxyacyl-coenzyme A dehydrogenases. J Biol Chem 1988;263:15462-15466.

Mulders JWM, Voorter CEM, Lamers C, et al. MP17, a fiber-specific intrinsic membrane protein from mammalian eye lens. Curr Eye Res 1988;7:207-219.

Nakano T, Yamamoto S, Kutsukade G, et al. Hereditary cataract in mice. Jpn J Clin Ophthalmol 1960;14:196.

Nene V, Dunne DW, Johnson KS, et al. Sequence and expression of a major egg antigen from Schistosoma mansoni: Homologies to heat shock proteins and $\alpha$-crystallins. Mol Biochem Parasitol 1986;21:179-88.

Nettleship E. On heredity in the various forms of cataract. Royal Lon Ophthalmol Hosp Reports. 1905;16:179.

Nettleship E. On some hereditary diseases of the eye. The Bowman Lecture (1909). Trans Ophthalmol Soc UK XXIX: LVII- CI.

Nettleship E. A peculiar form of hereditary congenital cataract. Trans Ophthalmol Soc UK. 1906;XXVI: 191-207.

Nettleship E. Seven new pedigrees of hereditary cataract. Trans Ophthalmol Soc UK 1909;XXIX:188-211.

Nickells RW, Browder LW. A role for glyceraldehyde-3-phsophate dehydrogenase in the development of thermotolerance in xenopus laevis embryos. J Cell Biol 1988;107: 1901-1909.

Norrie G. Arvelighed af graa stær. Ugeskr Lager 1896;5.rk III: 937-944.

O'Brien W, McInnes R, Kalumuck K, et al. Cloning and sequence analysis of cDNA for human argininosuccinate lysase. Proc Natl Acad Sci 1986;83:7211-7215.

Oda S-I, Watanabe K, Fujisawa $\mathrm{H}$, et al. Impaired development of lens fibres in genetic microphthalmia, Eye lens obsolescence, Elo, of the mouse. Exp Eye Res 1980;31:673-681.

Ozanics V, Jakobiec F: Prenatal development of the eye and its adnexae; in Jakobiec, Ocular anatomy, embryology and teratology, chapter 2,pp 11-96 (Harper \& Row, Philadelphia 1982).

Padma T, Ayyagari R, Murty JS, et al. Autosomal dominant zonular cataract with sutural opacities localized to chromosome 17q11-12. Am J Hum Genet 1995;57:840-845

Parks MM, Johnson DA, Reed GW. Long term visual results and complications in children with aphakia; a function of cataract type. Ophthalmology 1993;100:826-840.

Peters J, Searle AG. Linkage and synteny homologies in mouse and man. In: Lyon MF, Rastan S, Brown SDM, eds. Genetic Variants and Strains of the Laboratory Mouse. New York: Oxford University Press; 1996:1256-1312. 
Phelps Brown N, Bron AJ. (1996) Lens Disorders A Clinical manual of cataract diagnosis. Butterworth Heinemann, Oxford. pp23-28.

Phelps CD, Arafat NI. Open-angle glaucoma following surgery for congenital cataracts. Arch Ophthalmol 1977;95:1985-1987.

Piatigorsky J. Lens differentiation in vertebrates: A review of cellular and molecular features. Differentiation 1981;19: 134-153.

Piatigorsky J. Treton JA, King CR, et al. A molecular genetic approach to vision research: Crystallin gene expression in the lens. Ophthalmic Paediatr Genet 1983;3:6-72.

Piatigorsky J. Wistow GJ. Enzyme/crystallins: Gene sharing as an evolutionary strategy. Cell 1989;57:197-199.

Rae J, Kuszak J. The electrical coupling of epithelium and fibres in the frog lens. Exp Eye Res 1983;36:317-326.

Rao PV, Huang Q-L, Horwitz J, et al. Evidence that $\alpha$-crystallin prevents non-specific protein aggregation in the intact eye lens. Biochem Biophys Acta 1995;1245: 439-447.

Reese PD, Tuck-Miller CM, Maumenee IH. Autosomal dominant congenital cataract associated with chromosomal tranclocation [t(3;4)(p26.2;p15)] Arch Ophthalmol 1987;105:1382-1384.

Reizer J, Reizer A, Saier MH. The MIP family of integral membrane channel proteins. Curr Eye Biochem Mol Biol. 1993;28:235-257.

Renwick JH, Lawler SD. Probable linkage between a congenital cataract locus and the Duffy blood group locus. Ann Hum Genet 1963;27:67-84.

Riccardi VM. Chromosome imbalance in the aniridia-Wilms' tumor association: $11 \mathrm{p}$ interstitial deletion. Paediatrics 1978;61:604.

Rice NSC, Taylor D. Congenital cataract; A cause of preventable blindness in children. $B M J$ 1982;285(6342):581-582.

Richards J, Maumenee IH, Rowe S, et al. Congenital cataract possibly linked to haptoglobin. Cytogenet Cell Genet 1984;37: 570.

Robb RM, Petersen RA. Outcome of treatment for bilateral congenital cataracts. Ophthalmic Surg 1992;23:650-656.

Rodriguez IR, Gonzalez P, Zigler JS, et al. A splice-site deletion that causes a defective $\zeta$-crystallin is found in a congenital guinea pig cataract. Invest Ophthalmol Vis Sci 1991;32 (suppl), 782.

Rodriguez IR, Gonzalez P, Zigler JS, et al. A guinea pig hereditary cataract contains a splice site deletion in a crystallin gene. Biochem Biophys Acta 1992;1180: 44-52.

Rogaev EI, Rogaeva EA, Korovaitseva GI, et al. Linkage of polymorphic congenital cataract to the $\gamma$ crystallin gene locus on human chromosome 2q33-35. Hum Molec Genet 1996; 5;5:699-703.

Rubin SE, Nelson LB, Pletcher EA. Anterior polar cataract in two sisters with an unbalanced 3;18 chromosomal translocation. Am J Ophthalmol 1994;117:512-515.

Runge PE, Hawes NL, Heckenlively JR, et al. Autosomal dominant mouse' cataract (Lop-10). Invest Ophthalmol Vis Sci 1991;33:3202-3208.

Russell-Eggitt I, Zamiri P. Review of aphakic glaucoma after surgery for congenital cataract. $J$ Cataract Refract Surg 1997;23:664-668. 


\section{References}

Ryan SJ, Blanton FM,von Noorden GK. Surgery of congenital cataract. Am J Ophthalmol 1965;60:583-587.

Sæbø J. An investigation into the mode of heredity of congenital and juvenile cataracts. $B J$ Ophthalmol 1949: 601-629.

Sandilands A, Prescott AR, Carter JM, et al. Vimentin and CP49/Filensin form distinct networks in the lens which are independently modulated during lens fibre cill differentiation. $J$ Cell Sci 1995;108(4):1397-1406.

Sas DF, Sas MJ, Johnson KR et al Junctions between lens fibre cells are labelled with a monoclonal antibody shown to be specific for MP26. J Cell Biol 1985;100: 216-225.

Scott MH, Hejtmancik JF, Wozencraft LA, et al. Autosomal dominant congenital cataract. Interocular phenotypic variability. Ophthalmology 1994;101:866-871.

Segal S. Disorders of galactose metabolism. In The Metabolic basis of inherited disease. Vol 1. (eds Scriver, CR et al) 453-480. (McGraw-Hill, New York 1989).

Sidjanin DJ, Grimes PA, Pretsch W, et al. Mapping of the autosomal dominant cataract mutation (Coc) on mouse chromosome 16. IOVS 38: 2502-2507.

Shiels A, Griffen CS, Muggleton-Harris AL. Restriction fragment length polymorphisms associated with the gene for the major intrinsic protein of eye-lens fibre cell membranes in mice with hereditary cataracts, Biochem Biophys Acta 1991;1097: 81-85.

Shiels A, Griffen CS. Aberrant expression of the gene for lens major intrinsic protein in the CAT mouse. Curr Eye Res 1993;12:913-921.

Shiels A, Bassnett S. Mutations in the founder of the MIP gene family underlie cataract development in the mouse. Nature Genet 1996;12:212-215.

Shiels A, Mackay D, Ionides A, et al. A missense mutation in the human connexin50 gene (GJA8) underlies autosomal dominant 'zonular pulverulent' cataract on chromosome 1q. Am J Hum Genet 1998;62:526-532.

Shiels A, Mackay DM, Ionides A, et al. Connexin46 mutations in autosomal dominant congenital cataract. Am J Hum Genet 1999; In press (May 1999).

Shilloh Y, Donlon T, Bruns G, et al. Assignment of the human $\gamma$-crystallin gene cluster (CRYG) to the long arm of chromosome 2, region q33-36. Hum Genet 1986;73:17-19.

Siezen RJ, Anello RD, Thomson JA. Interactions of lens proteins. Concentration dependence of $\beta$ crystallin aggregation. Exp Eye Res 1986;43:293-303.

Simmoneau L, Herve B, Jacquiemin E, et al. State of differentiation of bovine epithelial cells in vitro. Cell Differ. 1983;13:185-190.

Sivak JG, Dovrat A. Embryonic lens of the human eye as an optical structure. Am J Optom physiol. Opt. 1987;64:599-603.

Skalka HW, Prchal JT. Presenile cataract formation and decreased activity of galactosemic enzymes. Arch Ophthalmol 98: 269-273.

Smith P. A pedigree of Doyne's discoid cataract. Trans Ophthalmol Soc UK 1910;XXX:37-42.

Sparkes RS, Mohandas T, Heinzmann C et al. The gene for the major intrinsic protein (MIP) of the ocular lens is assigned to human chromosome 12cen-q14. Invest Ophthalmol Vis Sci 1986;27:13511354. 
Sparrow JM, Bron AJ, Brown NAP, et al. Oxford Clinical cataract classification and grading system. Int Ophthalmol 1986;9:207-25.

Sparkes RS, Mohandas T, Gorin ṀB, et al. Assignmaent of a human beta-crystallin to 17cen-q23. Hum Genet 1986;74:133-136.

Spector A. An extrinsic membrane polypeptide associated with high molecular weight protein aggregates in human cataract. Science 1979;204:1323-1324.

Spector A, Chiesa R, Sredy J, et al. cAMP-dependent phosphorylation of bovine lens $\alpha$-crystallin. Proc Nat Acad Sci USA 1985;82:4712-4716.

Stabile M, Amoriello A, Capobianco ML, et al. Study of a form of pulverulent cataract in a large kindred. J Med Genet 1983;20: 419-421.

Stambolian D. Galactose and cataract. Survey of Ophthalmol 1988;32:333-349.

Stambolian D, Ai Y, Sidjanin D, Nesburn K, et al. Cloning of the galactokinase cDNA and identification of mutations in two families with cataracts. Nature Genet 1995;10: 307-312.

Stark WJ, Taylor HR, Michels RG, et al. Management of congenital cataracts. Ophthalmology 1979;86:1571-1578.

Stephan DA, Gillanders E, Vanderveen D, et al. Progressive juvenile-onset punctate cataracts caused by mutation of the gammaD-crystallin gene. Proc Natl Acad Sci USA 1999;96:1008-12.

Tardieu A, Delaye M. Eye lens proteins and transparency: from light transmission theory to solution X-ray structural analysis. Ann Rev Biophys Biophys Chem 1988;17:47-70.

Tayor VL, al Ghoul KJ, Lane CW, et el. Morphology of the normal human lens. IOVS 1996;37:1396410.

TenBroek E, Arneson M, Jarvis M, et al. The relationship between the fibre cell intrinsic membrane proteins MP20 and MP 70 in the mammalian lens. J Cell Sci 1992;103: 245-257.

Thomson J A, Augusteyn R C. Ontogeny of the human lens crystallins. Exp Eye Res. 1985;40:393410 .

Travis GH, Christerson L, Danielson PE, et al. The human retinal degeneration slow (RDS) gene: chromosome assignment and structure of the mRNA. Genomics 1991;10:733-739.

Tripathi BJ, Tripathi RC, Borisuth NSC, et al. Rodent models of congenital and hereditary cataract in man. Lens Eye Tox Res 1991;8:373-413.

Tulloh CG. Hereditary posterior polar cataract with report of a pedigree. Brit J Ophthalmol 1955;39:374.

Uga S, Kador PF, Kuwabara T. Cytological study of Philly mouse cataract. Exp Eye Res 1980;30:7992.

Van den Ijssel, Smulders RHPH, de Jong WW, et al. $\alpha$-crystallin: Molecular chaperone and heat shock protein. Opthalmic Res 1996;28:(suppl 1): 39-43.

Van Heyningen R. Flourescent compounds in the human lens. CIBA Found Symp 19: 151-164 (1973)

Van Leen RW, Van Roozenddaal KEP, Lubsen NH, et al. Differential expression of crystallin genes during development of the rat eye lens. Dev Biol 1987;120:457-464. 
Van Noort JM, Van Sechel AC, Bajramovic JJ, et al. The small heat-shock protein $\alpha \mathrm{B}$-crystallin as candidate autoantigen in multiple sclerosis. Nature 1995;375: 798-801.

Vérétout F, Delaye M, Tardieu A. Molecular basis of eye lens transparency. Osmotic pressure and Xray analysis of $\alpha$-crystallin solutions. $J$ Mol Biol 1989;205: 713-728.

Vogt A. Die spezifitat ander borener und erworbener starformer fur die einzelnen linsezonene. Albrecht Von Graefes Arch Klin Ophthalmol 1922;108: 219-228.

Vogt. Klin Mbl Augenheilk 62: 582 (1919). Atlas, Berlin (1921).

Vogt A. Lens and zonule. In Vol II Textbook and atlas of the living eye.Pub JP Weyenborgh. Bonn 1979.

Wallace DK, Plager DA. Corneal diameter in childhood aphakic glaucoma. J Pediatr Ophthalmol Strabismus 1996;33:230-234.

Willecke K, Jungbluth S, Dahl E, et al. Six genes of the human connexin gene family coding for gap junctional proteins are assigned to four different human chromosomes. Eur J Cell Biol 1990;53:275280.

Wistow G. Piatigorsky J. Recruitment of enzymes as lens strucural proteins. Science 1987;236:15541556.

Wistow GJ, Piatigorsky J. Lens crystallins: The evolution and expression of proteins for a highly specialised tissue. Ann Rev Biochem 1988;57:479.

Wistow GJ, Piatigorsky J. Lens crystallins: The evolution and expression of proteins for a highly specialised tissue. Ann Rev Biochem 1988;57:479-504.

Wistow G. The Ubiquitous crystallins: Stress protein recruites to the lens. In Molecular biology and evolution of crystallins: Gene recruitment and multifunctional proteins in the eye lens. Pub SpringerVerlag. Heidelberg, Germany. 1995.

Yates JRW. Recent advances. Medical genetics. BMJ 312:1021-1025.

Yokoyama Y, Narahara K, Tsuji K, et al. Autosomal dominant congenital cataract and microphthalmia associated with a familial $\mathrm{t}(2 ; 16)$ translocation. Hum Genet 1992;90:177-178.

Zampighi GA, Hall JE, Ehring GR, et al. The structural organisation and protein composition of lens fibre junctions. $J$ Cell Biol. 1989;108:2255-2275.

Zampighi GA, Simon SA, Hall JE. The specialised junctions of the lens.Int Rev Cytol 1992;136:185225.

Zigler JS. Animal models for the study of maturity onset and hereditary cataract. Exp Eye Res 1990;50: 651-657.

Zigman S. Selected aspects of lens differentiation. Biol Bull 1985;168:189-213. 
References

$\lambda$ 


\section{Appendices}

Appendix 1. Pedigrees 156

Appendix 2. Publications arising from this work $\quad 164$

Appendix 3. Presentations arising from this work 165 


\section{Pedigrees}

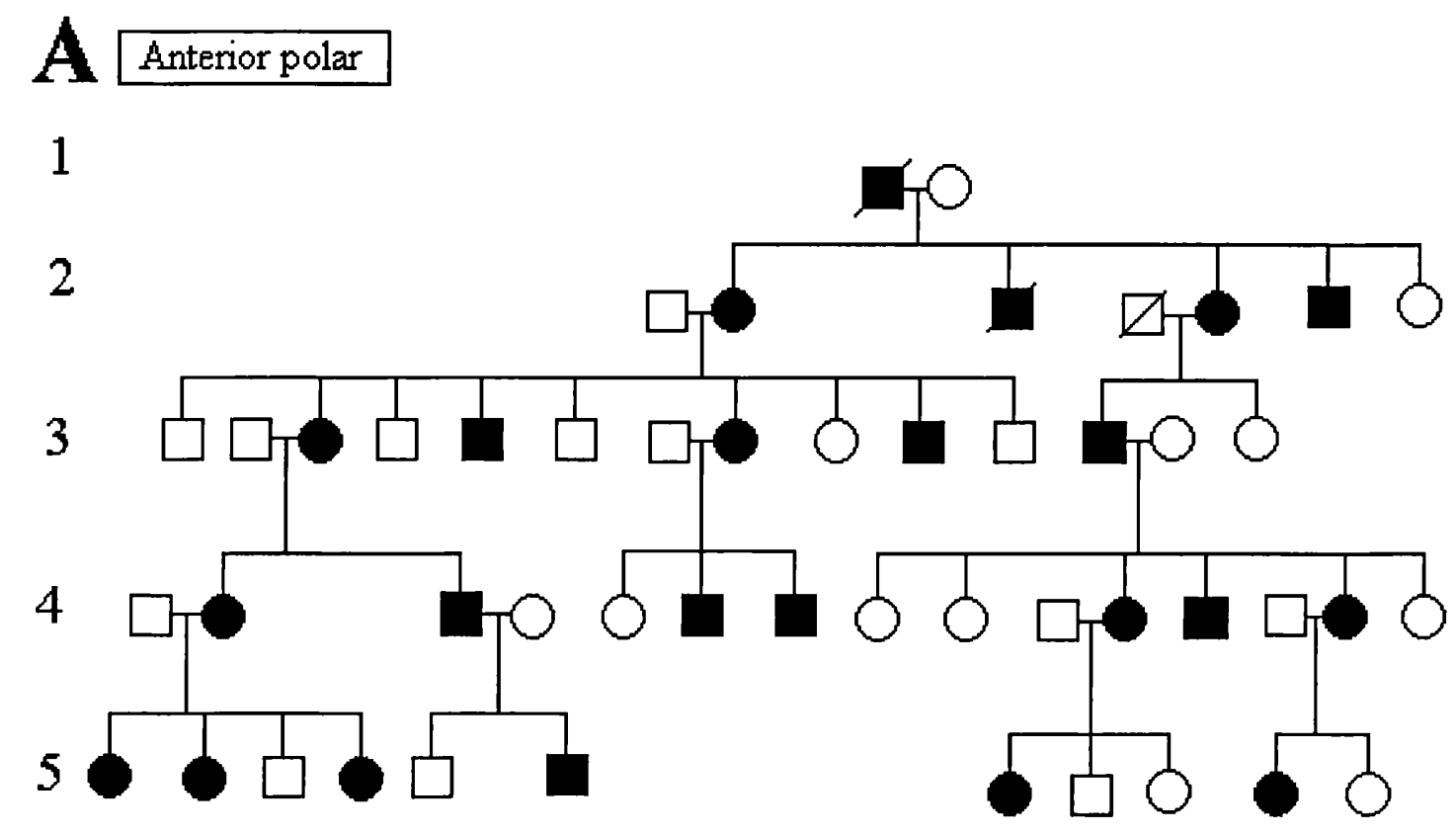

B Stationary posterior polar

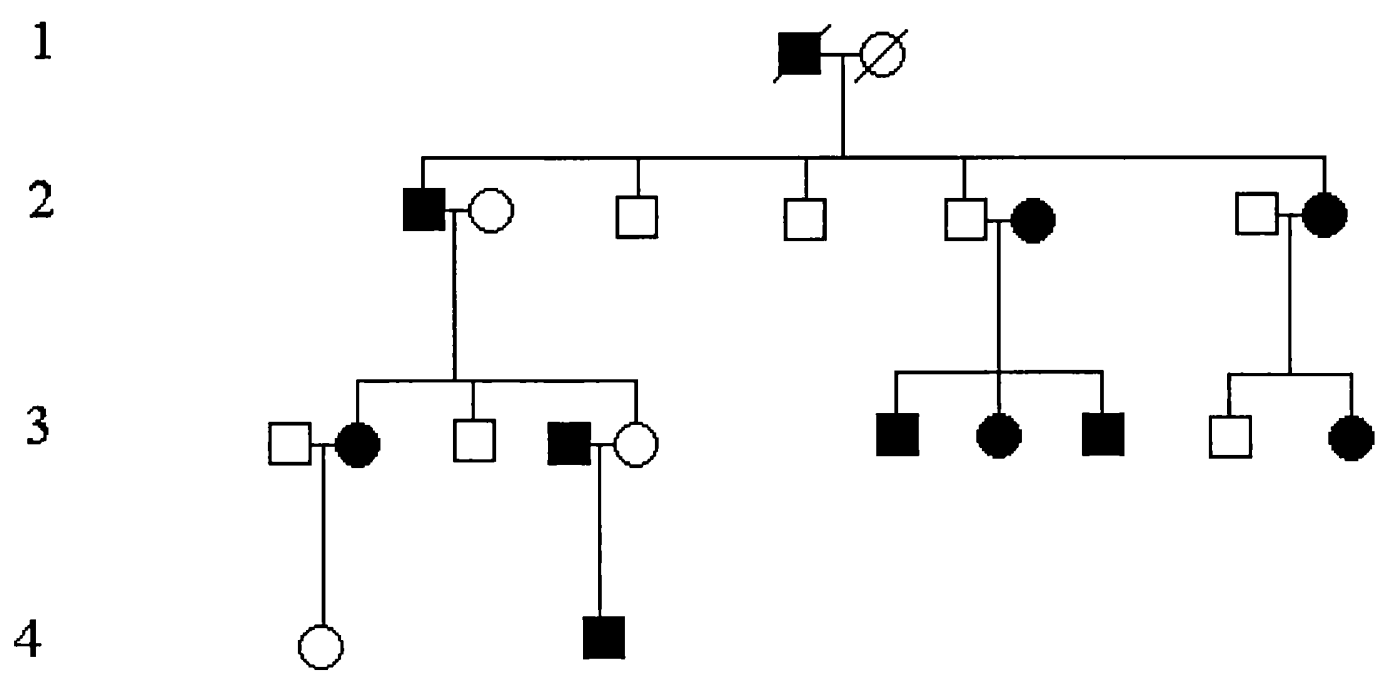




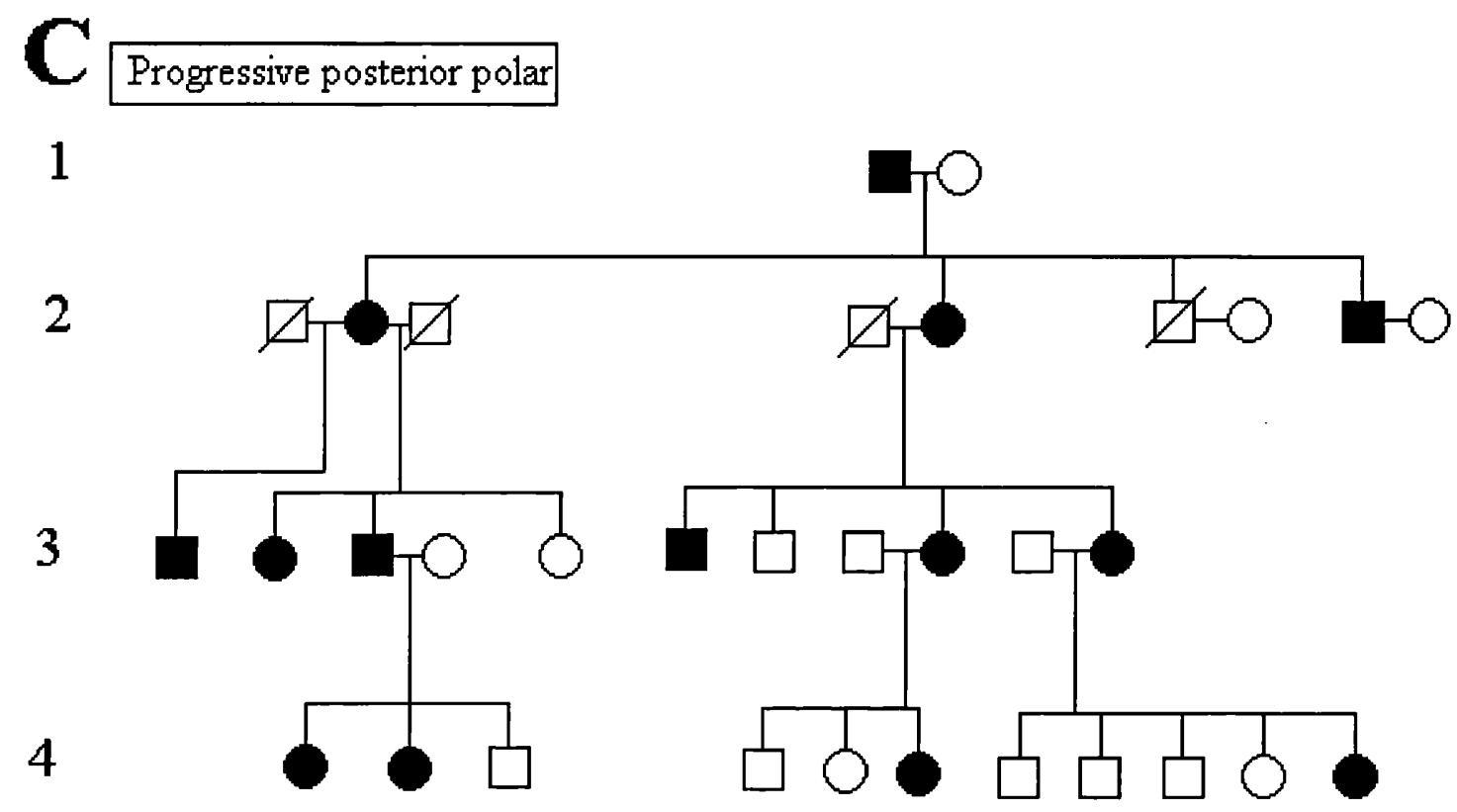

$D_{1}$ Nuclear

2

3

4

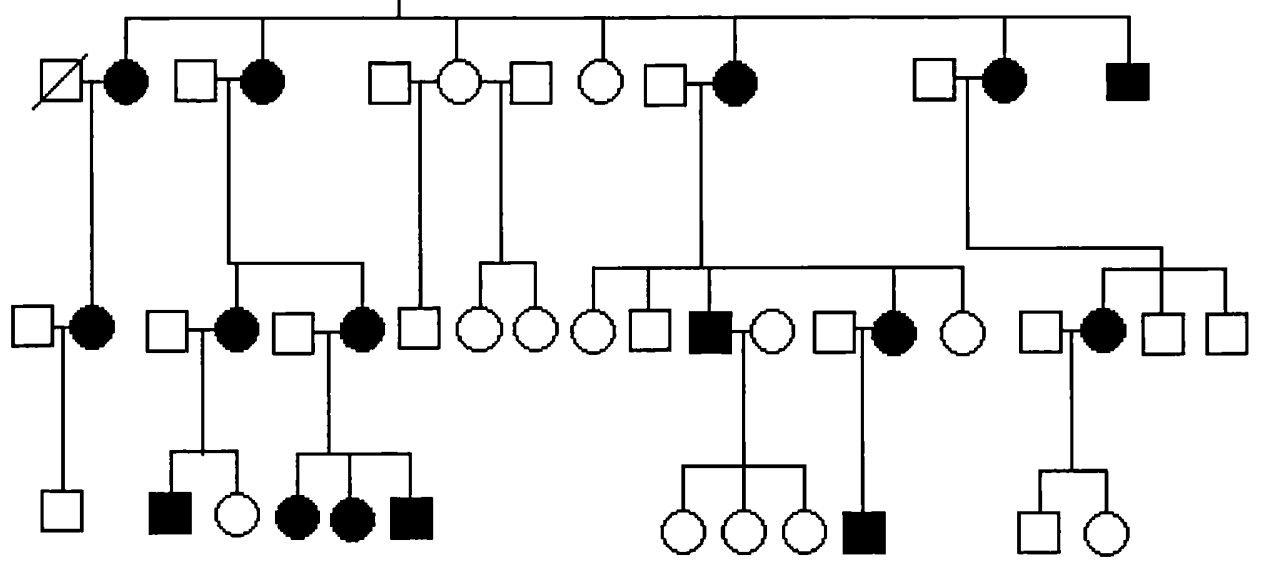


E Nuclear (CCL)

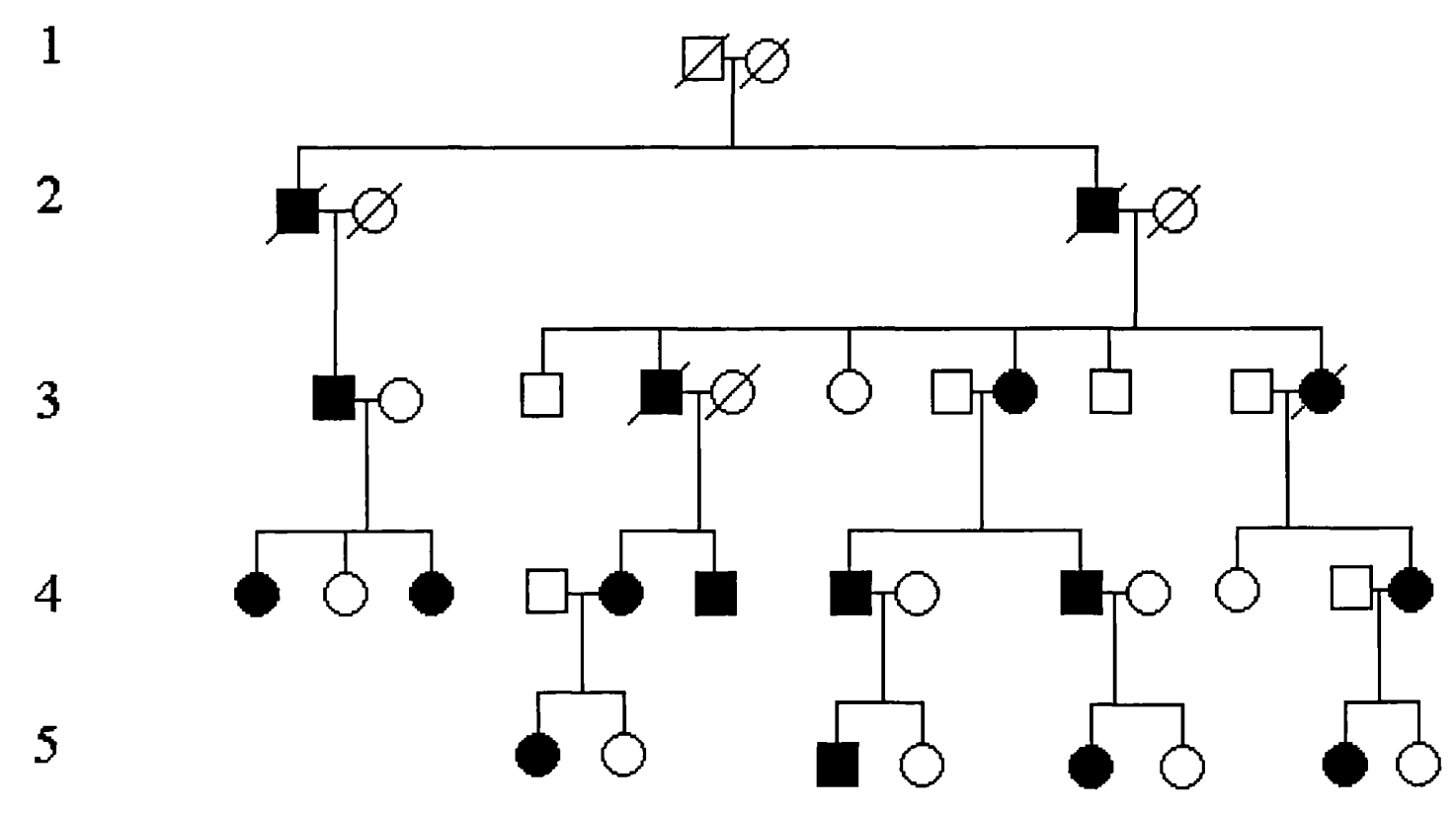

F Lamellar

1

2

3

1

2

3

4

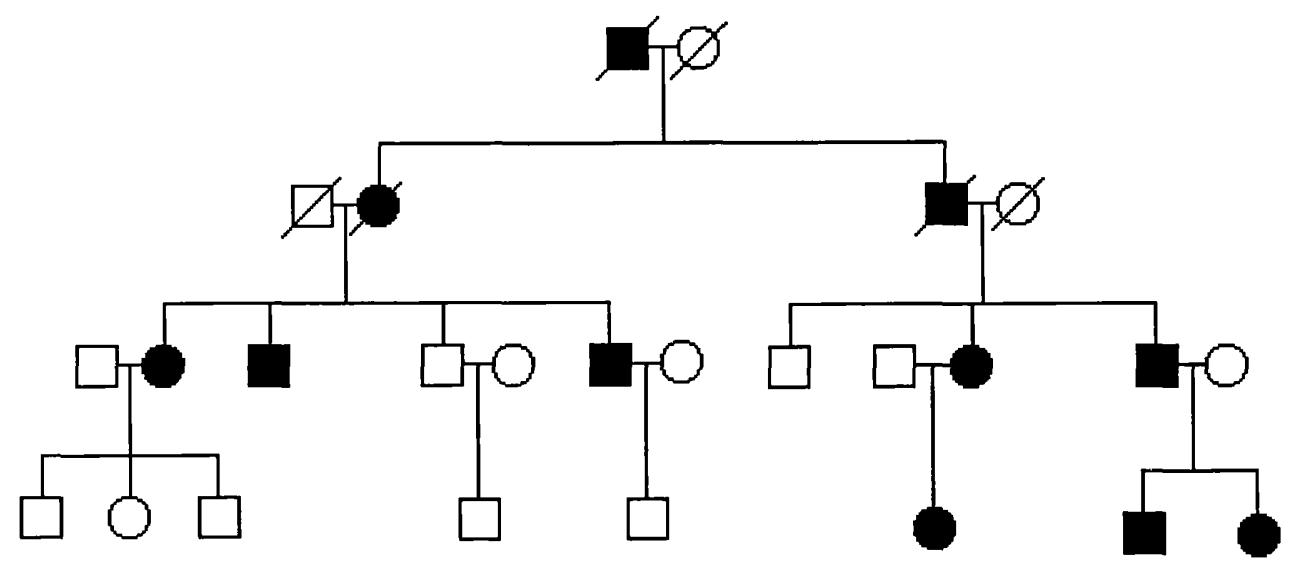



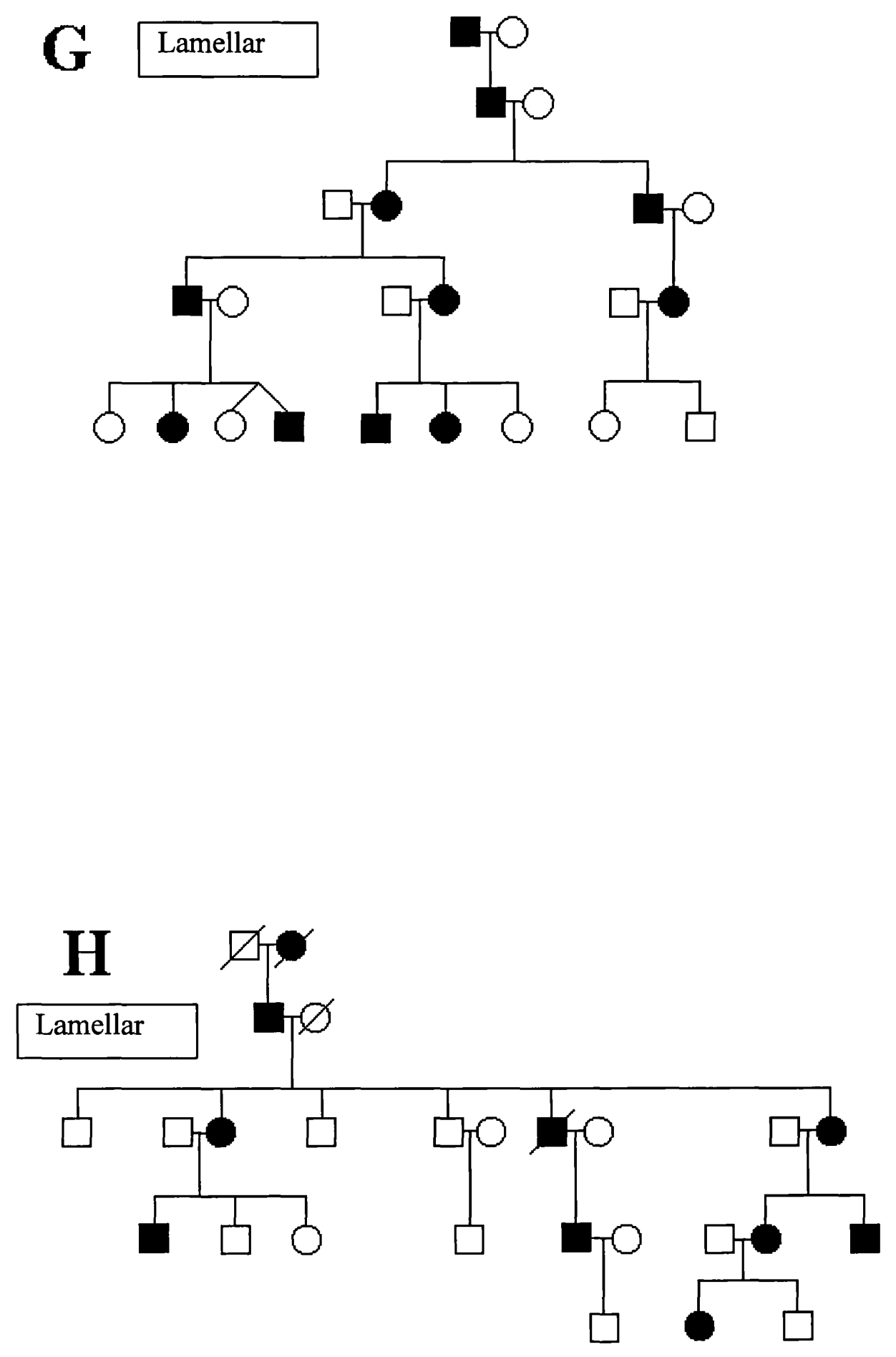

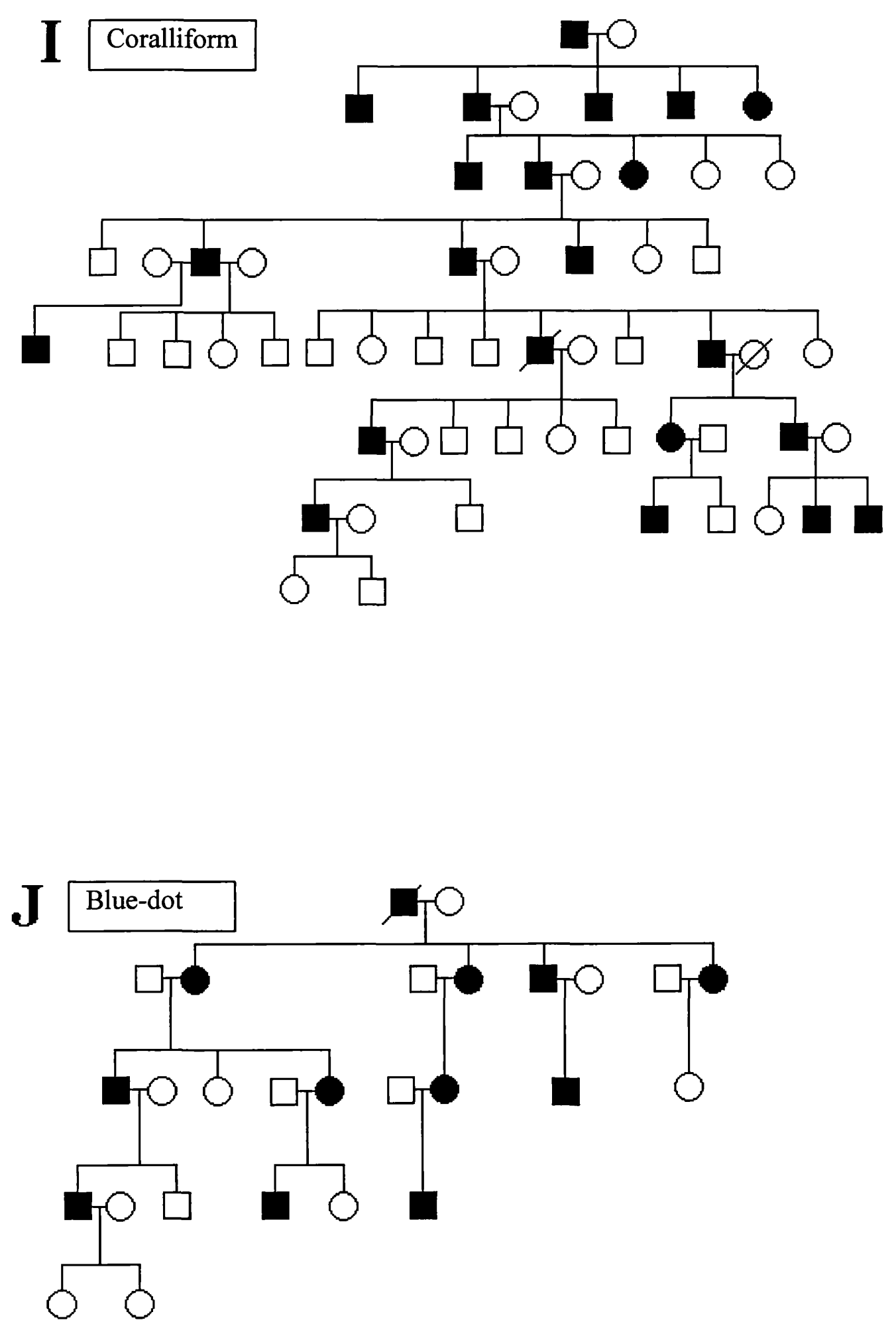

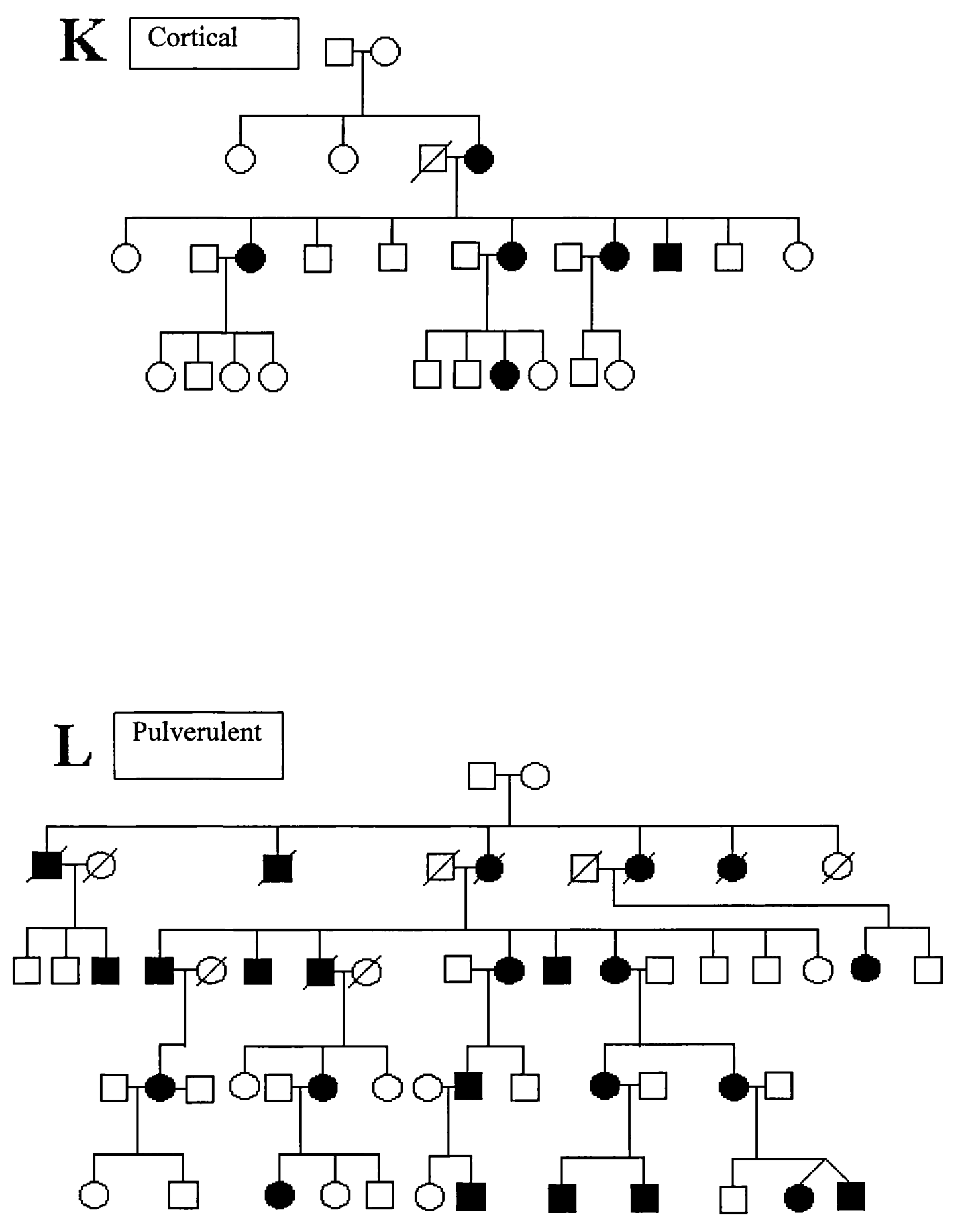

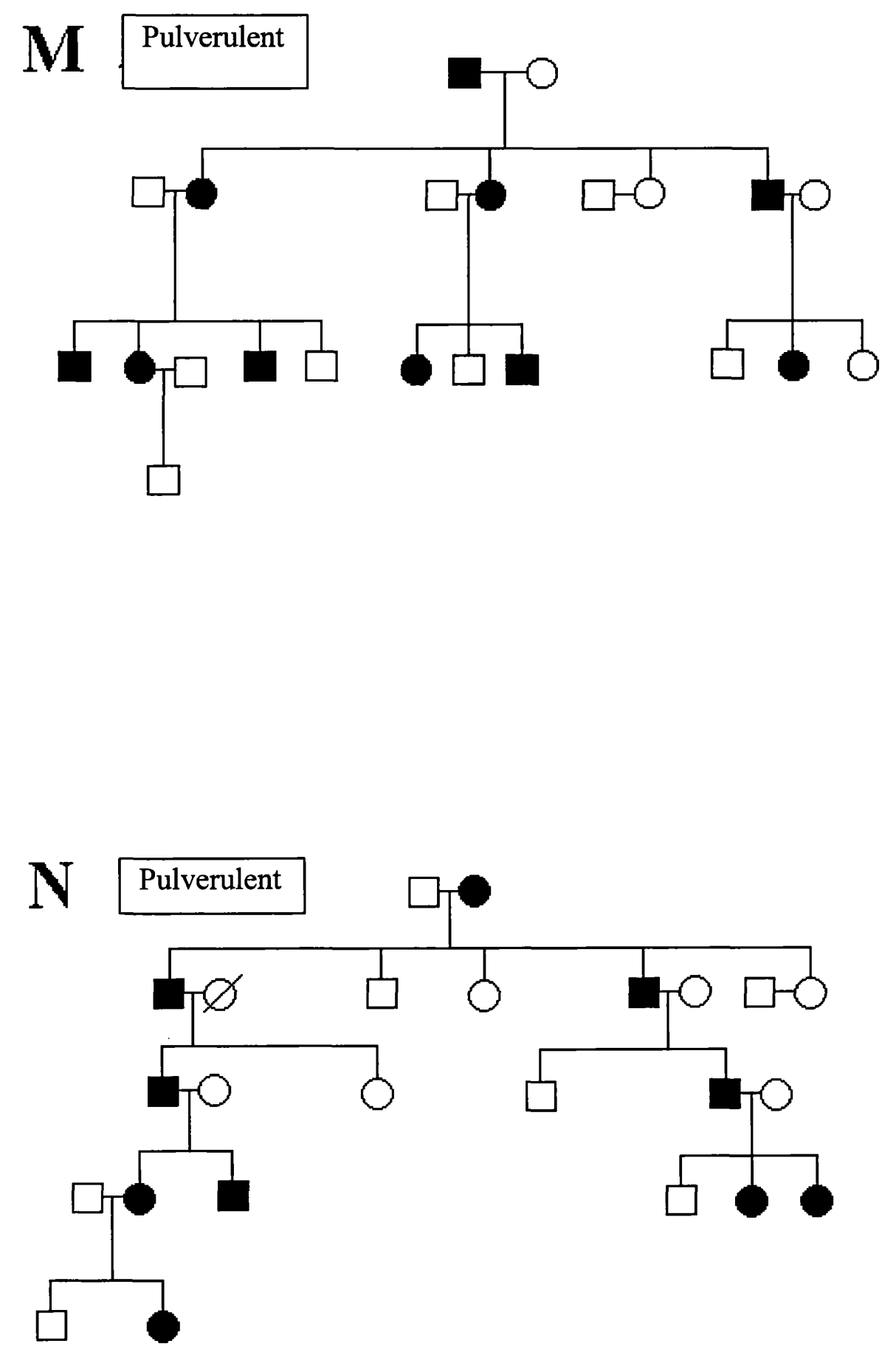

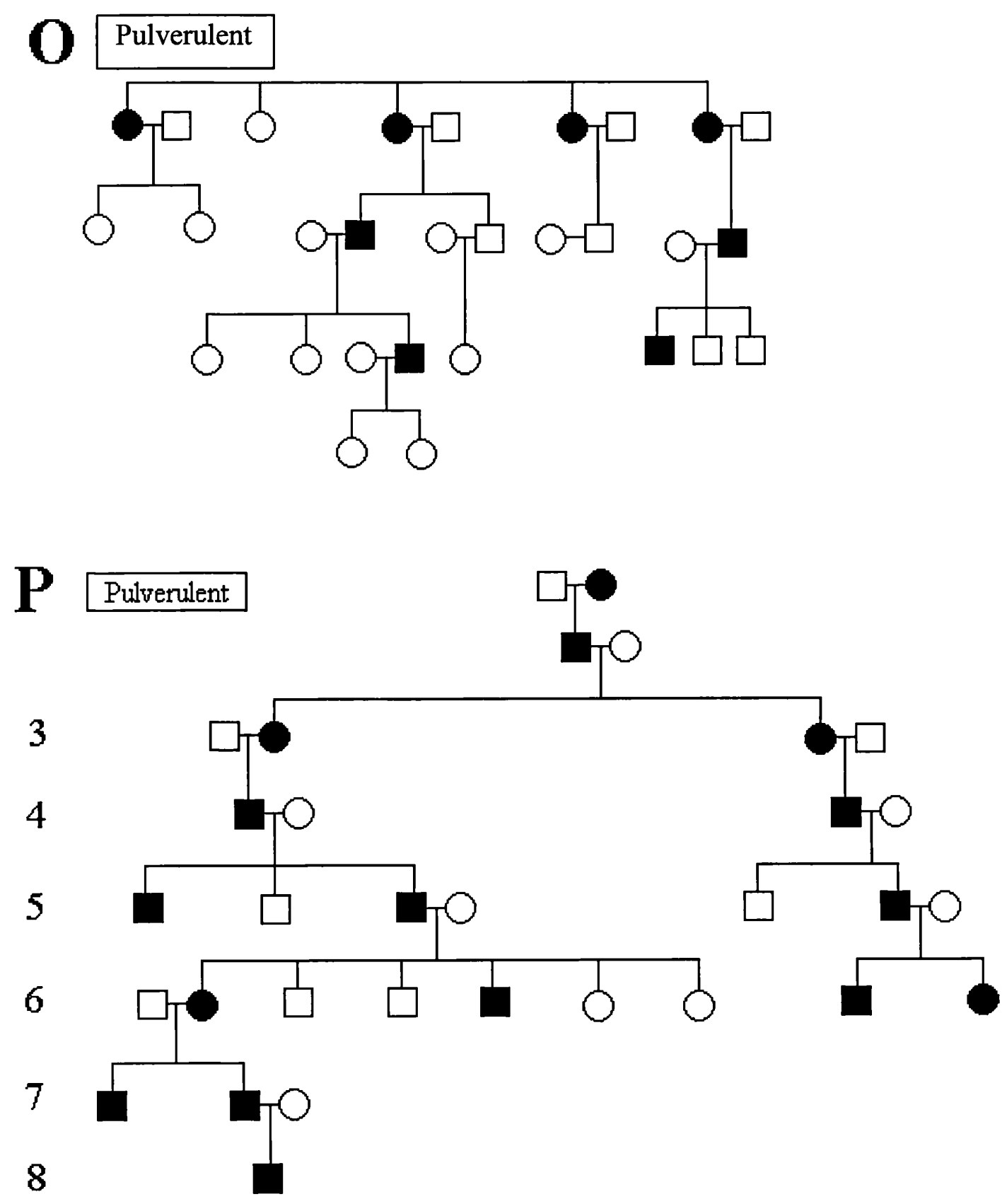


\section{Publications}

Ionides ACW, Francis P, Berry V, Mackay D, Bhattacharya SS, Shiels A, Moore AT. The clinical and genetic heterogeneity of autosomal dominant cataract. B J Ophthalmol.1999;83:802-808.

Mackay DM, Ionides A, Kibar Z, Rouleau G, Berry V, Moore A, Shiels A, Bhattacharya SS. Connexin46 mutations in autosomal dominant congenital cataract. Am J Hum Genet 1999;64:1357-1364.

Berry V, Mackay D, Khaliq S, Francis P, Hemeed A, Anwar K, Mehdi SQ, Newbold RJ, Ionides A, Moore T, Bhattacharya SS. Connexin 50 mutation in a family with congenital 'zonular nuclear' pulverulent cataract of Pakistani origin. Hum Genet 1999;105:168-170.

Ionides ACW, Berry V, Mackay D, Bhattacharya SS, Shiels A, Moore AT. Phenotypic variation in a single pedigree with anterior polar cataract. Eye 1998;12:234-236.

Shiels A, Mackay D, Ionides A, Berry V, Moore A, Bhattacharya S. A missense mutation in the human connexin 50 gene (GJA8) underlies autosomal dominant 'zonular pulverulent' cataract on chromosome 1q. Am J Hum Genet 1998;62:526-532.

Mackay DM, Ionides ACW, Berry V, Moore AT, Bhattacharya SS, Shiels A. Autosomal dominant 'zonular pulverulent' cataract linked to human chromosome 13. Am J Hum Genet. 1997;60:1474-1478.

Ionides ACW, Berry V, Moore AT, Plant C, Bhattacharya SS, Shiels A. A locus for autosomal dominant posterior polar cataract on chromosome 1p.Human Molecular Genetics 1997; 6:47-51.

Berry V, Ionides ACW, Moore AT, Plant C, Bhattacharya SS, Shiels A. A locus for autosomal dominant anterior polar cataract on chromosome 17p.Human Molecular Genetics 1996;5:415-419.

Ionides ACW, Berry V, Shiels A, Moore AT, Bhattacharya SS The Clinical and Genetic Heterogeneity of Autosomal Dominant Cataract. Acta Ophthalmologica Scand. 1996; 74(Suppl 219):40-41.

Francis PJ, Ionides ACW, Berry V, Bhattacharya SS, Moore AT. Visual outcome in patients with isolated autosomal dominant congenital cataract. In press. 


\section{Presentations}

Various aspects of this work have been presented at the following meetings.

Autosomal Dominant Cataract. Ionides ACW, Moore AT.

Sep 1995

European Paediatric Ophthalmology Group. Cambridge.UK.

Molecular Genetics of Autosomal Dominant Cataract. Ionides

Jan 1996

ACW, Bhattacharya SS, Moore AT. Moorfields Alumni.

London. UK.

An Autosomal Dominant Anterior Polar Cataract is linked to the

Apr 1996 short arm of human chromosome 17. Shiels A, Berry V, Ionides ACW, Moore AT, Bhattacharya SS. The Association for Research in Vision and Ophthalmology. Florida, USA.

A Clinical Classification for autosomal dominant cataract.

Apr 1996 Ionides ACW, Berry V, Mackay D, Shiels A, Bhattacharya SS, Moore AT. The Association for Research in Vision and Ophthalmology. Florida, USA.

Autosomal Dominant Cataract. Ionides ACW, Berry V, Mackay D, Shiels A, Bhattacharya SS, Moore AT. Royal May 1996 College of Ophthalmologists Annual Congress. Edinburgh, Scotland.

Morphological classification of autosomal dominant cataract.

Jun 1996 ACW Ionides, SS Bhattacharya, AT Moore. International Infantile Cataract Symposium. Great Ormond Street, London.

Phenotypic variation in a single pedigree of anterior polar cataract. Ionides ACW, Berry V, Mackay D, Shiels A, Bhattacharya SS, Moore AT Oxford Congress. UK.

Genes for human cataract. Ionides ACW, Berry V, Mackay D Shiels A, Bhattacharya SS, Moore AT. Moorfields Alumni. London.

Mapping genes for human cataract. Ionides ACW, Berry V, April 1997 Mackay D, Shiels A, Bhattacharya SS, Moore AT. Royal College of Ophthalmologists Annual Congress. Birmingham, England.

An autosomal dominant posterior polar cataract is linked to the May 1997 short arm of chromosome 1. Ionides ACW, Berry V, Mackay 
D, Shiels A, Bhattacharya SS, Moore AT The Association for Research in Vision and Ophthalmology. Florida, USA.

Autosomal dominant 'zonular pulverulent' cataract is linked to May 1997 human chromosome 13. Mackay D, Ionides ACW, Berry V, Shiels A, Bhattacharya SS, Moore AT. The Association for Research in Vision and Ophthalmology. Florida, USA.

Phenotypic variation and linkage analysis in a single pedigree affected by autosomal dominant stationary posterior polar cataract. Ionides ACW, Berry V, Mackay D, Shiels A, Bhattacharya SS, Moore AT. Royal College of Ophthalmolgists Annual Congress. Glasgow.

A connexin gene mutation causes human cataract. Ionides April 1998 ACW, Berry V, Mackay D, Shiels A, Bhattacharya SS, Moore April 1998 AT. Royal College of Ophthalmolgists Annual Congress. Glasgow. The Association for Research in Vision and Ophthalmology. Florida, USA.

Visual Outcome in patients with dominantly inherited cataract. Ionides ACW, Francis P, Berry V, Mackay D, Shiels A, Bhattacharya SS, Moore AT. ARVO Royal College of Ophthalmolgists annual congress. Cardiff, UK.

Genes for human cataract. Ionides ACW, Berry V, Mackay D, Shiels A, Bhattacharya SS, Moore AT. EVER, Palma, Mallorca. 


\title{
The clinical and genetic
}

\section{heterogeneity of autosomal dominant cataract}

\author{
Alexander Ionides ${ }^{1}$, Vanita Berry ${ }^{1}$, Tony Moore $^{2}$, \\ Shomi Bhattacharya ${ }^{1}$ and Alan Shiels ${ }^{1}$ \\ Institute of Ophthalmology ${ }^{1}$, University Colleze London and \\ Moorfields Eye Hospital ${ }^{2}$, London, UK
}

\begin{abstract}
As part of a linkage study we have reviewed over 150 patients with autosomal dominant cataract and suggest a clinical classification of the different phenotypes consisting of anterior and posterior polar, nuclear, cortical, blue-dot, lamellar, coralliform and pulverulent cataracts.
\end{abstract}

Key words: autosomal dominant cataract - clinical phenotypes.

Acta Ophthalmol. Scand. 1996: 74 (Suppl 219): 40-41

$\mathrm{T}$ here are now six loci known to be important in the development of autosomal dominant cataract. The first was discovered in 1963 by Renwick \& Lawler and in 1995 the team including Mette Warburg showed linkage of the Volkmann cataract to the short arm of chromosome 1 . During this time the precise genetic mutation has been identified at only one locus. There are many different phenotypes and it is likely that more loci will be shown to be involved in the formation of cataract.

\section{Clinical heterogeneity}

Autosomal dominant cataract is a collection of disorders that vary in morphology, in the effect on visual acuity, the age at presentation and the need for surgery. There is no agreed classification for autosomal dominant cataract and this has resulted in confusion as to the: terminology used in the descriptionus of the different phenotypes.

Cataract phenotypes have largely been narmed after the affected family, as in the Coppock and Volkmann cataracts, or after the ophthalmologist in- volved in their care, as in the Marner cataract.

In a study of over 150 affected patients with autosomal dominant cataract we have identified several distinct phenotypes; anterior polar, posterior polar, nuclear, cortical, blue-dot (cerulean), lamellar (zonular), coralliform and pulverulent. This clinical classification covers all the phenotypes encountered so far in this study. The phenotypes run true throughout the pedigrees in all the phenotypes except the pulverulent cataract. Families affected by pulverulent (dust-like) cataract show great heterogeneity between individuals and even between the eyes of an individual. This was also found to be the case in the family published by Scott et al. (1994). The dust like opacities may be confined to the Y-sutures. the nucleus or may be more widely spread to different regions of the lens. The dust-like, powdery opacities may even be so numerous as to create a total cataract. The zonular pulverulent. Coppock-like, Marner and perhaps the Volkmann cataract, could all be referred to as pulverulent under our classification.

\section{Genetic heterogeneity}

One of the first human diseases to be linked to a chromosomal site was the zonular pulverulent cataract (see Table 1). This is an autosomal dominant cataract ocurring in a family originally studied at the turn of the century by Nettleship (1909). Linkage with the Duffy blood group was discovered by Renwick \& Lawler (1963), and the Duffy blood group was later assigned to chromosome 1q (Donahue et al. 1968). This cataract is often incorrectly called the Coppock cataract. However, the Coppock cataract, described by Nettleship \& Ogilvie (1906) is a different phenotype and was later referred to as a central pulverulent cataract owing to the powdery opacities being central and not "zonular". The Coppock cataract is named after the affected family that originally came from Oxford (UK) and has not been included in any published linkage study.

The Coppock-like cataract (central pulverulent cataract) was the next phenotype to be linked (Lubsen et al. 1986) and is different from the zonular pulverulent cataract studied by Renwick and Lawler. In the Coppock-like cataract, first described by Harman (1910), the powdery opacities are restricted to the embryonic nucleus only, as in the central pulverulent (Coppock) cataract. The chromosome 1q cataract of Renwick \& Lawler (1963) differed from this in that it had powdery opacities in the central part of the lens bounded by a thin layer of fine opacities with opacities occasionally in the outer zones, hence the name, zonu- 
Table 1. Autosomal dominant cataract loci.

\begin{tabular}{lll}
\hline Zonular pulverulent & 1q21-25 & Renwick \& Lawler (1963) \\
Coppock-like & 2q33-36 & Lubsen et al. (1987) \\
Posterior polar & $16 q 22.1$ & Maumenee (1979) \\
Marner & $16 \mathrm{q} 22.1$ & Eiberg et al.(1988) \\
Blue-dot (cerulean) & $17 \mathrm{q} 24$ & Armitage et al.(1995) \\
Volkmann & $1 \mathrm{p} 36$ & Eiberg et al. (1995) \\
Zonular-sutural & $17 \mathrm{q} 11-12$ & Padma et al.(1995)
\end{tabular}

lar pulverulent cataract. Lubsen et al. (1986) showed the Coppock-like cataract to be linked to the $\gamma$-crystallin gene complex on chromosome 2 . The underlying mutation has now been shown to result in the activation of the $\gamma$ E-crystallin pseudogene (Brakenhoff et al. 1994).

Two other phenotypes, that differ in their morphology have been linked to the haptoglobin gene on 16q. A posterior polar cataract was possibly linked to the haptoglobin gene by Maumenee (1979) with a lod score of 1.8 at $\theta=0$, and the Marner cataract was later linked to the same site by Eiberg et al. (1988). The phenotype of the Marner cataract was described as “... fine, dispersed, pulverulent opacities in the embryonic nucleus. In the outer zone of this nucleus, equatorially orientated, linear condensations are found ... opposite the extremities of the anterior Y-suture." (Marner et al. 1989). From this description it can be appreciated that the form of the opacities is pulverulent in nature, but differs in the distribution of the powdery opacities. Under our classification this would be termed a pulverulent cataract.

With the development of microsatellite DNA markers covering the entire human genome (Gyapay et al. 1994), it is now possible to undertake gene mapping studies for autosomal dominant cataract loci. A blue-dot (cerulean) cataract has been linked to $17 q$ and Armitage et al. (1995) have proposed that the closely linked galactokinase gene may be involved, as a deficiency in this enzyme is associated with cataract. The Volkmann cataract has been mapped to $1 \mathrm{p}$ and Eiberg et al. (1995), have proposed that the enolase gene is involved on the basis that this enzyme has been recruited as tau crystallin in lower vertebrates. The Volkmann cataract is described as being “... a progressive, central, and zonular cataract, with opacities both in the embryonic, fetal and juvenile nucleus and around the anterior and posterior Y-suture." In a previous study of the same family the lens opacity is described as having "multiple discrete round opacities ... in the embryonic, fetal and juvenile nucleus." Finally, a zonular-sutural cataract has been linked to 17q and Padma et al. (1995) have proposed that the $\beta \mathrm{A} 3 / \mathrm{A} 1$ crystallin gene is a strong candidate for this phenotype. The pedigree is described as having "intra-familial phenotypic heterogeneity. Opacities vary from a uniform dense opacity to a collection of fine dots forming a hazy cloud." Both the Volkmann and the zonular-sutural cataract have similarities to pulverulent cataracts and could be classified within this group.

\section{Conclusion}

As more linkage information becomes available and the genetic aetiology undestood, a genetic classification of autosomal dominant cataract will be possible. Nonetheless, a simple clinical classification is needed to enable clinicians to compare phenotypes and to allow a more accurate prognosis to be given. Although it is likely that there will be variation in the pattern of lenticular opacities with mutations at different loci we have found that in the majority of families with autosomal dominant cataract, the phenotype can be identified as one of eight distinct types.

\section{References :}

Armitage MM, Kivlin JD \& Ferrell RE (1995): A progressive early onset cataract gene maps to human chromosome $17 \mathrm{q} 24$. Nature Genet 9: 37-40.
Brackenhoff RH, Henskens HAM, vanRossum MWPC, Lubsen NH \& Schoenmakers JGG (1994): Activation of the $\gamma \mathrm{E}$ crystallin pseudodogene in the human hereditary Coppock-like cataract. Hum Molec Genet 3: 279-283.

Donahue RP et al. (1968): Probable assignment of the Duffy blood group locus to chromosome 1 in man. Procl Natl Acad Sci USA 61: 949-955.

Eiberg H, Marner E, Rosenberg T \& Mohr J (1988): Marner's cataract (CAM) assigned to chromosome 16: Linkage to haptoglobin. Clin Genet 34: 272-275.

Eiberg H, Lund AM \& Warburg M (1995): Assignment of congenital cataract Volkmann type (CCV) to chromosome $1 \mathrm{p} 36$. Hum Genet 96: 33-38.

Harman NB (1910): Ten pedigrees of congenital and infantile cataract, lamellar, coralliform, discoid and posterior polar with microphthalmia. Trans Ophthalmol Soc UK 30: 251-274.

Hearne CM, Ghosh S \& Todd JA (1992): Microsatellites for linkage analysis of genetic traits. TIG Vol 8, 8: 288-294.

Lubsen NH, Renwick JH, Tsui LC, Breitman ML \& Schoenmakers JGG (1987): A locus for a human hereditary cataract is closely linked to the gamma- crystalin gene family. Procl Natl Acad Sci USA 84: 489-492.

Maumenee IH (1979): Classification of hereditary cataract in children by linkage analysis. Ophthalmology 86: 1554-1558.

Nettleship E \& Ogilvie FM (1906): A peculiar form of hereditary cataract. Trans Ophthalmol Soc UK 26: 191-207.

Nettleship E (1909): Seven new pedigrees of hereditary cataract. Trans Ophthalmol Soc UK 29: 188-211.

Padma T et al.(1995): Autosomal Dominant Zonular Cataract with Sutural Opacities Localized to Chromosome 17q11-12. Am J Hum Genet 57: 840-845.

Renwick JH \& Lawler SD (1963): Probable linkage between a congenital cataract locus and the Duffy blood group locus. Ann Hum Genet 27: 67-84.

Scott MH, Hejtmancik F, Wozencraft LA, Reuter LM, Parks MM \& Kaiser-Kupfer MI (1994): Autosomal dominant congenital cataract. Interocular phenotypic variability. Ophthalmology 101: 866-871.

Corresponding author:

Alexander Ionides

Institute of Ophthalmology

University College London

Bath Street

London EC1V 9EL, UK. 


\title{
Anterior polar cataract: clinical spectrum and genetic linkage in a single family
}

\begin{abstract}
Anterior polar cataract can occur as a sporadic finding, in association with other ocular abnormalities or as an inherited, autosomal dominant disorder. We have demonstrated linkage in a family with autosomal dominant anterior polar cataract to the short arm of chromosome 17, locating the gene to the region 17p12-13. All affected members of this large family had an opacity at the anterior pole of the lens that varied only in size and the effect on visual acuity. Anterior polar cataract is thought to have a minimal effect on visual acuity although in the affected members of this family there was a high incidence of unilateral amblyopia.
\end{abstract}

Key words Anterior polar, Cataract, Autosomal dominant, Linkage, Phenotype

Inherited cataract is a significant cause of visual impairment in childhood and is most often transmitted as a congenital autosomal dominant (AD) trait. ${ }^{1}$ Eight different loci have now been mapped for $\mathrm{AD}$ cataract $^{2-9}$ but the underlying

A. Ionides

V. Berry

D. Mackay

A. Shiels

S. Bhattacharya

Department of Molecular

Genetics

Institute of Ophthalmology London EC1V 9EL, UK

\section{A. lonides}

A. Moore

Moorfields Eye Hospital

City Road

London EC1V 2PD, UK

Tel: $+44(0) 1712533411$

Fax: +44 (0)1712534696

A. Moore

Addenbrooke's Hospital Cambridge

UK

Presented at the Oxford Congress, July 1996 genetic abnormality is known in only one case: the Coppock-like cataract has been shown to be related to the overexpression of a $\gamma$-crystallin pseudogene. ${ }^{10}$ We have demonstrated linkage of an $\mathrm{AD}$ anterior polar cataract (APC) to the short arm of chromosome $17^{11}$ in a single family and in this paper describe the clinical spectrum of the disease.

\section{Patients and methods}

The patients were from a large family with $\mathrm{AD}$ anterior polar cataract (Fig. 1) identified from the genetic data base at Moorfields Eye Hospital. Family members were invited to attend the hospital for an eye examination. The lens was examined by slit lamp and anterior segment photography was taken where possible. Blood was taken for DNA extraction to be used for the linkage analysis.
ALEXANDER IONIDES, VANITA BERRY, DONNA MACKAY, ALAN SHIELS, SHOMI BHATTACHARYA, ANTHONY MOORE

\section{Results}

The results of the molecular genetic study demonstrating linkage of the anterior polar cataract in this family to chromosome $17 p$ have already been published. ${ }^{11}$ Anterior polar cataracts were seen in all the affected family members. Thirty family members were examined and 19 found to be affected. Seven patients had undergone surgery and the phenotype was examined in the remaining 12 cases. The opacity was always in the same position of the lens, the anterior pole, but varied in severity. The larger opacities were pyramidal with a base of $4 \mathrm{~mm}$ and extended into the anterior chamber (Figs. 2, 3), whilst the smaller opacities consisted of a flat plaque measuring less than $1 \mathrm{~mm}$ in diameter (Figs. 4, 5). In one case the only sign of an anterior pole abnormality was an irregularity of the anterior capsule (Fig. 6). Seven of the affected patients underwent surgery, all between the age of 1 and 6 years, with a final visual acuity of $6 / 18$ to NPL. Two patients who had a visual acuity of NPL had both developed glaucoma and retinal detachment. One affected patient who had not undergone surgery but had minimal opacities had a visual acuity of $6 / 6$ in both eyes.

Ten of the 12 affected patients who had not undergone surgery were amblyopic in one eye with a visual acuity of $6 / 12$ to $6 / 36$ in the worse eye. The amblyopic eye was always the eye with the larger opacity.

\section{Discussion}

Anterior polar cataract has been reported to have a minimal effect on visual acuity. ${ }^{12,13}$ In this family unilateral amblyopia was common, suggesting that children with anterior polar cataracts should be offered regular follow-up. ${ }^{14}$ The unoperated patients had a better visual outcome than those who had surgery for their anterior polar cataracts. Although the visual outcome may reflect the severity of the cataract it suggests that better long-term results may be achieved with conservative treatment. 


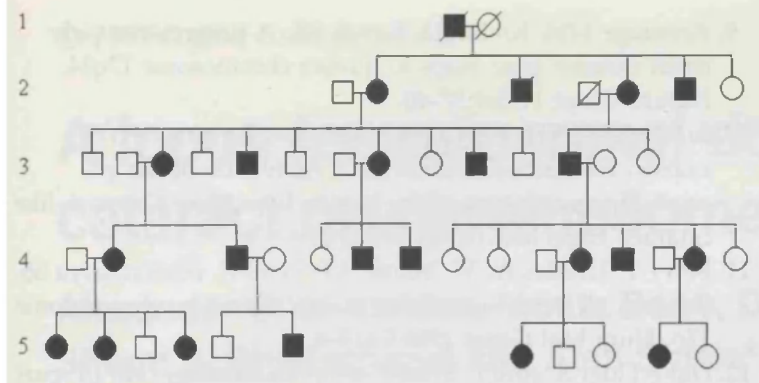

Fig. 1. Pedigree affected by anterior polar cataract.

AD cataract may show considerable phenotypic variability between family members. ${ }^{15}$ In this family, however, all affected individuals had lens opacities confined to the anterior pole of the lens. We have demonstrated that the anterior polar cataract in this family is linked to the short arm of chromosome $17 .{ }^{11}$ The mechanism by which the lens opacity is confined to the anterior pole is unclear but identification of the precise genetic mutation will help in understanding the pathogenesis. There are at present no candidate genes in this region on chromosome $17 \mathrm{p}$, but research to identify the causative gene continues.

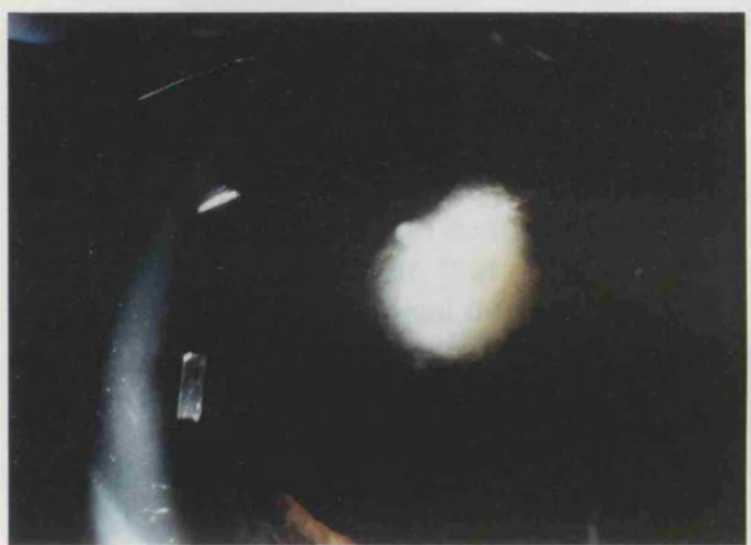

Fig. 2. Anterior polar cataract. Slit lamp photograph of a pyramidal cataract from individual 4:2.

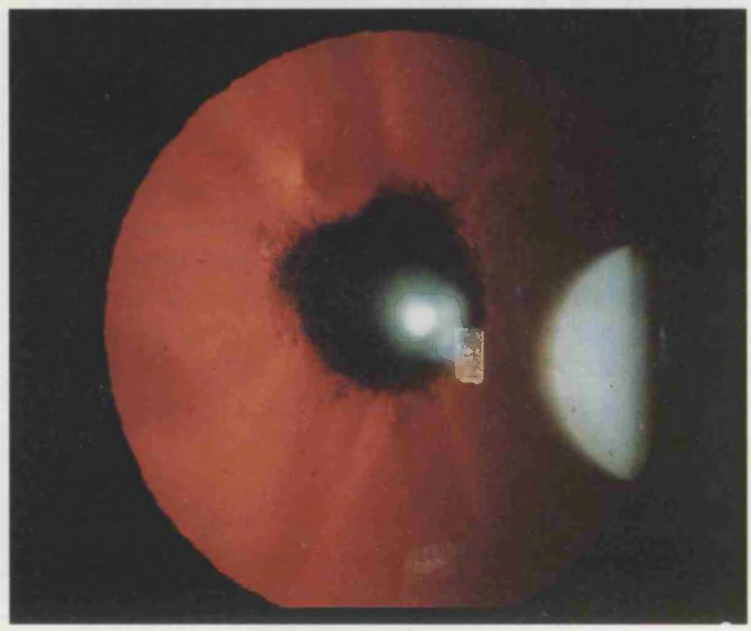

Fig. 3. Anterior polar cataract. Retroillumination of the pyramidal cataract from individual 4:2.

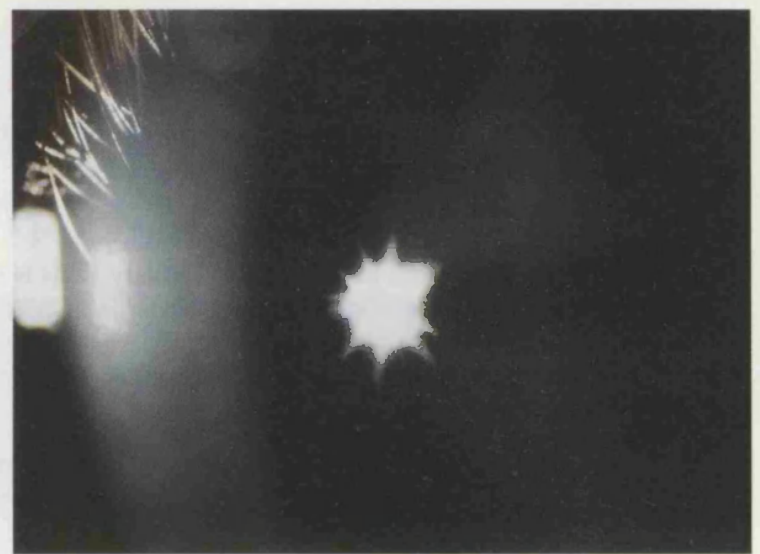

Fig. 4. Anterior polar cataract. Slit lamp photograph of a plaque-like opacity from individual $4: 3$.

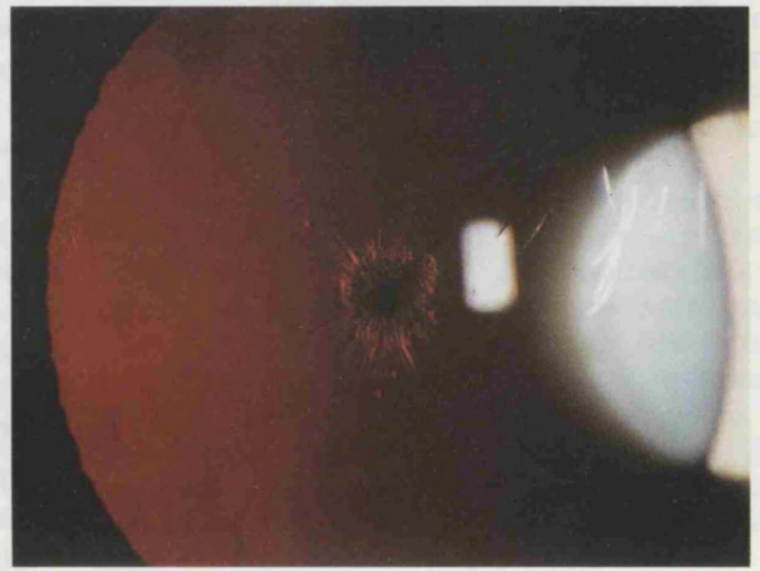

Fig. 5. Anterior polar cataract. Retroillumination of the plaque-like opacity from individual 4:3.

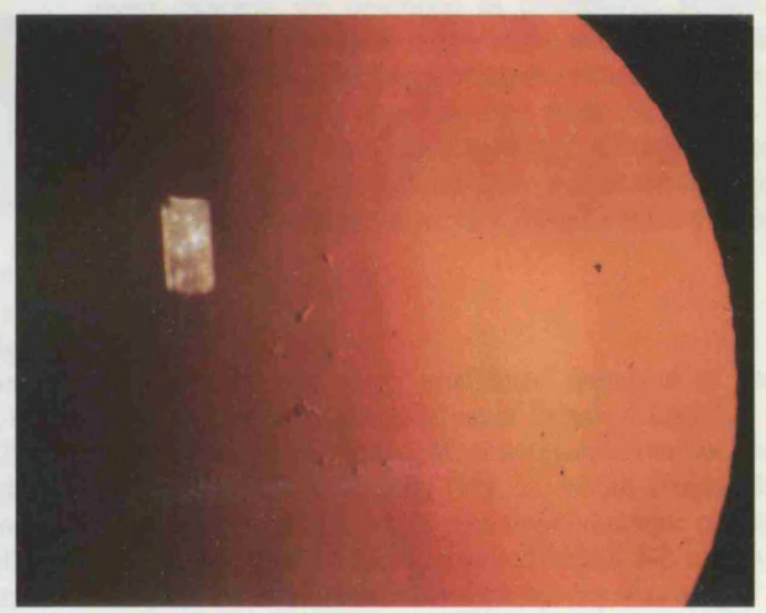

Fig. 6. Anterior polar cataract. Retroillumination of an anterior capsular irregularity from individual 5:6.

\section{References}

1. François J. Genetics of cataract. Ophthalmologica 1982;184:61-71.

2. Eiberg H, Lund AM, Warburg M, Rosenberg T. Assignment of congenital cataract Volkmann type (CCV) to chromosome 1p36. Hum Genet 1995;96:33-8. 
3. Ionides ACW, Berry V, Mackay DM, Moore AT,

Bhattacharya SS, Shiels A. A posterior polar cataract maps to chromosome 1p. Hum Mol Genet 1997;6:47-51.

4. Renwick JH, Lawler SD. Probable linkage between a congenital cataract locus and the Duffy blood group locus. Ann Hum Genet 1963;27:67-84.

5. Lubsen NH, Renwick JH, Tsui L-C, Breitman ML, Schoenmakers JGG. A locus for a human hereditary locus is closely linked to the $\gamma$-crystallin gene family. Proc Natl Acad Sci USA 1987;84:489-92.

6. Rogaev EI, Rogaeva EA, Korovaitseva GI, Farrer LA, Petrin AN, Keryanov SA, et al. Linkage of polymorphic congenital cataract to the $\gamma$-crystallin gene locus on human chromosome 2q33-35. Hum Mol Genet 1996;5:699-703.

7. Eiberg H, Marner E, Rosenberg T, Mohr J. Marner's cataract (CAM) assigned to chromosome 16: linkage to haptoglobin. Clin Genet 1988;34:272-5.

8. Padma T, Ayyagari R, Murty JS, Basti S, Fletcher T, Rao GN et al. Autosomal dominant zonular cataract with sutural opacities localised to chromosome 17q11-12. Am J Hum Genet 1995;57:840-5.
9. Armitage MM, Kivlin JD, Ferrell RE. A progressive early onset cataract gene maps to human chromosome $17 \mathrm{q} 24$. Nature Genet 1995;9:37-40.

10. Brackenhoff RH, Henskens HAM, van Rossum MWPC, Lubsen NH, Schoenmakers JGG. Activation of the $\gamma \mathrm{E}-$ crystallin pseudogene in the human hereditary Coppock-like cataract. Hum Mol Genet 1994;3:279-83.

11. Berry V, Ionides ACW, Moore AT, Plant C, Bhattacharya SS, Shiels A. A locus for anterior polar cataract on chromosome 17p. Hum Mol Genet 1996;5:415-9.

12. Duke-Elder S, editor. System of ophthalmology, vol III, part 2: Normal and abnormal development: congenital deformities. St Louis: CV Mosby, 1964:717-23.

13. Bouzas AG. Anterior polar congenital cataract and corneal astigmatism. J Pediatr Ophthalmol Strabismus 1992;29:210-2.

14. Jaafar MS, Robb RM. Congenital anterior polar cataract: a review of 63 cases. Ophthalmology 1984;91:249-52.

15. Scott MH, Hejtmancik MD, Wozencraft MS, Reuter LM, Parks MM, Keiser-Kupfer MD. Autosomal dominant congenital cataract: interocular phenotypic variability. Ophthalmology 1994;101:866-71. 


\title{
A locus for autosomal dominant posterior polar cataract on chromosome 1p
}

\author{
Alexander C. W. Ionides, Vanita Berry, Donna S. Mackay, Anthony T. Moore', \\ Shomi S. Bhattacharya and Alan Shiels*
}

Department of Molecular Genetics, Institute of Ophthalmology, University College London, 11-43 Bath Street, London EC1V 9EL, UK and ${ }^{1}$ Moorfields Eye Hospital, City Road, London EC1V 2PD, UK

Received July 16, 1996; Revised and Accepted October 10, 1996

\begin{abstract}
Autosomal dominant congenital cataract is a clinically and genetically heterogeneous lens disease. Here we report the linkage of a locus for autosomal dominant posterior polar cataract (CPP) to the distal short arm of chromosome 1. To map the CPP locus we performed molecular genetic linkage analysis using microsatellite markers in a three-generation pedigree. After exclusion of 13 known loci and candidate lens genes for autosomal dominant cataract, we obtained significantly positive LOD scores for markers $D 1 S 508$ $(\mathrm{Z}=3.14, \theta=0)$ and $D 15468(\mathrm{Z}=2.71, \theta=0)$. Multipoint analysis gave a maximum LOD score of $3.48(\theta=0.07)$ between markers $D 1 S 508$ and $D 1 S 468$. From haplotype data, however, CPPprobably lies in the telomeric interval D1S2845-1pter, which includes the locus for the clinically distinct Volkman congenital cataract (CCV). This study provides the first evidence for genetic heterogeneity of autosomal dominant posterior polar cataract for which a locus had been linked previously to chromosome 16q.
\end{abstract}

\section{INTRODUCTION}

Congenital cataract is a significant cause of visual impairment and blindness in childhood (1). Approximately $25 \%$ of all congenital cataract is inherited, most often as an autosomal dominant Mendelian trait (2) showing considerable inter- and intra-familial phenotypic variation (1-4). Currently, eight independent loci for autosomal dominant cataract have been linked to chromosomes 1p36 (5), 1q21-q25 (6), 2q33-q35 (7, 8), $16 \mathrm{q} 22.1(9-11), 17 \mathrm{p} 13$ (12), 17q11-12 (13), 17q24 (14) and 22q (15). The Coppock-like 'nuclear' cataract and a polymorphic 'lamellar' cataract map to the $\gamma$-crystallin gene cluster on $2 q$ and the former is associated with novel activation of the $\gamma \mathrm{E}$-crystallin pseudogene (7). Causative genes at the other seven human cataract loci have yet to be identified, however, the $\beta A 3 / A 1$ crystallin gene is a strong candidate for the 'zonular sutural' cataract on $17 q(13)$ and the 'cerulean' cataract on $22 q$ maps provocatively close to the $\beta$-crystallin gene cluster (15). In the mouse, autosomal dominant cataract has been associated with mutations in the genes for $\gamma \mathrm{E}$-crystallin on chromosome 1 (16), $\beta B 2$-crystallin on chromosome 5 (17) and lens major intrinsic protein on chromosome 10 (18). Mutation of the $\beta$-crystallin gene has also been shown to underlie autosomal dominant congenital cataract in the guinea-pig (19).

Posterior polar cataract is a clinically distinctive opacity located at the back of the lens and, because of its proximity to the optical centre of the eye, can have a marked effect on visual acuity. Posterior lens opacities are commonly acquired in age-related cataract (20) and may also present in neurofibromatosis type $2(21)$ and genetically heterogeneous retinal degenerations (22). Ultrastructural studies of such opacities have identified abnormal migration of 'dysplastic' swollen fibre cells and accumulation of granular extracellular material at the posterior pole of the lens (23-25). However, the underlying pathogenesis is poorly understood.

Dominantly inherited posterior polar congenital cataract $(9,10)$ has previously been linked with the haptoglobin locus $(H P)$ on $16 \mathrm{q}$, along with the dominant Marner congenital cataract (11). Both these cataracts are described as progressive, however, in the Mamer family opacities initiate at the nucleus rather than at the posterior pole of the lens suggesting that either allelic heterogeneity or two distinct cataract genes exist at the $16 \mathrm{q}$ locus. To obtain further insight into the genetic aetiology of congenital cataract we performed linkage analysis on a three-generation family of English descent with autosomal dominant posterior polar cataract.

\section{RESULTS}

Ten affected and three unaffected members of the family, including the 'critical recombinant' female 4.1 aged 17 years (see below), underwent a full ophthalmological examination by one of us (A.C.W.I.). The opacity (Fig. 1), which was bilateral in all cases, consisted of a single well defined plaque confined to the posterior pole of the lens and varied from $0.5-3 \mathrm{~mm}$ in diameter. Hospital records indicated that the opacity was usually present at birth or developed within the first few months of life but did not progress with age to other regions of the lens. There was no evidence of posterior lenticonus or high myopia and no family history of other ocular or systemic abnormalities. 


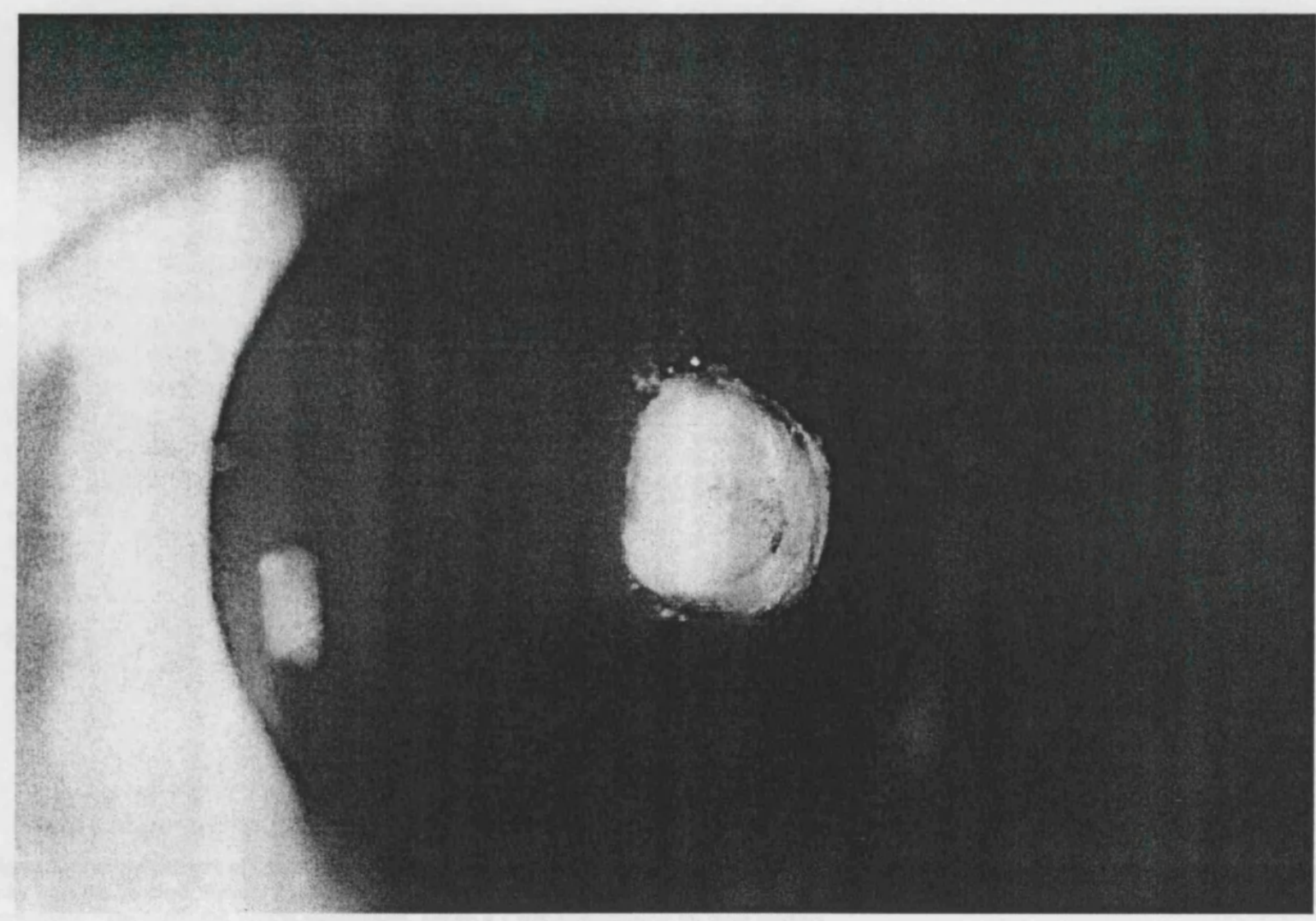

Figure 1. Slit-lamp photograph of the right eye of affected female 2.8 from the autosomal dominant cataract pedigree (Fig. 2) showing a single well defined opacity located at the posterior pole of the lens.

Table 1. Two-point LOD scores (Z) for linkage between the CPP locus and chromosome 1p markers

\begin{tabular}{|c|c|c|c|c|c|c|c|c|c|c|}
\hline \multirow[t]{2}{*}{ Marker } & \multirow[t]{2}{*}{$\mathrm{cM}$} & \multicolumn{3}{|c|}{ Recombination fraction $(\theta)$} & \multirow[b]{2}{*}{0.10} & \multirow[b]{2}{*}{0.20} & \multirow[b]{2}{*}{0.30} & \multirow[b]{2}{*}{0.40} & \multirow[t]{2}{*}{$\mathrm{Z}_{\max }$} & \multirow[t]{2}{*}{$\theta_{\max }$} \\
\hline & & 0.00 & 0.01 & 0.05 & & & & & & \\
\hline \multicolumn{11}{|l|}{ 1pter } \\
\hline DIS243 & 6.2 & 1.51 & 1.47 & 1.35 & 1.19 & 0.83 & 0.46 & 0.13 & 1.50 & 0.00 \\
\hline$D I S 468$ & 4.9 & 2.71 & 2.66 & 2.46 & 2.21 & 1.64 & 1.01 & 0.35 & 2.70 & 0.00 \\
\hline DIS2845 & 1.8 & $-\infty$ & 1.85 & 2.30 & 2.27 & 1.86 & 1.23 & 0.48 & 2.31 & 0.07 \\
\hline$D I S 2660$ & 3.5 & $-\infty$ & 1.85 & 2.30 & 2.27 & 1.86 & 1.23 & 0.48 & 2.31 & 0.07 \\
\hline DIS214 & 0.0 & 0.57 & 0.56 & 0.51 & 0.44 & 0.33 & 0.22 & 0.10 & 0.57 & 0.00 \\
\hline DIS2870 & 0.5 & $-\infty$ & -0.22 & 0.35 & 0.49 & 0.44 & 0.24 & 0.04 & 0.49 & 0.13 \\
\hline DIS2663 & 1.2 & $-\infty$ & 1.26 & 1.74 & 1.76 & 1.45 & 0.94 & 0.33 & 1.78 & 0.08 \\
\hline DIS508 & 4.8 & 3.14 & 3.08 & 2.85 & 2.54 & 1.88 & 1.15 & 0.39 & 3.14 & 0.00 \\
\hline DIS450 & 4.0 & $-\infty$ & 1.55 & 2.00 & 1.98 & 1.58 & 1.00 & 0.35 & 2.01 & 0.07 \\
\hline DIS2667 & 5.5 & $-\infty$ & 1.85 & 2.30 & 2.27 & 1.86 & 1.23 & 0.48 & 2.31 & 0.07 \\
\hline DIS228 & 15.3 & 1.03 & 1.01 & 0.91 & 0.78 & 0.53 & 0.30 & 0.11 & 1.03 & 0.00 \\
\hline DIS199 & 8.9 & $-\infty$ & 1.34 & 1.79 & 1.78 & 1.41 & 0.87 & 0.30 & 1.81 & 0.07 \\
\hline DIS234 & & $-\infty$ & -1.56 & -0.39 & -0.07 & 0.06 & 0.11 & 0.11 & 0.12 & 0.35 \\
\hline
\end{tabular}

Sex-averaged genetic distances between the markers (26) are shown in centi-Morgans (cM). 


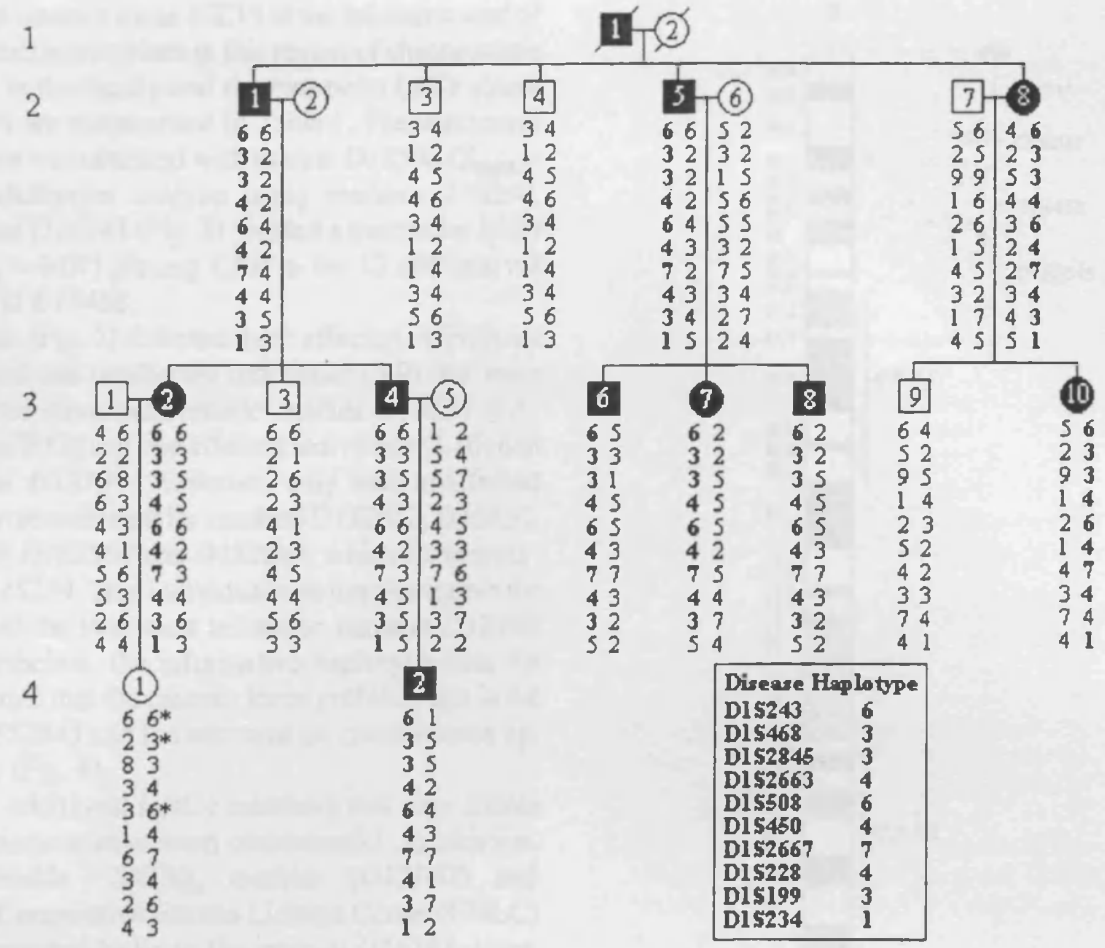

Figure 2. Abridged pedigree of the posterior polar cataract family used in this study showing the segregation of nine chromosome $1 \mathrm{p}$ markers listed in descending order from the telomere. Squares and circles symbolise males and females, respectively. Open and filled symbols indicate unaffected and affected individuals, respectively. *The unaffected 'critical recombinant' female 4.1 was uninformative for these markers.

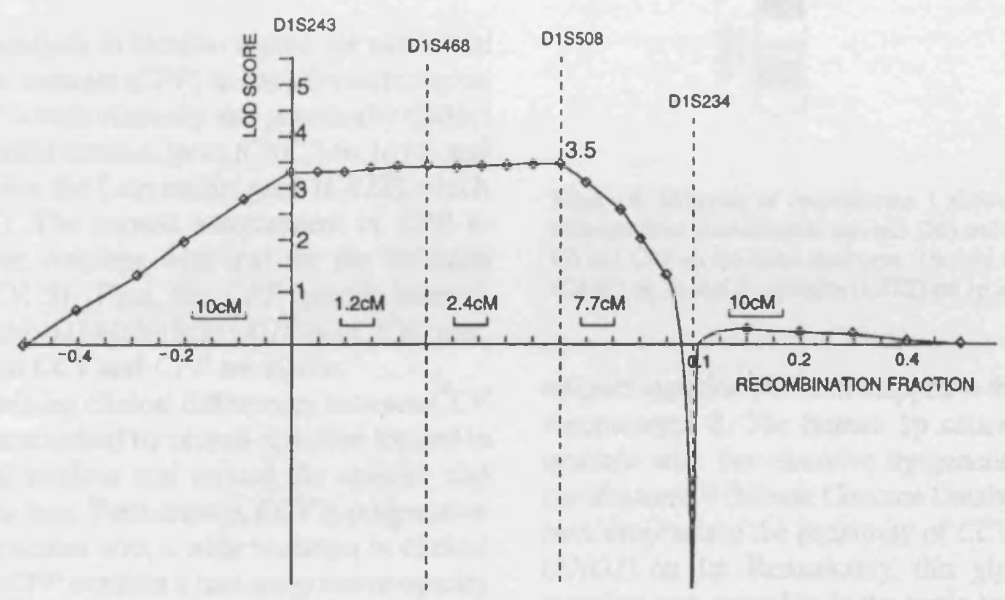

Figure 3. Multipoint linkage analysis between the CPP locus and chromosome lp markers, DIS234-(39 cM)-DIS508-(12 cM)-DIS468-(6 cM)-DIS243 (26).

For linkage analysis, 19 members of the pedigree (Fig. 2) including 10 affected individuals, five unaffected individuals and four spouses were genotyped with microsatellite markers from the Généthon ( $\mathrm{AC})_{n}$ map (26). We first excluded linkage of the cataract with $H P$ on $16 \mathrm{q}$ using markers $D 16 S 515(\mathrm{Z}=-3.31$, $\theta=0.05)$ and $D 16 S 503(Z=-1.76, \theta=0.05)$. We then proceeded to exclude 12 other known loci and candidate lens genes for autosomal dominant cataract on $22 q$ (cerulean cataract type 2 and $\beta$-crystallin), 21q ( $\alpha$ l-crystallin), 19q (lens integral membrane protein 2), 17q24 (cerulean cataract type 1), 17q11-q12 (zonular sutural cataract and $\beta A 3 / A 1$-crystallin), $17 \mathrm{p}$ (anterior polar cataract), 16p ( $\mu$-crystallin), 12q (lens major intrinsic protein), 11q ( $\alpha 2$-crystallin), 2q ( $\gamma$-crystallin), 1q (zonular pulverulent cataract), 1p ( $\zeta$-crystallin) (Human Genome Database, 1996). Following exclusion of the $\zeta$-crystallin gene $(C R Y Z)$ on $1 \mathrm{p} 31-\mathrm{p} 22$ with marker D1S201 $(\mathrm{Z}=-1.09, \theta=0.05)$ we detected positive LOD scores for markers DIS468 $(\mathrm{Z}=2.71, \theta=0)$ and $\operatorname{DIS} 243(\mathrm{Z}=1.51, \theta=0)$, which flank a $6 \mathrm{cM}$ interval close to the 
Volkman congenital cataract locus $(\mathrm{CCV})$ at the telomeric end of $1 \mathrm{p}(5)$. Ten other Généthon markers in this region of chromosome Ip were genotyped in the family and the two-point LOD scores of all 12 marker loci are summarised in Table 1. The maximum two-point LOD score was obtained with marker DIS508 $\left(\mathrm{Z}_{\max }=\right.$ 3.14, $\theta_{\max }=0$ ). Multipoint analysis using markers DIS234, DIS508, DIS468 and DIS243 (Fig. 3) yielded a maximum LOD score of $3.48\left(\theta_{\max }=0.07\right)$ placing $C P P$ in the $12 \mathrm{cM}$ interval between DIS508 and DIS468.

Haplotype analysis (Fig. 2) detected three affected individuals (3.6, 3.7 and 3.8) and one unaffected individual (3.9) that were recombinant with the most centromeric marker DIS234 (i.e., which lies closest to $C R Y Z$ ) and one affected individual (3.10) that was recombinant at DIS199. However, only one unaffected individual (4.1) was recombinant for markers D1S2667, DIS450, $D 1 S 2663, D 1 S 2870, D 1 S 2660$ and DIS2845, which lie increasingly telomeric to DIS234. This individual was uninformative for markers DIS508 and the two most telomeric markers DIS468 and DIS243. Nevertheless, the informative haplotype data for individual 4.1 indicated that the cataract locus probably lies in the interval between DIS2845 and the telomere on chromosome 1p, i.e., DIS2845-1pter (Fig. 4).

Attempts to trace additional family members that may enable further linkage refinement have been unsuccessful. In addition, the two tetranucleotide (GATA $)_{n}$ markers (DISI605 and DIS2133) from the Cooperative Human Linkage Center (CHLC) map (27) that are reported to lie in the interval D1S243-1pter, which contains the $C C V$ locus, were found to be uninformative in the family ( $\mathrm{Z}=-0.14$ and 0.25 at $\theta=0.05$, respectively).

\section{DISCUSSION}

We have used linkage analysis to localise a gene for autosomal dominant posterior polar cataract $(C P P)$ to the telomeric region of chromosome 1p. CPP is both clinically and genetically distinct from the zonular pulverulent cataract locus (CAEI) on $1 \mathrm{q}(6)$ and does not appear to involve the $\zeta$-crystallin gene $(C R Y Z)$ which maps to 1p31-p22 (28). The current assignmnent of $C P P$ to DIS2845-Ipter, however, overlaps with that for the Volkman congenital cataract $(C C V, 5)$. Thus, the $C P P$ genetic interval comprises DIS2845-(5cM)-DIS468-(6cM)-DIS243-CCV-1pter, raising the possibility that $C C V$ and $C P P$ are allelic.

There are, however, striking clinical differences between $C C V$ (5) and CPP. CCV is characterised by central opacities located in the embryonic and fetal nucleus and around the anterior and posterior Y-sutures of the lens. Furthermore, $C C V$ is progressive giving rise to zonular opacities with a wide variation in clinical appearance. In contrast, $C P P$ exhibits a non-progressive opacity that is confined to the back of the lens with a consistent appearance. Given that the current $C P P$ interval extends a further $\sim 11 \mathrm{cM}$ centromeric to the $C C V$ interval, it is possible that two independent genes underlie these clinically distinct types of congenital cataract on $1 \mathrm{p}$. Equally, a single gene for $C P P$ and $C C V$ cannot be excluded given the possibility of allelic heterogeneity for posterior polar cataract and the Marner 'nuclear' cataract on $16 \mathrm{q}(11)$.

The linkage of CPP to $1 \mathrm{p}$ has identified a second locus for inherited posterior polar cataract. In contrast with $C P P$, however, the $16 \mathrm{q}$ posterior polar cataract is described as progressive, eventually leading to a total opacification of the lens $(\theta-11)$. There is no obvious candidate gene for cataract at the $16 \mathrm{q}$ locus and no

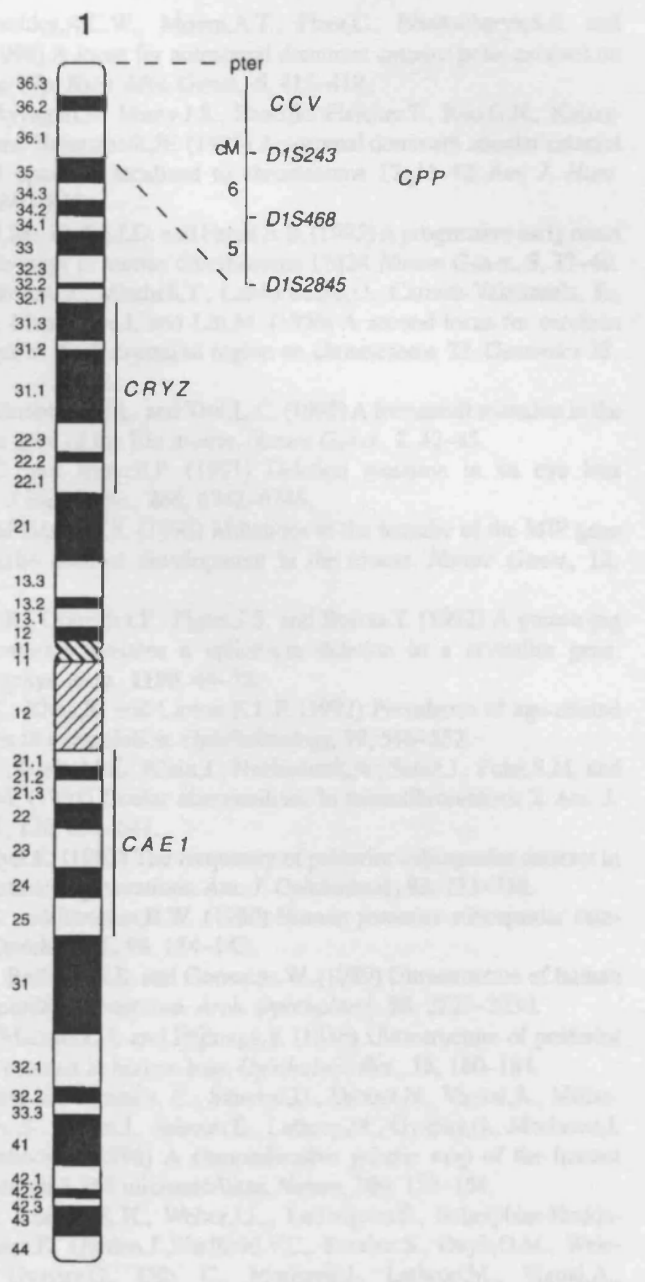

Figure 4. Idiogram of chromosome 1 showing the genetic distances (cM) between three microsatellite markers (26) and the calculated positions of $C C V$ (5) and $C P P$ on the distal short arm. The loci for zonular pulverulent cataract $(C A E I)$ on $\mathrm{lq}$ and $\beta$-crystallin (CRYZ) on $\mathrm{lp}$ are also indicated.

cataract mutation has been mapped to the syntenic region of mouse chromosome 8 . The human lp cataract loci, however, may be syntenic with the recessive dysgenetic lens mutation on mouse chromosome 4 (Mouse Genome Database, 1996). Eiberg et al. (5) have emphasised the proximity of $C C V$ to the gene for $\alpha$-enolase (ENOI) on 1p. Remarkably, this glycolytic enzyme has been recruited as $\tau$-crystallin in the turtle lens through an evolutionary process referred to as gene-sharing (29). However, the red-cell ENO1 activity is normal in the CCV family (5) and cataract has not been reported in hereditary ENO1 deficiency (30). Currently, we are attempting to exclude $E N O I$ as a candidate gene for $C P P$ and identify additional informative markers in the region to enable fine mapping and, ultimately, positional cloning of the underlying gene.

\section{MATERIALS AND METHODS}

\section{Genotyping}

Genomic DNA was extracted from EDTA-sequestered blood samples, taken with informed consent and local ethical approval, 
using the Nucleon II DNA extraction kit (Scotlab Bioscience) PCR-based genotyping using Généthon microsatellite markers (26) at 5-10 cM intervals was performed as described previously (12).

\section{Linkage analysis}

Data was collated using the LINKSYS (version 3.1) data management package (31). Two-point LOD scores were calculated using the MLINK and ILINK sub-programs of the LINKAGE (version 5.1) package (32). Allele frequencies calculated from the four spouses in the family were similar to those quoted by Généthon (26). Multipoint analysis was computed using LINKMAP (32) run on the UK Human Genome Mapping Project (HGMP) Resource Centre computing facilities (Cambridge, UK). A full penetrance and a gene frequency of 0.0001 were assumed for the cataract locus.

\section{ACKNOWLEDGEMENTS}

We thank the family for their cooperation in this study and the UK HGMP Resource Centre for microsatellite primer synthesis and use of computing facilities. This work is supported by a grant from The Wellcome Trust $(043073 / Z / 94 / Z)$ to A.S. and S.S.B. A.C.W.I. is supported by a grant from the Friends of Moorfields Eye Hospital and D.S.M. is a Wellcome Prize Student.

\section{REFERENCES}

1. Lund,A.M., Eiberg,H., Rosenberg,T. and Warburg,M. (1992) Autosomal dominant congenital cataract; linkage relations; clinical and genetic beterogeneity. Clin. Genet., 41, 65-69.

2. Francois,J. (1982) Genetics of cataract. Ophthalmoligica, 184, 61-71.

3. Scott,M.H., Hejtmancik,J.F., Wozencraft, L.A., Reuter,L.M., Parks,M.M. and Kaiser-Kupfer, M.I. (1994) Autosomal dominant congenital cataract-interocular phenotypic variability. Ophthalmology, 101, 866-871.

4. Ionides,A.C.W., Berry,V., Moore,A.T., Bhattacharya,S.S. and Shiels,A. (1996) Clinical and genetic heterogeneity of autosomal dominant cataract. Acta. Ophthalmol., 74, S219, 40-41.

5. Eiberg,H., Lund,A.M., Warburg,M. and Rosenberg,T. (1995) Assignment of congenital cataract Volkmann type (CCV) to chromosome 1p36. Hum Genet., 96, 33-38.

6. Renwick,J.H. and Lawler,S.D. (1963) Probable linkage between a congenital cataract locus and the Duffy blood group locus.Ann. Hum. Genet., 27, 67-84.

7. Brakenhoff,R.H., Henskens,H.A.M., van Rossum,M.W.P.C., Lubsen,N.H. and Schoenmakers,J.G.G. (1994) Activation of the $\gamma E$-crystallin pseudogene in the human hereditary Coppock-like cataract. Hum. Mol. Genet., 3, 279-283.

8. Rogaev,E.I., Rogaeva,E.A., Korovaitseva,G.I., Farrar,L.A., Petrin,A.N., Keryanov,S.A., Turaeva,S., Chumakov,I., St. George-Hyslop,P. and Ginter,E.K. (1996) Linkage of polymorphic congenital cataract to the $\gamma$-crystallin gene locus on human chromosome 2q33-35. Hum. Mol. Genet., $5,699-703$.

9. Maumenee,I.H. (1979) Classification of hereditary cataracts in children by linkage analysis. Ophthalmol., 86, 1554-1558.

10. Richards,J., Maumenee,I.H., Rowe,S. and Lovrien,E.W. (1984) Congenital cataract possibly linked to haptoglobin. Cytogenet. Cell Genet., 37, 570

11. Marner,E., Rosenberg,T. and Eiberg,H. (1989) Autosomal dominant congenital cataract: morphology and genetic mapping. Acta. Ophthalmol., 67, 151-158.
12. Berry,V., Ionides,A.C.W., Moore,A.T., Plant,C., Bhattacharya,S.S. and Shiels,A. (1996) A locus for autosomal dominant anterior polar cataract on chromosome 17p. Hum. Mol. Genet., 5, 415-419.

13. Padma,T., Ayyagari,R. Murty,J.S., Basti,S., Fletcher,T., Rao,G.N., KaiserKupfer,M. and Hejtmancik,JF. (1995) Autosomal dominant zonular cataract with sutural opacities localized to chromosome 17q11-12. Am. J. Hum. Genet., 57, 840-845.

14. Armitage,M.M., Kivlin,J.D. and Ferell,R.E. (1995) A progressive early onset cataract gene maps to human chromosome 17q24. Nature Genet., 9, 37-40.

15. Kramer,P., Yount, J., Mitchell,T., LaMorticella,D., Carrero-Valenzuela, R., Lovrien, E., Maumenee,I. and Lit,M. (1996) A second locus for cerulean cataract maps to the $\beta$ crystallin region on chromosome 22. Genomics 35 , 539-542.

16. Cartier,M., Breitman,M.L. and Tsui,L-C. (1992) A frameshift mutation in the $\gamma$ E-crystallin gene of the Elo mouse. Nature Genet., 2, 42-45.

17. Chambers,C. and Russell,P. (1991) Deletion mutation in an eye lens B-crystallin. J Biol Chem., 266, 6742-6746.

18. Shiels,A. and Bassnett,S. (1996) Mutations in the founder of the MIP gene family underlie cataract development in the mouse. Nature Genet., 12 212-215.

19. Rodriguez,I.R., Gonzalez,P., Zigler,J.S. and Borras,T. (1992) A guinea-pig hereditary cataract contains a splice-site deletion in a crystallin gene. Biochim. Biophys. Acta., 1180, 44-52.

20. Klein,B.E.K., Klein,R, and Linton,K.L.P. (1992) Prevalence of age-related lens opacities in a population. Ophthalmology, 99, 546-552.

21. Ragge, N.K., Baser,M.E., Klein,J., Nechiponuk,A., Sainz,J., Pulst,S.M. and Riccardi,V.M. (1995) Ocular abnormalities in neurofibromatosis 2. Am. J. Ophthalmol., 120, 634-641.

22. Heckenlively,J.R. (1982) The frequency of posterior subcapsular cataract in hereditary retinal degenerations. Am. J. Ophthalmol., 93, 733-738.

23. Eshaghian,J. and Streeten,B.W. (1980) Human posterior subcapsular cataract. Arch. Ophthalmol., 98, 134-143.

24. Eshagian,J., Rafferty,N.S. and Goossens,W. (1980) Ultrastructure of human cataract in retinitis pigmentosa. Arch. Ophthalmol., 98, 2227-2230.

25. Nagata,M., Matsuura,H. and Fujinaga, Y. (1986) Ultrastructure of posterior subcapsular cataract in human lens. Ophthalmic Res., 18, 180-184.

26. Dib, C., Faure, S., Fizames, C., Samson,D., Drouot,N., Vignal,A., Millasseau,P., Marc,S., Hazan,J., Seboun,E., Lathrop,M., Gyapay,G., Morissett,J. and Weissenbach, J. (1996) A comprehensive genetic map of the human genome based on 5,264 microsatellites. Nature, 380, 152-154.

27. Murray,J.C., Buetow,K.H., Weber,J.L., Ludwigsen,S., Scherpbier-Heddema,T., Manion,F., Quillen,J.,Sheffield,V.C., Sunden.S., Duyk,G.M., Weissenbach,J., Gyapay,G., Dib, C., Morissett,J., Lathrop,M., Vignal,A., White,R., Matsunami,N., Gerken,S., Melis,R., Albertsen,H., Plaetke,R. Odelberg,S., Ward,D., Dausset., Cohen,D. and Cann,H. (1994) A comprehensive human linkage map with centimorgan density. Science, 265, 2049-2054.

28. Heinzmann,C., Kojis,T.L., Gonzalez,P., Rao,P.V., Zigler,J.S., Polymeropoulos,M.H., Klisak,I., Sparkes,R.S., Mohandas,T. and Bateman,J.B. (1994) Assignment of the $\zeta$-crystallin gene (CRYZ) to human chromosome 1p22-31 and identification of restriction fragment length polymorphisms. Genomics, 23, 403-407.

29. Wistow,G., Lietman, T. and Williams,L.A. (1988) $\tau$-Crystallin/ $\alpha$-enolase: One gene encodes both an enzyme and a lens structural protein. J Cell Biol., $107,2729-2736$.

30. Lachant,N.A., Jennings,M.A. and Tanaka,K.R. (1986) Partial erythrocyte enolase deficiency: a hereditary disorder with variable clinical expression. Blood, 68, 55a.

31. Attwood,J. and Bryant,S.A. (1988) A computer program to make analysis with LIPED and LINKAGE easier to perform and less prone to input errors. Am. J. Hum. Genet., 52, 259.

32. Lathrop,G.M., Lalouel,J.M., Julier,C. and Ot,J. (1984) Strategies for multipoint linkage analysis in humans. Proc. Natl. Acad. Sci. USA, 81, 3443-3446. 


\title{
Clinical and genetic heterogeneity in autosomal dominant cataract
}

\author{
Alexander Ionides, Peter Francis, Vanita Berry, Donna Mackay, Shomi Bhattacharya, \\ Alan Shiels, Anthony Moore
}

\begin{abstract}
Aims-To determine the different morphologies of autosomal dominant cataract (ADC), assess the intra- and interfamilial variation in cataract morphology, and undertake a genetic linkage study to identify loci for genes causing ADC and detect the underlying mutation.
\end{abstract}

Methods-Patients were recruited from the ocular genetic database at Moorfields Eye Hospital. All individuals underwent an eye examination with particular attention to the lens including anterior segment photography where possible. Blood samples were taken for DNA extraction and genetic linkage analysis was carried out using polymorphic microsatellite markers.

Results-292 individuals from 16 large pedigrees with ADC were examined, of whom 161 were found to be affected. The cataract phenotypes could all be described as one of the eight following morphologies-anterior polar, posterior polar, nuclear, lamellar, coralliform, blue dot (cerulean), cortical, and pulverulent. The phenotypes varied in severity but the morphology was consistent within each pedigree, except in those affected by the pulverulent cataract, which showed considerable intrafamilial variation. Positive linkage was obtained in five families; in two families linkage was demonstrated to new loci and in three families linkage was demonstrated to previously described loci. In one of the families the underlying mutation was isolated. Exclusion data were obtained on five families.

Conchusions-Although there is considerable clinical heterogeneity in ADC, the phenotype is usually consistent within families. There is extensive genetic heterogeneity and specific cataract phe-

Accepted for publication

Table 1 Autosomal dominant cataract loci

\begin{tabular}{|c|c|c|c|}
\hline Phenotype & Locus & Mutated gene (if known) & Reference \\
\hline $\begin{array}{l}\text { Volkmann (pulverulent) } \\
\text { Posterior polar* } \\
\text { Zonular pulverulent } \\
\text { Coppock-like (nuclear) } \\
\text { Polymorphic (lamellar) } \\
\text { Total } \\
\text { Pulverulent* } \\
\text { Marner (pulverulent) } \\
\text { Anterior polar } \\
\text { Zonular-sutural (lamellar) } \\
\text { Cerulean } \\
\text { Zonular central nuclear } \\
\text { Cerulean }\end{array}$ & $\begin{array}{l}1 \mathrm{p} 36 \\
1 \mathrm{p} 36 \\
1 \mathrm{q} 21-25 \\
2 \mathrm{q} 33-36 \\
2 \mathrm{q} 33-36 \\
10 \mathrm{q} 24-25 \\
13 \mathrm{q} \\
16 \mathrm{q} 22.1 \\
17 \mathrm{p} 13 \\
17 \mathrm{q} 11-12 \\
17 \mathrm{q} 24 \\
21 \mathrm{q} 22.3 \\
22 \mathrm{q} 11.2\end{array}$ & $\begin{array}{l}\text { Connexin50t } \\
\gamma \text { cryıtallin } \\
\text { Pixx3 }\end{array}$ & $\begin{array}{l}24 \\
14 \\
23,46 \\
17,30 \\
47 \\
48 \\
9 \\
25 \\
13 \\
49 \\
27 \\
33 \\
28\end{array}$ \\
\hline
\end{tabular}

*Linkage first described by this study group.

tMutation first described by this study group. notypes appear to be associated with mutations at more than one chromosome locus. In cases where the genetic mutation has been identified the molecular biology and clinical phenotype are closely associated.

(Br F Ophthalmol 1999;83:802-808)

Infantile cataract is one of the commonest treatable causes of childhood blindness in the USA and Europe ${ }^{1}$ with a prevalence of $1-6$ cases per 10000 births. ${ }^{2}$ Inherited cataract accounts for up to half of all congenital cataract ${ }^{3}$ and the commonest mode of inheritance is autosomal dominant. There is considerable phenotypic variation in autosomal dominant cataract (ADC) but there have been few systematic studies of the different morphologies. Loci for the genes causing autosomal dominant cataract have now been identified across the human genome (Table 1).

In 1910 Harman $^{3}$ described the appearance of the lens opacities seen in families with inherited cataract and listed five groupslamellar, coralliform, stellate, anterior, and posterior polar, and finally an "undefined" group. Clapp later divided congenital cataract of all aetiologies into two broad groups, complete and partial, and then subdivided the partial cataracts into zonular, coralliform, punctate, discoid, pyramidal, $Y$ opacities, floriform, fusiform, disc-shaped, and Morgagnian. Duke-Elder, ${ }^{5}$ François, ${ }^{6}$ and Vogt have described the wide variety of phenotypes seen in individuals with inherited cataract but have not studied the pedigrees affected by ADC. We have undertaken a study of the clinical appearance of the lens in a large number of families with dominantly inherited cataract and have been able to identify a number of distinct phenotypes and to correlate some of these with the chromosomal location of the disease mutations.

\section{Patients and methods}

We examined 161 affected individuals with ADC from 16 pedigrees. The families were drawn from the genetic clinic database at Moorfields Eye Hospital and had no other ocular or systemic abnormalities. All patients underwent an eye examination with particular attention to the lens and cataract morphology. Families were included if there were three generations of affected individuals with at least four affected members. Anterior segment photographs were taken where possible and peripheral blood was collected for DNA extraction to be used in subsequent linkage 
Table 2 Pedigree details

\begin{tabular}{lccc}
\hline Phenotype & $\begin{array}{l}\text { No of family } \\
\text { members }\end{array}$ & $\begin{array}{l}\text { No of } \\
\text { affected } \\
\text { patients }\end{array}$ & $\begin{array}{l}\text { No of } \\
\text { pedigrees }\end{array}$ \\
\hline Anterior polar & 30 & 19 & 1 \\
Posterior polar & 36 & 21 & 2 \\
Nuclear & 40 & 23 & 2 \\
Lamellar & 42 & 25 & 3 \\
Coralliform & 19 & 8 & 1 \\
Blue dot & 13 & 7 & 1 \\
Cortical & 20 & 6 & 1 \\
Pulverulent & 92 & 52 & 5 \\
Total & 292 & 161 & 16 \\
\hline
\end{tabular}

studies. Ethical approval for the study was given by the hospital ethics committee and informed, signed consent was obtained from the patients. In subjects where surgery had been performed early, a description of the phenotype was taken from the hospital notes.

Genomic DNA was extracted from EDTA sequestered blood samples and linkage analysis using Généthon microsatellite markers ${ }^{8}$ was performed using a previously described protocol. ${ }^{9}$

\section{Results}

Eight phenotypes could be recognised that included all the pedigrees seen in the study. These phenotypes were anterior polar, posterior polar, nuclear, lamellar, coralliform, blue dot (cerulean), cortical, and pulverulent (Table 2). The morphology of the cataract in affected individuals within any single pedigree was the same for all except the pulverulent pedigrees, varying only in the severity and density of the opacity. In pedigrees with the pulverulent phenotype there was considerable variation in the cataract morphology among affected individuals from the same pedigree. Male to male transmission was seen in 12 families. In the remaining families, the severity of affected members was equal in both males and females suggesting autosomal dominant inheritance.

\section{ANTERIOR POLAR CATARACT}

Anterior polar cataracts are situated at the anterior pole of the lens and have been reported to have a minimal effect on visual acuity. ${ }^{10}$ "We studied a single family with anterior polar cataract. Thirty family members (excluding partners) were examined and 19 found to be affected. Seven patients had undergone surgery and the phenotype was examined in the remaining 12 cases. The opacity was always in the same position of the lens, the anterior pole, but varied in severity. ${ }^{12}$ The larger opacities were pyramidal with a base of 4 $\mathrm{mm}$ and extended into the anterior chamber (Fig 1a), while the smaller opacities consisted of a flat plaque measuring under $1 \mathrm{~mm}$ in diameter. In one affected individual who showed the disease haplotype the only sign of an anterior polar abnormality was an irregularity of the anterior capsule. We have demonstrated linkage of anterior polar cataract to chromosome $17 \mathrm{p}$ in this family ${ }^{13}$ showing significantly positive lod scores for markers D17S849 $\left(Z_{m}=4.01, \theta_{m}=0.05\right)$ and D17S796 $\left(Z_{\max }=4.17, \theta_{\max }=0.05\right)$. Multipoint analysis gave a maximum lod score of $\mathbf{5 . 2}$ between these two markers.
POSTERIOR POLAR CATARACT

In the pedigrees studied the posterior polar opacity was always at the posterior pole of the lens. Two types of posterior polar cataract were identified in this study-a stationary posterior polar cataract and a progressive posterior polar cataract. The stationary posterior polar cataract consisted of a single well defined posterior polar plaque (Fig 1b), which varied in size among individuals as well as between the eyes of an individual. No other part of the lens was affected and although we have not studied the family over a prolonged period, the clinical records suggest that the cataract did not increase significantly in size. In a pedigree affected by this stationary posterior polar cataract 15 members of the family were examined and 10 found to be affected. Seven patients had undergone surgery and details of the cataract were obtained from the notes in four of these cases, all of whom were described as having posterior polar cataract.

We have demonstrated linkage of this phenotype to chromosome $1 p^{14}$ with significantly positive lod scores for markers D1S508 $\left(Z_{\max }=3.14, \theta_{\max }=0\right)$ and D1S468 $\left(Z_{\max }=2.71\right.$, $\theta_{\max }=0$ ). Multipoint analysis gave a maximum lod score of $3.48\left(\theta_{\max }=0.07\right)$ between markers D1S508 and D1S468. The second family with posterior polar cataract was affected by a progressive posterior polar cataract that initially consisted of a posterior plaque but later developed posterior cortical extensions (Fig 1c) with punctate cortical opacities causing a progressive deterioration of visual acuity requiring cataract extraction. Twenty one family members were examined, 11 were affected and all but one unilateral case had undergone surgery. Clinical records available in nine of the 10 operated cases documented the progressive nature of the cataract; the average age of diagnosis was 5 years but surgery was performed at a mean age of 20 years (range $3-40$ years, median 19 years, mode 16 years). We have excluded linkage of this phenotype to the loci known to be associated with ADC.

\section{NUCLEAR CATARACT}

Nuclear cataract consists of opacities confined to the embryonic and fetal nuclei of the lens. The cataract varies such that some patients have dense central opacities surrounded by fine dots (Fig 1d), while others have fine dot opacities distributed throughout the embryonic and fetal nuclei (Fig 1e), with opacification of the anterior and posterior $Y$ sutures. The opacities are confined to the fetal nucleus. Two pedigrees affected by nuclear cataract were examined. In the first family 21 individuals were examined and 12 found to be affected. Of these, six had undergone surgery and the clinical notes were available in two cases. Preliminary linkage results in this family have excluded the loci known to be associated with ADC.

In the second family affected by nuclear cataract 19 family members were examined and 11 found to be affected. Eight patients had undergone surgery and in seven of these the clinical notes gave an accurate description of 
Figure 1 Autosomal dominant congenizal cataract phenotypes. (a) Slit lamp and

retroillumination view of anterior polar casarect (47) anterior polar cazaract (47 year old woman). (b) Slit lamp and retroillumination view of a stationary

posterior polar cataract (49 year old woman). (c) Slit lamp view of a progressive posterior polar cataract year old female). (d) Slit lamp and retroillumination view of a dense nuclear cataract (14 year old male). (e) Slit lamp and retroillumination view of nuclear opacities (50 year old woman). (f) Slit lamp and recroillumination vien of the Coppock-like

catarace with fine nuclear opacities (24 year old woman). (e) Slit lamp and retrillumination the Coppoch-like cataract the Coppock like cataract with dense central opacities (6 year old female). (h) Stit lamp view of lamellar cataract. (1) Slit lamp view of a blue dor (cerulean) cataract (32 year old man). (1) Slit lamp and

retroillumination view of a cortical cataract (45 year old woman). (k) Slit lamp view of a fine pulverulent cataract ( 32 year old man). (1) Slit lamp view of large pulverulent opacities (12 year old females.
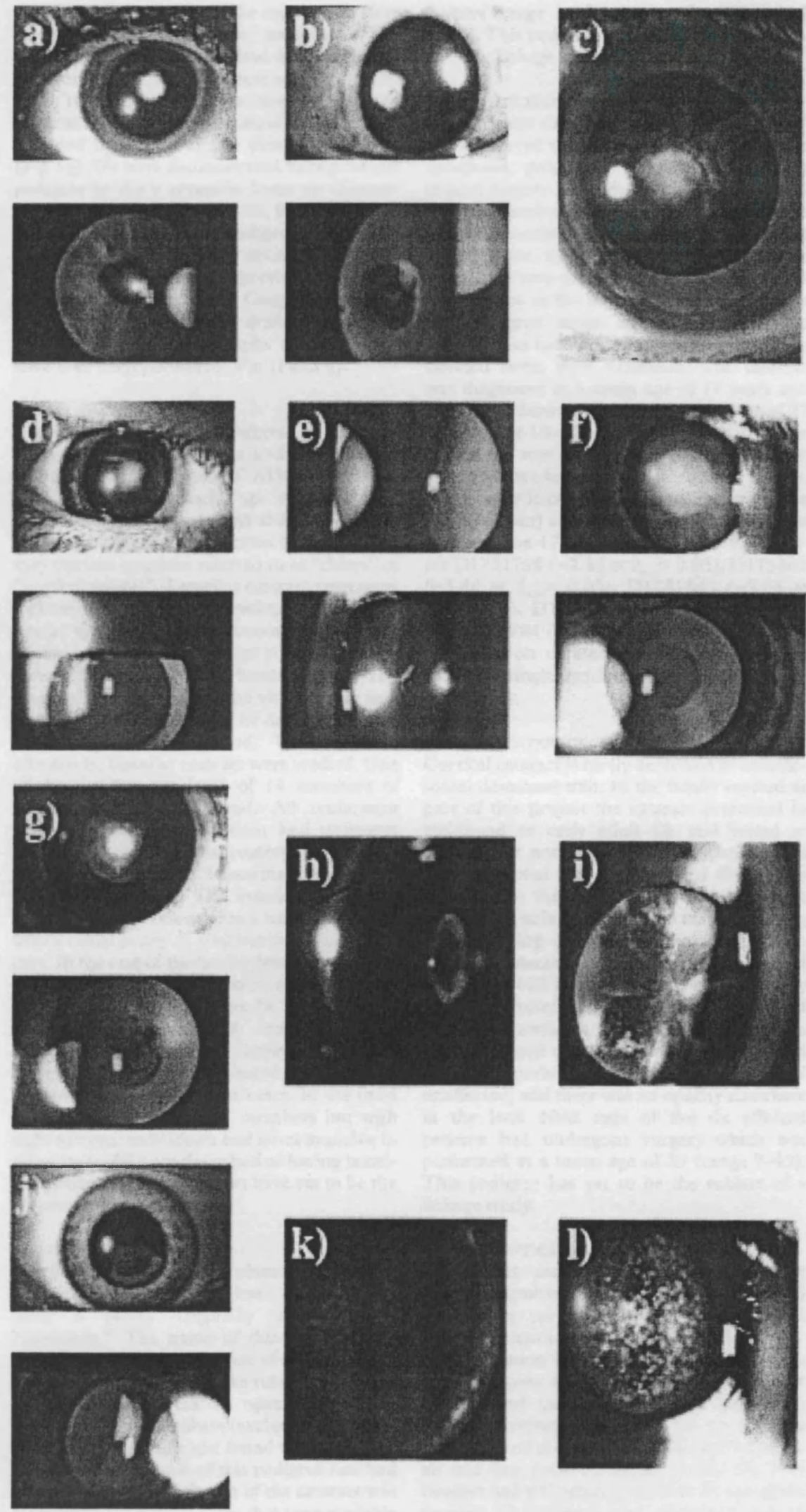

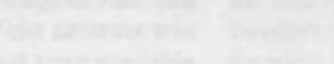


the cataract morphology. The cataracts in three unoperated patients were examined. The mildly affected individuals had dust-like opacities throughout the embryonic and fetal nuclei (Fig 1f) while the more severely affected patients had a dense central opacity surrounded by a haze of fine powdery opacities (Fig 1g). We have demonstrated linkage of this pedigree to the $\gamma$ crystallin locus on chromosome $2 \mathrm{q}\left(\mathrm{D} 2 \mathrm{~S} 157 \mathrm{Z}_{\mathrm{max}}=5.28, \theta_{\max }=0.00\right)$ but have discovered that this pedigree is related to the Coppock-like pedigree initially studied by $S^{S}$ mith $^{15}$ and Harman ${ }^{16}$ and previously linked to the $\gamma$ crystallin gene. ${ }^{17}$ The Coppock-like cataract phenotype is well described in the literature but no photographs of the opacity have ever been published (Fig If and $\mathrm{g}$ ).

\section{LAMELLAR CATARACT}

Lamellar cataract is also referred to by some authors as zonular cataract and is one of the commonest phenotypes of ADC. The inner fetal nucleus is made up of clear lens surrounded by an opacified shell which is in turn surrounded by clear cortex (Fig $1 \mathrm{~h}$ ) which may contain opacities referred to as "riders" or "cortical spokes". Lamellar cataract represents a disturbance in the lens development at a particular time and the cataractous "shell" varies in size according to the stage of fetal development at which the disturbance occurs. The cataract may be mild and the visual acuity may be well preserved or it may be dense enough to need surgery in childhood. Three families affected by lamellar cataract were studied. One of the families consisted of 14 members of whom eight were affected. All underwent surgery although one patient had unilateral cataract extraction. The surgery was carried out at a mean age of 7 months (range 2-36, mode 2, median 2). The individual who still had a cataract in one eye has a lamellar cataract with a visual acuity of $6 / 60$ but has refused surgery. In the rest of the family details of the phenotype were restricted to clinical records that were available in four cases. In the other two families all the affected individuals had undergone surgery. In one family of 14 people there were nine affected individuals and the notes were available in two cases. In the third family there were also 14 members but with eight affected individuals and notes available in three cases. All were described as having lamellar cataract. These pedigrees have yet to be the subject of linkage studies.

\section{CORALIIFORM CATARACT}

The single pedigree of this phenotype from the Moorfields genetic data base is descended from a family originally described by Nettleship. ${ }^{18}$ The name of this phenotype is derived from the resemblance of the cataract to sea coral, ${ }^{19}$ having finger-like tubular protuberances extending from an opacified nucleus. Nineteen family members (excluding partners) were examined and eight found to be affected. All affected members of this pedigree had had surgery and the description of the cataract was taken from the clinical notes that were available in seven cases. The mean age at operation was
5 years (range 1-12 years, median 5 , mode 7 years). This pedigree has not yet been the subject of a linkage study.

BLUE DOT (CERULEAN) CATARACT

The blue dot cataract first described by Vogt ${ }^{20}$ is not believed to be congenital but develops in childhood, progresses slowly, and does not require surgery until adulthood. ${ }^{21}{ }^{22}$ The opacities are distributed throughout the lens, with the outer nucleus containing blue-white dots that become more numerous in the cortex where they may form large cuneiform (wedgelike) shapes in the mid-periphery (Fig $1 \mathrm{i}$ ). In this pedigree seven of 13 patients were diagnosed as having the cataract and five of the affected seven were examined. The cataract was diagnosed at a mean age of 17 years and patients underwent surgery at a mean age of 27 years (range $10-47$, mode 25 , median 25 ). The phenotype was consistent within the family. This pedigree has been excluded from the two loci already known to be associated with blue dot (cerulean) cataract. The blue dot locus on chromosome 17 was excluded with the markers D17S1790 $\left(-2.46\right.$ at $\left.\theta_{\text {max }}=0.05\right)$, D17S802 $\left(-3.40\right.$ at $\left.\theta_{\max }=0.05\right), D 17 S 1847(-2.66$ at $\left.\theta_{\text {m }}=0.05\right), \mathrm{D} 17 \mathrm{~S} 836(-3.04$ at $\theta=0.05)$, and D17S784 $\left(-1.27\right.$ at $\left.\theta_{\max }=0.05\right)$. The blue dot locus on chromosome 22 was excluded with the single marker D22S315 $(-2.63$ at $\theta_{\max }=0.05$ ).

\section{CORTICAL CATARACT}

Cortical cataract is rarely described as an autosomal dominant trait. In the family studied as part of this project the cataract presented in childhood or early adult life and varied in severity but not in morphology. The nucleus was unaffected and the opacified fibres were restricted to the outer cortex in contact with the lens capsule affecting a sector of lens (Fig 1j) and being different in this respect from lamellar cataract. The pedigree we studied consisted of 20 family members of whom only six were affected with the cataract and four of these were available for examination. In three of the affected members the cataract affected only the superior cortex, the nucleus remained unaffected, and there was no opacity elsewhere in the lens. Nine eyes of the six affected patients had undergone surgery which was performed at a mean age of 23 (range 7-43). This pedigree has yet to be the subject of a linkage study.

\section{PULVERULENT CATARACT}

Pulverulent cataracts are characterised by powdery (pulverised) opacities that may be found in any part of the lens. Pedigrees affected by pulverulent cataract showed a wide intrafamilial variation in the cataract phenotype and, although some affected individuals from these families had cataracts similar to lamellar or nuclear cataract, pedigrees were classified as pulverulent if the majority of affected individuals had fine, powdery opacities (Fig $1 \mathrm{k}$ ). Five families had pulverulent cataract. In one of the families 23 members were examined and 16 found to be affected. The cataract varied 
between affected individuals. In some the fine opacities formed a lamellar distribution with a clear cortex and minimal inner fetal nuclear involvement. Others had more widely spread pulverised opacities extending into the cortex with no demarcation of the fetal nucleus. In some the cataract was mild and the fine dust-like opacities were clustered only around the anterior and posterior $\mathrm{Y}$ sutures. In this first pedigree nine individuals had undergone surgery at a mean age of 17 years (range 3-82, median 8 , mode 11 ). This pedigree has been linked to chromosome 13 with a maximum two point lod score of $4.06\left(\theta_{\max }=0.00\right)$ with marker D13\$175. In a second family with pulverulent cataract 15 members were examined and 10 were affected. Four had undergone bilateral cataract surgery, two unilateral, and four had not had surgery. The mean age at surgery was 14 years (range 5-22 years, median 17). The cataract had powdery opacities throughout the lens although they were more abundant in the fetal nucleus. In some the opacities were large and coarse (Fig 11) and in others finer and dust-like.

A third family affected by pulverulent cataract consisted of 15 family members of whom eight were affected by the cataract. Only two patients had undergone surgery and examination of the remaining six revealed fine dustlike opacities predominately in the fetal nucleus but also in the cortex, with moderate opacification of the $\mathrm{Y}$ sutures.

The fourth family affected by pulverulent cataract consisted of 21 family members with eight affected individuals. The phenotype in this family showed great intrafamilial variation, some had the typical fine dots throughout the lens, others had posterior opacities with the rest of the lens unaffected, and one individual had dense bilateral nuclear opacification.

A fifth family, previously shown in 1963 to cosegregate with the Duffy blood group locus on chromosome 1q was recontacted and 18 members of the pedigree (10 affected, six unaffected, and two spouses) examined. All affected individuals had previously undergone cataract surgery, their hospital records indicating that dense opacification was present at birth. Linkage to 1q has been confirmed (maximum multipoint lod score 5.22 at $\theta_{\max }=$ 0 ) and a missense mutation identified in the gap junction $\alpha 8$ gene that encodes connexin $50 .{ }^{23}$

\section{Discussion}

In this study of $A D C$ we have demonstrated that the phenotypes of the pedigrees encountered could be classified as one of the eight following types-anterior polar, posterior polar, nuclear, lamellar, coralliform, blue dot (cerulean), cortical, and pulverulent. This study was limited to large families that were suitable for linkage studies but this was thought not to affect the distribution of the affected phenotypes. Other phenotypes not encountered in this study have been reported but they have either been described in individual cases and not in families or are very uncommon. Although an attempt was made to examine the phenotypes of all family members at risk of inheriting the affected gene, the description of intrafamilial variation in the phenotypes was limited by the number of patients who had already undergone surgery. This is a limitation inherent in all studies of early onset inherited cataract and we attempted to obtain as detailed a description as possible from the hospital records in such cases.

In all the pedigrees apart from the pulverulent pedigrees the morphology was the same in all affected family members but varied in severity. In the pulverulent pedigrees the phenotype varied among affected individuals from the same family. Intrafamilial clinical heterogeneity in ADC has been described by many authors $\mathrm{s}^{24}$ including interocular variability in individuals affected by ADC. ${ }^{26}$ The pedigrees described as having this wide variation in morphology are characteristic of the pulverulent type described here. A total of 14 pedigrees have now been mapped to 13 different loci identified as containing genes that give rise to cataract (Table 1). In this study we have assigned a chromosomal locus in four pedigrees and 11 remain to be linked. An anterior polar pedigree maps to chromosome $17 p,{ }^{13}$ a posterior polar pedigree to $1 \mathrm{p}^{14}$ a nuclear pedigree now known to be related to the Coppock-like pedigree maps to the $\gamma$ crystallin region on chromosome $2 \mathrm{q}$, and a pulverulent pedigree maps to chromosome $13 .^{9}$ We have excluded linkage of a pedigree affected by the blue dot cataract to the two loci known to give rise to this phenotype and have also excluded linkage of a posterior polar pedigree and a pulverulent pedigree to the known cataract loci. Further linkage studies are under way.

Clinically similar phenotypes of autosomal dominant cataract map to different regions of the genome and different phenotypes map to the same locus: two unrelated pedigrees affected by blue dot (cerulean) cataract have been mapped to different chromosomes ${ }^{27} 28$ and two unrelated pedigrees affected by posterior polar cataract have also been mapped to different chromosomes. ${ }^{14}{ }^{29}$ Two different phenotypes, a posterior polar ${ }^{14}$ and the Volkmann cataract, ${ }^{24}$ both map to what may prove to be the same locus on chromosome $1 \mathrm{p}$. In contrast, in families where the underlying genetic mutation has been identified the resultant phenotype correlates with the underlying molecular biology of the lens: genes for human crystallin proteins have now been mapped and are important candidate genes for ADC formation. The Coppock-like cataract is a nuclear cataract caused by a mutation in the $\gamma$ crystallin gene complex on chromosome $2 q^{30}$ and the $\gamma$ crystallins are predominantly found in the lens nucleus. ${ }^{31}$ The blue dot (cerulean) cataract consists of multiple blue-white dots that predominate in the lens cortex and $\beta$ crystallins are more abundant in the outer (cortical) layers of the lens. A pedigree affected by blue dot (cerulean) cataract has been demonstrated to have a mutation in the $\beta$ crystallin region on chromosome $22 q^{28}$ with the affected members having a chain termination mutation in the human $\beta$ crystallin gene CRYBB2. ${ }^{32} \mathrm{~A}$ mis- 
sense mutation in the gene for connexin 50, a gap junction membrane protein, on chromosome 1q has been shown to give rise to pulverulent cataract in humans. ${ }^{23}$

A missense mutation in the human $\alpha$ crystallin gene CRYAA has been shown to give rise to a series of eye abnormalities including zonular central nuclear opacities, cortical and posterior subcapsular cataract, microcornea, and congenital microphthalmia. ${ }^{33}$ The $\alpha$ crystallin protein is found in many tissues in the eye and throughout the body and a mutation in this protein may be expected to have a considerable effect on ocular development.

In mouse models for ADC, mutations in the crystallin and membrane bound proteins have also been shown to give rise to cataract, although the relation between genotype and phenotype is not as clear. The Philly mouse has a nuclear and subcapsular cataract ${ }^{34}$ caused by a mutation in one of the $\beta$ crystallin genes ${ }^{35}$ and the Elo mouse, which is a model for microphthalmia secondary to abnormal lens formation ${ }^{36}$ is caused by a mutation in one of the $\gamma$ crystallin genes. ${ }^{37} \mathrm{~A}$ mutation in the gene for the major intrinsic protein (MIP) of the lens fibre cell membranes has been implicated as causing the cataracts in both the Cat $[\mathrm{Fr}$ ] mouse and the Lop mouse. ${ }^{38} 39$ The human gene for MIP has been mapped to chromosome $12 \mathrm{q}^{40}{ }^{41}$ but has not yet been implicated in human cataract.

Although in humans the major crystallins are the $\alpha, \beta$, and $\gamma$ crystallins, contributing $90 \%$ of the water soluble proteins of the lens, ${ }^{42}$ there are many other species specific crystallins that may be relevant to human cataract formation. These crystallins are enzymes that in some cases have been shown to have a different function outside the lens but have been recruited during evolution to perform as lens crystallins owing to their stable structures and/or in some cases their original enzyme activity. ${ }^{43}$ The Volkmann and the posterior polar cataract both map to a region on chromosome Ip within which lies the $\tau$ crystallin/a enolase gene. This crystallin is not known to be expressed in the human lens. Indeed, no mutation has been found in the gene in these families and the single family described with red cell enolase deficiency does not have cataract. However, it is tempting to speculate that an abnormality in the gene may be associated with cataract in humans. ${ }^{45}$

This study of lens morphology in ADC has demonstrated wide clinical heterogeneity. There is clearly considerable genetic heterogeneity and the identification of the causative mutations will allow for a more detailed comparison between the precise mutations and the clinical phenotype as well as offering further insight into the mechanism of human cataractogenesis.

We thank the families for agrecing to participate in this study and the UK HGMP Resource Centre for microsatellite primer synthesis and the use of computing facilities. The work was supSTB; 053416 to ATM and SSB). ACWI was supported by a
grant from The Friends of Moorficlds Eyc Hospital and DSM is a Wellcome Prize student.
1 Evans J, Rooney C, Ashwood F, et al. Blindness and partial sight in England and Wales: April 1990-March 1991. Health Frends 1996;28:5-12.

2 Lambert S, Drack A. Infantile Cataracts. Surv Ophthalmol 1996;40:427-58.

3 Harman N. Treasury of human inheritance. Part 4. Section XIIIa. Congenital cataract. Eugenics Library Memoir XI 1910.

4 Clapp C. Cataract its aetiology and treatment. London: Henry Kimpton, 1934.

5 Duke-Elder $\mathrm{S}$. The lens. In: Duke-Elder $\mathrm{S}$, ed. A system of ophthalmology. London: Henry Kimpton, 1964:715-59. François J. Congenital cataracts. Springfield, IL: Charles C Thomas, 1963.

7 Vogt A. Lens and zonule. Bonn: JP Weyenborgh, 1979.

Gyapay G, Morisette J, Vignal A, et al The 1993-1994 Genethon human linkage map. Nat Genet 1994;7:246-339. congenital cataract linked to chromosome 13. Am $\mathrm{f}$ Hum Genet 1997;60:1474-8.

$10 \mathrm{Jazfar} M$, Robb R. Congenital anterior polar cataract: review of 63 cases. Ophthalmology 1984;91:249-52.

11 Bouzas A. Anterior polar congenital cataract and corneal astigmatism. I Paediatr Ophthalmol Strabismus 1992;29: $210-12$.

12 Ionides A, Berry V, Mackay D, et al Anterior polar cataract: clinical spectrum and genetic linkage in a single family. Eye 1998;12:224-6.

13 Berry V, Ionides A, Moore A, et al. A locus for autosomal dominant anterior polar

14 Ionides A, Berry V, Mackay D, et al. A locus for autosomal dominant posterior polar cataract on chromosome 1p.
Hum Mol Genet 1997;6:47-51.

15 Smith P. A pedigree of Doyne's discoid cataract. Trans Oph-

15 Smith P. A pedigree of Doyne's discoid cataract. Trans Oph-
thalmol Soc UK 1910;30:37-42. cataract; lamellar, coralliform, discoid and posterior pola with microphthalmia. Trans Ophthalmol Soc UK 1910;30: 251-74.

17 Lubsen N, Renwick J, Tsui L-C, et al A locus for human hereditary cataract is closely linked to the gamma-crystallin gene family. Proc Natl Acad Sci USA 1987;84:489-92.

18 Nettleship E. On heredity in the forms of cataract. The Royal Lond Ophth Hosp Rep 1906;1 1:218-22.

9 Gunn RM. Peculiar coralliform cataract with crystals in the lens. Trans Ophthalmol Soc UK 1895;XV:119.

20 Vogt A. Die spezifitat auder borener und erworbener starformer fur die einzelnen linsezouene. Albrecht Von

Kraefes Arch Chin Exp Ophth 1922;108:219-28. cerulean cataract and PGP. Cyrogenet Cell Genet 1985;40 669.

22 Bodker F, Lavery $M$, Mitchell T, et al. Microphthalmos in the presumed homozygous offspring of a first cousin marriage and linkage analysis of a locus in a family with auto-
somal dominant cerulean congenital cataracts. Am 9 Med Genet 1990;37:54-9.

23 Shiels A, Mackay D, Ionides A, et al. A missense mutation in the human connexin 50 gene (GJA8) underlies autosomal dominant "zonular pulverulent" catarach 19. Am J Hum Genet 1998;62:526-32.

Eiberg H, Lund A, Warburg $M$, et al. Assignment of congenital cataract Volkmann-type
1 36 . Hum Genet 1995;96:33-8.

25 Eiberg E, Marner E, Rosenberg T, et al Marner's cararact (CAM) assigned E, Rosenberg T, et al Marner's cataract toglobin. Clin Genet 1988;34:272-5.

26 Scott M, Hejtmancik J, Wozencraft I, et al. Autosomal dominant congenital cataract. Interocular phenotypic variability. Ophthalmology 1994;101:866-71.

27 Armitage M, Kivlin J, Ferrel R. A progressive early onset cataract gene maps to human chromosome 17q24. Nat Genet 1995;9:37-40

28 Kramer $\mathrm{P}$, Yount J, Michell $T$, et al. A second gene for cerulean cataract maps to the beta-crystallin region on chromosome 22. Genomics 1996;35:539-42.

29 Richards J, Maumenee I, Rowe S, et al. Congenital cataract possibly linked to haptoglobin. Cytogenet Cell Gener

0 Brackenhoff R, Heskens H, Rossum MV, et al. Activation of the gamma-E-crystallin pseudogene in the human herditary

31 Mcavoy J. Developmental biology of the lens. In: Dument.

G, ed. Mechanisms of cararact formation in the human lens. G, ed. Mechanisms of cararact formation
London: Academic Press, 1981:7-46.

32 Litt M, Carrera-Valenzuela $R$, LeMorticella $D$, et al. Autosomal dominant congenital cataract is associated with a chain termination mutation in the human beta-crystallin gene CRYBB2. Hum Mol Genet 1997;6:665-8.

33 Litt M, Kramer P, LaMorticella D, et al. Autosomal dominant congenital cataract associated with a missense mutation in the human alpha crystallin gene CRYAA. Hum Mol Gener 1998;7:471-4.

34 Kador $\mathrm{P}$, Fukui $\mathrm{H}$, Fukushi $\mathrm{S}$, ez al. A new model of hereditary cataract. Exp Eye Res 1980;30:59.

Chambers C, Russell P. Deletion mutation in an eye lens beta-crystallin. I Biol Chem 1991;266:6742-6. Oda S-I, Watanabe $\mathrm{K}$, Fujisawa $\mathrm{H}$, at al. Impaired development of lens fibres in genetic microph thalmia, eye lens obso-
lescence, elo, of the mouse. Exp Eye Res 1980;31:673-81.

37 Cartier M, Bretman M, Tsui L A frameshift mutation in the gammaE-crystallin gene of the ELO mouse. Nat Genet 1992;2:42-5. 
38 Muggleton-Harris A, Festing M, Hall M. A gene location Muggleton-Harris A, Festing M, Hall M. A gene location
for the inheritance of the Cataract Fraser (CatFr) mouse

39 Shiels A, Bassnett $S$. Mutations in the founder of the MIP gene family underlie cataract development in the mouse. gene family underlie cataract
Nat Genet 1996;12:212-15.

40 Noort Jv, Sechel Av, Bajramovic J, et al The small beat shock protein alphaB-crystallin as candidate autoantigen in multiple sclerosis. Nature 1995;375:798-801.

41 Sparkes R, Mohandas T, Heinzman C. The gene for the major intrinsic protein (MIP) of the ocular lens is assigned to human chromosome 12cen-q14. Invest Ophthalmol $V_{i t}$

42 Cartier M, Tsui L, Ball S, ex al. Crystallin genes and cararaca. Switzerland: Modern Genetics Series Harwood Academic Press, 1994.

43 Piatigorsky J. Multifunctional lens crystallins and corneal enzymes. More than meets the eye. Ann NY Acad Sci 1998; 842:7-15.
44 Wistow G, Piatigorsky J. Recruitment of enzymes as lens structural proteins. Science 1987;236:1554-5.

45 Wistow $G$, Leins. Science 1 ias7,236: enolase: one gene encodes both an enzyme and a lens structural protein. I Cell Biol 1988;107:2729-36.

46 Renwick J, Lawler S. Probable linkage between a congenital cataract locus and the Duffy blood group locus. Ann Hum Genet 1963;27:67-84.

47 Rogaev E, Rogaeva E, Korovaitseva G, F et al Linkage of polymorphic congenital cataract to the gamma-crystallin locus on human chromosome 2q33-35. Hum Mol Gener

48 Semina E, Ferrell R, Mintz-Hittner H, et al. A novel homeobox gene PITX3 is mutated in families with autosomal 70.

9 Padma T, Ayyagari R, Murty J, et al. Autosomal dominan zonular cataract with sutural opacities localised to chromo some 17q11-12. Am \} Hum Genet 1995;57:850-5. 